\title{
The contribution of CNS inflammation and Glycogen Synthase Kinase-3 (GSK-3)-cascades on adverse memory learning on mouse models of emotional stress
}

Citation for published version (APA):

Pavlov, D. (2020). The contribution of CNS inflammation and Glycogen Synthase Kinase-3 (GSK-3)cascades on adverse memory learning on mouse models of emotional stress. [Doctoral Thesis, Maastricht University]. Maastricht University. https://doi.org/10.26481/dis.20200305dp

Document status and date:

Published: 01/01/2020

DOI:

$10.26481 /$ dis.20200305dp

Document Version:

Publisher's PDF, also known as Version of record

Please check the document version of this publication:

- A submitted manuscript is the version of the article upon submission and before peer-review. There can be important differences between the submitted version and the official published version of record. People interested in the research are advised to contact the author for the final version of the publication, or visit the DOI to the publisher's website.

- The final author version and the galley proof are versions of the publication after peer review.

- The final published version features the final layout of the paper including the volume, issue and page numbers.

Link to publication

\footnotetext{
General rights rights.

- You may freely distribute the URL identifying the publication in the public portal. please follow below link for the End User Agreement:

www.umlib.nl/taverne-license

Take down policy

If you believe that this document breaches copyright please contact us at:

repository@maastrichtuniversity.nl

providing details and we will investigate your claim.
}

Copyright and moral rights for the publications made accessible in the public portal are retained by the authors and/or other copyright owners and it is a condition of accessing publications that users recognise and abide by the legal requirements associated with these

- Users may download and print one copy of any publication from the public portal for the purpose of private study or research.

- You may not further distribute the material or use it for any profit-making activity or commercial gain

If the publication is distributed under the terms of Article 25fa of the Dutch Copyright Act, indicated by the "Taverne" license above, 
The contribution of CNS inflammation and Glycogen Synthase

Kinase-3 (GSK-3)-cascades on adverse memory learning on mouse models of emotional stress

\section{$\mathrm{PhD}$ thesis}

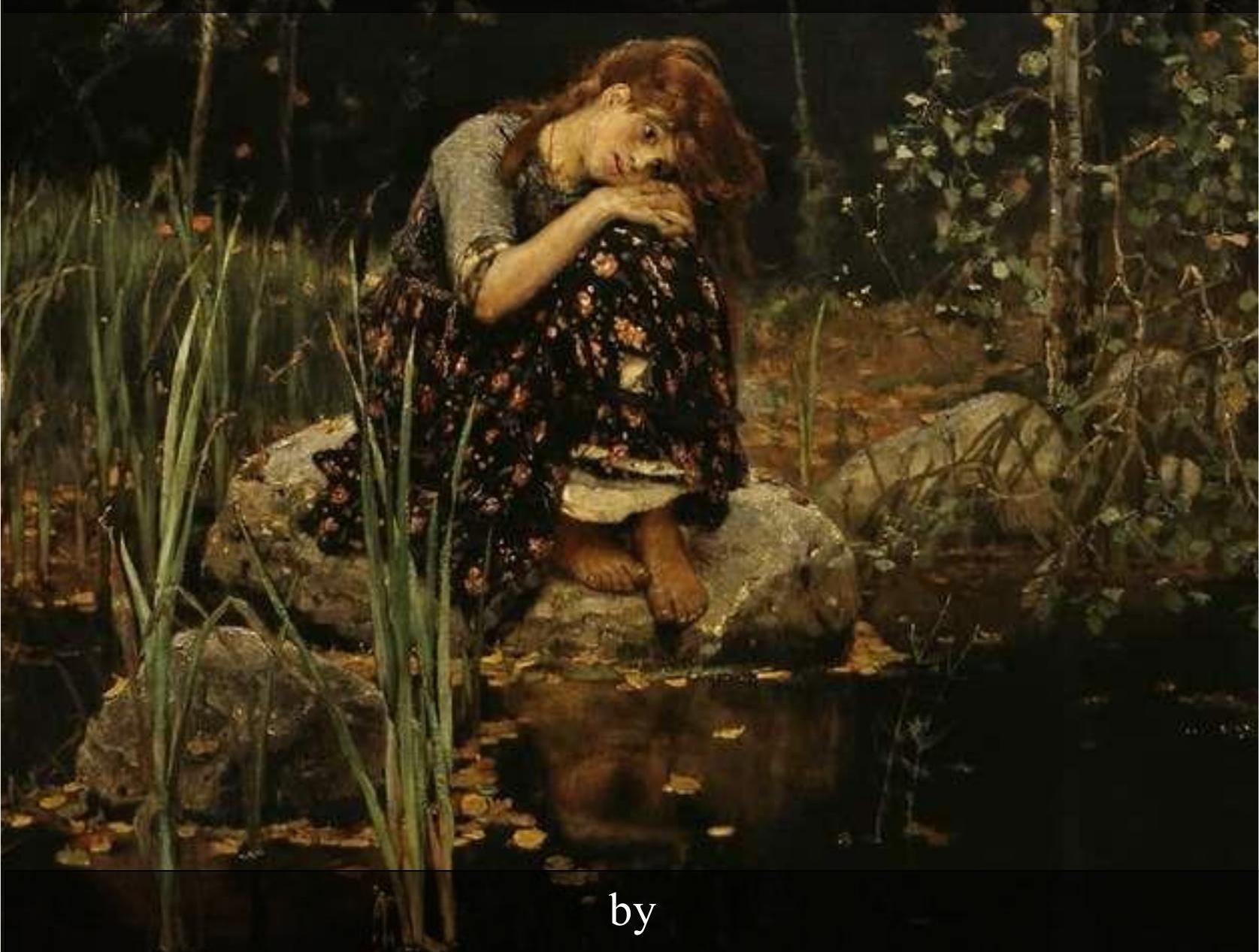


(C) D. Pavlov, Maastricht 2020.

The contribution of CNS inflammation and Glycogen Synthase Kinase-3 (GSK-3)-cascades on adverse memory learning on mouse models of emotional stress

All rights reserved. No parts of this book may be reproduced or transmitted in any form or by any means, without prior permission in writing by the author, or when appropriate, by the publishers of the publication.

Cover page contains a representation of painting "Alyonushka" (1881) by Viktor Vasnetsov, Russian artist. The state Tretyakov Gallery, Moscow, Russia. 


\title{
The contribution of CNS inflammation and Glycogen Synthase Kinase-3 (GSK-3)-
} cascades on adverse memory learning on mouse models of emotional stress

\author{
DISSERTATION
}

to obtain the degree of Doctor at Maastricht University, on the authority of the Rector Magnificus, Prof. dr. Rianne M. Letschert in accordance with the decision of the Board of Deans, to be defended in public on Thursday 5th of March 2020 at 14:00 hours by

Dmitrii Pavlov 


\section{Supervisor}

Prof. dr. K.P. Lesch, professor für Molekulare Psychiatrie, Universität

Klinikum Würzburg and Associate professor, dept. Psychiatry and

Neuropsychology, Maastricht University

\section{Co-supervisors}

Dr. T. Strekalova, Senior Researcher, Maastricht University

Prof. dr. L. Bettendorff, GIGA-Neurosciences, University of Liège

\section{MEMBERS OF THE DEGREE COMMITTEE}

1. Prof. David Linden

2. Dr. Sarah-Anna Hescham

3. Dr. Nicole Leibold

4. Prof. Christian Grandfils

5. Prof. Pierre Leprince 


\section{TABLE OF CONTENTS:}

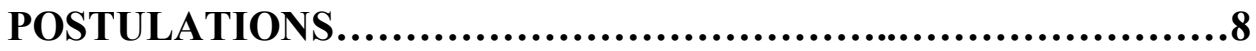

LIST OF ABBREVIATIONS.....................................10

CHAPTER 1. INTRODUCTION...................................15

1. Aetiology of major depression and the role of emotional stress in its pathogenesis...........................................15

2. Enhanced cognitive processing as a pathologic mechanism in major depressive disorder .22

3. Brain regions involved in the pathogenesis of depressive syndrome. 25

4. Disrupted plasticity and oxidative stress in the brain as pathophysiological factors of depressive disorder 28

5. Rodent models of depression 33

6. Changes in glycogen synthase kinase-3 (GSK-3)-related cascades during depression. 38

7. The role of vitamin B1 (thiamine) in the mechanisms of neuropsychiatric disorders

Hypothesis and aims .45 


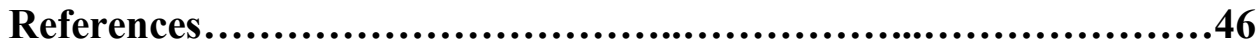

CHAPTER 2. Elucidating the functions of brain GSK3a: Possible synergy with GSK3 $\beta$ upregulation and reversal by antidepressant treatment in a mouse model of depressive-like behaviour. .58

CHAPTER 3. Enhanced conditioning of adverse memories in the mouse modified swim test is associated with neuroinflammatory changes: effects of treatments with antidepressant properties.........94

CHAPTER 4. Neuroinflammation and aberrant hippocampal plasticity in a mouse model of emotional stress evoked by exposure to ultrasound of alternating frequencies.................................153

CHAPTER 5. DISCUSSION AND SOCIETAL IMPACT .............250

5.1 GSK-3-related molecular and neuroinflammatory changes as common mechanisms of the depressive syndrome .250

5.2 The role of GSK-3 isoforms in altered neuroplasticity and oxidative stress in depressive syndromes 257

5.3 Pro-inflammatory changes during stress, depression and neuropsychiatric pathology associated with abnormal retention of adverse memories. .260 
5.4 Validity of novel models of depression using an ultrasound-induced"emotional stress" and modified swim test of enhanced conditioning of adverse memories .263

5.5 Clinical implications of anti-depressant-like activity of thiaminerelated compounds .267

REFERENCES. .270

SUMMARY. 277

SAMENVATTING .281

VALORIZATION .283

ACKNOWLEGMENTS.

ABOUT THE AUTHOR 


\section{POSTULATIONS}

1. In the model of ultrasound-induced "emotional stress", brain overexpression of GSK-3 isoforms is accompanied by markers of microglia activation and oxidative stress (this thesis);

2. Expression of GSK-3 $\alpha$ and GSK-3 $\beta$ is differentially altered both in the model of ultrasound stress and in the model of enhanced learning of adverse context (this thesis);

3. In the examined models, GSK-3 $\beta$ overexpression correlates with depressive-like behavior, cytokine production, and oxidative stress markers, suggesting overlapping molecular mechanisms underlying the depressive syndrome (this thesis);

4. Brain upregulation of the GSK-3 cascade in a mouse model of enhanced learning of adverse memories is associated with increased production of pro-inflammatory cytokines, c-Fos and markers of oxidative stress (this thesis);

5. These changes are prevented by a pre-treatment with antidepressant compounds, as well as anti-oxidant vitamin B1 (thiamine) that is useful for fundamental and pre-clinical studies (valorization);

6. Contextual learning occurs in the presence of background stimuli; 
7. Stress-linked inflammation is a coherent mechanism to enhance animal survival;

8. The majority of currently used antidepressants are discovered around half a century ago;

9. "Not everything that is faced can be changed, but nothing can be changed until it is faced" (James Baldwin)

10. "I take vitamins" (Hillary Clinton)

11. "To attain any assured knowledge about the soul is one of the most difficult things in the world" (Aristotle) 


\section{LIST OF ABBREVIATIONS}

Akt- protein kinase B

AktpSer473- phosphorylated at Serine 473 protein kinase B

BDNF- brain-derived neurotropic factor

BLBP- brain lipid binding protein

CNS- central nervous system

COX-1 - cyclooxigenase-1

CREB - cAMP response element-binding protein

D - Day

DG- dentate gyrus

DCX-doublecortin

FOXO3a- forkhead box $\mathrm{O} 3$

FST- forced swim test

GABA- gamma-aminobutyric acid

GAPDH- glyceraldehyde 3-phosphate dehydrogenase 
GSK-3 $\alpha$ - glycogen synthase kinase 3 alpha

GSK-3 $\beta$ - glycogen synthase kinase 3 beta

Iba-1- ionized calcium binding adaptor molecule 1 factor

IL-1 $\beta$ - interleukin-1 $\beta$

IL-2- interleukin-2

IL-6- interleukin-6

IL-8- interleukin-8

IL-15- interleukin-15

Imi- imipramine

Hip- hippocampus

HPA axis- hypothalamic-pituitary-adrenal axis

LTD- long-term depression

LTP- long-term potentiation

MDA- malondialdehyde

modFST- modified forced swim test 
MRI- magnetic resonance imaging

NGF- nerve growth factor

NT-3- neurotropnin-3

NT-4- neurotropnin-4

NF-kB- nuclear factor-kB

PCR- polymerase chain reaction

PFC- prefrontal cortex

PI3K- phosphoinositide 3-kinase

PTEN- phosphatase and tensin homolog deleted on chromosome 10

PTSD- post-traumatic stress disorder

RNA-ribonucleic acid

ROS- reactive oxygen species

RNS- reactive nitrogen species

SGZ- subgranular zone of hippocampus

SSRI-selective serotonin reuptake inhibitor 
Thi- thiamine

TrkB- tropomyosin receptor kinase B

TNF- tumor necrosis factor

US- ultrasound stress

VEGF- vascular endothelial growth factor

VTA- ventral tegmental area

3-NT- 3-nitrotyrosine 
Chapter 1

Introduction 


\section{CHAPTER 1. INTRODUCTION}

\section{Aetiology of major depression and the role of emotional stress in its pathogenesis}

Ebers Papyrus, an Egyptian medical papyrus dated about 1500 BC, describes the first knowledge of mental disorders similar to depression; in those times term "melancholy" was used to indicate this state (Okasha, 1978). This term almost uncheangeably had been used until 19th century, when "depression" came into use in physiology and psychiatry (Berrios, 1988). The modern concept of depression covers a wide range of mental health problems characterized by low mood, negative thoughts, fatigue, indecisiveness and a broad constellation of associated symptoms (Kessler et al., 2003). One of the core symptoms of depression is anhedonia, or decreased ability to experience pleasure, that is a clinical presentation of reward circuit dysregulation that can be detected in humans, apes and rodents (Gong et al., 2015). Depression is often associated with cognitive and motivational decline, aberrations of exploratory behavior and memory loss (Ramponi et al., 2004) due to disruption of neurogenic processes and 
deficient neuroplasticity in the main limbic brain structures (Kheirbek et al., 2012; Boku et a., 2018).

Clinical depression, also referred to as major depressive disorder (MDD), is characterized by at least 5 of these criteria that should be persistent during 2 consecutive weeks, according to the 5th edition of the Diagnostic and Statistical Manual of Mental Disorders (DSM-V) (APA., 2013).

Today, depressive disorders are recognized as a group of severe and debilitating diseases that affect more than 300 million people all over the globe (http://www.who.int/healthinfo/global_burden_disease/ estimates).

Depressive disorders are often roughly classified into bipolar depressions (manic-depressive conditions; the presence of an episode of mania is crucial), and unipolar (no oscillation between depression and mania) (Cuellar et al., 2005). Major depressive disorder is an example of unipolar depression along with minor depressive disorder (at least two depressive criteria are present for two consecutive weeks) and atypical depression (with mood reactivity, hyperphagia and hypersomnia) (Benazzi et al., 2006). These disorders are also classified into reactive subtype of depression (situational, stress-related) and endogenous depression (caused by genetic or other internal factors) based on the occurrence of the 
pathology following the presence or absence of stress in their etiology (Showraki, 2019).

It is known that depression may not only diminish emotional state of affected individuals but also somatic health (Lopez et al., 1998; Evans et al., 2005). Indeed, patients with depression more often have cerebrovascular, cardiovascular, and other somatic disorders compared with general population (Uzun et al., 2008). Interestingly, depression may supercede cardiovascular disease as the leading cause of disability in the year 2020 according to the report of World Health Organization (Robinson, 2018).

Taking together, depression decreases the daily productivity and motivation of individuals that potentially may lead to losing a job that can further deepen depression and put individuals at risk of suicidal thoughts (Meltzer et al., 2011; Jesulola et al., 2018). In fact, clinical studies have documented strong association of depressive disorders with suicide ideation and suicide attempts (Ribeiro et al., 2018).

Emotional (psychosocial) stress is regarded as one of the main environmental risk factors for the genesis of a depressive-like state. Animal models of social stress are valuable tools to study the phenomenon and one 
of the most extensively used translational paradigms is the social defeat stress paradigm (Bjorkqvist, 2001; Rygula et al., 2006). The stressful condition here is based on circumstances that lead to intermale confrontation and fighting, whereby a dominant male attacks a subdominant male (Golden et al., 2011). Repeated negative experience in this model leads to the development of a depressive-like state in a subdominant male: it is accompanied by anhedonic states, suppressed locomotion and exploratory behavior, and cognitive declines (Kudryavtseva et al., 1991; Krishnan et al., 2007). These behavioral manifestations are often paralleled by disturbance in monoamine systems in the central nervous system (Goto et al., 2015).

There are also a variety of models that make use of the concept of isolation as another environmental factor implicated in depression, for example social isolation. These are widely used to model depressive syndromes (Zanier-Gomes et al., 2015; Ieraci et al., 2016). Maternal separation is another way to induce depressive syndrome in rodent models, where littermates are separated from their mothers (Gardner et al., 2005; Fabricius et al., 2008; Roque et al., 2014). There is growing concern that this kind of stress can increase the vulnerability to develop emotional abnormalities, 
psychopatologies and social behavioral deficits (Huot et al., 2001; Roque et al., 2014).

Environmental stress is one of the most crucial set of factors that can trigger depression. The famous Canadian scientist Hans Selye is a pioneer in stress research and has shown the deleterious effects of stress in somatic health. He postulated three distinct stages of a stress response that are triggered by an unspecific stress hit: general anxiety, resistance and general exhaustion of all adaptative mechanisms (Selye, 1936). Harmful effects of a stress reaction can be detected at the very first instance, and they are generally referred to in the literature as acute stress effects. Mobilisation of an organism's internal capacities to overcome this acute stress often leads to resistance of an organism to the applied disturbance (see Fig. 1). 


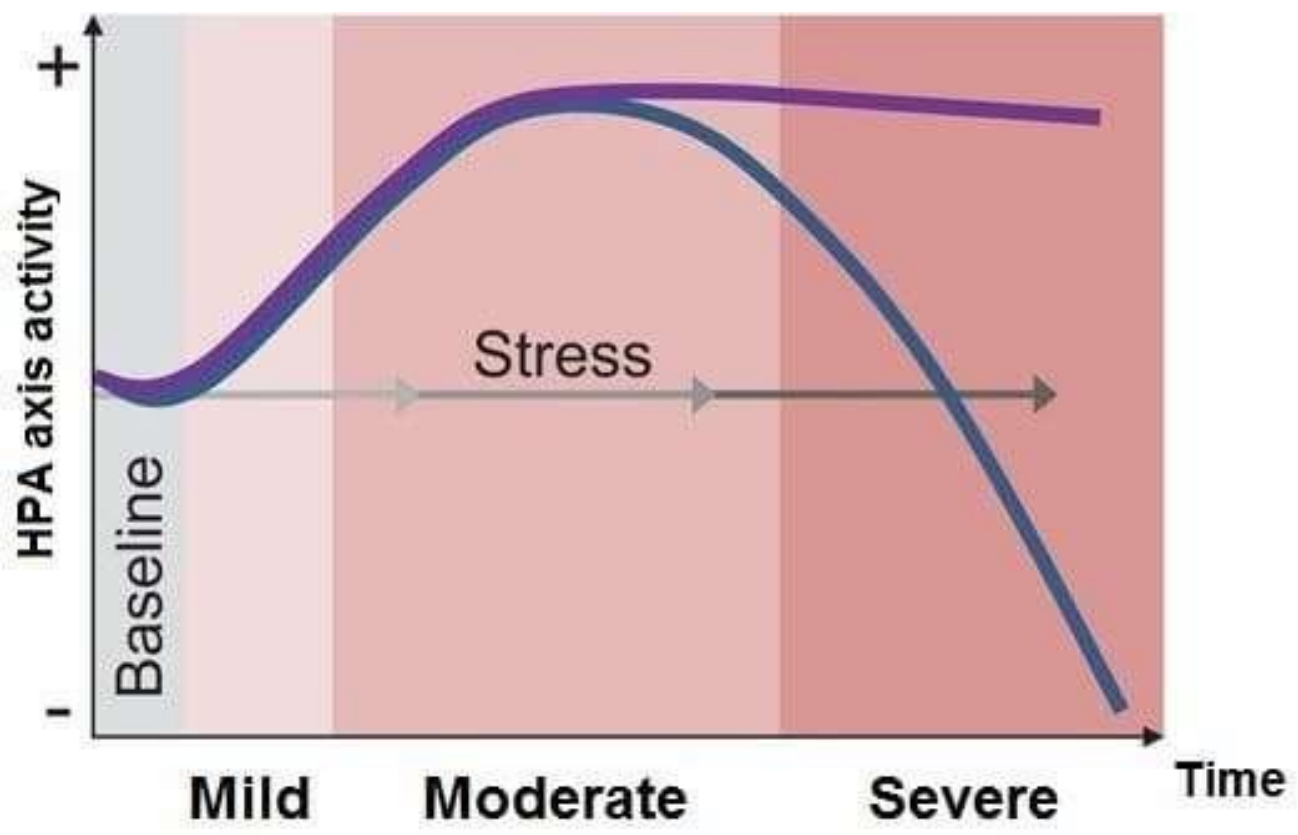

Figure 1. Stress models associated with two distinct patterns of HPA axis activation. Purple and Blue lines respectively represent modern and Selye's views on susceptibility to stress-associated diseases depending on HPA axis activation. Adapted from Kim et al., 2015.

In the organism there is a pathway that amplificates the stress response the hypothalamic-pituitary-adrenal pathway. The hypothalamus is particularly sensitive to a stress hit and initiates boostered production of major stress hormones - glucocorticoids. An important region for glucocorticoid production is the PVN nucleus of the hypothalamus, that 
secrets $\mathrm{CRH}$ (corticotropin-releasing factor), in turn triggering biochemical changes in the pituitary gland (Jiang et al., 2018). Receptors for glucocorticoids are widely expressed throughout the nervous system and through negative feedback mechanisms respond to an excess of glucocorticoids by decreasing the upstream synthesis of CRH (Herman et al., 2016). It was shown that injections of CRH induce robust prodepressant changes in rodents and lead to altered locomotor activity, decreased food intake and disturbed sleep (Holsboer, 2001).

Depression can manifest as a number of various symptoms, including low mood, anhedonia, feelings of helplessness, irritability and sleep changes, making it a complex disease to treat (Kendler et al., 2016). There are many types of mood stabilizers, such as antidepressants (imipramine, fluoxetine), antipsychotics (olanzapine), anticonvulsants (lamotrigine) and lithium (Baldessarini et al., 2013). Among these drugs lithium gained a unique position as it has both antimanic and antidepressant activity and is used to treat bipolar disorder (Can et al., 2014). Lithium is a potent suppressor of glycogen synthase kinase 3 (GSK-3), a marker of a distress and depression, the functions of which are discussed below (Freland et al., 2012). Being the most potent drug therapying the treatment of depression, lithium is effective 
for a third of depressed patients and upregulates neurotrophins and their cognate receptors (see below; Gideons et al., 2017).

\section{Enhanced cognitive processing as a pathological mechanism in major} depressive disorder

Mechanisms of depression are poorly understood (Kessler et al., 2015). Of particular significance is to study what molecular cascades underpin the enhanced conditioning of environmental adversities as they constitute an important vulnerability factor for the development of a depressive syndrome (Clark et al., 2009). Identification of the mechanisms or molecular targets involved in this phenomenon may be of particular significance to find novel approaches to treat depressive disorders associated with enhanced conditioning of adversities. Up to now, a very limited amount of data are available to describe these mechanisms and in the present work we addressed these phenomena. We used a relevant model of a modified forced swim test that was established recently (Strekalova et al., 2016). We believe that widening of the current knowledge of molecular mechanisms implicated in these conditions can potentially facilitate management of these conditions associated with augmented acquisition to adverse experiences. It is known that a faster ability to acquire negative 
memories and their inappropriate recall can provoke deleterious effects on the health and trigger cognitive and emotional aberrations (Strekalova et al., 2016). These conditions can decrease quality of life as they interfere with normal daily functioning and may be manifested as signs of behavioral despair, inability to experience pleasure and other traits of depressive syndrome. Enhanced memorizing of negative experiences can be a factor of additional stress by its own and further worsen mental and physical health conditions (Yehuda et al., 2010) (Fig. 2). In patients with phobias and post traumatic stress disorder (PTSD) the high incidence of inappropriate retention of adverse memories is prevalent (Chrousos and Gold, 1992).

To model augmented memorizing of adversities we employed a modified forced swim test paradigm (modFST). 


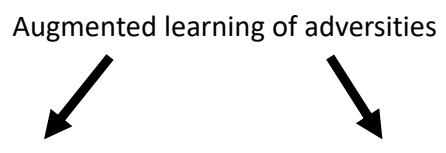

Enhanced memorizing of adverse experiences and inappropriate retention of negative memories

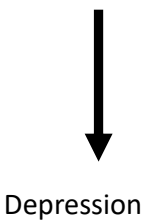

Flash back memories and severe nightmares

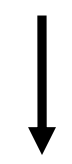

PTSD

Figure 2. Augmented learning of adverse memories in the symptoms of depression and post-traumatic stress disorder (PTSD). Abnormal memorizing and retention of adversities can result in the development of depression and PTSD (adapted from Yehuda et al., 2010).

In comparison to the classical two-day protocol of Porsolt's test (Porsolt et al., 1977), the modFST test consists of three swimming sessions on days 1 , 2 and 5. During delayed swimming session animals typically demonstrate increased duration of floating behavior in the first two minutes of the test that suggests that these rodents are prone to float. In this regard the parameter of duration of floating can be regarded as a parameter of learned 
immobility and can be a measure of enhanced cognitive processing. At the same time, modFST similarly to the classical Porsolt's paradigm triggers alterations relevant to a depressive syndrome, that makes modFST to be a useful tool to model these conditions.

\section{Brain regions involved in the pathogenesis of depressive syndrome}

Various signals including danger and emotional stressors are transduced by sensory afferents to the central nervous system where this information is processed by limbic brain circuits (Human et al., 2007). Despite the fact that there is still no clear understanding of specific neuroanatomical connections that underlie different types of depression, many brain regions can be implicated (Drevets, 1998). From research dedicated to uncovering anatomical features of depression, disturbances in monoaminergic regions were considered key to the development of the depressive syndrome (Delgado, 2000). Nowadays pivotal roles of serotonergic, noradrenergic and dopaminergic neurons in diverse neural circuits in a depressive syndrome are widely accepted and have been proven in pharmacological and genetic animal models of depression (Hasler, 2010).

The most important constellation of serotonergic neurons in the midbrain are located in the regions of medial, dorsal and caudal raphe nuclei and 
lateral medullary reticular formation (Muller and Jacobs, 2009). These nuclei send projections to cortex areas, brainstem, cerebellum, hippocampus and other brain structures that regulate depression, sickness behavior and comorbid chronic pain conditions such as fibromyalgia (Fig. 3). The noradrenergic system constitutes nuclei that are located in the locus coeruleus (in the pons) and sympathetic ganglia of the autonomic nervous system; main brain projections are to the cerebral cortex (coeruleo-cortical pathway), thalamus, amygdala and basal forebrain (Moore and Bloom, 1979) (Fig. 3). As for the clustering of dopaminergic neurons, the most important are identified in the substantia nigra, periventricular and arcuate nuclei, ventral tegmental area and zona incerta (Saltiel and Silvershein, 2015). The most important group of dopaminergic neurons projects to the prefrontal cortex (mesocortical pathway) and nucleus accumbens (mesolimbic pathway) (Bjorklund and Dunnett, 2007). 


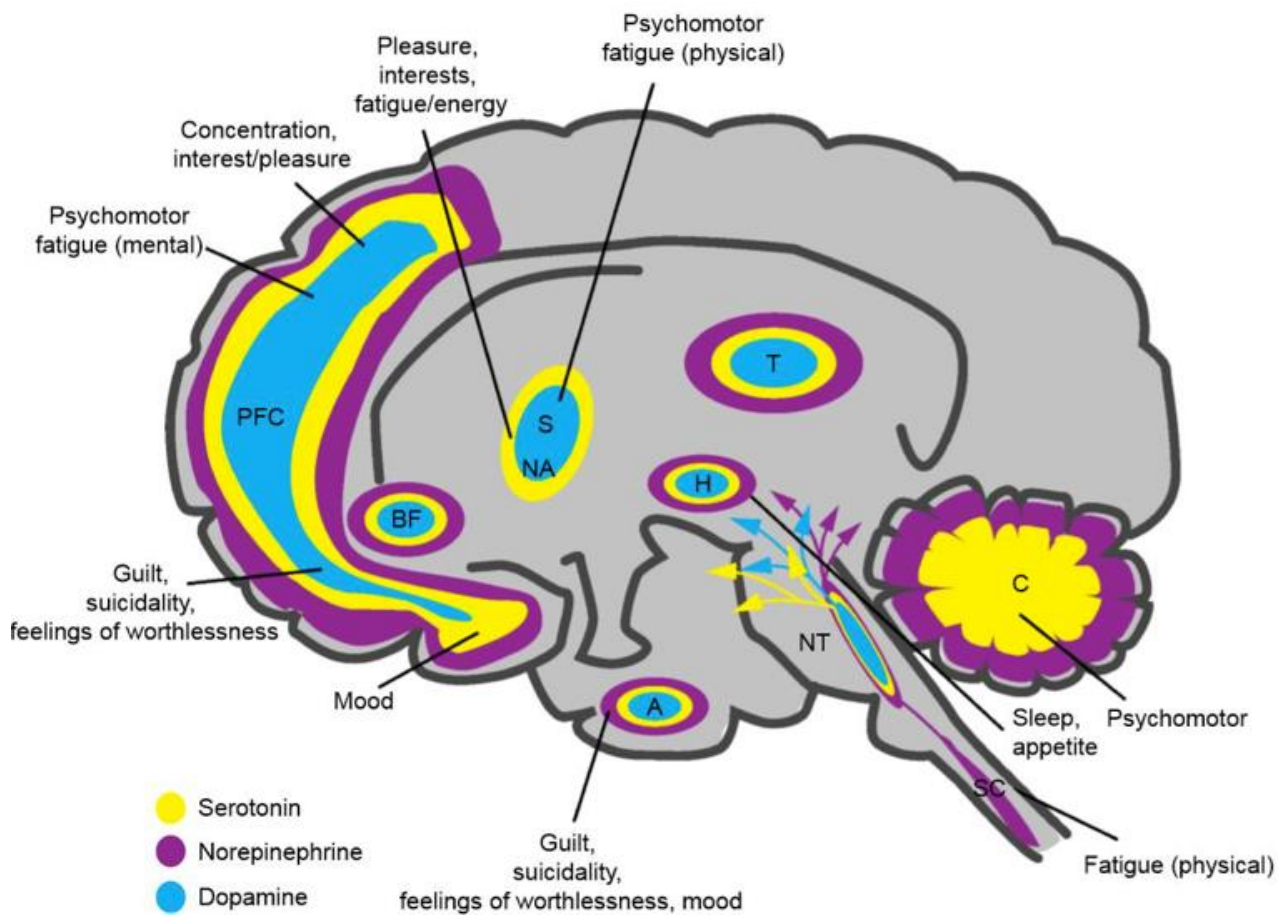

Figure 3. Schematic representation of brain regions involved in the pathogenesis of depression. (Saltiel et al., 2015).

Legend: A - tonsil; BF - basal forebrain; $\mathrm{C}$ is the cerebellum; $\mathrm{H}$ hypothalamus; NA - nucleus accumbens; NT - neurotransmitter centers; PFC - prefrontal cortex; S - striatum; SC - spinal cord; T - thalamus. 
The extensively reported data about neuroanatomic substrates of depression obtained by imaging technologies are dedicated to dramatic volumetric changes in two main brain areas - the prefrontal cortex and hippocampus (Krishnan et al., 2008).

In the prefrontal cortex, the degeneration of astrocytes (Domin et al., 2014), microglial pro-apoptotic changes (Banasr et al., 2008) and long-term depression (Vialou et al., 2014) are commonly reported to be associated with pro-depressant behavioral changes. Clinical data demonstrate atrophy of hippocampal neurons (Schmidt et al., 2007) and volumetric changes (Sheline et al., 1996) in postmortem brains of depressed patients. Depression is often accompanied by reduced hippocampal volume (Campbell et al., 2004), deficient neurogenesis (Henn et al., 2004) and downregulated expression of neuroplasticity factors (Shafia et al., 2017).

\section{Disrupted plasticity and oxidative stress in the brain as pathophysiological factors of depressive disorder}

An important hypothesis of mechanisms involved in the vulnerability to depression is aberrant neuroplasticity in the brain as this mechanism of neuronal adaptation is disrupted in depression (Wainwright et al., 2013). Neurotrophic factors, related molecules and signaling kinases associated 
with structural neuroplasticity and synaptoplasticity are among the crucial factors that are involved in the pathophysiology of depressive disorders (Schmidt et al., 2006). Stressors, e.g. emotional stressors, can diminish their expression, affecting neuronal survival, plasticity, cell migration and neurogenesis (Duman et al., 2012; Phillips, 2017).

Prominent neurotrophins include BDNF, GDNF, FGF, VEGF, FGF-2, NGF, NT-3 and NT-4; they are implicated in an animal emotionality and cognition (Jansson, 2011). In particular, signaling via BDNF and its receptor tropomyosin receptor kinase B TrkB plays an important role in the pathophysiology of depression and in the therapeutic mechanisms of antidepressants as BDNF-TrkB signaling is an integral part of learning, memory and long-term potentiation processes (Harrisberger et al., 2015) .

BDNF is a protein that promotes survival of neurons and widely expressed in the developing and adult central nervous system acting as a regulator of neuroplasticity, neurogenesis and synapse development (Choo et al., 2017). Considerable research has proven an important role of BDNF dysregulation, such as peripheral reduction in serum BDNF, in the development of depressive-like traits (Erickson et al., 2012; Yoshida et al., 2012). In consistency, postmortem studies of persons with clinical depression have 
revealed decreased protein BDNF content in the hippocampus (Duman and Monteggia, 2006). Importantly, altered BDNF signaling may affect homeostasis of microglia and astrocytes in the key depression-associated brain areas that can be reversed following abtidepressant treatment (Rial et al., 2015). Notably, following antidepressant treatment BDNF content is upregulated (Russo-Neustadt et al., 1999); subcutaneous or intrahippocampal injections of BDNF produce robust antidepressant and anxiolytic-like effects accompanied by increased cell survival in the hippocampus (Hoshaw et al., 2005; Schmidt and Duman, 2010). It is interesting to note, that injection of BDNF in the ventral tegmental area provokes depressive syndrome (Eisch et al., 2003). BDNF binding to its cognate receptor TrkB triggers downstream cascades, and among them phosphatidyl inositol-3 kinase (PI3K) - protein kinase B (Akt) cascade is the most extensively studied in depression research (Duman et al., 2012). Consistent with BDNF content reduction in the brain limbic regions following stress exposure, PI3K-Akt pathway activity is lowered in depressed individuals (Dwiwedi et al., 2006). Interestingly, there is a notion that genetic ablation of genes encoding BDNF is insufficient to cause depressive syndrome (Duman et al., 2012). This notion leads us to speculate that BDNF cannot be a major factor for the development of a susceptibility 
to a depressive syndrome by itself and some downstream elements of BDNF-related cascades can be better targets for understanding the role of BDNF in the development of depressive disorders (Duman et al., 2012).

Besides BDNF's role in depressive disorders, other neurotrophins may also contribute to neuroplasticity changes associated with depression (Naumenko et al., 2013). For instance, glial cell-line derived neurotrophic factor GDNF is an important factor for survival of serotonergic and dopaminergic neurons (Naumenko et al., 2013) and is downregulated following chronic stress paradigms of depressive syndrome (Liu et al., 2012). For the involvement of GDNF it was shown that stress-susceptible $\mathrm{BALB} / \mathrm{c}$ mice are characterized by reduced expression of this factor, while resilient animals of the C57 strain are characterized by upregulated basal level of GDNF (Palumbo et al., 2009).

VEGF is traditionally associated with the formation of new blood vessels while its overexpression is regarded as a marker of antidepressant-like changes (Warner-Schmidt and Duman, 2007). The relevance of VEGF as a marker of depression has also been highlighted through clinical research indicating the strong comorbidity between cardiovascular disorders and depression (Musselman et al., 1998; Salaycik et al., 2007; Newton et al., 
2013). Interestingly, astrocytes and microglia have direct interactions with blood vessels (Mulligan et al., 2004) and overexpression of VEGF by these cells is associated with increased permeability of the blood brain barrier (Argaw et al., 2012) that potentially may lead to increased infiltration of monocytes from systemic circulation thus exacerbating pro-inflammatory changes that typically accompany a stress response.

There is emerging concern about the role of oxidative stress in the pathogenesis of depression (Liu et al., 2015). Naturally, low levels of reactive oxygen species (ROS) and reactive nitrogen species (RNS) are produced by mitochondria (Cadenas et al., 2000) and play important roles in cell homeostasis (Cheignon et al., 2018). But ROS/RNS are high risk factors to damage brain tissue as brain contains relatively high levels of redox-active metals (Garbarino et al., 2015).

It is speculated that inconsistency of ameliorative results following antidepressant treatments can be related to differences in the brain contents of oxidative stress markers (Lindqvist et al., 2018) as disturbance in the ratio of pro-oxidants/anti-oxidants leads to the development of oxidative stress (Birben et al., 2012), a condition that is regarded as one of the fundamental 
vulnerability factors for the development of depressive syndrome (Michel et al., 2012).

A process of lipid peroxidation triggered by excessive ROS generation is an especially relevant marker of oxidative stress as the brain contains a high content of polyunsaturated lipids (Patel et al., 2016). A prominent marker of oxidative stress related to lipid peroxidation is malondialdehyde (MDA), that was shown to be upregulated in depressed individuals (Bajpai et al., 2014). Excessive production of ROS can also damage proteins generating irreversible protein carbonylation that is often accompanied by depressive syndrome and deficient hippocampal neuroplasticity (Vignisse et al., 2017).

\section{Rodent models of depression}

To model human disorders in animals is an important and challenging task as multiple psychological, emotional and physiological symptoms have subjective nature and can be affected by unique environmental conditions in human society (Nestler et al., 2010). It is important to notice that none of currently used animal models of depressive syndrome may perfectly replicate human depression and multiple limitations still exist (Berton et al., 2006). However, overlapping mechanisms and brain alterations between clinical data, post-mortem research, and animal models have resulted in the 
discoveryof effective treatment strategies that were elaborated in the first instance in animal models of depressive syndrome (Nestler et al., 2010). To establish a relevant animal model that can recapitulate and mimic some of the human disorder manifestations, certain validity criterion should be met (Strekalova et al., 2011), such as face validity, construct validity, and predictive validity (Willner, 1984). Face validity displays symptomatic traits of the disease; construct validity reflects interspecies similarity of the biochemical pathways (McKinney et al., 1969); and predictive validity confirms common effects upon pharmaceutical treatment (Willner, 1984).

Currently used translational models of depression can be divided into several groups, such as invasive models (e.g. bulbectomy based), genetic models (e.g. knock-out of genes important for serotonergic neurotransmission), stress models (e.g. intermale confrontation, maternal separation) and others (Fuchs et al., 2006; Valvassori et al., 2013). Below I will briefly review some of the established animal models of depressive syndrome that are especially frequently used.

Olfactory bulbectomy is an important invasive model of depression (Jarosic et al., 2007). Bulbectomy provokes profound biochemical changes that mimic a profile of human depression, and are also paralleled by behavioral 
alterations such as anhedonic state and despair behavior (Slattery et al., 2014).

Among depressive models that use physical stimuli a concept of repeated social defeats has gained extensive attention (Strekalova et al., 2008; Hammels et al., 2015) as it implicates excessive competition behavior and provokes development of depressive syndrome (Berton et al., 2006). In this model there is a situation of intermale confrontation, where one animal ascertains dominance and aggression whilst the other becomes submissive with depressive-like features (Krishnan et al., 2007). Following repeated experience of social defeat an animal displays a submissive phenotype reminiscent of depressive syndrome in humans, as well as anhedonia and motivational deficits (Kudryavtseva et al., 1991) that are reversible by antidepressant treatment (Rygula et al., 2006).

Stress models of depression are of particular significance (Duman, 2010). A learned helplessness model is a classical one (Bali et al., 2015) in this regard. In this model an animal is placed in a situation where it cannot escape from the dangerous environment that results in the formation of a state of helplessness, that is manifested as an absence of any attempts to struggle (Vollmayr et al., 2013). This model of coping deficit was initially 
elaborated in dogs and consisted of foot shock applications (Overmier et al., 1967) that was subsequently recapitulated in rodents (Maier et al., 1990).

Additional ways to model designated conditions is to use a paradigm of unpredictable mild stress of prolonged duration (Strekalova et al., 2004; Willner, 2005; Strekalova et al., 2006; Strekalova et al., 2011). Under these conditions the development of a depressive syndrome can be initiated following at least 14 days of stress exposure (Willner, 2005) and this model triggers a wide range of behavioral abnormalities, including depressive syndrome, aggression, cognitive deficits and fatigue, prevented by antidepressant treatments (Mutlu et al., 2014). As a stressor here can be employed random alteration of different conditions such as frequent change of the bedding, watering of bedding, disrupted day/night cycle, deprivation of food, water or social contacts. An important limitation of this model is great inter-strain differences in response to an applied hit: C57 mouse strain is a particularly vulnerable to this model while CD-1 strain has a higher proportion of resilient animals (Jung et al., 2014).

While these experimental models are widely applied in the preclinical study of depression, there is a certain need in experimental models that employs naturalistic approaches instead of artificial situations. Naturalistic 
challenges are of particular significance for depression research as they mimic risk factors typical for human society that we encounter in our daily life. Emotional stress is one of the most important risk factors for developing depressive syndrome in human society and their respective animal models are of a great use to overcome current limitations that invasive animal models or models of artificial challenges have. In this regard in chapter 4 we discuss our model of ultrasound of alternating frequencies.

To sum up it can be concluded that there is a lack of valid depression models based on naturalistic stimuli. In our daily life we encounter mostly emotional challenges that are associated with our social sphere. This notion makes methods and approaches based on emotional stress the most relevant when conducting translational research on predisposing factors of depression that we face in human society. Emotional stress does not implement any physical elements or elements of organic nature and it is based purely on cognitive processes of evaluation of information. 


\section{Changes in glycogen synthase kinase-3 (GSK-3)-related cascades during depression}

GSK-3 is a serine-threonine kinase that is activated and upregulated under various stress conditions that are extensively used to induce depressive syndrome (Pavlov et al., 2017). GSK-3 refers to two separate isoforms alpha and beta that have a high rate of homology and structural similarity, though structural differences determine the distinct functions between these molecules (Pavlov et al., 2017). While functions of beta isoform is well documented for its role in apoptosis, distress, and affective disorders, functions of alpha isoform remain largely unaddressed. Functional similarity of both isoforms have been suggested, but some regulatory activities of alpha isoform cannot be substituted by its beta isoform and vice versa. For example, genetic knock-out of the GSK-3 $\alpha$ isoform is not a lethal mutation, but result in deficient cognitive functions, whereas ablation of genes that encode the beta isoform is lethal, revealed by mouse studies (Sayas et al., 2012; Maurin et al., 2013).

Neuronal alpha isoform knock-out models generate mice that tend to be more anxious and with lowered explorative behavior (Kaidanovich-Beilin et al., 2009). Partial knock-out of beta isoform is not a lethal mutation but 
besides heightened anxiety these mice have severe cognitive impairments, memory deficiencies and lowered vertical activity. Knock-in GSK-3 $\beta$ models that produce mice with increased expression of beta isoform with replacement of Serine 9 to Alanine and thus resistant to inhibitory phosphorylation, provoke hyperactive behavioral phenotype that mimic traits of bipolar disorder (Prickaerts et al., 2006).

Emotional stress-induced activation of GSK-3 in wild type animals is underpinned by decreased pro-inhibitory serine phosphorylations that takes place in conjunction with increased corticosterone (CORT) release (Dobarro et al., 2013). This activation is closely linked to upstream proinflammatory changes (Fig. 5), as antagonists of TLR4 receptors prevent GSK-3 upregulation following stress exposure (Cheng et al., 2016). Activated GSK-3 is a potent suppressor of neuroplasticity and neurogenesis that can lead to deleterious effects on brain tissue (Beurel et al., 2015). Interestingly, GSK-3 underpins regulation of neuroplasticity and neurogenic processes during the embryonic stages of development, including cell migration and neuronal maturation (Sayas et al., 2012). While it was traditionally assumed that only the beta isoform was important for neural developmental processes, genetic methods of interference of 
regulatory RNAs display key role of alpha isoform as well (Gartido et al., 2006).

Regulation of GSK-3 activity consists of both regulation of expression and regulation of activity of these kinases. Functional antagonism of protein kinase B (Akt) and GSK-3 (Fig. 4) makes these two kinases to be convenient markers of depressive syndrome (Karege et al., 2011). In various paradigms of despair behavior elevated content of active GSK-3 $\beta$ isoforms is paralleled with decreased content of functionally inactive, phosphorylated, GSK-3 isoforms (Polter et al., 2010); pharmacological agents with antidepressant properties such as imipramine of fluoxetine also increase content of inactive forms of GSK-3. 


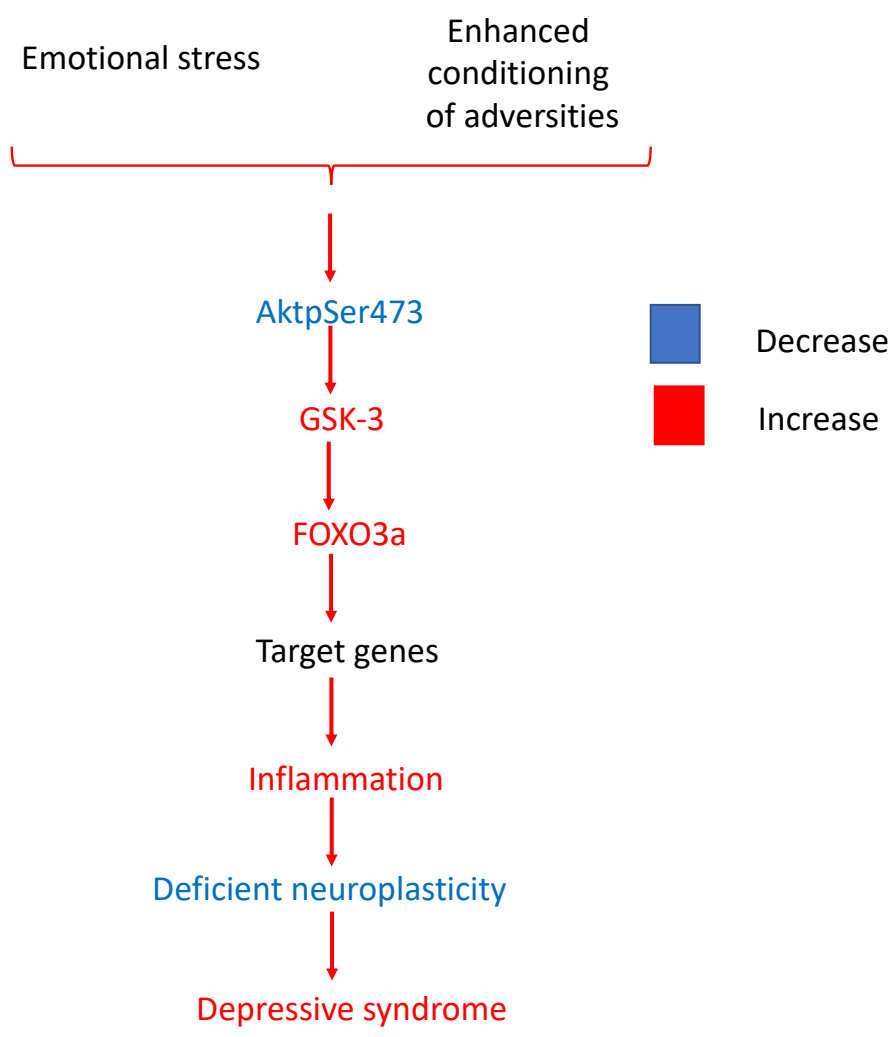

Figure 4. Schematic representation of top-to-bottom stress-induced molecular alterations related to GSK-3 cascade.

Severe stress disrupts brain neuroplasticity and especially neuroplasticity of limbic structures that is often associated with changes in glutamatergic neurons (Calabrese et al., 2012) that largely affects synaptic plasticity, an important component of learning processes and memory retention. GSK-3 
was shown to affect these processes leading to reduction of formation of new synapses and subsequently to long-term depression. GSK-3 $\beta$ antagonists prevent these stress-induced effects and increase NMDAdependent neurotransmission (Peineau et al., 2007).

\section{The role of vitamin $B 1$ (thiamine) in the mechanisms of neuropsychiatric disorders}

Vitamin B1 (thiamine) is a crucial vitamin to maintain normal animal physiology (Liu et al., 2017). Lack of thiamine can provoke profound metabolic disturbances, apoptotic changes, neurodegeneration and diminished neuroplasticity and neurogenesis (Liu et al., 2017). These data make thiamine supplementation an important approach to counteract these changes. Recently it was shown that thiamine pre-treatment prior to predation stress prevented stress-evoked suppression of hippocampal neurogenesis, manifesting in reduced densities of BrdU-positive and Ki67positive cells (Vignisse et al., 2017). Importantly, thiamine supplementation rescued stress-induced upregulation of protein carbonyl content, a marker of irreversible protein damage by oxidative stress (Vignisse et al., 2017). Thiamine deficiency affects brain functioning in many ways and impaired oxidative glucose metabolism is thought to underlie many of these changes 
(Gibson, 2007). Some studies have shown that thiamine is implicated in depression and affective disorders through modulation of GSK-3 activity as thiamine-based supplementations can exert anti-depressant-like effects and counteract stress-induced GSK-3 overexpression (Markova et al., 2016; Vignisse et al., 2017).

It is known that thiamine can display neuroprotective roles by affecting the activity of several regulatory proteins, such as cofactors of synthesis of adenosine triphosphoric acid (ATP) (thiamine phosphate and pyridoxal phosphate; Bettendorff et al., 2014). Additionally, thiamine is involved in regulation of mitochondrial metabolism thus affecting production of ROS (Abdou et al., 2015). Deficiency in thiamine content can provoke development of Gaie - Wernicke encephalopathy, polyneuropathy and other serious conditions, e.g. neurodegenerations, that affect normal functioning of the central nervous system and limbic structures (Abdou et al., 2015). Thiamine deficiency can be provoked by disbalanced diet or perturbations in the digestive tract, such as malabsorption syndrome; all these conditions are comorbid with major depression as suggested by clinical data (Torshin, 2009). Vitamin B1 deficiency was shown to aggravate the effect of ethanol toxicity on the nervous system, thus provoking alcoholic polyneuropathy 
with $10 \%$ prevalence rate among 40 to 70 y.o. cohort of people with alcoholism (Torshin, 2009).

Neuroprotective mechanisms of thiamine are of particular significance as long-lasting daily thiamine supplementation compared to standard selective serotonin reuptake inhibitors treatment exerted better Hamilton Depression Rating Scores in a clinical study (Ghaleiha et al., 2016). Interestingly, vitamin B1 has not only neuroprotective effects but also analgesic activity (Onk et al., 2018). Employment of thiamine as a supplement treatment to counteract these disabling conditions is advantageous for several reasons: thiamine is a nontoxic and has no side effects, can moderate pain and increase hippocampal neurogenesis thus also affecting cognitive skills (Vignisse et al., 2017; Onk et al., 2018). Nowadays there are treatment strategies that include combined application of thiamine and prominent antidepressants, glucocorticosteroids and other drugs that substantially increase effectiveness of the employed treatments (Johnson et al., 2018). 


\section{HYPOTHESIS AND AIMS}

We hypothesized that depressive syndromes of various aetiologies might have overlapping molecular mechanisms. Upregulation of GSK-3, functionally related pro-inflammatory mechanisms and oxidative stress likely underlie these disorders. To study these conditions, we used two mouse models of depressive syndrome of distinct aetiologies: an ultrasound model of "emotional stress" and modified forced swim test that models enhanced learning of adverse memories.

In the ultrasound stress study part mice were chronically exposed to randomly alternated ultrasound frequencies that mimicked signals of distress that are naturally emitted by rodents. We studied depressive-like behavioral changes as well as hippocampal gene and protein expression of both GSK-3 $\beta$ and GSK-3 $\alpha$ and associated molecules FOXO3a, PTEN and AktpSer473. We also aimed to study the relationships between expression of neuroplasticity factors and expression of pro-inflammatory cytokines, microglial activation and parameters of oxidative stress in animals with depressive syndrome. 
In the modified forced swim test we aimed to investigate whether or not overexpression of GSK-3 isoforms have distinct profiles. Correlation analysis between pro-inflammatory cytokine expression and GSK-3 isoforms was performed. Concentration of stress hormone corticosterone, brain content of oxidative stress markers and c-Fos activation was assessed as well. Furthermore, we investigated whether these changes can be prevented by thiamine and imipramine supplementations.

\section{References}

APA. Diagnostic and Statistical Manual of Mental Disorders-5. Washington, DC. American Psychiatric Association. 2013.

Abdou E, Hazell AS. Thiamine deficiency: an update of pathophysiologic mechanisms and future therapeutic considerations. Neurochem. Res. 2015. 40: 353-361.

Argaw AT, Asp L, Zhang J, Navrazhina K, Pham T, Mariani JN, Mahase S, Dutta DJ, Seto J, Kramer EG, Ferrara N, Sofroniew MV, John GR. Astrocyte-derived VEGF-A drives blood-brain barrier disruption in CNS inflammatory disease. J Clin Invest. 2012. 122: 2454-2468.

Bajpai A, Verma AK, Srivastava M, Srivastava R. Oxidative stress and major depression. J. Clin. Diagn. Res. 2014. 8 (12) : Cc04-Cc07. doi: 10.7860/ JCDR/2014/10258.5292

Baldessarini RJ. Mood-stabilizing agents. Chapter 3 in: Chemotherapy in Psychiatry: Pharmacologic Basis of Treatments for Major Mental Illness (3rd edition). 2013. 89-154.

Bali A, Jaggi AS. Electric foot shock stress: a useful tool in neuropsychiatric studies Rev. Neurosci. 2015. 26(6): 655-677.

Banasr M, Duman RS. Glial loss in the prefrontal cortex is sufficient to induce depressive-like behaviors. Biol. Psychiatry. 2008. 64(10): 863-870. http://dx.doi.org/10.1016/j.biopsych.2008. 06.008 
Berrios G.E. Melancholia and Depression during the 19th Century: A Conceptual History. Brit. J. of Psychiatry. 1988. 153: 298-304.

Berton O, Nestler EJ. New approaches to antidepressant drug discovery: beyond monoamines. Nat. Rev. Neurosci. 2006. 7(2): 137-151. http://dx.doi.org/10.1038/nrn1846

Beurel E, Grieco SF, Jope RS. Glycogen synthase kinase-3 (GSK3): regulation, actions, and diseases. Pharmacol Ther. 2015. 148, 11431. DOI:10.1016/j.pharmthera.2014.11.016

Birben, E., Sahiner, U. M., Sackesen, C., Erzurum, S., and Kalayci, O. Oxidative stress and antioxidant defense. World Allergy Organ J. 2012. (1), 9-19. doi: 10.1097/WOX.0b013e3182439613

Bjorklund A, Dunnett SB. Dopamine neuron systems in the brain: an update. Treands Neurosci. 2007. 30(5):194-202.

Bjorkqvist K. Social defeat as a stressor in humans. Physiol Behav. 2001; 73:435-442.

Boku S, Nakagawa S, Toda H, Hishimoto A. Neural basis of major depressive disorder: beyond monoamine hypothesis. Psychiatry Clin Neurosci. 2018. 72(1):3-12.

Bravo JA, Dinan TG, Cryan JF. Early-Life Stress Induces Persistent Alterations in 5-HT1A Receptor and Serotonin Transporter MRNA Expression in the Adult Rat Brain. Front. in Mol. Neurosci. 2014. 7: $1-9$.

Cadenas E, Davies KJ. Mitochondrial free radical generation, oxidative stress, and aging. Free Radic. Biol. Med. 2000. 29 (3-4), 222-230. doi: 10.1016/S0891-5849(00)00317-8

Campbell S, Marriott M, Nahmias C, MacQueen GM. Lower hippocampal volume in patients suffering from depression: a meta-analysis. Am. J. Psychiatry. 2004. 161: 598-607.

Can A, Schulze TG, Gould TD. Molecular actions and clinical pharmacogenetics of lithium therapy. Pharmacol Biochem Behav 2014. 123: 3-16.

Calabrese F, Guidotti G, Molteni R, Racagni G, Mancini M. Stress-Induced Changes of Hippocampal NMDA Receptors: Modulation by Duloxetine Treatment. PLoS ONE. 2012. 7:5.

Cheignon C, Tomas M, Bonnefont-Rousselot D, Faller P, Hureau C, Collin F. Oxidative stress and the amyloid beta peptide in alzheimer's disease. Redox. Biol. 2018. 14: 450-464. doi: 10.1016/j.redox.2017.10.014

Cuellar A, Johnson SL, Wintters R. Distinctions between bipolar and unipolar depression. Clin Psychol Rev. 2005. 25(3): 307-339. 
Choo M, Miyazaki TT, Yamazaki M, Kawamura TT, Nakazawa T, Zhang J, Tanimura A, Uesaka N, Watanabe M, Sakimura K, Kano M. Retrograde BDNF to TtrkB signaling promotes synapse elimination in the developing cerebellum. Nat Commun. 2017. 8, 195.

Chrousos GP, Gold PW. The concepts of stress and stress system disorders. Overview of physical and behavioural homeostasis. JAMA. 1992. 267, 1244-52.

Clark L, Chamberlain SR, Sahakian BJ. Neurocognitive mechanisms in depression: implications for treatment. Annu Rev Neurosci. 2009. 32: 57-74. doi: 10.1146/annurev.neuro.31.060407.125618

Delgado PL. Depression: The case for a monoamine deficiency. J. of Clin. Psych. 2000. 61(6): 7-11.

Dobarro M, Gerenu G, Ramirez M. Propranolol reduces cognitive deficits, amyloid and tau pathology in Alzheimer's transgenic mice. Int J Neuropsychopharmacol. 2013. 16(10): 2245-57.

Domin H, Szewczyk B, Wozniak M, Wawrzak-Wlecial A, Smialowska M. Antidepressant-like effect of the mGluR5 antagonist MTEP in an astroglial degeneration model of depression. Behav. Brain Res., 2014. 273: 23-33. http://dx.doi.org/ 10.1016/j.bbr.2014.07.019

Drevets WC. Functional neuroimaging studies of depression: the anatomy of melancholia. Annu Rev Med. 1998. 49:341-61.

Duman CH. Models of depression. Vitam. Horm. 2010. 82: 1-21.

Duman RS, Monteggia LM. A neurotrophic model for stress-related mood disorders. Biological Psychiatry. 2006. 59(12):1116-1127.

Duman RS, Voleti B. Signaling pathways underlying the pathophysiology and treatment of depression: novel mechanisms for rapid-acting agents. Trends Neurosci. 2012. 35(1): 47-56. http://dx.doi.org/10.1016/j.tins.2011.11.004

Dwivedi Y, Rizavi HS, Conley RR, Pandey GN. ERK MAP kinase signaling in post-mortem brain of suicide subjects: differential regulation of upstream Raf kinases Raf-1 and B-Raf. Mol. Psychiatry. 2006. 11(1): 86-98. http://dx.doi.org/10.1038/sj. mp.4001744

Eisch AJ, Bolanos CA,de Wit J, Simonak RD, Pudiak CM, Barrot M, Verhaagen J, Nestler EJ. Brain-derived neurotrophic factor in the ventral midbrain-nucleus accumbens pathway: a role in depression. Biol psychiatry. 2003. 54(10):994-1005.

Erickson KI, Miller DL, Roecklein KA. The aging hippocampus: interactions between exercise, depression, and BDNF. Neuroscientist. 2012. 18(1): 82-97. 
Evans DL, Charney DS, Lewis L, Golden RN, Gorman JM, Krishnan KR, Nemeroff CB, Bremner JD, Carney RM, Coyne JC, Delong MR, Frasure-Smith N, Glassman AH, Gold PW, Grant I, Gwyther L, Ironson G, Johnson RL, Kanner AM, Katon WJ, Kaufmann PG, Keefe FJ, Ketter T, Laughren TP, Leserman J, Lyketsos CG, McDonald WM, McEwen BS, Miller AH, Musselman D, O'Connor C, Petitto JM, Pollock BG, Robinson RG, Roose SP, Rowland J, Sheline Y, Sheps DS, Simon G, Spiegel D, Stunkard A, Sunderland T, Tibbits P Jr, Valvo WJ. Mood disorders in the medically ill: scientific review and recommendations. Biol Psychiatry. 2005. 58:175-189.

Fabricius K, Wo E. The impact of maternal separation on adult mouse behavior and on the total neuron number in the mouse hippocampus. Brain Struct. Funct. 2008. 403-416 http://dx.doi.org/10.1007/s00429-007-0169-6.

Freland L, Beaulieu JM. Inhibition of GSK3 by lithium, from single molecules to signaling networks. Front Mol Neurosci. 2012. 5: 14.

Fuchs E, Flïugge G. Experimental animal models for the simulation of depression and anxiety. Dialogues. Clin. Neurosci. 2006. 8(3): 323333.

Garbarino VR, Orr ME, Rodriguez KA, Buffenstein R. Mechanisms of oxidative stress resistance in the brain: lessons learned from hypoxia tolerant extremophilic vertebrates. Arch. Biochem. Biophys. 2015. 576, 8-16. doi: 10.1016/j.abb.2015.01.029

Gardner KL, Thrivikraman KV, Lightman SL, Plotsky PM, Lowry CA. Early life experience alters behavior during social defeat: focus on serotonergic systems. Neuroscience. 2005. 136:181-191.

Gartido JJ, Sim D, Varea O, Wandosell F. GSK3 alpha and GSK3 beta are necestaty for axon formation. FEBS Lett. 2007. 581. 8: 15791586.

Ghaleiha A, Davari H, Jahangard L, Haghighi M, Ahmadpanah M, Seifrabie MA, Bajoghli H, Holsboer-Trachsler E, Brand S. Adjuvant thiamine improved standard treatment in patients with major depressive disorder: results from a randomized, double-blind, and placebo-controlled clinical trial. Eur. Arch. Psychiatry. Clin. Neurosci. 2016. doi: 10.1007/s00406-016-0685-6.

Gideons ES, Lin PY, Mahgoub M, Kavalali ET, Monteggia LM. Chronic lithium treatment elicits its antimanic effects via BDNF-TrkB dependent synaptic downscaling. Elife. 2017. 16: 6. doi: 10.7554/eLife. 25480 . 
Golden SA, Covington HE 3rd, Berton O, Russo SJ. A standardized protocol for repeated social defeat stress in mice. Nat Protoc. 2011. 6: 1183-1191.

Gong Q, He Y. Depression, neuroimaging and connectomics: a selective overview. Biol Psychiatry. 2015. 77(3): 223-235

Goto T., Toyoda A. A Mouse Model of Subchronic and Mild Social Defeat Stress for Understanding Stress-induced Behavioral and Physiological Deficits. J. Vis. Exp. 2015. 105: 1-11.

Hammels C, Pishva E, De Vry J, van der Hove DL, Prickaerts J, van Winkel R, Selten JP, Lesch KP, Daskalakis NP, Steinbusch HW, van Os J, Kenis G, Rutten BP. Defeat stress in rodents: from behavior to molecules. Neurosci. Biobehav. 2015. 59: 111-140.

Harrisberger F, Smieskova R, Schmidt A, Lenz C, Walter A, Wittfeld K, Grabe HJ, Lang UE, Fusar-Poli P, Borgwardt S. BDNF Val66Met polymorphism and hippocampal volume in neuropsychiatric disorder: a systematic review and meta-analysis. Neurosci Biobehav Rev. 2015. 55:107-118.

Hasler G. Parhophysiology of depression: do we have any solid evidence of interest to clinicians? World Psych. 2010. 9:155-161.

Henn FA, Vollmayr B. Neurogenesis and depression: etiology or epiphenomenon? Biol. Psychiatry. 2004. 56(3): 146-150.

Herman JP, McKlveen JM, Ghosal S, Kopp B, Wulsin A, Makinson R, Scheimann J, Myers B. Regulation of the hypothalamic-pituitaryadrenocortical stress response. Compr Physiol. 2016. 6(2): 603-621.

Holsboer F. Stress, hypercortisolism and corticosteroid receptors in depression: imlpications for therapy. J Affect Disord. 2001. 62, 7791.

Hoshaw BA, Malberg JE, Lucki I. Centraladministration of IGF-I and BDNF leads tolong-lasting antidepressantlike effects. // Brain Research. 2005. 1037: 204-208.

Huot RL, Thrivikraman KV, Meaney MJ, Plotsky PM. Development of adult ethanol preference and anxiety as a consequence of neonatal maternal separation in Long Evans rats and reversal with antidepressant treatment. Psychopharmacology (Berlin). 2001. 158: 366-373.

Hyman SE. How mice cope with stressful social situations. Cell. 2007. 131(2): 232-234. http://dx.doi.org/10.1016/j.cell.2007.10.008

Ieraci A, Mallei A, Popoli M. Social isolation stress induces anxiousdepressive-like behavior and alterations of neuroplasticity-related genes in adult male mice. Neural Plast. 2016. 2016:6212983. 
Jansson L. Studies on cellular changes and amnesia in rat model of electroconvulsive therapy. Academic Dissertation. 2011.

Jesulola E, Micalos P, Baguley IJ. Understanding the Pathophysiology of Depression: From Monoamines to the Neurogenesis Hypothesis Model - Are We There Yet? Behavioural Brain Research. 2018. 341: 79-90.

Jiang Z, Rajamanickam S, Justice NJ. Local corticotropin-releasing factor signaling in the hypothalamic paraventricular nucleus. J Neurosci. 2018. 38(8):1874-1890.

Johnson J, Fox V. Beyond Thiamine: Treatment for Cognitive Impairment in Korsakoff's Syndrome. Psychosomatics. 2018. 59(4): 311-317. doi: 10.1016/j.psym.2018.03.011.

Jung YH, Hong SI, Ma SX, Hwang JY, Kim JS, Lee JH, Seo JY, Lee SY, Jang CG. Strain differences in the chronic mild stress animal model of depression and anxiety in mice. Biomol Ther (Seoul). 2014. 22: 453-459.

Karege F, Perroud N, Burkhardt S, Fernandez R, Ballmann E, La Harpe R, Malafosse A. Alterations in phosphatidylinositol 3-kinase activity and PTEN phosphatase in the prefrontal cortex of depressed suicide victims. Neuropsychobiotogy. 2011. 63: 224-231

Kheirbek MA, Klemenhagen KC, Sahay A, Hen R. Neurogenesis and generalization: a new approach to stratify and treat anxiety disorders. Nat Neurosci. 2012. 15:1613-1620.

Kessler RC, Berglund P, Demler O, Jin R, Koretz D, Merikangas KR, Rush AJ, Walters EE, Wang PS. The epidemiology of major depressive disorder results from the national comorbidity survey replication (NCS-R). JAMA 289, 3095-3105.

Kessler RC, Bromet EJ. The epidemiology of depression across cultures. Annu. Rev. Public Health. 2013. 34: 119-38.

Kendler KS. The phenomenology of major depression and the representativeness and nature of DSM criteria. Am J Psychiatry 2016. 173: 771-780

Kim S, Lee KU. Research on Potential Biomarker Correlates for Suicidal Behavior: A Review. Asia-Pacific Psychiatry. 2017. 9(4): 1-11.

Krishnan V, Han MH, Graham DL, Berton O, Renthal W, Russo SJ, Laplant Q, Graham A, Lutter M, Lagace DC, Ghose S, Reister R, Tannous P, Green TA, Neve RL, Chakravarty S, Kumar A, Eisch AJ, Self DW, Lee FS, Tamminga CA, Cooper DC, Gershenfeld HK, Nestler EJ. Molecular adaptations underlying susceptibility and resistance to social defeat in brain reward regions. Cell. 2007. 131:391-404 
Krishnan V, Nestler EJ. The molecular neurobiology of depression. Nature. 2008. 455(7215): 894-902. http://dx.doi.org/10. 1038/nature07455

Kudryavtseva NN, Bakshtanovskaya IV, Koryakina LA. Social model of depression in mice of C57BL/6J strain. Pharmacol Biochem Behav. 1991. 38: 315-320.

Liu Q, Zhu HY, Li B, Wang YQ, Yu J, Wu GC. Chronic clomipramine treatment restores hippocampal expression of glial cell line-derived neurotrophic factor in a rat model of depression. J Affect Disord. 2012. 141(2-3):367-372.

Liu T, Zhong S, Liao X, Chen J, He T, Lai S. A meta-analysis of oxidative stress markers in depression. PLoS One. 2015. 10 (10): e0138904. doi: 10.1371/journal.pone.0138904

Liu D, Ke Z, Luo J. Thiamine Deficiency and Neurodegeneration: The Interplay among oxidative stress, endoplasmic reticulum stress and autophagy. Mol Neurobiol. 2017. 54: 5440-5448.

Lindqvist D, Wolkowitz OM, Picard M, Ohlsson L, Bersani FS, Fernstrom, J. Circulating cell-free mitochondrial DNA, but not leukocyte mitochondrial DNA copy number, is elevated in major depressive disorder. Neuropsychopharmacology. 2018.43 (7): 1557-1564. doi: 10.1038/s41386-017-0001-9

Lopez AD, Murray CC. The global burden of disease, 1990-2020. Nat Med. 1998. 4: 1241-1243.

Maier SF. Role of fear in mediating shuttle escape learning deficit produced by inescapable shock. J Exp Psychol Anim Behav Process. 1990. 16: 137-149.

Maurin H, Lechat B, Dewachter I, Ris L, Louis J, Borghgraef P, Devijver $H$, Jaworski T, van Leuvin F. Neurological characterization of mice deficient in GSK3a highlight pleiotropic physiological functions in cognition and pathological activity as Tau kinase. Mol Brain. 2013. 6-27.

McKinney WT Jr, Bunney WE Jr. Animal model of depression. I. Review of evidence: implications for research. Arch Gen Psychiatry. 1969. 21: 240-248.

Meltzer H, Vostanis P, Ford T, Bebbington P, Dennis MS. Victims of bullying in childhood and suicide attempts in adulthood. Eur Psychiatry. 2011. 26: 498-503.

Michel TM, Pulschen D, Thome J. The role of oxidative stress in depressive disorders. Curr. Pharm. Des. 2012. 18 (36): 5890-5899. doi: $10.2174 / 138161212803523554$ 
Moore RY, Bloom FE. Centtral catecholamine neuron systems: anatomy and physiology of the norepinephrine and epinephrine systems. Ann Rev Neurosci. 1979. 2:113-168.

Muller C, Jacobs B. Handbook of the behavioral neurobiology of serotonin. London: Academic. Volume 21. 51-59.

Mulligan SJ, MacVicar BA. Calcium transients in astrocyte endfeet cause cerebrovascular constrictions. Nature. 2004. 431: 195-199.

Musselman DL, Evans DL, Nemeroff CB. The relationship of depression to cardiovascular disease: epidemiology, biology, and treatment. Arch Gen Psychiatry. 1998. 55: 580-592.

Mutlu O, Gumuslu E, Ulak G, Celikyurt IK, Kokturk S, Kir HM, Akar F, Erden F. Effects of fluoxetine, tianeptine and olanzapine on unpredictable chronic mild stress-induced depression-like behavior in mice. Life Sci. 2012. 91: 1252-1262.

Naumenko VS, Bazovkina DV, Semenova AA, Tsybko AS, Il'chibaeva TV, Kondaurova EM, Popova NK. Effect of glial cell line-derived neurotrophic factor on behavior and key members or the brain serotonin system in mouse strains genetically predisposed to behavioral disorders. J Neurosci Res. 2013. 91(12):1628-1638.

Nestler E., Hyman S. Animal models of neuropsychiatric disorders. Nat. Neurosci. 2010. 13: 1161-1169.

Newton SS, Fournier NM, Duman RS. Vascular growth factors in neuropsychiatry. Cell Mol Life Sci. 2013. 70: 1739-1752.

Okasha A. Mental Health in Pharaonic Egypt. Egypt J Psychiatry.1978. $1(1): 3-12$.

Onk D, Mammadov R, Suleyman B, Ferda Keskin Cimen, Cankaya M, Gul V, Altuner D, Senol O, Kadioglu Y, Malkoc I, Suleyman H. The effect of thiamine and its metabolites on peripheral neuropathic pain induced by cisplatin in rats. Exp Anim. 2018. 67(2): 259-269. doi: 10.1538/expanim.17-0090

Overmier JB, Seligman ME. Effects of inescapable shock upon subsequent escape and avoidance responding. J Comp Physiol Psychol. 1967. 63: 28-33.

Palumbo ML, Zorrilla Zubilete MA, Cremaschi GA, Genaro AM. Different effect of chronic stress on learning and memory in BALB/c and C57BL/6 inbred mice: Involvement of hippocampal NO production and PKC activity. Stress. 2009. 12(4): 350-361. http://dx.doi.org/10.1080/10253890802506383. 
Patel M. Targeting oxidative stress in central nervous system disorders. Trends Pharmacol. Sci. 2016. 37 (9): 768-778. doi: 10.1016/j.tips.2016.06.007

Pemeau S, Taghibigtou C, Bradtey C, Wong TP, Liu L, Lu J, Lo E, Wu D, Saute E, Bouschet T, Matthews P, Isaac JT, Bortolotto ZA, Wang YT, Collingridge GL. LTP inhibits LTD in the hippocampus via regulation of GSK3beta. Neuron. 2007. 53: 703-717.

Pratt LA, Brody DJ. Depression in the United States household population, 2005-2006. United States of America: NCHS Data Brief. 2008. 7: $1-8$.

Prickaerts J, Moechars D, Cryns K. Transgenic mice overexpressing glycogen synthase kinase 3P: a putative model of hyperactivity and mania. Journal of Neuroscience. 2006. 26(35): 9022-9029

Pollak DD, Rey CE, Monje FJ. Rodent models in depression research: classical strategies and new directions. Ann. Med. 2010. 42(4): 252264.

Polter A, Beurel E, Yang S, Garner R, Song L, Miller CA, Sweatt JD, McMahon L, Bartotucci AA, Li X, Jope RS. Defciency in the inhibitory serine-phosphorylation of glycogen synthase kinase- 3 increases sensitivity to mood disturbance. Neuropsychopharmacotogy. 2010. 35(5): 1761 - 1774 .

Porsolt R, Pichon M, Jalfre M. Depression: a new animal model sensitive to antidepressant treatments. Nature. 1977. 266. 5604: 730-732.

Phillips C. Brain-Derived Neurotrophic Factor, Depression, and Physical Activity: Making the Neuroplastic Connection. Neural Plasticity. 2017. doi: $10.1155 / 2017 / 7260130$.

Ramponi C, Barnard PJ, Nimmo-Smith I. Recollection deficits in dysphoric mood: an effect of schematic models and executive mode? Memory. 2004. 12(5): 655-670.

Benazzi F. Various forms of depression. Dialogues Clin Neurosci. 2006. 8(2): 151-161.

Reus GZ, Fernandes GC, de Moura AB, Silva RH, Darabas AC, de Souza TG, Abelaira HM, Carneiro C, Wendhausen D, Michels M, Pescador B, Dal-Pizzol F, Macedo DS, Quevedo J. Early life experience contributes to the developmental programming of depressive-like behavior, neuroinflammation and oxidative stress. J. Psychiatr. Res. 2017. 95: 196-207.

Rial D, Lemos C, Pinheiro H, Duarte JM, Goncalves F, Real J, Prediger Rn Goncalves N, Gomes CA, Canas P, Agostinho P, Cunha R. 
Depression as a glial-based synaptic dysfunction. Front Cell Neurosci. 2016. 9:521.

Ribeiro JD, Huang X, Fox KR, Franklin JC. Depression and hopelessness as risk factors for suicide ideation, attempts and death: meta-analysis of longitudibal studies. Br J Psychiatry. 2018. 212(5): 279-286.

Robinson ESJ. Translational new approaches for investigating mood disorders in rodents and what they may reveal about the underlying neurobiology of major depressive disorder. Philos. Trans. R. Soc. Lond. B. Biol. Sci. 2018. 373: 1-11.

Roque S, Mesquita AR, Palha JA, Sousa N, Correia-Neves M. The behavioral and immunological impact of maternal separation: a matter of timing. Front. Behav. Neurosci. 2014. 8: 1-10.

Russo-Neustadt A, Beard R, Cotman C. Excersie, antidepressant medications, and enhanced brain derived neurotrophic factor expression. Neuropsychopmarmacology. 1999. 21(5):679-82.

Rygula R, Abumaria N, Domenici E, Hiemke C, Fuchs E. Effects of fluoxetine on behavioral deficits evoked by chronic social stress in rats. Behav Brain Res. 2006. 174: 188-192

Saltiel PF, Silvershein DI. Major Depressive Disorder: Mechanism-Based Prescribing for Personalized Medicine. Neuropsychiatric Disease and Treatment. 2015. 11: 875-888.

Salaycik KJ, Kelly-Hayes M, Beiser A, Nguyen AH, Brady SM, Kase CS, Wolf PA. Depressive symptoms and risk of stroke: the Framingham Study. Stroke. 2007. 38: 16-21.

Sayas CL, Jurado J, Avila J, Villanueva N. Structural and Functional Relationships Between GSK3 Proteins Current Biotechnotogy. 2012. 1: $80-87$.

Schmidt HD, Duman RS. The role of neurotrophic factors in adult hippocampal neurogenesis, antidepressant treatments and animal models of depressive-like behavior. Behav. Pharmacol. 2007. 18(56): 391-418. http://dx.doi.org/10.1097/FBP.0b013 e3282ee2aa8

Schmidt HD, Duman RS. Peripheral BDNF produces antidepressant-like effects in cellular and behavioral models. Neuropsychopharmacology. 2010. 35(12):2378-2391.

Shafia S, Vafaei AA, Samaei SA, Bandegi AR, Rafiei A, Valadan R, Hosseini-Khah Z, Mohammadkhani R, Rashidy-Pour A. Effects of moderate treadmill exercise and fluoxetine on behavioural and cognitive deficits, hypothalamicpituitary- adrenal axis dysfunction and alternations in hippocampal BDNF and mRNA expression of apoptosis - related proteins in a rat model of post-traumatic stress 
disorder. Neurobiol. Learn. Mem. 2017. 139: 165-178. doi: 10.1016/j.nlm.2017.01.009.

Sheline YI, Wang PW, Gado MH, Csernansky JG, Vannier MW. Hippocampal atrophy in recurrent major depression. Proc. Natl. Acad. Sci. U.S.A. 1996. 93: 3908-3913.

Showraki M. Reactive depression: Lost in translation! J Nerv Ment Dis. 2019. 207(9): 755-759.

Selye H. A syndrome produced by diverse nocuous agents. Nature. 1936. 138: 32.

Slattery DA, Cryan JF. The ups and downs of modelling mood disorders in rodents. ILAR. J. 2014. 55(2): 297-309.

Strekalova T, Spanagel R, Bartsch D, Henn F, Gass P. Stressed-induced anhedonia in mice is associated with deficits in forced swimming and exploration. Neuropsychopharm. 2004. 11: 2007-2017.

Strekalova T, Gorenkova N, Schunk E, Dolgov O, Bartsch D. Selective effects of citalopram in the mouse model of stress-induced anhedonia with control effects for chronic stress. Behav Pharm. 2006. 17:271-287. doi: 10.1097/00008877-200605000-00008.

Strekalova T. In: Behavioral models in stress research. Volume I. Kalueff A, LaPorte J, editor. New York, Nova Science Publishers Inc. Optimization of the chronic stress depression model in C57 BL/6 mice: evidences for improved validity. 2008. 111-157.

Strekalova T, Couch Y, Kholod N, Boyks M, Malin D, Leprince P, Steinbusch HM. Update in the methodology of the chronic stress paradigm: internal control matters. Behav Brain Funct. 2011. 7: 9. doi: 10.1186/1744-9081-7-9.

Torshin IY. Sensing the change from molecular genetics to personalized medicine. Nova Biomedical Books, NY, USA. In "Bioinformatics in the Post-Genomic Era" series, 2009. ISBN 1-60692-217-0.

Uzun S, Kozumplik O, Topic R, Jakovjevik M. Depressive disorders and comorbidity: somatic illness vs. side effect. Psychiatr. Danub. 2009. 21(3): 391-8.

Valvassori SS, Budni J, Varela RB, Quevedo J. Contributions of animal models to the study of mood disorders Rev. Bras. Psiquiatr. 2013. 35: 121-131.

Vialou V, Bagot RC, Cahill ME, Ferguson D, Robison AJ, Dietz DM, Fallon B, Mazei- Robison M, Ku SM, Harrigan E, Winstanley CA, Joshi T, Feng J, Berton O, Nestler EJ. Prefrontal cortical circuit for depression- and anxiety-related behaviors mediated by 
cholecystokinin: role of DeltaFosB. J. Neurosci. 2014. 34(11): 3878-3887. http://dx. doi.org/10.1523/JNEUROSCI.1787-13.2014

Wainwright S, Galea L. The neural plasticity theory of depression: assessing the roles of adult neurogenesis and PSA-NCAM within thte hippocampus. Neural Plast. 2013. 2013:805497.

Warner-Schmidt JL, Duman RS. VEGF is an essential mediator of the neurogenic and behavioral actions of antidepressants. Proc. Natl. Acad. Sci. USA. 2007. 104(11): 4647-4652.

Willner P. The validity of animal models of depression. Psychopharmacol. 1984. 83(1): 1-16.

Willner P. Chronic mild stress (CMS) revisited: consistency and behavioural neurobiological concordance in the effects of CMS. Neuropsychobiol. 2005. 52: 90-110.

Yehuda R, Joëls M, Morris RG. The memory paradox. Nat Rev Neurosci. 2010. 11(12): 837-9. doi: 10.1038/nrn2957.

Yoshida T, Ishikawa M, Niitsu T, Nakazato M, Watanabe H, Shiraishi T, Shiina A, Hashimoto T, Kanahara N, Hasegawa T, Enohara M, Kimura A, Iyo M, Hashimoto K. Decreased serum levels of mature brain-derived neurotrophic factor (BDNF), but not its precursor proBDNF, in patients with major depressive disorder. PloS One. 2012. 7(8):e42676.

Zanier-Gomes PH, de Abreu Silva TE, Zanetti GC, Benati ER, Pinheiro NM, Murta BM, CremaVO. Depressive behavior induced by social isolation of predisposed female rats. Physiol Behav. 2015. 151:292297. 


\section{Chapter 2}

Elucidating the functions of brain GSK3 $\alpha$ : Possible synergy with GSK3 $\beta$ upregulation and reversal by antidepressant treatment in a mouse model of depressive-like behaviour 
Elucidating the functions of brain GSK3 $\alpha$ : possible synergy with GSK3 $\beta$ upregulation and reversal by antidepressant treatment in a mouse model of depressive-like behaviour

Dmitri Pavlova,b*, Nataliia Markovab,c,d*, Lucien Bettendorffa, Vladimir Chekhonine, Igor Pomytkinf, Victoria Ludinovag, Andrei Svistunovb, Eugene Ponomarevh, Klaus-Peter Leschb,c,i, Tatyana Strekalova,b,c,i\#

aGIGA-Neurosciences, University of Liege, Liege, Belgium; bSechenov First Moscow State Medical University, Institute of Molecular Medicine, Laboratory of Psychiatric Neurobiology and Department of Normal Physiology, Moscow, Russia; cDepartment of Neuroscience, Maastricht University, Maastricht University, Maastricht, Netherlands; dLaboratory of Cognitive Dysfunctions, Institute of General Pathology and Pathophysiology, Moscow, Russia; eSerbsky Federal Medical Research Center for Psychiatry and Narcology, Department of Basic and Applied Neurobiology, Moscow, Russia; fSechenov First Moscow State Medical University, Department of Advanced Cell Technologies, Institute of Regenerative Medicine; gPavlov Institute of Experimental Medicine, St. 
Petersburg, Russia, hSchool of Biomedical Sciences, Faculty of Medicine, The Chinese University of Hong Kong, Shatin, N.T., Hong Kong; iDivision of Molecular Psychiatry, Clinical Research Unit on Disorders of Neurodevelopment and Cognition, Center of Mental Health, University of Wuerzburg, Germany.

*equal contribution

\#Corresponding author

Dr. Tatyana Strekalova

Department of Neuroscience

Maastricht University

Universiteitssingel 40, NL 6229 ER Maastricht, The Netherlands

Tel: 0031433884110 Fax: 0031433671096

E-mail: t.strekalova@maastrichtuniversity.nl 


\section{Abstract}

Glycogen synthase kinase 3 (GSK3) has been linked to the mechanisms of stress, mood regulation, and the effects of antidepressants. The functions of the GSK3 $\beta$ isoform have been extensively investigated, but little is known about the $\alpha$-isoform, although they may functionally related. In a recently established modified swim test with a third delayed swim exposure, brain GSK3 $\beta$ mRNA expression positively correlated with floating behavior on the third test. A two-week-long pretreatment regime with imipramine (7.5 $\mathrm{mg} / \mathrm{kg} / \mathrm{day}$ ) or thiamine (200 $\mathrm{mg} / \mathrm{kg} / \mathrm{day})$, which is known to have antidepressant properties, reduced the GSK3 $\beta$ over-expression and decreased floating behavior on day 5 . GSK3 $\alpha$ mRNA levels were measured in the hippocampus and prefrontal cortex on Days 1,2 and 5. GSK3 $\alpha$ expression was decreased in the prefrontal cortex on day 2 and increased on day 5. In this model, GSK3 $\alpha$ mRNA changes were prevented by imipramine or thiamine treatment. There was a significant correlation between the expression of the two isoforms in the prefrontal cortex on day 2 in untreated group. These results provide the first evidence for the potential involvement of GSK3 $\alpha$ in depressive-like behaviours and as a target of anti-depressant therapy. Furthermore, the correlations suggest some cross-talk may exist between the two GSK3 isoforms. 
Key words: GSK3 $\alpha$, depression, prefrontal cortex, imipramine, thiamine, mice.

Glycogen synthase kinase-3 (GSK3) is a multifunctional serine/threonine kinase with numerous regulatory roles, whose functions have been well studied for its beta isoform (GSK3 $\beta$ ) [1,2], but not for its alpha isoform (GSK3 $\alpha$ ). Recent data suggest that both GSK3 isoforms are independently implicated in the regulation of similar molecular and cellular functions, and that there is also cross-talk between them, thereby regulating their activities $[3,4]$. Given that GSK3 $\beta$ is well documented to play critical roles in cell development, apoptosis, and the mechanisms of distress and depression [14], similar functions have been suggested for GSK3 $\alpha$.

While the functions of GSK3 $\alpha$ and GSK $\beta$ in a cell may overlap, GSK3 $\alpha$ determines a number of processes that are specific for this kinase and may be not substituted by its beta isoform [5]. In particular, there are difference in the contribution of the two isoforms in the formation, elongation and branching of hippocampal neuronal axons during different periods of neuronal growth [6]. Knock out of GSK3 $\alpha$ was shown to result in impaired cognition and reduced LTP in mice, suggesting that GSK $\beta$ cannot 
compensate [7]. GSK3 $\alpha$, but not GSK $\beta$, has been implicated in fast (shortterm) spine shape remodeling and plasticity in the hippocampal formation [8]. Clock protein phosphorylation was found to differ for the two GSK3 isoforms [9]. Moreover, pharmacological manipulation of GSK3 $\alpha$ function alters the rate of apoptosis and has greater therapeutic effects than the GSK3 $\beta$-targeting treatments [10]. Biochemical evidence has shown that GSK $3 \alpha$ is generally involved in fast and relatively short-lasting cellular events, whereas GSK $\beta$ activities tend to be associated with delayed and longer-lasting changes [2].

While several studies have addressed a potential involvement of GSK3 $\alpha$ in stress response and depression, no direct evidence for such role for GSK $3 \alpha$ has been reported to date. Based on above-mentioned functional links between two isoforms of GSK3, we hypothesized that changes in brain GSK3 $\alpha$ might be brought on by a depressive-like state associated with altered GSK $\beta$ activities. Therefore, we studied GSK3 $\alpha$ expression in a modified swim test with repeated testing, in which the over-expression of brain GSK3 $\beta$ plays a critical role $[16,17]$. In this new modification of the classic two-day protocol of Porsolt test, an additional swimming session is performed on day 5 following the initial exposure, at a time when there is increased floating behaviour and GSK $3 \beta$ expression for both mRNA and 
protein in the prefrontal cortex and hippocampus. These increases are not observed during the classic Porsolt test. Moreover, over-expression of GSK3 $\beta$ mRNA in prefrontal cortex during the delayed testing session was previously shown to correlate with other parameters of behaviour despair in this model that are not observed in other swim test protocols [16].

In this study, the expression of both isoforms of GSK3 was studied in the hippocampus and prefrontal cortex in pharmacologically naïve mice. Furthermore, after the administration of two antidepressant treatments from different classes, imipramine and thiamine (vitamin B1), which were shown to normalize GSK3 $\beta$ expression in this and other paradigms $[17,18]$, was applied.

3-month-old male C57BL6 mice were obtained from Stolbovaja-RAS, Moscow region (http://www.spf-animals.ru/about/providers/animals) and housed individually under standard conditions (light on 9.00; see Supplementary Data). Experimental protocols conformed to directive 2010/63/EU, and were approved by the local veterinarian committee. Using a modified swim test in mice $[16,17]$ (see below), we studied their floating behaviour on Day 1, Day 2 and Day 5. The levels of GSK3amRNA and GSK3 3 mRNA in the hippocampus and prefrontal cortex were investigated 
on each day of the test in pharmacologically naïve mice (Study 1, Fig.1A), and on Day 5 in mice that were non-treated or pre-treated with imipramine (7.5 mg/kg/day) or thiamine, (200 mg/kg/day) for two weeks, via drinking water (Study 2, Fig.1B, see Supplementary Data). In Study 2, half of the samples was used for GSK3 3 mRNA gene expression analysis and results were reported elsewhere [17]. Both treatments were applied as described elsewhere $[17,18]$ and were previously shown to preclude stress-related changes in this model. Control naïve for swimming mice were sacrificed simultaneously with the experimental animals, which were killed $10 \mathrm{~min}$ after swimming; group sized are indicated in Figure legends. 
A

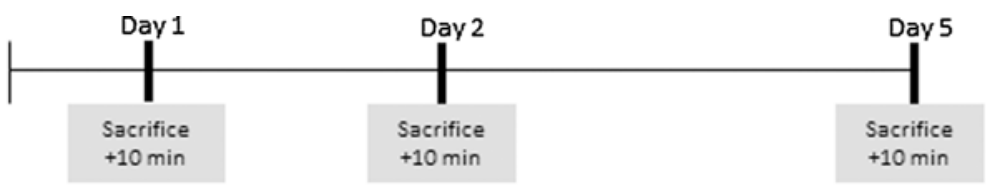

B

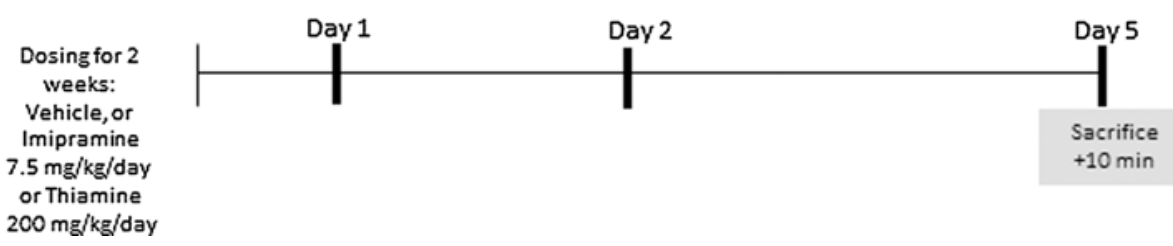

Figure 1. Schematic timeline of the modified swim test and culling. (A)

In Study 1, pharmacologically naïve mice were tested for their floating behaviour and culled on Day 1, Day 2 or Day 5. (B) In Study 2, non-treated or pre-treated with imipramine or thiamine mice were studied for their floating behavior and culled on Day 5.

Mice were subjected to two 6-min swimming sessions, with intervals of 24 h on Days 1 and 2 and 48h thereafter (Day 5 following the initial test), as described elsewhere [16,17] (see Supplementary Data). The duration of floating behaviour was defined by the absence of any directed movements of the animals' bodies and was scored using previously validated the criteria, as described elsewhere [16-19]. 
Mice were sacrificed by cervical dislocation. The prefrontal cortex and hippocampi were then isolated and stored at -80 .C. Extraction of mRNA, cDNA synthesis and quantitative RT-PCR (qRT-PCR) of GSK3 $\alpha$ and GSK3 $\beta$ gene expression were performed; the housekeeping gene glyceraldehyde-3-phosphate dehydrogenase (GAPDH) was selected as the reference gene based on previous studies [16]. Data were normalized to GAPDHmRNA and calculated as relative-fold changes compared to the control mice, as well as in percent from mean control values (see Supplementary Data and Table 1).

Data were analyzed with GraphPad Prism v.5.0 (San Diego, CA, USA). Wilcoxon, Mann-Whitney and Kruskall-Wallis tests were used to perform repeated measures, two- and multiple-group comparisons, respectively. Spearman correlation was used for correlation analysis. The level of confidence was set at $95 \%(\mathrm{p}<0.05)$, all data are mean \pm SEM. Statistical values of group comparisons are in Supplementary Tables 2-5.

In Study 1, mice floated for a significantly longer duration from Day 1 to Day $2(p=0.0001$, Wilcoxon test), and from Day 2 to Day $5(p=0.0002$, Fig.2A). On Day 1, brain GSK3 $\alpha \mathrm{mRNA}$ and GSK3 $\beta m R N A$ were unaltered 
(p $>0.05$ vs.control, Mann-Whitney test; Fig.2B-C, Table 1, Supplementary Table 2).

Table 1

Normalized brain GSK3 $\beta$ mRNA levels in the modified swim experiments on untreated and pharmacologically treated mice.

Data for groups from Study 1 and Study 2 are expressed in percent from means of control groups and presented as Mean \pm SEM. Significant differences vs. control group are indicated in bold, arrows indicates a direction of changes vs. control group. FST-imi: imipramine-treated mice subjected to forced swim test; FST-Thi: thiamine-treated mice subjected to forced swim test.

\begin{tabular}{|c|c|c|c|}
\hline \multicolumn{2}{|c|}{ Swimming sessions, groups and Studies } & \multirow{2}{*}{$\frac{\text { GsK3pmRNA, hippocampus fold change, } \$ \text { from Control }}{100.01 \pm 11.69}$} & \multirow{2}{*}{$\begin{array}{l}\text { GSK3ßmRNA, prefrontal cortex fold change, \% } \\
100.5 \pm 8.33\end{array}$} \\
\hline Day 1-Study 1 & Con & & \\
\hline Day 1. Study 1 & FST & $89.04 \pm 13.33$ & $86.42=18.54$ \\
\hline Day 2-Study 1 & Con & $100.50 \pm 24.02$ & $99.9 \pm 17.12$ \\
\hline Day 2. Study 1 & FST & $77.44 \pm 19.76$ & $102.2=27.80$ \\
\hline Day 5- Study 1 & Con & $100.3 \pm 14.99$ & $99.9 \pm 23.45$ \\
\hline Day 5- Study 1 & FST & $174.46=13.82 \uparrow$ & $134.02=8.24 \uparrow$ \\
\hline Day 5. Study 2 & Con & $91.7 \pm 15.53$ & $100.2 \pm 19.45$ \\
\hline Day 5- Study 2 & FST.Vehicle & $163.1 \pm 16.7 \uparrow$ & $143.3=18.23 \uparrow$ \\
\hline Day 5. Study 2 & FST-Imi & $39.21 \pm 4.90$ & $46.15 \pm 6.73 \uparrow$ \\
\hline Day 5. Study 2 & FST-Thi & $B 3.29 \pm 12.74 \uparrow$ & $55.8 \pm 9.8$ \\
\hline
\end{tabular}

On Day 2, hippocampal GSK3amRNA levels were unchanged ( $p>0.05$, vs.control). There was a significant decrease of this measure in the prefrontal cortex $(p<0.05$, vs.control), whereas GSK3ßmRNA brain concentrations were unchanged $(p>0.05$ vs.control, Fig.2D-E, 
Supplementary Table 2). Significant positive correlation between GSK3 $\alpha$ mRNA and GSK3 3 mRNA was found in the prefrontal cortex of non-treated mice on Day $2(\mathrm{p}=0.0016, \mathrm{r}=0.8754$, Spearman correlation, Fig.2E). On Day 5, there were no changes in hippocampal levels of GSK3amRNA ( $>0.05$ vs.control) and a significant increase of its expression in the prefrontal cortex $(\mathrm{p}<0.05$ vs.control); GSK3 $3 \mathrm{mRNA}$ levels were significantly increased in both brain areas $(p<0.05$ vs.control, Fig.2E-F, Supplementary Table 2). No significant correlations between GSK3amRNA and floating behavior were revealed ( $p>0.05$, Spearman correlation). 
A

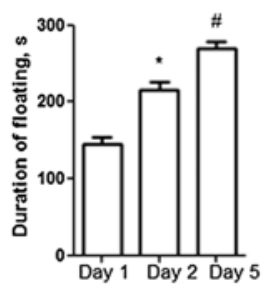

B

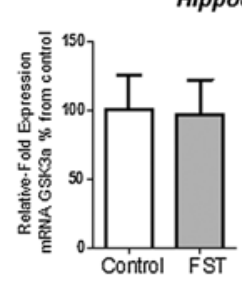

C Prefrontal cortex

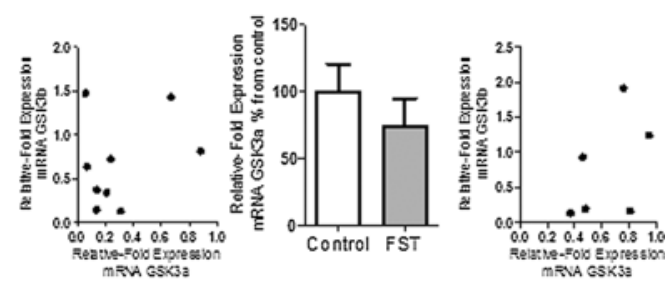

DAY 2

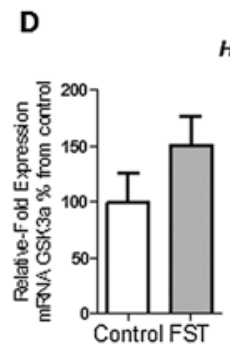

HIppocampus

E
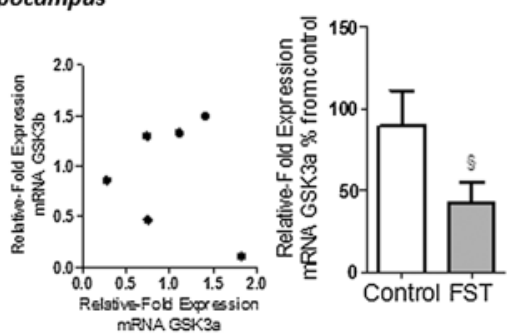

Prefrontal cortex

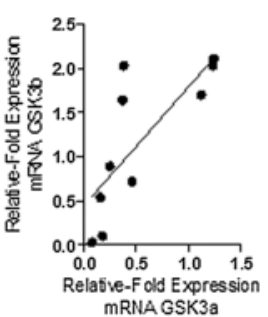

DAY 5
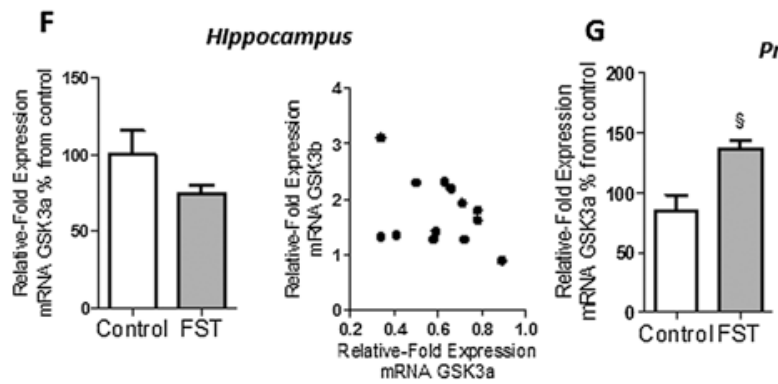

Prefrontal cortex

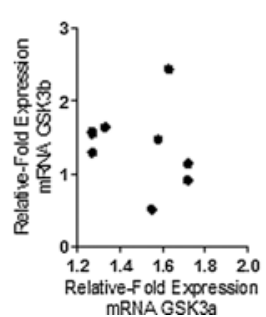

Figure 2. Brain GSK3 $\alpha \mathrm{mRNA}$ levels and duration of floating behaviour in pharmacologically naïve mice subjected to the modified swim test.

(A) Duration of floating on Day 1, Day 2, and Day $5\left({ }^{*} \mathrm{p}<0.05\right.$, Day 1 vs.

Day 2; $\# p<0.05$, Day 2 vs. Day $5 ; n=14)$. The levels of GSK3 $a m R N A$ in 
the hippocampus $(n=9-13)$ and prefrontal cortex $(n=6-9)$ and correlations with GSK3 $\beta m R N A$ levels after swimming sessions on Day 1 (B,C), Day 2 (D,E) and Day 5 (F,G) $(\S p<0.05$, vs. control, $n=)$. Line: $\mathrm{p}<0.05$, Spearman correlation for linear trend. FST: modified forced swim test. Data in the bars are mean \pm SEM normalized to control.

In Study 2, there was a significant group difference in floating behaviour (Kruskal-Wallis statistic 29.16, $\mathrm{p}<0.001$ ); non-treated mice floated significantly longer from Day 2 to Day $5(\mathrm{p}=0.005)$. This increase was not found in the imipramine-treated mice $(\mathrm{p}=0.252)$, nor in the thiamine-treated group ( $\mathrm{p}=0.18$, Fig.3A). On Day 5, there was significant group difference in hippocampal GSK3amRNA levels $(\mathrm{p}<0.5$, Kruskal-Wallis $)$. This parameter was unchanged in non-treated and imipramine-treated groups were unchanged ( $p>0.05$, vs.control, Mann-Whitney test), thiamine-treated mice displayed a significant increase in this measure $(\mathrm{p}<0.05$, vs.control, Fig.3B, Table 1 and Supplementary Table 4). Hippocampal GSK3 $\beta$ mRNA levels were significantly different between the groups $(\mathrm{p}<0.05$, KruskalWallis) and increased in non-treated mice ( $<<0.05$, vs. control). In comparison to the latter group and to naïve mice, GSK3 $\beta$ mRNA 
concentrations were significantly decreased in imipramine- and thiaminetreated animals $(\mathrm{p}<0.05)$.

\section{AY 5: EFFECTS OF ANTIDEPRESSANT TREATMENT}

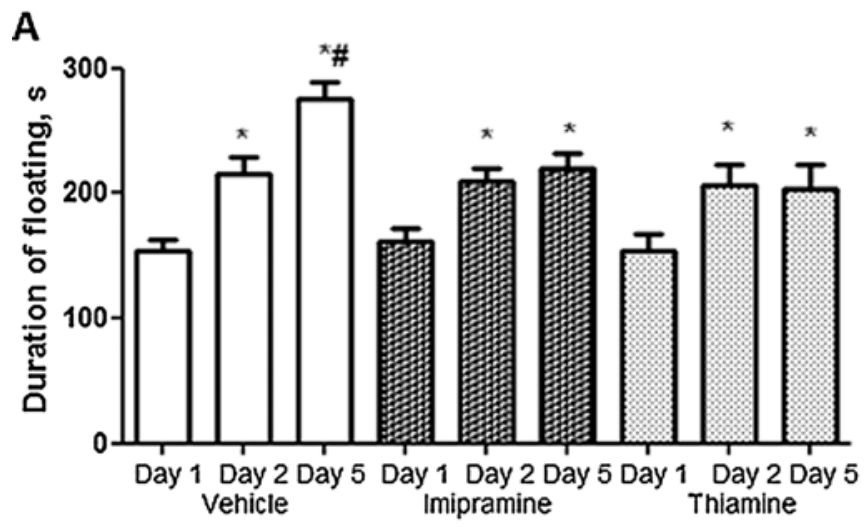

B

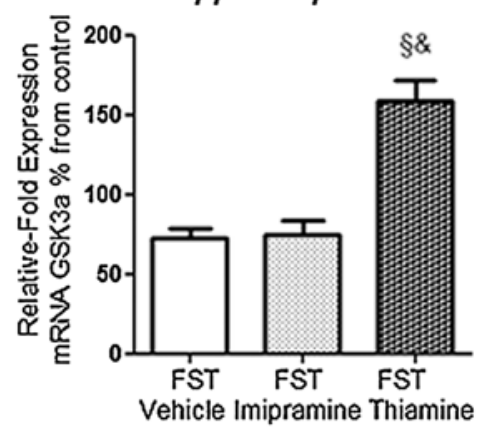

C

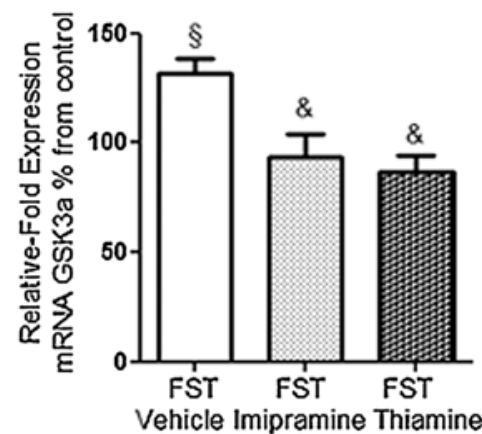

Imipramine

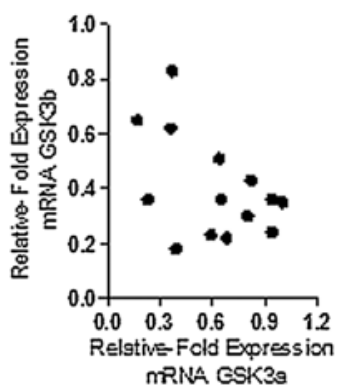

Imipramine

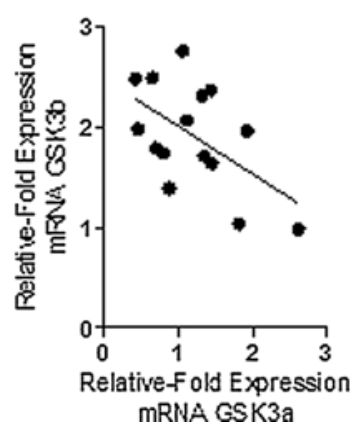

Thiamine

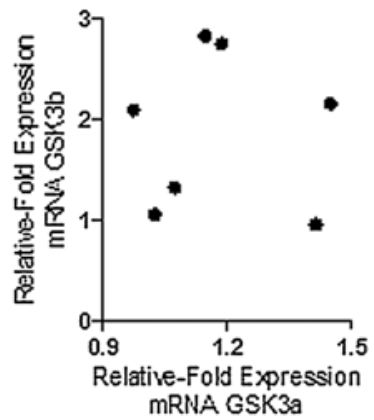

Thiamine

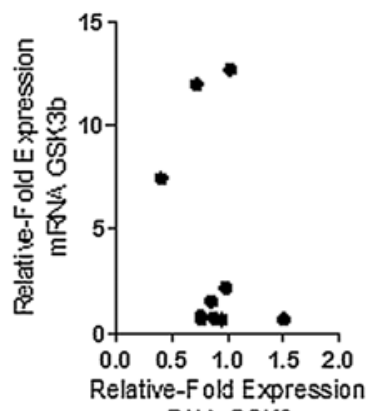

mRNA GSK3a 
Figure 3. Brain GSK3amRNA levels and duration of floating behaviour in mice subjected to the antidepressant treatment and modified swim test. (A) Duration of floating on day 2 and day 5 in non-treated, imipraminetreated or thiamine-treated mice $(\# p<0.05$, vs. day 2,). The levels of GSK3 3 mRNA in the hippocampus (B) and prefrontal cortex (C) and correlations with GSK3ßmRNA after swimming sessions on day 5 in mice pre-treated with imipramine or thiamine $(\S p<0.05$, vs.control, $\& p<0.05$, vs.non-treated mice $n=13-18$ ). Line: $\mathrm{p}<0.05$, Spearman correlation for linear trend. FST: modified forced swim test. Data in the bars are mean \pm SEM normalized to control.

In the prefrontal cortex, the levels of both GSK3amRNA and GSK3 3 mRNA were significantly between the groups (Kruskall Wallis statistic 10.31 and $17.48, \mathrm{p}=0.0161$ and $\mathrm{p}=0.0006$, respectively). Both parameters were elevated in non-treated animals and unaltered in imipramine-and thiamine-treated mice in comparison to controls, $(\mathrm{p}<0.05$, vs.control, Mann-Whitney tests, Fig.3C, Table 1, Supplementary Table 3). In comparison to non-treated mice, dosed animals showed significantly reduced expression of both isoforms of GSK3 in this brain area $(p<0.05)$. 
No significant correlations between GSK3 $\alpha \mathrm{mRNA}$ and floating behavior were revealed across this study ( $\mathrm{p}>0.05$, Spearman correlation). A positive correlation between GSK3 $\alpha \mathrm{mRNA}$ level and GSK3 $\beta$ mRNA were found in the prefrontal cortex of imipramine-treated mice on Day $5(p=0.0498, r=-$ 0.5143, Fig.3D).

To summarize, we found significant changes in GSK3amRNA expression in the prefrontal cortex and hippocampus in mice subjected to the modified swim test, and also during antidepressant treatments with imipramine or thiamine. These findings provide the first evidence for the involvement of GSK3 $\alpha$ in depressive-like phenotype and the effects of antidepressant treatments in an animal model of depression. Our results reveal certain similarities in the direction of expression change of GSK $3 \alpha$ and GSK3 $\beta$ and a role of the prefrontal cortex in their neuroanatomic localization during depressive-like state in the modified swim test. Furthermore, the present data demonstrate a dynamic expression profile for the two molecules throughout the repeated swim tests.

Analysis of the behavioural changes and effects of pre-treatment with imipramine or thiamine revealed similar results to those previously reported $[16,17]$. Behavioural effects of the treatments were in accordance with 
previously demonstrated anti-stress effects of employed here dosing with imipramine and thiamine in a rat exposure stress. These ameliorative effects concern stress-related anxiety-like behaviours [16], hippocampal neurogenesis and elevated serum corticosterone levels [18].

No change in the GSK3 3 mRNA was found after the first exposure to swimming, when GSK3 $\beta$ expression on gene and protein levels was unaltered too [16]. Notably, the concentration of GSK3 $\alpha$ mRNA in the prefrontal cortex was reduced when GSK3 $\beta$ expression was unchanged at the gene level and GSK3 $\beta$ activities were increased at the protein level (day 2) [16]. These data suggest differences in the dynamics of the expression changes in response to external challenges for GSK3 $\alpha$ and GSK3 $\beta$ that could be accounted, as for instance, for unique interactions with several major regulators of cellular functions, such as Akt, protein kinase $\mathrm{C}$, protein phosphatase-1 (PP1), IL-1, mTOR and other regulatory factors $[2,4,21,22]$. As mentioned above, besides differences in the signaling mechanisms, there is also evidence of distinct functional effects exerted by GSK3 $\alpha$ and GSK3 $\beta$. The regulation of hippocampal plasticity $[7,8]$ is likely to be contributor to the requirement for dynamic expression of the GSK3 isoforms. Of note, the present study revealed that GSK3 $\alpha$ brain expression changes do not occur after a single swim, but after repeated swimming, 
accompanied by altered GSK3 $\beta$ protein/gene activities, even though biochemical studies suggest faster reaction of GSK3 $\alpha$ mechanism in response to various challenges [2]. In a similar manner to the results presented here, no changes in brain GSK3 $\beta$ was found after a single swimming session in a previous study [16]. Together, current results indirectly suggest a link between functional activation of both isoforms of GSK3.

In this study we found that GSK3 $\alpha$ was over-expressed in the prefrontal cortex of untreated, swim exposed mice on the last day of testing that paralleled the increase in GSK3 $\beta$ mRNA levels. The latter measure was previously reported to correlate with floating behavior at this stage of repeated testing in the paradigm employed here [16]. No over-expression of GSK3 $\alpha$ was found in the prefrontal cortex of imipramine- or thiaminetreated groups. Similar findings were obtained with GSK3 $\beta$ expression in imipramine- and thiamine-treated animals in current and previous studies $[16,17]$. Remarkably, there were no significant changes in hippocampal GSK3 $\alpha$ mRNA in our experiments, with the exception of the effects of administration of thiamine, whose stimulating effects of this measure can be associated with its memory-enhancing properties [17,23,24]. Of note, a particular link between molecular changes with the development of a 
depressive-like behavior in the modified swim test was previously shown for the prefrontal cortex and not the hippocampus [16,17].

Our data showed similar suppressive effects of two antidepressant treatments, imipramine and thiamine, on GSK3 $\alpha$ and GSK3 $\beta$ expression. This observation supports the view that GSK3 $\alpha$ as plays an analogues role to that of GSK3 $\beta$ during depression and may be considered as an additional target in the pharmacotherapy of depression. Together, the present results demonstrate that GSK3 $\alpha$ can be an important factor in depression and a mediator of antidepressant therapy, where GSK3 $\alpha$ possibly indirectly regulates GSK-3 $\beta$ activities. Further identification of mechanisms and functions associated with GSK $3 \alpha$ and GSK $3 \beta$ that are differentially regulated during depression may lead the way towards the development of therapeutic interventions that can predominantly affect one isoform more than the other that hopefully could improve pharmacological management of depressed patients. A modified swim test with an additional testing session might be a suitable model for further investigation into these functions of GSK3 $\alpha$ and potential drug development. 


\section{ACKNOWLEDGEMENTS}

This work was supported by RFBR grant 16-34-01165 to NM. We also thank 5-100 Russian Academic Excellence Project, Prof. Bart Rutten for his comments and Prof. Daniel C. Anthony for valuable scientific input and kind help with language.

\section{References}

[1] C.A. Grimes, R.S. Jope, The multifaceted roles of glycogen synthase kinase 3beta in cellular signaling, Prog. Neurobiol. 65 (2001) 391-426.

[2] B.W. Doble, J.R. Woodgett, GSK-3: tricks of the trade for a multitasking kinase, J. Cell Sci. 116 (2003) 1175-1186.

[3] M.H. Liang, D.M. Chuang, Regulation and function of glycogen synthase kinase-3 isoforms in neuronal survival, J. Biol. Chem. 282 (2007) 3904-3917.

[4] E. Beurel, S.F. Grieco, R.S. Jope, Glycogen synthase kinase-3 (GSK3): regulation, actions, and diseases, Pharmacol. Ther. 148 (2015) 114131.

[5] M.H. Liang, D.M. Chuang, Differential roles of glycogen synthase kinase-3 isoforms in the regulation of transcriptional activation, J. 
Biol. Chem. 281 (2006) 30479-30484.

[6] J.J. Garrido, D. Simón, O. Varea, F. Wandosell, GSK3 alpha and GSK3 beta are necessary for axon formation, FEBS Lett. 581 (2007) 15791586.

[7] H. Maurin, B. Lechat, I. Dewachter, L. Ris, J.V. Louis, P. Borghgraef, H. Devijver, T. Jaworski, F. Van Leuven, Neurological characterization of mice deficient in GSK3 $\alpha$ highlight pleiotropic physiological functions in cognition and pathological activity as Tau kinase. Mol. Brain. 6 (2013) 27 doi: 10.1186/1756-6606-6-27.

[8] I.A. Cymerman, A. Gozdz, M. Urbanska, J. Milek, M. Dziembowska, J. Jaworski, Structural Plasticity of Dendritic Spines Requires GSK3 $\alpha$ and GSK3 $\beta$, PLoS One. 10 (2015) e 0134018.

[9] R.C. Besing, J.R. Paul, L.M. Hablitz, C.O. Rogers, R.L. Johnson, M.E. Young, K.L. Gamble, Circadian Rhythmicity of Active GSK3 Isoforms Modulates Molecular Clock Gene Rhythms in the Suprachiasmatic Nucleus, J. Biol. Rhythms. 30 (2015) 155-160.

[10] L.L. Remsing Rix, B.M. Kuenzi, Y. Luo, E. Remily-Wood, F. Kinose, G. Wright, J. Li, J.M. Koomen, E.B. Haura, H.R. Lawrence, U. Rix, 
GSK3 Alpha and Beta Are New Functionally Relevant Targets of Tivantinib in Lung Cancer Cells, ACS Chem. Biol. 9 (2014) 353-358.

[11] H.M. Lachman, E. Pedrosa, O.A. Petruolo, M. Cockerham, A. Papolos, T. Novak, D.F. Papolos, P. Stopkova, Increase in GSK3beta gene copy number variation in bipolar disorder, Am. J. Med. Genet. B. Neuropsychiatr. Genet. 144 (2007) 259-265.

[12] A. Polter, E. Beurel, S. Yang, R. Garner, L. Song, C.A. Miller, J.D. Sweatt, L. McMahon, A.A. Bartolucci, X. Li, R.S. Jope, Deficiency in the Inhibitory Serine-Phosphorylation of Glycogen Synthase Kinase-3 Increases Sensitivity to Mood Disturbances, Neuropsychopharmacology. 35 (2010) 1761-1774.

[13] C. Chen, M. Ji, Q. Xu, Y. Zhang, Q. Sun, J. Liu, S. Zhu, W. Li, Sevoflurane attenuates stress-enhanced fear learning by regulating hippocampal BDNF expression and Akt/GSK-3 $\beta$ signaling pathway in a rat model of post-traumatic stress disorder. J. Anesth. 29 (2014) 600608.

[14] G. Li, T. Liu, X. Kong, L. Wang, X. Jin, Hippocampal Glycogen Synthase Kinase $3 \beta$ is Critical for the Antidepressant Effect of CyclinDependent Kinase 5 Inhibitor in Rats, J. Mol. Neurosci. 54 (2014) 92- 
99.

[15] E. Jiménez, B. Arias, M. Mitjans, J.M. Goikolea, E. Roda, V. Ruíz, A. Pérez, P.A. Sáiz, M. Paz García-Portilla, P. Burón, J. Bobes, E. Vieta, A. Benabarre, Association between GSK3 $\beta$ gene and increased impulsivity in bipolar disorder, Eur. Neuropsychopharmacol. 24 (2014) 510-518.

[16] T. Strekalova, N. Markova, E. Shevtsova, O. Zubareva, A. Bakhmet, H.M. Steinbusch, S. Bachurin, K.P. Lesch, Individual Differences in Behavioural Despair Predict Brain GSK-3beta Expression in Mice: The Power of a Modified Swim Test, Neural Plast. 2016 (2016) 5098591.

[17] N. Markova, N. Bazhenova, D.C. Anthony, J. Vignisse, A. Svistunov, K.P. Lesch, L. Bettendorff, T. Strekalova, Thiamine and benfotiamine improve cognition and ameliorate GSK-3 $\beta$-associated stress-induced behaviours in mice, Prog. Neuro-Psychopharmacology Biol. Psychiatry 75 (2016) 148-156.

[18] J. Vignisse, M. Sambon, A. Gorlova, D. Pavlov, N. Caron, B. Malgrange, E. Shevtsova, A. Svistunov, D.C. Anthony, N. Markova, N. Bazhenova, B. Coumans, B. Lakaye, P. Wins, T. Strekalova, L. 
Bettendorff, Thiamine and benfotiamine prevent stress-induced suppression of hippocampal neurogenesis in mice exposed to predation without affecting brain thiamine diphosphate levels. Mol. Cell. Neuroscience. (2017) (in press).

[19] E. Malatynska, H.M. Steinbusch, O. Redkozubova, A. Bolkunov, A. Kubatiev, N.B. Yeritsyan, J. Vignisse, S. Bachurin, T. Strekalova, Anhedonic-like traits and lack of affective deficits in 18-month-old C57BL/6 mice: Implications for modeling elderly depression, Exp. Gerontol. 47 (2012) 552-564.

[20] T. Strekalova, D.C. Anthony, O. Dolgov, K. Anokhin, A. Kubatiev, H.M. Steinbusch, C.Schroeter. The differential effects of chronic imipramine or citalopram administration on physiological and behavioral outcomes in naïve mice, Behav. Brain Res. 245 (2013) $101-106$.

[21] N. Goode, K. Hughes, J.R. Woodgett, P.J. Parker, Differential regulation of glycogen synthase kinase-3 beta by protein kinase $\mathrm{C}$ isotypes, J. Biol. Chem. 267 (1992) 16878-16582.

[22] Q.M. Wang, I.K. Park, C.J. Fiol, P.J. Roach, A.A. DePaoli-Roach, Isoform differences in substrate recognition by glycogen synthase 
kinases 3 alpha and 3 beta in the phosphorylation of phosphatase inhibitor 2, Biochemistry. 33 (1994) 143-147.

[23] E. Abdou, A.S. Hazell, Thiamine deficiency: an update of pathophysiologic mechanisms and future therapeutic considerations, Neurochem. Res. 40 (2015) 353-361.

[24] L. Bettendorff, B. Lakaye, G. Kohn, P. Wins, Thiamine triphosphate: a ubiquitous molecule in search of a physiological role, Metab. Brain Dis. 29 (2014) 1069-1082. 


\section{Animals and housing conditions}

Experiments were performed on male C57BL6 mice that were 12 weeks old. All animals were provided by Stolbovaja, RAS, Moscow region, a provider licensed by Charles River (http://www.spfanimals.ru/about/providers/animals). Mice were housed individually in standard plastic cages $(27 \times 22 \times 15 \mathrm{~cm}$ for mice) and maintained on a 12 hour light/dark cycle, under controllable laboratory conditions $\left(22 \pm 1^{\circ} \mathrm{C}\right.$, $55 \%$ humidity, room temperature $22^{\circ} \mathrm{C}$ ), food and water were available ad libitum. Housing conditions and all experimental procedures were set up and maintained in accordance with a Directive 2010/63/EU of 22 September 2010 and carried out under approval of the local veterinarian committee. All efforts were undertaken to minimize the potential discomfort of experimental animals.

\section{Modified swim tests with additional delayed testing}

Mice were subjected to one or two swimming sessions with an interval of $24 \mathrm{~h}$, or, to three session, where after the first two tests the third test was 
carried out on Day 5 following the initial test on Day 1 as described elsewhere (Strekalova et al., 2016; Markova et al., 2016). All sessions were 6-min long and were performed by placing a mouse in a transparent cylinder (Ø $17 \mathrm{~cm})$ filled with water $\left(+23{ }^{\circ} \mathrm{C}\right.$, water height $13 \mathrm{~cm}$, height of cylinder $20 \mathrm{~cm}$ ). The duration of floating behavior that was defined by the absence of any directed movements of the animals' head and body, was scored manually using criteria, which were previously validated by automated scoring with Noldus EthoVision XT 8.5 (Noldus Information Technology, Wageningen, The Netherlands) and CleverSys (CleverSys, Reston, VA, USA) as described elsewhere (Malatynska et al., 2012; Strekalova et al., 2015). Time spent with floating was evaluated for the entire duration of the test. In all assays mice were sacrificed ten minutes after swimming. Imipramine- and thiamine-treated mice were tested in all three session and sacrificed after the last session, alone with respective non-treated control mice. With all tests, naïve control groups that were not exposed to a swimming were sacrificed simultaneously with experimental groups of mice.

\section{Drug delivery}


Experimental solutions replaced normal drinking water. Thiamine and imipramine were obtained from Sigma-Aldrich, St. Louis, MO, USA. All agents were dissolved in tap water and were changed every 4-5 days (Strekalova et al., 2016, Vignnisse et al., 2017). Drinking behaviour of mice was monitored by evaluating a 24-h liquid intake during the first three days of dosing. The dose of imipramine dose $(7.5 \mathrm{mg} / \mathrm{kg} / \mathrm{day})$, was based on previous results showing that this dose had no effect on general locomotor behaviour (Strekalova et al., 2015; Costa-Nunes et al., 2015).

\section{Brain dissection, RNA extraction and qRT-PCR}

Mice were sacrificed by cervical dislocation a $10 \mathrm{~min}$ after the last swimming, brains were dissected and the prefrontal cortex and hippocampi were isolated as previously reported (Couch et al., 2013; Markova et al., 2016) and stored at $-80_{\circ} \mathrm{C}$ until use. mRNA was extracted by using TRI Reagent (MRC, Cincinnati, OH, USA). First-strand cDNA synthesis was performed using random primers and Superscript III transcriptase (Invitrogen, Darmstadt, Germany); $1 \mu \mathrm{g}$ total RNA was converted into cDNA. Quantitative RT-PCR (qRT-PCR) of the GSK-3beta gene and the housekeeping gene glyceraldehyde-3-phosphate dehydrogenase (GAPDH) was performed using the SYBR Green master mix (Bio-Rad Laboratories, 
Philadelphia, PA, USA) and the CFX96 Real-time System (Bio-Rad Laboratories, Philadelphia, PA, USA). A reference gene was selected in previous experiments that demonstrated relatively low variability in GAPDH expression in the limbic structures under employed (Strekalova et al., 2016; Markova et al., 2016). Data were normalized to GAPDH mRNA expression and calculated as relative-fold changes compared to control mice that were not exposed to swimming, as described elsewhere (Strekalova et al., 2016; Markova et al., 2016); data were additionally calculated as percent from the mean of control groups. Further details, sequences of primers used are listed below (Supplementary Table 1). Data are given as expressionfolds compared to the mean expression values in non-stressed control mice and in percent expressed from the means of control groups that were not exposed to swimming.

Table 1. Sequences of primers used

\begin{tabular}{|l|l|l|}
\hline Gene & Forward primer $\mathbf{5}^{\prime} \mathbf{- 3} \mathbf{3}^{\prime}$ & Reverse primer 5'-3' \\
\hline GAPDH & TGCACCACCAACTGCTTAG & GGATGCAGGGATGATGTTC \\
\hline GSK3 $\alpha$ & AATCTTGGCCAGTCTGAGCT & TCAGTCCTGGTGAACTGTCC \\
\hline GSK3 $\beta$ & TCCATTCCTTTGGAATCTGC & CAATTCAGCCAACACACAGC \\
\hline
\end{tabular}


The qRT-PCR was performed in a $25 \mu \mathrm{l}$ reaction volume containing a 10xPCR Buffer $(2.5 \mu \mathrm{l}), 25 \mathrm{mmol} \mathrm{MgCl} 2(4 \mu \mathrm{l}), 10 \mathrm{mmol}$ dNTPs $(2 \mu \mathrm{l})$, specific forward and reverse primers at $20 \mathrm{pmol} / \mu \mathrm{l}$ concentration $(1 \mu \mathrm{l})$, cDNA $(2 \mu \mathrm{l}), 5 \mathrm{u} / \mu \mathrm{l}$ Taq DNA polymerase $(1 \mu \mathrm{l})$ (Beagle, st. Petersburg, Russia), and ddH2O (10 $\mu$ l). All samples were run in duplicate. Cycling was performed at $95 \mathrm{C}^{\circ}$ for 5 min followed by a 45 -cycle amplification at $95^{\circ} \mathrm{C}$ for $10 \mathrm{~s}$, then at the annealing temperature defined previously for $15 \mathrm{~s}$ and at the temperature $72^{\circ} \mathrm{C}$ for $20 \mathrm{~s}$.

Results of the qPCR measurements were expressed as $\mathrm{Ct}$ values, where $\mathrm{Ct}$ is defined as the threshold cycle of PCR at which amplified product was $0.05 \%$ of normalized maximal signal. We used the comparative $\mathrm{Ct}$ method and computed the difference between the expression of the gene of interest and GAPDH expression in each cDNA sample (2- $\Delta \Delta \mathrm{Ct}$ method). Results are expressed as folds of expression compared to the mean values of expression in non-stressed control animals (Couch et al., adapted from Livak and Schmittgen, 2001).

\section{Statistical values of data comparison}

Table 2. Summary of comparisons between naïve control mice and mice that underwent swim testing on Days 1, Day 2 and Day 5, in the duration 
of floating (Wilcoxon test for repeated group comparisons) and levels of GSK3 $\alpha m R N A$ and GSK3 $\beta m R N A$ (Mann-Whitney test, for two-group comparison); significant differences are in bold. The values of GSK3 $\alpha$ mRNA expression in the hippocampus were not significantly different between the groups (Kruskal-Wallis statistic 7.920, $\mathrm{p}=0.1607$ ), but in the prefrontal cortex (Kruskal-Wallis statistic $=15.06, \mathrm{p}=0.0101)$. There was a significant group difference in the expression of GSK3 $\beta$ mRNA in the hippocampus (Kruskal-Wallis statistic 17.034, $\mathrm{p}=0.0036$ ) and in the prefronal cortex (Kruskal-Wallis statistic 11.284, $\mathrm{p}=0.0462$ ).

\begin{tabular}{|c|c|c|c|}
\hline \multirow{2}{*}{ Parameters } & \multicolumn{3}{|c|}{ Days of testing } \\
\hline & Day 1 & Day 2 & Day 5 \\
\hline $\begin{array}{l}\text { Duration of floating } \\
\text { behavior }\end{array}$ & - & $\begin{array}{l}\text { vs. Day 1: } \\
W=93.00, p=0.0002\end{array}$ & $\begin{array}{l}\text { vs. Day 1: } \\
\mathrm{W}=78.00, \mathbf{p}=\mathbf{0 . 0 0 0 5} \\
\text { vs. Day } 2 \text { : } \\
\mathrm{W}=78.00, \mathbf{p}=\mathbf{0 . 0 0 0 5}\end{array}$ \\
\hline $\begin{array}{l}\text { GSK3 } 3 \text { mRNA: } \\
\text { hippocampus }\end{array}$ & $\mathrm{U}=28.00, \mathrm{p}=0.4321$ & $\mathrm{U}=30.00, \mathrm{p}=0.8746$ & $\mathrm{U}=11.00, \mathrm{p}=0.1010$ \\
\hline $\begin{array}{l}\text { GSK3 } 3 \alpha \mathrm{mRNA}: \\
\text { prefrontal cortex }\end{array}$ & $\mathrm{U}=51.00, \mathrm{p}=0.3712$ & $U=14.00, p=0.0149$ & $U=12.00, \mathbf{p}=\mathbf{0 . 0 3 9 0}$ \\
\hline $\begin{array}{l}\text { GSK } 3 \beta \mathrm{mRNA} \\
\text { hippocampus }\end{array}$ & $\mathrm{U}=15.00, \mathrm{p}=0.2345$ & $\mathrm{U}=11.50, \mathrm{p}=0.3539$ & $\mathrm{U}=7.00, \mathbf{p}=\mathbf{0 . 0 2 3 4}$ \\
\hline $\begin{array}{l}\text { GSK3 } 3 \text { mRNA: } \\
\text { prefrontal cortex }\end{array}$ & $\mathrm{U}=7.00, \mathrm{p}=0.3758$ & $\mathrm{U}=15.00, \mathrm{p}=0.8763$ & $U=5.00, p=0.0480$ \\
\hline
\end{tabular}


Table 3. Summary of comparisons between mice that underwent swim testing and were not treated with drugs (FST), or received imipramine (FST imipramine) or thiamine (FST thiamine), on Day 5, in duration of floating. Wilcoxon tests was used for repeated measures and KruskallWallis followed by Mann-Whitney tests were used for group comparisons (significant differences are in bold). There was no significant difference between the groups in floating behavior on Day 1 (Kruskal-Wallis statistic 0.2771, $\mathrm{p}=0.8706)$, Day 2 (Kruskal-Wallis statistic 0.09189, $\mathrm{p}=0.9551$, but Day 5 (Kruskal-Wallis statistic 9.754, $\mathrm{p}=0.0076$ ). 


\begin{tabular}{|c|c|c|c|}
\hline \multirow{2}{*}{$\begin{array}{l}\text { Duration } \\
\text { of floating }\end{array}$} & \multicolumn{3}{|c|}{ Groups } \\
\hline & FST Vehicle & FST imipramine & FST thiamine \\
\hline Day 2 & $\begin{array}{l}\text { vs. Day 1: } \\
\text { W=66.00, p=0.0010 }\end{array}$ & $\begin{array}{l}\text { vs. Day } 1 \text { : } \\
\mathrm{W}=66.00, \mathrm{p}=0.0010 \\
\text { vs. FST Vehicle Day 2: } \\
\mathrm{U}=58.00, \mathrm{p}=0.8812 \\
\text { vs. FST thiamine Day } 2 \text { : } \\
\mathrm{U}=49.0, \mathrm{p}=0.9742\end{array}$ & $\begin{array}{l}\text { vs. Day 1: } \\
\mathrm{W}=45.00, \mathrm{p}=\mathbf{0 . 0 0 3 9} \\
\text { vs. FST Vehicle Day 2: } \\
\mathrm{U}=45.00, \mathrm{p}=0.7463\end{array}$ \\
\hline Day 5 & $\begin{array}{l}\text { vs. Day } 1 \text { : } \\
\mathrm{W}=66.00, \mathrm{p}=\mathbf{0 . 0 0 1 0} \\
\text { vs. Day } 2 \text { : } \\
\mathrm{W}=66.00, \mathrm{p}=\mathbf{0 . 0 0 1 0}\end{array}$ & $\begin{array}{l}\text { vs. Day 1: } \\
\mathrm{W}=66.00, \mathrm{p}=0.0010 \\
\text { vs. Day 2: } \\
\mathrm{W}=16.00, \mathrm{p}=0.5039 \\
\text { vs. FST Vehicle Day } 5 \text { : } \\
\mathrm{U}=18.00, \mathrm{p}=\mathbf{0 . 0 0 4 1} \\
\text { vs. FST thiamine Day } 5 \text { : } \\
\mathrm{U}=40.00, \mathrm{p}=0.4903\end{array}$ & $\begin{array}{l}\text { vs. Day } 1 \text { : } \\
W=39.00, p=0.0195 \\
\text { vs. Day } 2 \text { : } \\
W=-16.00, p=0.3906 \\
\text { vs. FST Vehicle Day } 5 \text { : } \\
U=17.00, p=\mathbf{0 . 0 1 2 4}\end{array}$ \\
\hline
\end{tabular}


Table 4. Summary of comparisons between naïve control mice (Con), and mice that underwent swim testing and were not treated (FST), or received imipramine (FST imipramine) or thiamine (FST thiamine), on Day 5, in the GSK3amRNA and GSK3ßmRNA (Kruskall-Wallis and Mann-Whitney tests; significant differences are in bold). There was significant group difference in hippocampal GSK3 $\alpha$ mRNA levels (KruskalWallis statistic 22.24, $\mathrm{p}<0.0001$ ) and GSK3 $\beta$ mRNA levels (Kruskal-Wallis statistic 26.93, $\mathrm{p}<0.0001$ ), as well as in the levels of both GSK3amRNA and GSK $3 \beta$ mRNA in the prefrontal cortex (Kruskall Wallis statistic 10.31 and $17.48, p=0.0161$ and $p=0.0006$, respectively). 


\begin{tabular}{|c|c|c|c|}
\hline \multirow{2}{*}{ Parameters } & \multicolumn{3}{|c|}{ Groups } \\
\hline & FST Vehicle & FST imipramine & FST thiamine \\
\hline $\begin{array}{l}\text { GSK3amRNA: } \\
\text { hippocampus }\end{array}$ & $\mathrm{U}=11.00, \mathrm{p}=0.1006$ & $\begin{array}{l}\text { vs. Con: } \\
U=40.00, p=0.1564 \\
\text { vs. FST Vehicle: } \\
U=85.00, p=0.7896\end{array}$ & $\begin{array}{l}\text { vs. Con: } \\
\mathrm{U}=0.00, \mathrm{p}=0.0050 \\
\text { vs. FST Vehicle: } \\
\mathrm{U}=0.00, \mathrm{p}=0.01\end{array}$ \\
\hline $\begin{array}{l}\text { GSK3 } 3 \text { mRNA: } \\
\text { prefrontal cortex }\end{array}$ & $\mathrm{U}=12.00, \mathrm{p}=0.0388$ & $\begin{array}{l}\text { vs. Con: } \\
U=65.00, p=0.9754 \\
\text { vs. FST Vehicle: } \\
U=27.00, p=0.0320\end{array}$ & $\begin{array}{l}\text { vs. Con: } \\
U=14.00, p=0.2086 \\
\text { vs. FST Vehicle: } \\
U=2.00, p=0.008\end{array}$ \\
\hline $\begin{array}{l}\text { GSK3ßmRNA: } \\
\text { hippocampus }\end{array}$ & $\mathrm{U}=19.00, \mathrm{p}=0.04513$ & $\begin{array}{l}\text { vs. Con: } \\
\mathrm{U}=30.50, \mathrm{p}=0.002 \\
\text { vs. FST Vehicle: } \\
\mathrm{U}=1.50, \mathrm{p}<0.001\end{array}$ & $\begin{array}{l}\text { vs. Con: } \\
U=35.00, p=0.9631 \\
\text { vs. FST Vehicle: } \\
U=48.00, p=0.0229\end{array}$ \\
\hline $\begin{array}{l}\text { GSK3 } 3 \text { mRNA: } \\
\text { prefrontal cortex }\end{array}$ & $\mathrm{U}=17.00, \mathrm{p}=0.04876$ & $\begin{array}{l}\text { vs. Con: } \\
U=14.00, p=0.2086 \\
\text { vs. FST Vehicle: } \\
U=2.00, p=0.008\end{array}$ & $\begin{array}{l}\text { vs. Con: } \\
U=24.00, p=0.4698 \\
\text { vs. FST Vehicle: } \\
U=7.00, p=0.010\end{array}$ \\
\hline
\end{tabular}




\section{Chapter 3}

Enhanced conditioning of adverse memories in the mouse modified swim test is associated with neuroinflammatory changes: effects of treatments with antidepressant properties 
Enhanced conditioning of adverse memories in the mouse modified swim test is associated with neuroinflammatory changes: effects of treatments with antidepressant properties

Dmitrii Pavlova,b,c*, Anna Gorlovaa,b*, Lucien Bettendorffc, Allan Kalueffd,e, Aleksei Umriukhinb,f, Andrey Proshinf, Alexander Lyskog, Rainer Landgrafb,h, Daniel Anthonyh, Tatyana Strekalovaa,b\#

aDepartment of Psychiatry and Neuropsychology, Maastricht University, Maastricht University, Maastricht, Netherlands; bSechenov First Moscow State Medical University, Institute of Molecular Medicine Laboratory of Psychiatric Neurobiology and Department of Normal Physiology, Moscow, Russia; cLaboratory of Neurophysiology, GIGA-Neurosciences, University of Liège, Liège, Belgium; dSchool of Pharmacy, Southwest University, Chongqing, China; eInstitute of Translational Biomedicine, St. Petersburg State University, St.Petersburg, Russia; fFederal State Budgetary Scientific Institution "P.K. Anokhin Research Institute of Normal Physiology"; gLaboratory of Cognitive Dysfunctions, Institute of General Pathology and Pathophysiology, Moscow, Russia; hMax Planck Institute of Psychiatry, Munich, Germany; iDepartment of Pharmacology, Oxford University, Oxford, UK. 
*equal contribution

\#Corresponding author

Dr. Tatyana Strekalova

Department of Psychiatry and Neuropsychology

Maastricht University

Universiteitssingel 40, NL 6229 ER Maastricht, The Netherlands

Tel: 0031433884110 Fax: 0031433671096

E-mail: t.strekalova@maastrichtuniversity.nl

\begin{abstract}
Deficient learning and memory are well-established pathophysiologic features of depression, however, mechanisms of the enhanced learning of aversive experiences associated with this disorder are poorly understood. Currently, neurobiological mechanisms of enhanced retention of aversive memories during depression, and, in particular, their relation to neuroinflammation are unclear. As the association between major depressive disorder and inflammation has been recognized for some time, we aimed to address whether neuroinflammatory changes are involved in enhanced learning of adversities during depressive state. To study this


question, we used a recently proposed mouse model of enhanced contextual conditioning of aversive memories, the modified forced swim model (modFST). In this model, the classic two-day forced swim is followed by an additional delayed session on Day 5, where increased floating behaviour and upregulated glycogen synthase kinase-3 (GSK-3) are contextdependent. Here, increased time spent floating on Day 5, a parameter of enhanced learning of the adverse context, was accompanied by hypercorticosteronemia, increased gene expression of GSK-3 $\alpha$, GSK-3 $\beta$, cFos, cyclooxygenase-1 (COX-1) and pro-inflammatory cytokines interleukin-1 beta (IL-1 $\beta$ ), tumor necrosis factor (TNF), and elevated concentrations of protein carbonyl, a marker of oxidative stress in the prefrontal cortex and hippocampus. There were significant correlations between cytokine levels and GSK-3 $\beta$ gene expression. Two-week administration of drugs with antidepressant properties, imipramine $(7.5 \mathrm{mg} / \mathrm{kg} /$ day) or thiamine (vitamin B $1 ; 200 \mathrm{mg} / \mathrm{kg} /$ day) counteracted most of our reported alterations. Thus, enhanced learning of adverse memories is associated with pro-inflammatory changes that should be considered for optimizing pharmacotherapy of depression associated with enhanced learning of aversive memories. 
Key words: major depression, enhanced learning of adverse memories, cytokines, glycogen synthase kinase-3 (GSK-3), oxidative stress, mice.

Abbreviations: GSK-3 glycogen synthase kinase; TNF - tumor necrosis factor, IL - interleukin, modFST - modified forced swim test, ROS - reactive oxygen species, NF$\kappa \mathrm{B}$ - nuclear factor- $\mathrm{kB}, \mathrm{COX}-1$ - cyclooxigenase-1, GAPDH glyceraldehyde 3-phosphate dehydrogenase, PTSD - post-traumatic stress disorder, HPA - hypothalamic-pituitary-adrenal axis, D - Day. 


\section{Introduction}

While impaired brain plasticity is a well-established pathophysiologic feature of depression, little is known about disorder-associated enhanced cognitive processing. Enhanced cognitive processing of adverse events is one of the most critical elements in the pathology of major depression that can contribute to the development of stress-related depressive symptoms (Clark et al., 2009; Gold and Korol, 2012; Gold et al., 2012; de Bitencourt et al., 2013). However, its neurobiological mechanisms are currently unclear. At the same time, the association between depressive disorders and inflammation has been recognized for some time (Dantzer, 2009; Leonard and Maes, 2012; Anthony and Patossi, 2014). However, it remains elusive to which aspects of this highly heterogeneous disorder inflammation may specifically contribute (Michopoulos et al., 2017; Harro, 2018).

Enhanced acquisition and retention of aversive memories is characteristic of melancholic and anxiety-associated depression (Monzon et al., 2010) and depression comorbid with post-traumatic stress disorder (PTSD) (Flory and Yehyda, 2015). Positive correlations between blood levels of C-reactive protein, pro-inflammatory cytokines such as interleukin-1 beta (IL-1 $\beta$ ), interleukin-6 (IL-6), tumor necrosis factor (TNF), as well as 
cyclooxygenase-1 (COX-1) and augmented learning of aversive memories has been demonstrated in patients with PTSD (Lindqvist et al., 2017; Miller et al, 2018; Toft et al., 2019). This condition is well known to share many symptoms with depression and is highly comorbid with this disease, as well as with generalized anxiety disorder and panic disorder (Michopoulos et al., 2016). Central overexpression of pro-inflammatory cytokines functionally interferes with increased activities of glycogen synthase kinase-3 (GSK-3) and is associated with treatment resistance in depressed patients with comorbidity for PTSD (Cortes-Vieyra et al., 2012; Bailey et al., 2013; Costemale-Lacoste et al., 2016). Up-regulation of GSK-3 was shown to be implicated in the processing of aversive memories during PTSD (Lopresto et al., 2016), and emotional and cognitive dysregulation during depressive syndrome (Jope and Roh et al., 2006).

Up to now, very few mechanistic studies have explored the role of neuroinflammation in the enhanced processing of aversive memories. While translational approach was extensively used to study depressionrelated pro-inflammatory changes in models of stress (Couch et al., 2013, 2016; Patel et al., 2019), helplessness (Chover-Gonzalez et al., 2000) and other depression paradigms (Mesquita et al., 2008, Dudek et al., 2019), to date, limited literature described neuroinflammatory mechanisms 
associated with inappropriate learning of aversive memories in animals. Recently, we established a mouse paradigm of enhanced contextual conditioning of adverse memories, in which the classic two-day swimming test is followed by an additional swimming testing on Day 5 (Strekalova et al., 2016; Markova et al., 2017; Pavlov et al., 2017).

In this modified forced swim model $(\operatorname{modFST})$, increased floating behaviour and GSK-3 $\beta$ activities during the delayed swimming session were found to be context-dependent and reversible by a pre-treatment with antidepressant compounds (Strekalova et al., 2016; Markova et al., 2017). In the modFST, the increase of floating behavior during delayed testing on Day 5 correlates with brain over-expression of GSK-3 $\beta$ and was validated as a parameter of enhanced learning of adverse context. Both changes were associated with an exposure of animals to a context alone and are reversible by a pre-treatment of a low dose of tricyclic antidepressant imipramine (Strekalova et al., 2016). While imipramine can ameliorate behavioural despair in the classic Porsolt test, lower doses are often unable to affect behavioural parameters. Here, in the modFST model, low doses of imipramine were found to prevent an increase in floating behavior and overexpression of GSK-3 $\beta$ associated with swimming on Day 5 in the modFST (Strekalova et al., 2016; Markova et al., 2016). As forced swimming on day 
5 was shown to provoke similar molecular changes with the experience of swimming itself, this suggests the presence of classical Pavlovian contextual conditioning in our model.

We hypothesized that augmented contextual conditioning in the modFST is accompanied by central pro-inflammatory changes. Therefore, we sought to explore whether expression of interleukin-1 beta IL- $1 \beta$, TNF and COX-1 is altered in the hippocampus and prefrontal cortex of mice exposed to the modFST. As elevated expression of pro-inflammatory cytokines is accompanied by an increased corticosterone secretion and activation of hypothalamic-pituitary-adrenal axis (HPA) axis (Uchoa et al., 2014), leading to oxidative stress in the CNS (Sato et al., 2010), we also studied blood corticosterone concentrations and c-Fos expression, where overexpression is associated with increased production of GSK3 and cytokines (Kadry et al., 2018), as well as oxidative stress marker, protein carbonyl content (Vignisse et al., 2017; Frijhoff et al., 2015). We administered a twoweek pre-treatment regime with a low dose of imipramine or thiamine (vitamin B1), an important metabolism regulator with antioxidant, antistress and anti-inflammatory properties (Pan et al., 2010; Bettendorff et al., 2014; Mkrtchyan et al., 2015; Gorlova et al., 2019), whose chronic administration to mice prevented increases in floating behaviour and GSK- 
3 functions in mice subjected to the modFST (Markova et al., 2017; Pavlov et al., 2017).

\section{Methods}

\subsection{Animals}

3-month-old male C57BL6/J mice were obtained from Stolbovaja-RAS, Moscow region (http://www.spf-animals.ru/about/providers/animals) and housed individually under standard conditions (light on 9.00-21.00). Experimental protocols conformed to directive 2010/63/EU, and were approved by the local veterinarian committee (MSMU \#11-18-2018; see Supplementary file).

\subsection{Experimental outline}

Animals were studied for their floating behaviour in 6-min sessions split by three 2-min intervals on Day 1, Day 2 and Day 5 and had tap water (FST group) or were pre-treated with imipramine or thiamine (Imi-FST and ThiFST groups) for two weeks, via drinking water; dosing of selected drug concentrations was controlled as described in Supplementary file (see also Pavlov et al., 2017). Floating behaviour was defined by the absence of any directed movements of mice and was scored using validated method with 
CleverSys (Clever Sys Inc, Reston, VA, USA; Malatynska et al., 2012). Mice subjected modFST were killed 10 min after swimming on Day 5 at the same time as naïve controls that were not subjected to swimming but handled on the respective days of testing. Mice were terminally anaesthetized with an intraperitoneal injection of Nembutal (Bayer, Wiesbaden, Germany) and then were transcardially perfused with $10 \mathrm{ml}$ of the ice-cold $0.9 \% \mathrm{NaCl}$. Their brains were dissected, and prefrontal cortex and the whole hippocampus were isolated as described elsewhere (Gorlova et al., 2019). Blood serum was collected as described elsewhere (Couch et al., 2016; Pavlov et al., 2019) and stored at $-80{ }^{\circ} \mathrm{C}$ for subsequent in vitro assays; each group had 6-7 animals per experimental run (Fig.1A). Data from one run were used for all assays except the correlation analysis between floating behavior and gene expression, for which cDNA from three experimental runs were used, including previously obtained material (Pavlov et al., 2017). Both vehicle- and drug-treated mice exposed to the modFST were included in the correlation analysis.

\subsection{Biochemical assays}

CORT ELISA was performed using ab108821 kit (Abcam, Cambridge, UK) as previously described (Vignisse et al., 2017; Gorlova et al., 2019), 
for details see Supplementary file. For protein carbonyl assay, OxiSelect ${ }^{\mathrm{TM}}$ Protein Carbonyl Fluorometric Assay kit (Cell Biolabs, Inc., San Diego, CA, USA) kit was used as described elsewhere (Vignisse et al., 2017; Gorlova et al., 2019, see Supplementary file). Extraction of mRNA, cDNA synthesis and quantitative RT-PCR were performed to study brain concentrations of GSK $3 \alpha / \beta$, IL- $1 \beta$, TNF, COX-1 and c-Fos mRNA as described elsewhere (Couch et al., 2013; Markova et al., 2016; Pavlov et al., 2017, 2019; Gorlova et al., 2019). Mice were sacrificed 10 min after the last swimming, brains were dissected and the prefrontal cortex and hippocampi were isolated as previously reported (Couch et al., 2013; Markova et al., 2016) and stored at $-80^{\circ} \mathrm{C}$ until use. Expression data were normalized to glyceraldehyde-3-phosphate dehydrogenase (GAPDH), used as housekeeping gene. Sequences for primers are listed in the Supplementary Table 1. mRNA was extracted by using TRI Reagent (MRC, Cincinnati, OH, USA). First-strand cDNA synthesis was performed using random primers and Superscript III transcriptase (Invitrogen, Darmstadt, Germany); $1 \mu \mathrm{g}$ total RNA was converted into cDNA. Quantitative RT-PCR (qRT-PCR) was performed using the SYBR Green master mix (Bio-Rad Laboratories, Philadelphia, PA, USA) and the CFX96 Real-time System (Bio-Rad Laboratories, Philadelphia, PA, USA). The qRT-PCR was 
performed in a $25 \mu \mathrm{l}$ reaction volume containing a 10xPCR Buffer $(2.5 \mu \mathrm{l})$, $25 \mathrm{mmol} \mathrm{MgCl} 2(4 \mu \mathrm{l}), 10 \mathrm{mmol}$ dNTPs $(2 \mu \mathrm{l})$, specific forward and reverse primers at $20 \mathrm{pmol} / \mu \mathrm{l}$ concentration $(1 \mu \mathrm{l}), \mathrm{cDNA}(2 \mu \mathrm{l}), 5 \mathrm{u} / \mu \mathrm{l}$ Taq DNA polymerase $(1 \mu \mathrm{l})$ (Beagle, st. Petersburg, Russia), and ddH2O (10 $\mu \mathrm{l})$. All samples were run in duplicate. Cycling was performed at $95^{\circ} \mathrm{C}$ for $5 \mathrm{~min}$ followed by a 45 -cycle amplification at $95^{\circ} \mathrm{C}$ for $10 \mathrm{~s}$, then at the annealing temperature defined previously for $15 \mathrm{~s}$ and at the temperature $72^{\circ} \mathrm{C}$ for 20 S.

Results are expressed as folds of expression compared to the mean values of expression in non-stressed control animals (Couch et al., adapted from Livak and Schmittgen, 2001). To calculate $\Delta \mathrm{Ct}$ for each sample, $\mathrm{Ct}$ of GAPDH was subtracted from respective Ct of gene of interest. Mean control $\Delta \mathrm{Ct}$ value was subsequently calculated and subtracted from every other $\Delta \mathrm{Ct}$ values to get $\Delta \Delta \mathrm{Ct}$ value for each particular sample. Afterwards these data were processed $\left(2^{\wedge}(-\Delta \Delta \mathrm{Ct})\right)$ and normalized to control group; data were additionally calculated as percent from the mean of control group (unpresented results) to facilitate discussion and literature search where applicable.

\subsection{Statistics}


Data were analyzed with GraphPad Prism v.6.0 (San Diego, CA, USA). Repeated measures ANOVA and two-way ANOVA were used to treat behavioral and the corticosterone data, one-way ANOVA was applied to analyze results of PCR and ELISA assays. Tukey's test was used for post hoc analysis. Spearman correlation was employed for correlation analysis. The level of confidence was set at $95 \%(\mathrm{p}<0.05)$, all data are mean and SEM.

\section{Results}

\subsection{Overproduction of brain protein carbonyl and blood CORT accompany behavioral despair during delayed swim session: effects of imipramine and thiamine}

In the modified forced swim test, repeated two-way ANOVA with session and treatment as factors revealed significant effects of sessions $\left(\mathrm{F}_{2,48}=14.57\right.$, $\mathrm{p}<0.0001)$ and treatment $\left(\mathrm{F}_{2,48}=4.218, \mathrm{p}=0.0114\right)$ on total duration of floating (Fig.1B). A significant effect of sessions, but not treatment, on duration of floating was found in minutes $1-2\left(\mathrm{~F}_{2,48}=10.66, \mathrm{p}=0.0001\right.$ and $\mathrm{F}_{2,48}=1.21, \mathrm{p}=0.307$, respectively). For minutes $3-4$, a significant effect on duration of floating of both sessions $\left(\mathrm{F}_{2,48}=7.27, \mathrm{p}=0.0017\right)$ and treatment $\left(F_{2,48}=10.66, p=0.0001\right)$ was revealed. No significant effect of sessions and 
treatment on duration of floating was revealed in minutes $5-6\left(\mathrm{~F}_{2,48}=0.38\right.$, $\mathrm{p}=0.68$ and $\mathrm{F}_{2,48}=2.64, \mathrm{p}=0.08$, respectively); there was no significant interaction between these factors $\left(\mathrm{F}_{2,48}=0.36, \mathrm{p}=0.83\right)$. In all groups, duration of floating was significantly elevated during the first two time intervals on Day 2 in comparison to Day 1, that was not shown for the last time interval of the test $(\mathrm{p}<0.05$ and $\mathrm{p}>0.05$, respectively; repeated measures ANOVA and Tukey's test, Supplementary Table 2). On Day 5, total duration of floating and duration of floating for 1-2 min interval were significantly increased in comparison with values registered on Day 2 in the FST group $(\mathrm{p}<0.05$; repeated measures ANOVA and Tukey's test; Fig.1B, Supplementary Table 2), but not Imi- or Thi-FST groups $(\mathrm{p}>0.05)$. No significant group differences were found in each time interval of testing, except significantly shortened duration of total floating in Thi-FST group in comparison with FST mice (Supplementary Table 2). Together, analysis of floating behavior by 2 -min intervals indicate that treatment could significantly affect the expression of floating behavior at the first two period of the test, but not during the last 2 min of the swimming session. This may be interpreted as possible sign of effects of drugs on cognitive factors in this test, rather than on despair behavior caused by prolonged unescapable swimming. The overall analysis showed significantly elevated total 
duration of floating during delayed session on Day 5, a measure of enhanced contextual conditioning in this test was observed in pharmacologically naïve mice, but not in groups treated with thiamine or imipramine. 
A

Days 1-14

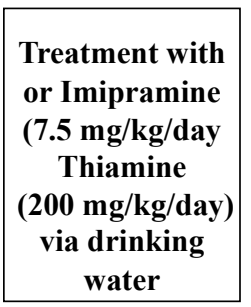

B
Day 20

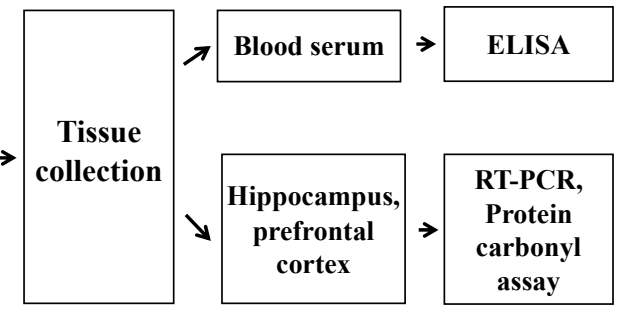

C

\section{CORTICOSTERONE}
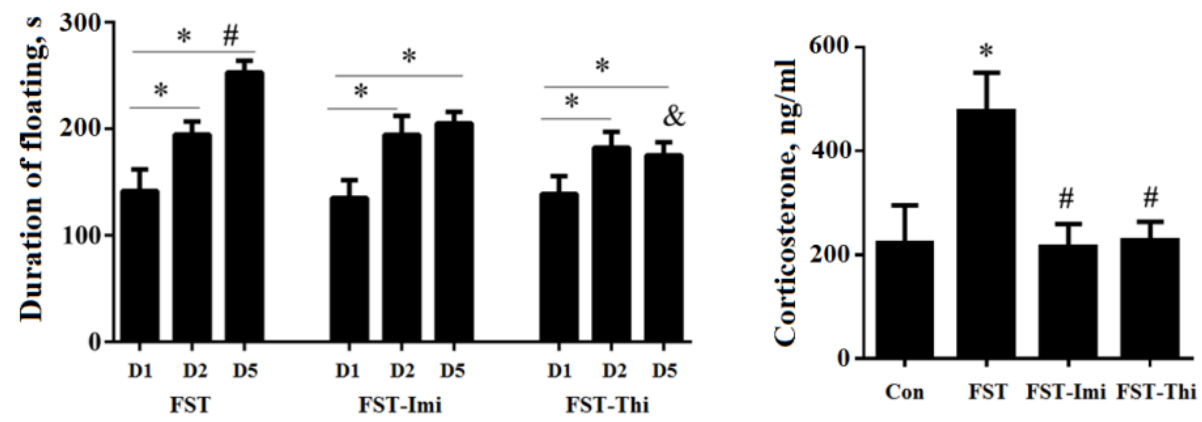

\section{PROTEIN CARBONYL}

D
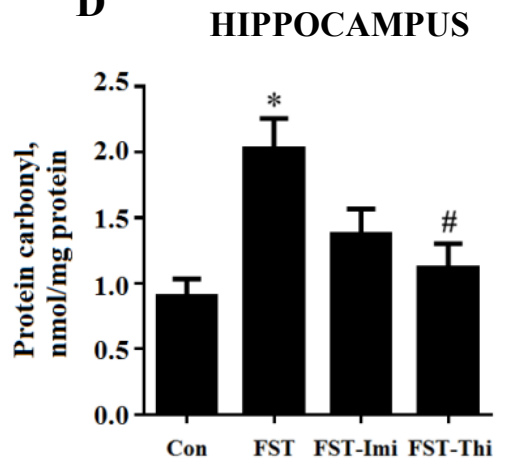

E PREFRONTAL CORTEX

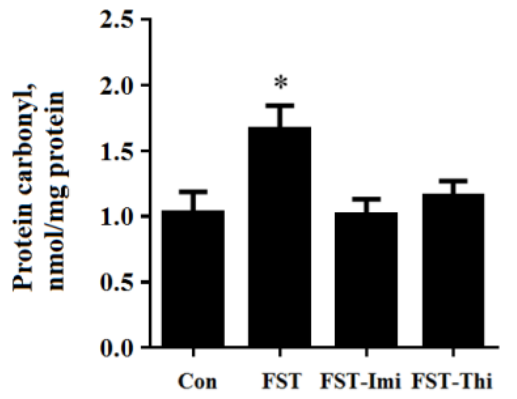


Figure 1. Experimental outline, potentiated behavioral despair and accompanying brain oxidation and systemic CORT upregulation during delayed swimming session.

(A) After pre-treatment with imipramine or thiamine mice were subjected to 5-day modified swim paradigm and killed; their brains were dissected for in vitro assays, including quantitative reverse transcription polymerase chain reaction (qRT-PCR) and measurement of carbonyl protein content; blood was collected for measurement of corticosterone levels. (B) On testing Day 2 and 5, total floating behavior was increased in comparison to the one at Day 1. Total duration of floating on Day 5 was also significantly increased in comparison with Day 2. This parameter was decreased in ThiFST group in comparison with FST group on Day 5. (C) FST mice on Day 5 displayed increased systemic CORT level in comparison with controls. Thiamine or imipramine counteracted this effect. (D) FST mice on Day 5 displayed increased protein carbonyl content in the hippocampus and (E) in the prefrontal cortex in comparison with controls. Mice treated with thiamine, but not imipramine, did not differ from controls in protein carbonyl content in the hippocampus and displayed significant decrease of this measure in comparison with non-treated group. ${ }^{*} \mathrm{p}<0.05 \mathrm{vs}$. testing Day $1, \# p<0.05$ vs. testing Day 2, \&p<0.05 vs. testing Day 5 of FST group, repeated measures and two-way ANOVA, post hoc Tukey's test. D1: Day 1; D2: Day 2; D5: Day 5 of modified swim test paradigm.

There were significant group differences in CORT levels in blood $\left(\mathrm{F}_{3,38}=5.48, \mathrm{p}=0.003\right.$, one-way ANOVA). Specifically, this measure was increased in FST mice in comparison with controls ( $p=0.04$; Tukey's test;

Fig.1C). In contrast, CORT levels in Thi-FST and Imi-FST mice were not different from control values $(p=0.56$ and $p=0.27$, respectively) and were significantly decreased in comparison with FST group $(\mathrm{p}=0.006$ and 
$\mathrm{p}=0.01$, respectively). We found significant group differences in protein carbonyl contents in the prefrontal cortex $\left(\mathrm{F}_{3,38}=6.58, \mathrm{p}=0.002\right.$, one-way ANOVA; Fig.1D) and hippocampus ( $F 3,38=6.209, \mathrm{p}=0.003$, Fig.1E). There was a significant increase of this measure in the hippocampus and prefrontal cortex of FST group in comparison with controls $(\mathrm{p}=0.025$ and $\mathrm{p}=0.03$, respectively, Tukey's test). No such changes were shown for Imi-FST and Thi-FST groups ( $\mathrm{p}=0.44$ and $\mathrm{p}=0.90$, respectively), and the latter but not the former group displayed a significantly lower protein carbonyl concentration in the hippocampus than the FST group ( $\mathrm{p}=0.406$ and $\mathrm{p}=0.01$; respectively).

\subsection{Brain over-expression of pro-inflammatory factors and c-Fos is} associated with increased floating in the modified swim test and precluded by thiamine and imipramine

We revealed significant group differences in mRNA expression of GSK-3 $\beta$ and GSK-3 $\alpha$ in the hippocampus $\left(\mathrm{F}_{3,38}=4.39, \mathrm{p}=0.008\right.$ and $\mathrm{F}_{3,38}=4.13$, $\mathrm{p}=0.01$, respectively) and of GSK-3 3 , but not GSK $-3 \alpha$, in the prefrontal cortex $\left(\mathrm{F}_{3,38}=3.92, \mathrm{p}=0.03\right.$ and $\mathrm{F}_{3,38}=2.35, \mathrm{p}=0.096$, one-way ANOVA; data not shown). This replicated our former findings of an upregulation of gene expression of GSK-3 in the brain of mice exposed to the modFST. There were significant group differences in IL-1 $\beta$ mRNA expression in the 
hippocampus $\left(\mathrm{F}_{3,38}=3.73, \mathrm{p}=0.01\right)$, but not in the prefrontal cortex $\left(\mathrm{F}_{3,38}=0.42, \mathrm{p}=0.73\right.$; Fig.2A,B). TNF mRNA expression was significantly different between the groups in the hippocampus $\left(\mathrm{F}_{3,38}=3.64, \mathrm{p}=0.01\right)$ and prefrontal cortex $\left(\mathrm{F}_{3,38}=4.57, \mathrm{p}=0.007\right)$. There was a significant increase in the FST group in comparison with control mice in this measure in hippocampus and in the prefrontal cortex ( $\mathrm{p}=0.03$ and $\mathrm{p}=0.01$, respectively) that was not found in Imi-FST and Thi-FST groups $(p=0.35$ and $p=0.17$, respectively, and $\mathrm{p}=0.52$ and $\mathrm{p}=0.09$, respectively; Fig. $2 \mathrm{C}, \mathrm{D})$. 

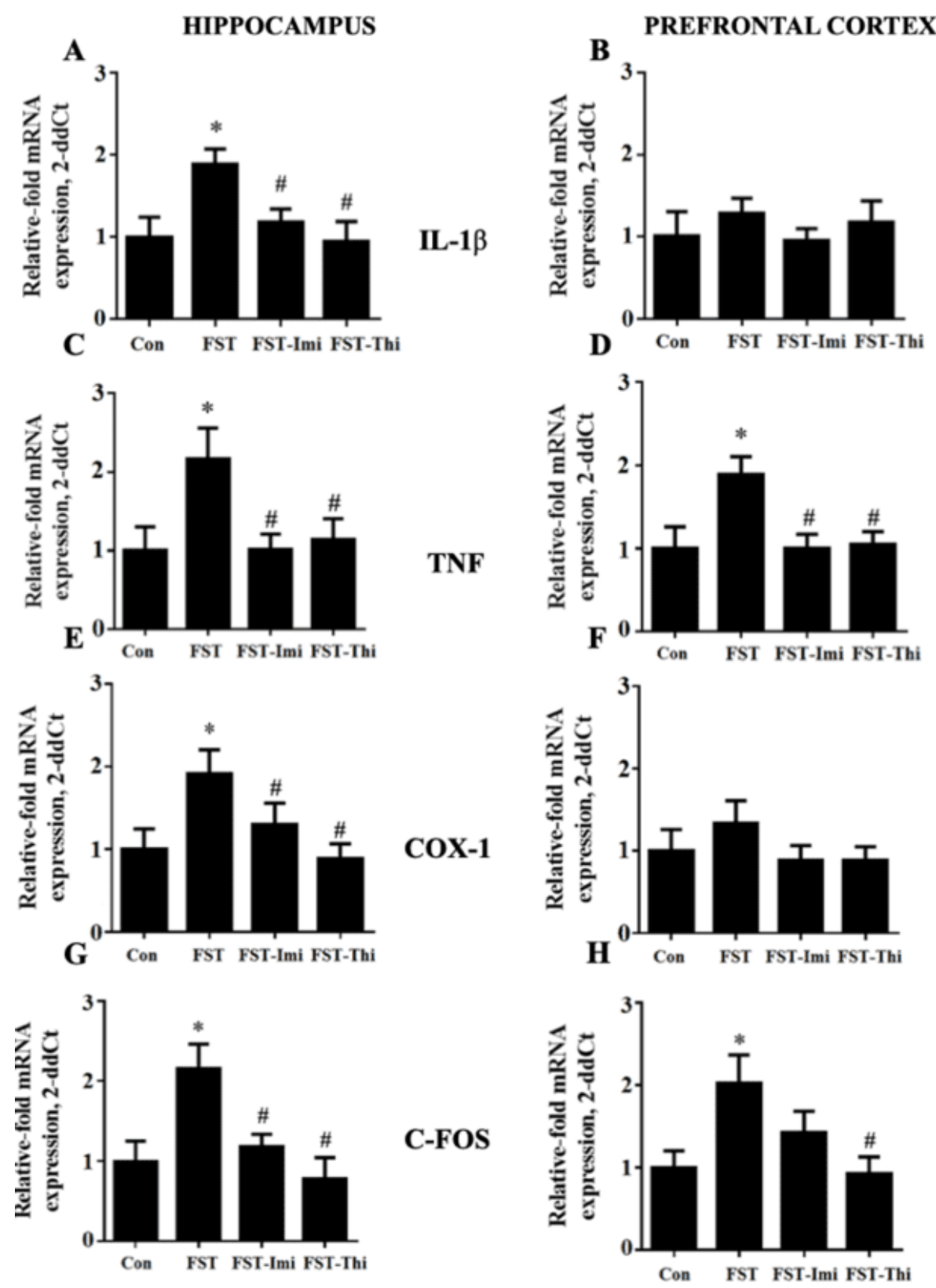
Figure 2. Pro-inflammatory changes during delayed swimming session.

Mice on Day 5 displayed increased (A) IL-1 $\beta$ mRNA expression, (C) TNF expression, (E) COX-1 expression and (G) c-Fos expression in the hippocampus in comparison with controls. Mice treated with imipramine or thiamine did not differ from controls in these parameters and displayed significant decrease of these measures in comparison with FST group. Moreover, on Day 5, these mice displayed increased (D) TNF expression and $\mathbf{( H )}$ c-Fos expression in the prefrontal cortex in comparison with controls. Mice treated with imipramine or thiamine did not differ from controls in TNF expression and displayed significant decrease of this measure in comparison with non-treated group. At the same time, only ThiFST, but not Imi-FST, mice had significantly decreased c-Fos expression in the prefrontal cortex in comparison with FST group. There were no significant differences between groups in (A) IL-1 $\beta$ and (F) COX-1 mRNA levels in the prefrontal cortex. ${ }^{*} \mathrm{p}<0.05$ vs. controls, $\# \mathrm{p}<0.05$ vs. non-treated mice on Day 5; one-way ANOVA and post hoc Tukey's test.

Significant group differences in mRNA expression of COX-1 was found in the hippocampus $\left(\mathrm{F}_{3,38}=3.42, \mathrm{p}=0.02\right)$, but not in the prefrontal cortex $\left(\mathrm{F}_{3,38}=0.84, \mathrm{p}=0.47\right)$. In the hippocampus, this parameter showed a significant increase in the FST group in comparison with control mice $(p=0.04)$ that was not found in Imi-FST and Thi-FST groups $(p=0.28$ and $\mathrm{p}=0.14$, respectively; Fig.2E, F).

Finally, significant group differences in mRNA expression of c-Fos were shown both in the hippocampus $\left(\mathrm{F}_{3,38}=5.68, \mathrm{p}=0.002\right)$ and prefrontal cortex $\left(F_{3,38}=3.66, p=0.01\right)$; significant over-expression of this gene was found in FST groups ( $p=0.01$ and $p=0.03$, respectively) but not in Imi- and Thi-FST 
groups in comparison with controls $(\mathrm{p}=0.55$ and $\mathrm{p}=0.97$, respectively and $\mathrm{p}=0.63$ and $\mathrm{p}=0.75$, respectively; Fig. $2 \mathrm{G}, \mathrm{H})$.

\subsection{Correlation analysis of expression of GSK-3 isoforms with behavioral and molecular alterations during delayed swimming session}

Significant correlations were found between GSK-3 $\alpha$ expression and IL-1 $\beta$ expression in the hippocampus $(\mathrm{p}=0.04, \mathrm{r}=0.37$, Spearman correlation; Fig. $3 \mathrm{~A})$ and $\mathrm{TNF}$ expression in the prefrontal cortex $(\mathrm{p}=0.01, \mathrm{r}=0.46$; Fig.3G). There were significant correlations between GSK-3 $\beta$ expression and expression of IL- $1 \beta$ in the hippocampus $(p=0.007, r=0.49$; Fig. $3 B$ ) and in the prefrontal cortex $(\mathrm{p}=0.013, \mathrm{r}=0.22$; Fig.3D), expression of TNF in the hippocampus $(\mathrm{p}=0.02, \mathrm{r}=0.43$; Fig. $3 \mathrm{~F}$ ) and $\mathrm{c}-\mathrm{Fos}$ expression in the prefrontal cortex $(\mathrm{p}=0.01, \mathrm{r}=0.45 ;$ Fig. $3 \mathrm{P})$. No significant correlations were found between GSK-3 $\alpha$ expression and expression of IL-1 $\beta$ in the prefrontal cortex $(p=0.26, r=-0.21$; Fig. $3 C)$, expression of TNF in the hippocampus $(\mathrm{p}=0.48, \mathrm{r}=-0.19$; Fig.3E), c-Fos expression in the hippocampus $(\mathrm{p}=0.12$, $\mathrm{r}=-0.29$; Fig. $3 \mathrm{M})$ and prefrontal cortex $(\mathrm{p}=0.99, \mathrm{r}=-0.002$; Fig. $3 \mathrm{~K})$ and expression of COX-1 in the hippocampus ( $\mathrm{p}=0.079, \mathrm{r}=0.11$; Fig.3I) and prefrontal cortex $(\mathrm{p}=0.21, \mathrm{r}=0.24$; Fig.3O). Notably, mRNA expression of 
IL-1 $\beta$ in the hippocampus positively correlated with total duration of floating ( $\mathrm{p}=0.03 \mathrm{r}=0.352$; data not shown). 
HIPPOCAMPUS
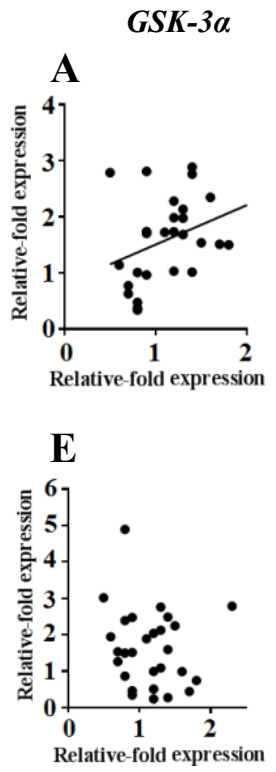

I

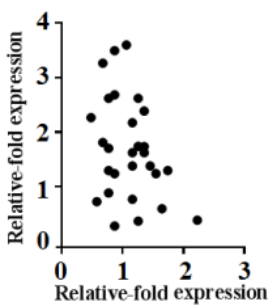

M

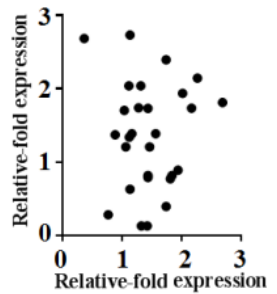

GSK-3及
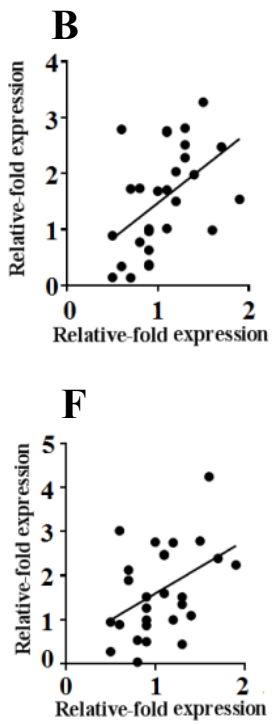

$\mathbf{J}$

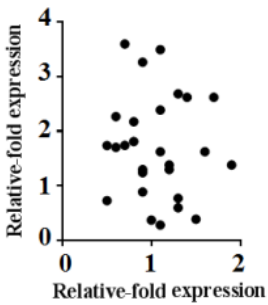

$\mathbf{N}$

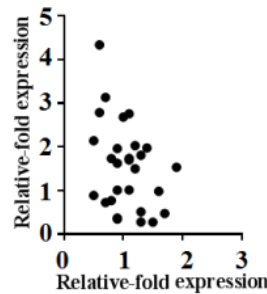

PREFRONTAL CORTEX

GSK-3a

GSK-3及
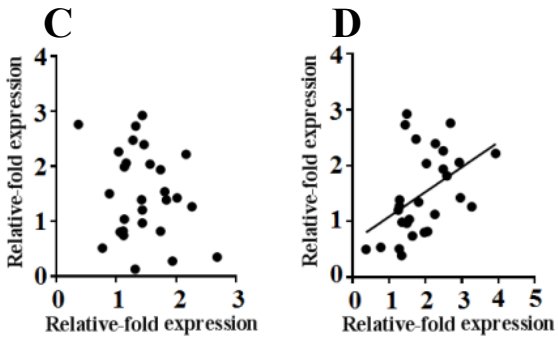

G

H
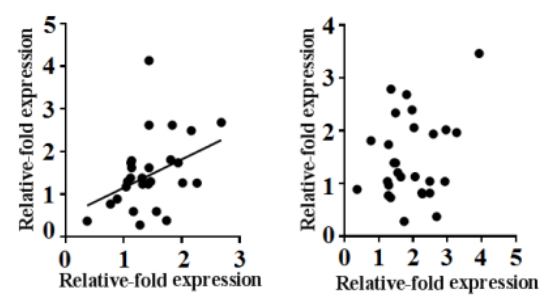

K

$\mathbf{L}$
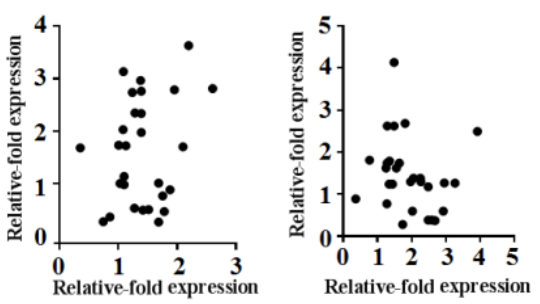

$\mathbf{P}$

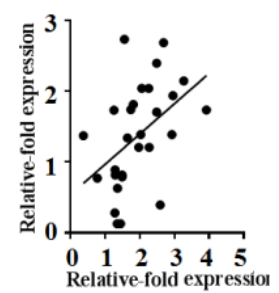


Figure 3. Correlation analysis between gene expression of GSK-3 isoforms and stress-associated molecules.

(A) Significant correlations were found between GSK-3 $\alpha$ expression and IL-1 $\beta$ expression in the hippocampus and (G) TNF expression in the prefrontal cortex. (B) Significant correlations were also found between GSK-3 $\beta$ expression and IL-1 $\beta$ expression in the hippocampus and (D) in the prefrontal cortex, (F) TNF expression in the hippocampus and (P) c-Fos expression in the prefrontal cortex. (C) No significant correlations were found between GSK-3 $\alpha$ gene expression and IL-1 $\beta$ expression in the prefrontal cortex, (E) TNF expression in the hippocampus, (M) c-Fos expression in the hippocampus and (O) prefrontal cortex, (I) COX-1 expression in the hippocampus and $(\mathbf{K})$ in the prefrontal cortex. (H) There were no significant correlations between GSK-3 $\beta$ expression and TNF expression in the prefrontal cortex, (N) c-Fos expression in the hippocampus, (J) COX-1 expression in the hippocampus and ( $\mathbf{L})$ in the prefrontal cortex. $\mathrm{p}<0.05$, trend line indicates significant correlations; Spearman correlation.

No other significant correlations were found, including correlations between expression of GSK-3 $\beta$ and other molecules: TNF expression in the prefrontal cortex $(\mathrm{p}=0.33, \mathrm{r}=0.19$; Fig. $3 \mathrm{H})$, $\mathrm{c}-\mathrm{Fos}$ expression in the hippocampus ( $\mathrm{p}=0.06, \mathrm{r}=0.35$; Fig. $3 \mathrm{~N}$ ) and expression of COX-1 in the hippocampus ( $\mathrm{p}=0.68, \mathrm{r}=0.079$; Fig.3J) and prefrontal cortex $(\mathrm{p}=0.206$, $\mathrm{r}=0.13$; Fig.3L). 


\section{Discussion}

To summarize, we found an upregulation in the pro-inflammatory factors IL-1 $\beta$, TNF and COX-1 mRNA expression in the hippocampus and prefrontal cortex of mice subjected to the modFST, which was prevented by antidepressant treatments with imipramine or thiamine. These findings provide the first evidence for the involvement of pro-inflammatory mechanisms in an animal model of enhanced learning of adverse memories and the effects of antidepressant treatments on these changes. Furthermore, we found significant correlations of most of pro-inflammatory changes with key molecular features of the employed paradigm, particularly the expression of GSK-3 $\alpha$ and GSK-3 $\beta$; the expression of IL1- $\beta$ correlated with floating behavior. Pro-inflammatory changes were accompanied by signs of oxidative stress, i.e. increased concentration of protein carbonyl, in the prefrontal cortex and hippocampus. Markers of increased systemic stress response, brain over-expression of c-Fos and hypercorticosteronaemia were found in modFST groups as well. The majority of these neurobiological abnormalities were prevented by chronic pre-treatment with low dose of imipramine and administration of anti-oxidant thiamine. 
We previously reported that in the modFST increased floating scores and brain GSK-3 $\beta$ activities during an additional delayed swimming session, which are positively correlated and context-dependent (Strekalova et al., 2016; Pavlov et al., 2017). In accordance with earlier results, increased floating behaviour and brain GSK-3 $\beta$ over-expression was prevented by pre-treatment with imipramine or thiamine (Markova et al., 2016; Pavlov et al., 2017). Detailed behavioural analyses of delayed swimming session revealed a significant increase of floating behavior only during its initial period in comparison with preceding session in pharmacologically naïve mice. This suggests that exposure to aversive context of swimming, not unescapable swimming itself, was likely to be the cause of this increase. Such increase was not found in pharmacologically-treated groups supporting our previous results (Markova et al., 2017; Pavlov et al., 2017).

Given established links between stress-induced release of glucocorticoids and elevated GSK-3 activities (Beurel et al., 2015), both of which were found in our study, and pro-inflammatory consequences of the latter (Huang et al., 2009; Chang et al., 2013), we suggest that over-expression of IL-6, TNF and COX-1 in modFST results from these changes. Elevated GSK-3 activities were previously shown to inhibit expression of calciumresponsive-element-binding protein (CREB) and anti-inflammatory 
cytokine IL-10 (Huang et al., 2009) and promote expression of proinflammatory cytokines via activation of nuclear factor- $\kappa \mathrm{B}(\mathrm{NF}-\kappa \mathrm{B})$ (Chang et al., 2013). In a contrary, the blockade of Toll-like receptor 4 (TLR4), a major mediator of inflammatory processes (Buchanan et al., 2010) during psychological stress in mice ameliorated GSK-3 activities and depressive-like symptoms (Cheng et al., 2016).

Over the years, most attention has focused on the role of central IL-1 $\beta$ expression in the generation of sickness behaviour while by now IL-1 $\beta$ signaling pathways are established as mediators of chronic stress in the induction of depressive-like changes in the brain (Gadek-Mishalska, 2013; D'Mello and Swain, 2017). Over-expression of IL-1 $\beta$ in the brain was shown to correlate with individual predisposition to stress-induced anhedonia in mice (Couch et al., 2013) and accompany the depressive syndrome induced in other models in mice and rats (Cordeiro et al., 2019; Fang et al., 2019), including the ultrasound stress model of "emotional stress" (Morozova et al., 2016; Pavlov et al., 2018; Gorlova et al., 2019). The present study revealed up-regulation of this cytokine both in the prefrontal cortex and hippocampus, as well as its correlation with floating behaviour and overexpression of GSK-3 $\beta$ in the prefrontal cortex. Notably, 
overproduction of IL-1 $\beta$ was shown in patients with PTSD (Wang et al., 2017; Toft et al., 2019) indicating its translational potential.

TNF, another cytokine studied in our work, was over-expressed in the brain of mice exposed to modFST. The potential for TNF to contribute to mood disorders has gained attention based on the basal 'antidepressant' phenotype of TNF and TNF receptor knockout mice (Simen et al., 2006), "prohedonic" effects of targeted deletion of TNF receptor 2 in sucrose intake test (Yamada et al., 2000) and evidence that TNF blockade can reduce depression symptoms (Krugel et al., 2013). The present study revealed a link between TNF over-expression and augmented learning of adverse memories that is in line with clinical data suggesting altered TNF expression during PTSD and depression (Passos et al., 2015; Miller et al., 2018; Yuan et al., 2019).

Our study also revealed an increase in gene expression of hippocampal COX-1, which previously appeared to accompany the development of stress-induced anhedonia in mice (Couch et al., 2013). In line with these findings, mice lacking COX-1 were reported to be resilient to social stressinduced anhedonia (Tanaka et al., 2012). COX-1 was found to be overexpressed in depressed patients as well as in patients with acute PTSD 
(Passos et al., 2015; Powers et al., 2019; Michopoulos et al., 2019). The reported significant correlations between molecular markers and floating behavior in the modFST suggests functional relationship between these factors in the regulation of floating behavior in the test and the acquisition of aversive memories. This was particularly true for the pro-inflammatory cytokines that were investigated here and both isoforms of GSK3.

Additionally, we demonstrated that administration of imipramine and thiamine exerted central anti-inflammatory and anti-oxidative stress effects in the modFST. These treatments were previously shown to normalize depressive- and anxiety-like behaviours, GSK-3 expression, markers of oxidative stress and hippocampal cell proliferation during predation stress, the ultrasound model of emotional stress and the modFST (Cline et al., 2012, 2014, 2015; Vignisse et al., 2017; Pavlov et al., 2017; Gorlova et al., 2019). As over-production of cytokines, including TNF has been shown to stimulate glutamate release from astrocytes (Bezzi et al., 2001) and microglia (Takeuchi et al., 2006) that can result in excessive intracellular calcium, leading to activation of calcium-dependent lipases and upregulation of reactive oxygen species (Dargelos et al., 2010), these mechanisms can explain increases in brain oxidative stress markers during the modFST. Administration of thiamine or imipramine ameliorated protein 
carbonyl levels in the brain, suggesting improved balance of direct oxidation processes by reactive oxygen species (ROS) of amino acid residues (Cecarini et al., 2007). These data are in line with the literature suggesting compromised markers of oxidative stress during depression and comorbid disorders such as PTSD, anxiety disorders and their normalization by antidepressant treatment (Berk et al., 2013; Miller et al., 2018). Finally, the above-mentioned effects of treatments were accompanied by lowered cFos expression in the hippocampus and prefrontal cortex of the experimental animals suggesting activity-dependent normalizing changes in these brain structures, which may be due to previously described functional links to oxidative stress, GSK3, and neuroinflammatory mechanisms (Kadry et al., 2018; Rana and Singh, 2018).

\section{Conclusions}

Taken together, our study suggests that the development of enhanced contextual conditioning of adverse memories in the modFST mouse paradigm is associated with a proinflammatory profile and signs of oxidative stress. These changes are likely to be due to increases in blood glucocorticoid levels and GSK-3 activities (Thoeringer et al., 2012). A pretreatment with low dose of tricyclic antidepressant imipramine and thiamine 
can prevent the most of these changes. Given that patients with symptoms of depression and PTSD disorders revealed signs of neuroinflammation (Michopoulos et al., 2017, 2019), it seems likely that treatments employed here may have considerable therapeutic potential. Our findings are in line with clinical data on the pathophysiology of depression, suggesting that depression of distinct forms leads to elevated levels of inflammation and an oxidant/antioxidant imbalance (Ogtodek and Just, 2018), as well as emphasize a role for neuroinflammatory processes during augmented learning of aversive memories (Miller et al., 2018). They further validate the applied model as a tool for studying inappropriate learning of aversive memory in the pathophysiology of depressive syndromes and highlight future directions for the development of novel therapeutics targeting oxidative stress and inflammation in patients with related psychopathologies.

\section{Appendices}

\subsection{Acknowledgments}

The authors' work reported here was supported by the Horizon 2020 Research and Innovation Program under Grant No. 728018 (Eat2beNICE, to KPL and TS), (EURON mobility grant 2019 to TS, DP and LB), and "5- 
100" Russian Research Excellence program (to TS and KPL). LB is Research Director of the F.R.S.-FNRS (Belgium).

\subsection{Conflict of Interest Statement}

None.

\section{References}

Anthony DC, Pitossi FJ. (2013). Special issue commentary: the changing face of inflammation in the brain. Mol Cell Neurosci. 53:1-5. DOI: 10.1016/j.men.2012.11.005.

Bailey R, Cordell E, Sobin S, Neumeister A. (2013). Recent Progress in Understanding the Pathophysiology of Post-Traumatic Stress Disorder: Implications for Targeted Pharmacological Treatment. CNS Drugs. 27(3), 221-232. DOI: 10.1007/s40263-013-0051-4.

de Bitencourt RM, Pamplona FA, Takahashi RN. (2013). A current overview of cannabinoids and glucocorticoids in facilitating extinction of aversive memories: potential extinction enhancers. Neuropharmacology. 64,389-95. DOI: 10.1016/j.neuropharm.2012.05.039. 
Berk M, Williams LJ, Jacka FN, O'Neil A, Pasco JA, Moylan S, Allen NB, Stuart AL, Hayley AC, Byrne ML, Maes M. (2013). So depression is an inflammatory disease, but where does the inflammation come from? BMC Med. 12, 11:200. DOI: 10.1186/1741-7015-11-200.

Bettendorff L, Lakaye B, Kohn G, Wins P. (2014). Thiamine triphosphate: a ubiquitous molecule in search of a physiological role. Metab Brain Dis. 29(4), 1069-82. DOI:10.1007/s11011-014-9509-4.

Beurel E, Grieco SF, Jope RS. (2015). Glycogen synthase kinase-3 (GSK3): regulation, actions, and diseases. Pharmacol Ther. 148, 114-31. DOI:10.1016/j.pharmthera.2014.11.016

Buchanan MM, Hutchinson M, Watkins LR, Yin H (2010). Toll-like receptor 4 in $\mathrm{CNS}$

Bezzi P, Domercq M, Brambilla L, Galli R, Schols D, De Clercq E, Vescovi A, Bagetta G, Kollias G, Meldolesi J, Volterra A. (2001). CXCR4-activated astrocyte glutamate release via TNFalpha: amplification by microglia triggers neurotoxicity. Nat Neurosci. 4(7), 702-10. DOI:10.1038/89490.

Cao Q, Karthikeyan A, Dheen ST, Kaur C, Ling EA. (2017). Production of proinflammatory mediators in activated microglia is synergistically 


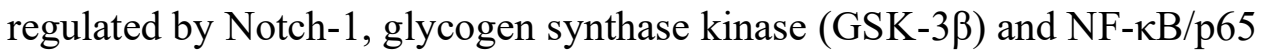
$\begin{array}{llll}\text { signalling. } & P L O S & \text { One. } & 12,\end{array}$ DOI:10.1371/journal.pone.0186764.

Cecarini V, Gee J, Fioretti E, Amici M, Angeletti M, Eleuteri AM, Keller JN. (2007). Protein oxidation and cellular homeostasis: Emphasis on metabolism. Biochim Biophys Acta. 1773(2), 93-104. DOI:10.1016/j.bbamcr.2006.08.039.

Chang YT, Chen CL, Lin CF, Lu SL, Cheng MH, Kuo CF, Lin YS. (2013). Regulatory role of GSK-3 $\beta$ on NF- $\kappa$ B, nitric oxide, and TNF- $\alpha$ in group A streptococcal infection. Mediators Inflamm. 2013:720689 DOI:10.1155/2013/720689.

Cheng Y, Pardo M, Armini RS, Martinez A, Mouhsine H, Zagury JF, Jope RS, Beurel E. (2016). Stress-induced neuroinflammation is mediated by GSK3-dependent TLR4 signaling that promotes susceptibility to depression-like behavior. Brain Behav Immun. 53, 207-222. DOI:10.1016/j.bbi.2015.12.012.

Chover-Gonzalez AJ, Jessop DS, Tejedor-Real P, Gibert-Rahola J, Harbuz MS. (2000). Onset and severity of inflammation in rats exposed to the 
learned helplessness paradigm. Rheumatology (Oxford). 7, 764-71. DOI:10.1093/rheumatology/39.7.764 .

Costemale-Lacoste JF, Guilloux JP, Gaillard R. (2016). The role of GSK-3 in treatment-resistant depression and links with the pharmacological effects of lithium and ketamine: A review of the literature. Encephale. 42(2), 15664. DOI:10.1016/j.encep.2016.02.003.

Cordeiro RC, Chaves Filho AJM, Gomes NS, Tomaz VS, Medeiros CD, Queiroz AIG, Maes M, Macedo DS, Carvalho AF. (2019). Leptin Prevents Lipopolysaccharide-Induced Depressive-Like Behaviors in Mice: Involvement of Dopamine Receptors. Front Psychiatry. 12, 10:125. DOI: 10.3389/fpsyt.2019.00125.

Cortés-Vieyra R, Bravo-Patiño A, Valdez-Alarcón JJ, Juárez MC, Finlay BB, Baizabal-Aguirre VM. (2012). Role of glycogen synthase kinase-3 beta in the inflammatory response caused by bacterial pathogens. J Inflamm (Lond). 9, 1:23 DOI:10.1186/1476-9255-9-23

Cline BH, Costa-Nunes JP, Cespuglio R, Markova N, Santos AI, Bukhman YV, Kubatiev A, Steinbusch HW, Lesch KP, Strekalova T. (2015). Dicholine succinate, the neuronal insulin sensitizer, normalizes behavior, REM sleep, hippocampal pGSK3 beta and mRNAs of NMDA receptor 
subunits in mouse models of depression. Front. Behav. Neurosci. 26, 9-37. DOI:10.3389/fnbeh.2015.00037.

Couch Y, Anthony DC, Dolgov O, Revischin A, Festoff B, Santos AI, Steinbusch HW, Strekalova T. (2013). Microglial activation, increased TNF and SERT expression in the prefrontal cortex define stress-altered behaviour in mice susceptible to anhedonia. Brain Behav. Immun. 29, 136146. DOI:10.1016/j.bbi.2012.12.017.

Couch Y, Trofimov A, Markova N, Nikolenko V, Steinbusch HW, Chekhonin V, Schroeter C, Lesch KP. (2016). Low-dose lipopolysaccharide (LPS) inhibits aggressive and augments depressive behaviours in a chronic mild stress model in mice. J. Neuroinflammation. 13, 1-8.

DOI: 10.1186/s12974-016-0572-0.

Clark L., Chamberlain S. R., Sahakian B. J. (2009). Neurocognitive Mechanisms in Depression: Implications for Treatment. Annals and $\begin{array}{lll}\text { Reviews in } \quad \text { in } \quad \text { 5euroscience, } & \text { 32(7), }\end{array}$ DOI:10.1146/annurev.neuro.31.060407.125618. 
D'Mello C, Swain MG. (2017). Immune-to-Brain Communication Pathways in Inflammation-Associated Sickness and Depression. Curr Top Behav Neurosci. 31, 73-94. DOI: 10.1007/7854_2016_37.

Dargelos E, Brulé C, Stuelsatz P, Mouly V, Veschambre P, Cottin P, Poussard S. (2010). Up-regulation of calcium-dependent proteolysis in human myoblasts under acute oxidative stress. Exp Cell Res. 316(1), 11525. DOI:10.1016/j.yexcr.2009.07.025.

Dantzer R. (2009). Cytokine, Sickness Behavior, and Depression. Immunol Allergy Clin North Am. 29(2), 247-264. DOI: 10.1016/j.iac.2009.02.002.

Dudek KA, Dion-Albert L, Kaufmann FN, Tuck E, Lebel M, Menard C. (2019). Neurobiology of resilience in depression: immune and vascular insights from human and animal studies. Eur J Neurosci. [Epub ahead of print] DOI: 10.1111/ejn.14547.

Fang X, Zhan G, Zhang J, Xu H, Zhu B, Hu Y, Yang C, Luo A. (2019). Abnormalities in Inflammatory Cytokines Confer Susceptible to Chronic Neuropathic Pain-related Anhedonia in a Rat Model of Spared Nerve Injury.

Clin Psychopharmacol Neurosci,17(2), 189-199. DOI: 10.9758/cpn.2019.17.2.189. 
Frijhoff J, Winyard PG, Zarkovic N, Davies SS, Stocker R, Cheng D, Knight AR, Taylor EL, Oettrich J, Ruskovska T, Gasparovic AC, Cuadrado A, Weber D, Poulsen HE, Grune T, Schmidt HH, Ghezzi P. (2015). Clinical Relevance of Biomarkers of Oxidative Stress. Antioxid Redox Signal. 23(14), 1144-70. DOI:10.1089/ars.2015.6317.

Flory JD, Yehuda R.( 2015). Comorbidity between post-traumatic stress disorder and major depressive disorder: alternative explanations and treatment considerations. Dialogues Clin Neurosci. 2, 141-50. PMID: 26246789.

Gądek-Michalska A, Tadeusz J, Rachwalska P, Bugajski J. (2013). Cytokines, prostaglandins and nitric oxide in the regulation of stressresponse systems. Pharmacol Rep. 65(6), 1655-62. PMID: 24553014.

Gold P.E., Korol D.L. (2012). Making memories matter. Frontiers integrative neuroscience. 1(12), 6:116. DOI: 10.3389/fnint.2012.00116, 2012.

Gorlova A, Pavlov D, Anthony DC, Ponomarev ED, Sambon M, Proshin A Shafarevich I, Babaevskaya D, Lesch KP, Bettendorff L, Strekalova T. (2019). Thiamine and benfotiamine counteract ultrasound-induced aggression, normalize AMPA receptor expression and plasticity markers, 
and reduce oxidative stress in mice. Neuropharmacology. 15, 156:107543 DOI:10.1016/j.neuropharm.2019.02.025.

Harro J. (2019). Animal models of depression: pros and cons. Cell Tissue Res. 377, 1: 5-20. DOI: 10.1007/s00441-018-2973-0.

Hughes M, Connor T, Harkin A. (2016). Stress-Related Immune Markers in Depression: Implications for Treatment. Int J Neuropsychopharmacol. pii: pyw001. DOI:10.1093/ijnp/pyw001.

Huang WC, Lin YS, Wang CY, Tsai CC, Tseng HC, Chen CL, Lu PJ, Chen PS, Qian L, Hong JS, Lin CF. (2009). Glycogen synthase kinase-3 negatively regulates anti-inflammatory interleukin-10 for lipopolysaccharide-induced iNOS/NO biosynthesis and RANTES production in microglial cells. Immunology. 128:e275-86. DOI:10.1111/j.1365-2567.2008.02959.x.

Jeon S, Kim Y. (2016). Neuroinflammation and cytokine abnormality in major depression: Cause or consequence in that illness? World J Psychiatry. 6(3), 283-293.DOI:10.5498/wjp.v6.i3.283. 
Jope RS, Cheng Y, Lowell JA, Worthen RJ, Sitbon YH, Beurel E (2017). Stressed and Inflamed, Can GSK3 Be Blamed? Trends Biochem Sci. 42(3), 180-192. DOI:10.1016/j.tibs.2016.10.009

Jope RS, Roh MS. (2006). Glycogen synthase kinase-3 (GSK3) in psychiatric diseases and therapeutic interventions. Curr Drug Targets. 7(11), 1421-34. DOI:10.2174/1389450110607011421.

Ogłodek EA, Just MJ. (2018). The association between inflammatory markers (iNOS, HO-1, IL-33, MIP-1 1 ) and depression with and without posttraumatic stress disorder. Pharmacol Rep. 70(6), 1065-1072. DOI: 10.1016/j.pharep.2018.06.001.

Kadry M, Abdel-Megeed R, El-Meliegy E, Abdel-Hamid Z. (2018). Crosstalk between GSK-3, c-Fos, NFkB and TNF- $\alpha$ signaling pathways play an ambitious role in Chitosan Nanoparticles Cancer Therapy. Toxicol Rep. 5: 723-727. DOI: 10.1016/j.toxrep.2018.06.002

Köhler O, Benros ME, Nordentoft M, Farkouh ME, Iyengar RL, Mors O, Krogh J. (2014). Effect of anti-inflammatory treatment on depression, depressive symptoms, and adverse effects: a systematic review and metaanalysis of randomized clinical trials. JAMA Psychiatry. 71(12), 1381-91. DOI:10.1001/jamapsychiatry.2014.1611. 
Krügel U, Fischer J, Radicke S, Sack U, Himmerich H. (2013). Antidepressant effects of TNF- $\alpha$ blockade in an animal model of $\begin{array}{lllll}\text { depression. } & J & \text { Psychiatr } & \text { Res. 47(5), 611-6. }\end{array}$ DOI:10.1016/j.jpsychires.2013.01.007.

Leonard B, Maes M. (2012). Mechanistic explanations how cell-mediated immune activation, inflammation and oxidative and nitrosative stress pathways and their sequels and concomitants play a role in the pathophysiology of unipolar depression. Neurosci Biobehav Rev. 36(2), 764-85. DOI: 10.1016/j.neubiorev.2011.12.005.

Lindqvist D, Mellon SH, Dhabhar FS, Yehuda R, Grenon SM, Flory JD, Bierer LM, Abu-Amara D, Coy M, Makotkine I, Reus VI, Aschbacher K, Bersani FS, Marmar CR, Wolkowitz OM. (2017). Increased circulating blood cell counts in combat-related PTSD: Associations with inflammation and PTSD severity. Psychiatry Res. 258, 330-336. DOI: 10.1016/j.psychres.2017.08.052.

Livak KJ, Schmittgen TD. (2001). Analysis of relative gene expression data using real-time quantitative PCR and the $2^{\wedge}[$-delta delta $\mathrm{C}(\mathrm{T})]$ method. Methods. 25(4), 402-8. 
Lopresto D, Schipper P, Homberg JR. (2016). Neural circuits and mechanisms involved in fear generalization: Implications for the pathophysiology and treatment of posttraumatic stresss disorder. Neurosci Biobehav Rev. 60, 31-42. DOI:10.1016/j.neubiorev.2015.10.009.

Markova N, Bazhenova N, Anthony DC, Vignisse J, Svistunov A, Lesch KP, Bettendorff L, Strekalova T. (2017). Thiamine and benfotiamine

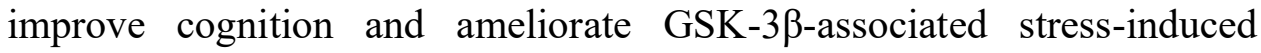
behaviours in mice. Prog. Neuro-Psychopharmacol. Biol. Psychiatry. 75, 148-156. DOI:10.1016/j.pnpbp.2016.11.001.

Mesquita AR, Correia-Neves M, Roque S, Castro AG, Vieira P, Pedrosa J, Palha JA, Sousa N. (2008). IL-10 modulates depressive-like behavior. $J$ Psychiatr Res. 43(2), 89-97. DOI:10.1016/j.jpsychires.2008.02.004.

Miller A, Raison C. (2016). The role of inflammation in depression: from evolutionary imperative to modern treatment target. Nat Rev Immunol. 2016. 16(1): 22-34. DOI: 10.1038/nri.2015.5.

Miller MW, Lin AP, Wolf EJ, Miller DR. (2018). Oxidative Stress, Inflammation, and Neuroprogression in Chronic PTSD. Harv Rev Psychiatry. 2, 57-69. DOI:10.1097/HRP.0000000000000167. 
Michopoulos V, Powers A, Gillespie CF, Ressler KJ, Jovanovic T. (2017). Inflammation in Fear- and Anxiety-Based Disorders: PTSD, GAD, and Beyond. Neuropsychopharmacology. 42(1), 254-270. DOI: 10.1038/npp.2016.146.

Mkrtchyan G, Aleshin V, Parkhomenko Y, Kaehne T, Luigi Di Salvo M, Parroni A, Contestabile R, Vovk A, Bettendorff L, Bunik V. (2015). Molecular mechanisms of the non-coenzyme action of thiamin in brain: biochemical, structural and pathway analysis. Sci. Rep. 5:12583. DOI:10.1038/srep12583.

Monzon S, Gili M, Vives M, Serrano M, Bausa N, Molina R, Garcia-Toro M, Salva J, Llobera J, Roca M. (2010). Melancholic versus nonmelancholic depression: differences on cognitive function. A longitudinal study protocol. BMC Psychiatry.10, 10:48. DOI:10.1186/1471-244X-1048.

Morozova A, Zubkov E, Strekalova T, Kekelidze Z, Storozeva Z, Schroeter CA, Bazhenova N, Lesch KP, Cline BH, Chekhonin V. (2016). Ultrasound of alternating frequencies and variable emotional impact evokes depressive syndrome in mice and rats. Prog. Neuro-Psychopharmacol. Biol. Psychiatry. 68, 52-63. DOI:10.1016/j.pnpbp.2016.03.003. 
Ogłodek EA, Just MJ. (2009). Neurocognitive mechanisms in depression: implications for treatment. Annu Rev Neurosci. 32, 57-74. DOI: 10.1146/annurev.neuro.31.060407.125618.

Oliveira TQ, de Sousa CN, Vasconcelos GS, de Sousa LC, de Oliveira AA, Patrocínio CF, Medeiros ID, Honório Júnior JE, Maes M, Macedo D, Vasconcelos SM. (2017). Brain antioxidant effect of mirtazapine and reversal of sedation by its combination with alpha-lipoic acid in a model of depression induced by corticosterone. J Affect Disord. 219, 49-57. DOI: 10.1016/j.jad.2017.05.022.

Pan X, Gong N, Zhao J, Yu Z, Gu F, Chen J, Sun X, Zhao L, Yu M, Xu Z, Dong W, Qin Y, Fei G, Zhong C, Xu TL. (2010). Powerful beneficial effects of benfotiamine on cognitive impairment and beta-amyloid deposition in amyloid precursor protein/presenilin-1 transgenic mice. Brain. 133, 13421351. DOI:10.1093/brain/awq069.

Passos IC, Vasconcelos-Moreno MP, Costa LG, Kunz M, Brietzke E, Quevedo J, Salum G, Magalhães PV, Kapczinski F, Kauer-Sant'Anna M. (2015). Inflammatory markers in post-traumatic stress disorder: a systematic review, meta-analysis, and meta-regression. Lancet Psychiatry. 2(11), 1002-12. DOI: 10.1016/S2215-0366(15)00309-0. 
Patel D, Kas MJ, Chattarji S, Buwalda B. (2019).Rodent models of social stress and neuronal plasticity: Relevance to depressive-like disorders. Behav Brain Res. 369:111900. DOI: 10.1016/j.bbr.2019.111900.

Pavlov D, Bettendorff L, Gorlova A, Olkhovik A, Kalueff AV, Ponomarev ED, Inozemtsev A, Chekhonin V, Lesch KP, Anthony DC, Strekalova T. (2019). Neuroinflammation and aberrant hippocampal plasticity in a mouse model of emotional stress evoked by exposure to ultrasound of alternating frequencies. Prog. Neuro-Psychopharmacol. Biol. Psychiatry. 90:104-116. DOI:10.1016/j.pnpbp.2018.11.014.

Pavlov D, Markova N, Bettendorff L, Chekhonin V, Pomytkin I, Lioudyno V, Svistunov, A., Ponomarev E, Lesch KP, Strekalova T. Elucidating the functions of brain GSK3 $\alpha$ : Possible synergy with GSK3 $\beta$ upregulation and reversal by antidepressant treatment in a mouse model of depressive-like behaviour. Behav. Brain Res. 335, 122-127. DOI:10.1016/j.bbr.2017.08.018.

Powers A, Dixon HD, Conneely K, Gluck R, Munoz A, Rochat C, Mendoza H, Hartzell G, Ressler KJ, Bradley B, Pace TWW, Umpierrez GE, Schwartz AC, Michopoulos V, Gillespie CF. (2019). The differential effects of PTSD, MDD, and dissociation on CRP in trauma-exposed 
women. Compr Psychiatry. 93, 33-40. DOI: 10.1016/j.comppsych.2019.06.007.

Rana AK, Singh D. (2018). Targeting glycogen synthase kinase-3 for oxidative stress and neuroinflammation: Opportunities, challenges and future directions for cerebral stroke management. Neuropharmacology. 139:124-136.DOI:10.1016/j.neuropharm.2018.07.006

Sato H, Takahashi T, Sumitani K, Takatsu H, Urano S. (2010). Glucocorticoid Generates ROS to Induce Oxidative Injury in the Hippocampus, Leading to Impairment of Cognitive Function of Rats. J Clin Biochem Nutr. 47(3), 224-32. DOI: 10.3164/jcbn.10-58.

Strekalova T, Markova N, Shevtsova E, Zubareva O, Bakhmet A, Steinbusch HM, Bachurin S, Lesch KP. (2016). Individual differences in behavioural despair predict brain GSK-3beta expression in mice: the power of a modified swim test. Neural Plast. (2016). 5098591. DOI:10.1155/2016/5098591.

Simen BB, Duman CH, Simen AA, Duman RS. (2006). TNFalpha signaling in depression and anxiety: behavioral consequences of individual receptor 


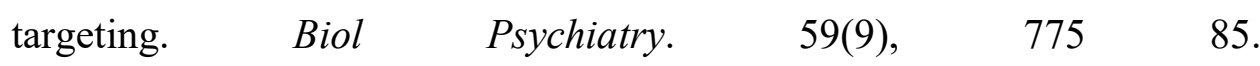

DOI:10.1016/j.biopsych.2005.10.013.

Tanaka K, Furuyashiki T, Kitaoka S, Senzai Y, Imoto Y, Segi-Nishida E, Deguchi Y, Breyer RM, Breyer MD, Narumiya S. (2012). Prostaglandin E2-mediated attenuation of mesocortical dopaminergic pathway is critical for susceptibility to repeated social defeat stress in mice. J Neurosci. 32(12), 4319-29.DOI:10.1523/JNEUROSCI.5952-11.2012.

Takeuchi H, Jin S, Wang J, Zhang G, Kawanokuchi J, Kuno R, Sonobe Y, Mizuno T, Suzumura A. (2006). Tumor necrosis factor-alpha induces neurotoxicity via glutamate release from hemichannels of activated microglia in an autocrine manner. $J$ Biol Chem. 281(30), 21362-8. DOI:10.1074/jbc.M600504200.

Thoeringer CK, Henes K, Eder M, Dahlhoff M, Wurst W, Holsboer F, Deussing JM, Moosmang S, Wotjak CT. (2012).Consolidation of remote fear memories involves Corticotropin-Releasing Hormone (CRH) receptor type 1-mediated enhancement of AMPA receptor GluR1 signaling in the dentate gyrus. Neuropsychopharmacology. 37(3)787-96. doi: 10.1038/npp.2011.256. 
Toft H, Lien L, Neupane SP, Abebe DS, Tilden T, Wampold BE, Bramness JG. (2019).Cytokine concentrations are related to level of mental distress in inpatients not using anti-inflammatory drugs. Acta Neuropsychiatr. 2, 1-22. DOI: $10.1017 /$ neu.2019.36.

Uchoa ET, Aguilera G, Herman JP, Fiedler JL, Deak T, de Sousa MB. (2014). Novel aspects of glucocorticoid actions. J Neuroendocrinol. 26(9), 557-72. DOI:10.1111/jne.12157.

Vignisse J, Sambon M, Gorlova A, Pavlov D, Caron N, Malgrange B, Shevtsova E, Svistunov A, Anthony D, Markova N, Bazhenova N, Coumans B, Lakaye B, Wins P, Strekalova T, Bettendorff L. (2017). Thiamine and benfotiamine prevent stress-induced suppression of hippocampal neurogenesis in mice exposed to predation without affecting brain thiamine diphosphate levels. Mol. Cell. Neurosci. 82, 126-136 DOI:10.1016/j.mcn.2017.05.005.

Wang Z, Caughron B, Young MRI. (2017). Posttraumatic Stress Disorder: An Immunological Disorder? Front Psychiatry. 8:222. DOI: $10.3389 /$ fpsyt.2017.00222.

Yamada K, Iida R, Miyamoto Y, Saito K, Sekikawa K, Seishima M, Nabeshima T. (2000). Neurobehavioral alterations in mice with a targeted 
deletion of the tumor necrosis factor-alpha gene: implications for emotional behavior. $J$ Neuroimmunol. 111(1-2), 131-8. DOI:10.1016/s0165$5728(00) 00375-1$.

Yuan N, Chen Y, Xia Y, Dai J, Liu C. (2019). Inflammation-related biomarkers in major psychiatric disorders: a cross-disorder assessment of reproducibility and specificity in 43 meta-analyses. Transl Psychiatry. 18, 9(1):233. DOI: 10.1038/s41398-019-0570-y. 


\section{SUPPLEMENTARY DATA}

\section{Animals and housing conditions}

Experiments were performed on male C57BL6 mice that were 12 weeks old. All animals were provided by Stolbovaja, RAS, Moscow region, a provider licensed by Charles River (http://www.spfanimals.ru/about/providers/animals). Mice were housed individually in standard plastic cages $(27 \times 22 \times 15 \mathrm{~cm}$ for mice) and maintained on a 12 hour light/dark cycle, under controllable laboratory conditions (lights are on at $21.00 ; 22 \pm 1^{\circ} \mathrm{C}, 55 \%$ humidity, room temperature $22^{\circ} \mathrm{C}$ ), food and water were available ad libitum. Housing conditions and all experimental procedures were set up and maintained in accordance with a Directive 2010/63/EU of 22 September 2010 and carried out under approval of the local veterinarian committee (MSMU \#11-18-2018). All efforts were undertaken to minimize the potential discomfort of experimental animals.

\section{Modified swim tests with additional delayed testing}

Mice were subjected to one or two swimming sessions with an interval of $24 \mathrm{~h}$, or, to three session, where after the first two tests the third test was carried out on Day 5 following the initial test on Day 1 as described 
elsewhere (Strekalova et al., 2016; Markova et al., 2016). All sessions were 6-min long and were performed by placing a mouse in a transparent cylinder (Ø $17 \mathrm{~cm})$ filled with water $\left(+23{ }^{\circ} \mathrm{C}\right.$, water height $13 \mathrm{~cm}$, height of cylinder $20 \mathrm{~cm}$ ). The duration of floating behavior that was defined by the absence of any directed movements of the animals' head and body, was scored manually using criteria, which were previously validated by automated scoring with Noldus EthoVision XT 8.5 (Noldus Information Technology, Wageningen, The Netherlands) and CleverSys (CleverSys, Reston, VA, USA) as described elsewhere (Malatynska et al., 2012; Strekalova et al., 2015). Time spent with floating was evaluated for the entire duration of the test. In all assays mice were sacrificed ten minutes after swimming. ImiFST and Thi-FST mice were tested in all three session and sacrificed after the last session, alone with respective non-treated control mice. With all tests, naïve control groups that were not exposed to a swimming were sacrificed simultaneously with experimental groups of mice.

\section{Administration of drugs}

Experimental solutions replaced normal drinking water. Thiamine and imipramine were obtained from Sigma-Aldrich, St. Louis, MO, USA. All agents were dissolved in tap water and were changed every 4-5 days (Pavlov 
et al., 2017, Vignnisse et al., 2017). Drinking behaviour of mice was monitored by evaluating a 24-h liquid intake during the first three days of dosing. The dose of imipramine dose $(7.5 \mathrm{mg} / \mathrm{kg} /$ day $)$, was based on previous results showing that this dose had no effect on general locomotor behaviour (Strekalova et al., 2015; Costa-Nunes et al., 2015).

\section{Sequences of primers}

Sequences of primers used are listed below (Supplementary Table 1).

\section{Table 1. Sequences of primers used}

\begin{tabular}{|l|l|l|}
\hline Gene & Forward primer $\mathbf{5}^{\prime} \mathbf{-} \mathbf{3}^{\prime}$ & Reverse primer 5'-3' \\
\hline GAPDH & TGCACCACCAACTGCTTAG & GGATGCAGGGATGATGTTC \\
\hline GSK3 $\alpha$ & AATCTTGGCCAGTCTGAGCT & TCAGTCCTGGTGAACTGTCC \\
\hline GSK3 $\beta$ & TCCATTCCTTTGGAATCTGC & CAATTCAGCCAACACACAGC \\
\hline IL-1 $\beta$ & AACCTGCTGGTGTGTGACGTTC & CAGCACGAGGCTTTTTTGTTGT \\
\hline TNF & GCCTGTAGCCCACGTCGTA & GGCACCACTAGTTGGTTGTCTTTG \\
\hline COX-1 & TCGGAGCCCCAGATATAGCA & TTTCCGGCTAGAGGTGGGTA \\
\hline c-Fos & ATCCTTGGAGCCAGTCAAGA & ATGATGCCGGAAACAAGAAG \\
\hline
\end{tabular}




\section{Enzyme-linked immunosorbent assay of CORT}

To study the concentrations of CORT in the blood plasma, mouse enzymelinked immunosorbent assay (ELISA) was performed using MOUSE ab108821 kit (Abcam, Cambridge, UK) according to the manufacturer's instructions. The microwell absorbance was measured at $450 \mathrm{~nm}$ with Promega microplate reader (Madison, WI, USA).

\section{Protein carbonyl}

Determination of protein carbonyls using the OxiSelect ${ }^{\mathrm{TM}}$ Protein Carbonyl Fluorometric Assay kit (Cell Biolabs, Inc., San Diego, USA). Glass-glass homogenization followed by a sonification was performed on ice in $1 \mathrm{ml}$ of 1xSample Diluent from the OxiSelect ${ }^{\mathrm{TM}}$ kit, centrifuged at $10000 \mathrm{~g}$ for 5 min at $+4^{\circ} \mathrm{C}$, and the supernatant was removed. The total protein concentration was adjusted to $1-10 \mathrm{mg} / \mathrm{ml}$ with $1 \times$ Sample Diluent and protein carbonyls were determined according to the guidelines of the manufacturer using the GloMax Multi Detection System (Promega, Madison, WI, USA) equipped with a fluorescence module $(485 / 540 \mathrm{~nm}$ filter set). Results were normalized to protein concentration as described previously (Vignisse et al., 2017; Pavlov et al., 2019). 


\section{Supplementary tables}

Table 2. Floating behavior in the modified swim test. Total duration of floating and floating for $1-2 \mathrm{~min}$ period at Day 5 were significantly increased in comparison with these measures scored on Day 2 in the FST group, but not in Imi-FST or Thi-FST groups. On day 5, total duration of floating was significantly shorter in Thi-FST group than in the FST group. In comparison to values obtained on Day 1, all groups showed significantly elevated total duration of floating and duration of floating during the first two periods of scoring as compared with Day 2 and Day 5. Significant differences are in bold $(\mathrm{p}<0.05$, repeated measures ANOVA and Tukey's test). FST - vehicle-treated FST group; Imi-FST - imipramine-treated FST group; Thi- FST - thiamine-treated FST group. 


\begin{tabular}{|c|c|c|c|}
\hline \multirow[b]{2}{*}{$\begin{array}{c}\text { FST } \\
\text { period }\end{array}$} & \multicolumn{3}{|c|}{ Days of testing in modified F S T } \\
\hline & $\begin{array}{l}\text { Day } 1 \\
\text { duration of } \\
\text { floating, } s\end{array}$ & $\begin{array}{c}\text { Day } 2 \\
\text { duration of floating, } s \\
\text { and repeated ANOVA analysis }\end{array}$ & $\begin{array}{c}\text { Day } 5 \\
\text { duration of floating, s } \\
\text { and repeated ANOVA analysis }\end{array}$ \\
\hline $1-2 \mathrm{~min}$ & $\begin{array}{l}\text { FST: } 34.4 \pm 5.4 \\
\text { Imi-FST: } 18.2 \pm 2.4 \\
\text { Thi-FST: } 31.5 \pm 3.7\end{array}$ & $\begin{array}{l}\text { FST: } 67.2 \pm 8.5 ; \text { Imi-FST: } \\
52.4 \pm 3.7 \text {; Thi-FST: } 58.5 \pm 12.1 \\
\text { vs. Day } 1 \text { for control: } \mathbf{p}=\mathbf{0 . 0 3} \\
\text { vs. Day } 1 \text { for Imi-FST: } \mathbf{p}=\mathbf{0 . 0 4} \\
\text { vs. Day } 1 \text { for Thi-FST: } \mathbf{p}=\mathbf{0 . 0 4}\end{array}$ & $\begin{array}{l}\text { FST: } 74.3 \pm 14.5 \text {; Imi-FST: } 55.2 \pm 8.6 \text {; } \\
\text { Thi-FST: } 42.7 \pm 4.9 \\
\text { vs. Day } 1 \text { for control: } \mathbf{p}=\mathbf{0 . 0 2} \\
\text { vs. Day } 2 \text { for control: } \mathbf{p}=\mathbf{0 . 0 1} \\
\text { vs. Day } 1 \text { for Imi-FST: } \mathbf{p}=\mathbf{0 . 0 1} \\
\text { vs. Day } 2 \text { for Imi-FST: } \mathrm{p}=0.2 \\
\text { vs. Day } 1 \text { for Thi-FST: } \mathrm{p}=0.4 \\
\text { vs. Day } 2 \text { for Thi-FST: } \mathrm{p}=0.3\end{array}$ \\
\hline $\begin{array}{l}3-4 \\
\text { min }\end{array}$ & $\begin{array}{l}\text { FST. } 55.2 \pm 6.7 \\
\text { Imi-FST: } 81.3 \pm 7.5 \\
\text { Thi-FST: } 94 \pm 4.8\end{array}$ & $\begin{array}{l}\text { FST: } 67.9 \pm 5.7 \text {; Imi-FST: } \\
84.3 \pm 9.5 \text {; Thi-FST: } 105.1 \pm \mathbf{1 4 . 5} \\
\text { vs. Day } 1 \text { for control: } \mathbf{p}=\mathbf{0 . 0 2} \\
\text { vs. Day } 1 \text { for Imi-FST: } \mathbf{p}=\mathbf{0 . 0 2} \\
\text { vs. Day } 1 \text { for Thi-FST: } \mathbf{p}=\mathbf{0 . 0 1}\end{array}$ & $\begin{array}{l}\text { FST: } 59.3 \pm 4.7 ; \text { Imi-FST: } 50.4 \pm 3.2 \text {; } \\
\text { Thi-FST: } 72.5 \pm 7.2 \\
\text { vs. Day } 1 \text { for control: } \mathbf{p}=\mathbf{0 . 0 3} \\
\text { vs. Day } 2 \text { for control: } \mathrm{p}=0.75 \\
\text { vs. Day } 1 \text { for Imi-FST: } \mathbf{p}=\mathbf{0 . 0 2} \\
\text { vs. Day } 2 \text { for Imi-FST: } \mathbf{p}=\mathbf{0 . 0 3} \\
\text { vs. Day } 1 \text { for Thi-FST: } \mathbf{p}=\mathbf{0 . 0 4} \\
\text { vs. Day } 2 \text { for Thi-FST: } \mathrm{p}=\mathbf{0 . 7 2}\end{array}$ \\
\hline $\begin{array}{l}5-6 \\
\text { min }\end{array}$ & $\begin{array}{l}\text { FST: } 63.8 \pm 3.7 \\
\text { Imi-FST: } 76.5 \pm 7.5 \\
\text { Thi-FST: } 69.8 \pm 7.9\end{array}$ & $\begin{array}{l}\text { FST: } 84.3 \pm 3.6 \text {; Imi-FST: } \\
85.8 \pm 6.4 \text {; Thi-FST: } 56.4 \pm 7.5 \text {. } \\
\text { vs. Day } 1 \text { for control: } \mathrm{p}=0.50 \\
\text { vs. Day } 1 \text { for Imi-FST: } \mathrm{p}=0.64 \\
\text { vs. Day } 1 \text { for Thi-FST: } \mathrm{p}=0.93\end{array}$ & $\begin{array}{l}\text { FST: } 105.2 \pm 12.1 ; \text { Imi-FST: } 62.4 \pm 2.7 \text {; } \\
\text { Thi-FST: } 59.5 \pm 4.6 \\
\text { vs. Day } 1 \text { for control: } \mathrm{p}=0.97 \\
\text { vs. Day } 2 \text { for control: } \mathrm{p}=0.07 \\
\text { vs. Day } 1 \text { for Imi-FST: } \mathrm{p}=0.52 \\
\text { vs. Day } 2 \text { for Imi-FST: } \mathrm{p}=0.09 \\
\text { vs. Day } 1 \text { for Thi-FST: } \mathrm{p}=0.91 \\
\text { vs. Day } 2 \text { for Thi-FST: } \mathrm{p}=0.25\end{array}$ \\
\hline Total & $\begin{array}{l}\text { FST: } 182.3 \pm 15.5 \\
\text { Imi-FST: } \\
167.3 \pm 12.6 ; \\
\text { Thi-FST: } 58.1 \pm 13.7\end{array}$ & $\begin{array}{l}\text { FST: } 208.2 \pm 15.6 \\
\text { Imi-FST: } 215.3 \pm 12.9 \\
\text { Thi-FST: } 209.7 \pm 15.2 \\
\text { vs. Day } 1 \text { for control: } \mathbf{p}=\mathbf{0 . 0 2} \\
\text { vs. Day } 1 \text { for Imi-FST: } \mathbf{p}=\mathbf{0 . 0 1} \\
\text { vs. Day } 1 \text { for Thi-FST: } \mathbf{p}=\mathbf{0 . 0 1}\end{array}$ & $\begin{array}{l}\text { FST: } 263.4 \pm 16.7 ; \text { Imi-FST: } \\
225.2 \pm 12.5 ; \text { Thi-FST: } 189.1 \pm 11.8 \\
\text { vs. Day } 1 \text { for control: } \mathbf{p}=\mathbf{0 . 0 4} \\
\text { vs. Day } 2 \text { for control: } \mathbf{p}=\mathbf{0 . 0 1} \\
\text { vs. Day } 1 \text { for Imi-FST: } \mathbf{p}=\mathbf{0 . 0 3} \\
\text { vs. Day } 2 \text { for Imi-FST: } p=0.61 \\
\text { vs. Day } 1 \text { for Thi-FST: } \mathbf{p}=\mathbf{0 . 0 2} \\
\text { vs. Day } 2 \text { for Thi-FST: } \mathrm{p}=0.08\end{array}$ \\
\hline
\end{tabular}


Table 3. Gene expression in the hippocampus and prefrontal cortex of mice subjected to modFST. Following delayed swimming session brain overexpression of GSK-3 $\beta$ and $\alpha$ isoforms, IL-1 $\beta$, TNF, c-Fos and COX-1 was overall augmented. Groups that were re-treated with thiamine and imipramine treatments demonstrated normalized expression of investigated genes. Significant differences are in bold $(p<0.05$, one-way ANOVA and Tukey's test). FST - non-treated FST group; Imi-FST - imipramine-treated FST group; Thi-FST - thiamine-treated FST group. 


\begin{tabular}{|c|c|c|}
\hline \multirow{2}{*}{ mRNA } & \multicolumn{2}{|c|}{ D a y 5} \\
\hline & Hippocampus & Prefrontal cortex \\
\hline GSK- $3 \beta$ & $\begin{array}{l}\text { FST vs. control: } \mathbf{p}=\mathbf{0 . 0 1} \\
\text { FST-Imi vs. FST: } \mathbf{p}=\mathbf{0 . 0 3} \\
\text { FST-Imi vs. control: } \mathrm{p}=0.08 \\
\text { FST-Thi vs. FST: } \mathbf{p}=\mathbf{0 . 0 4} \\
\text { FST-Thi vs. control: } \mathrm{p}=0.16\end{array}$ & $\begin{array}{l}\text { FST vs. control: } \mathbf{p}=\mathbf{0 . 0 0 7} \\
\text { FST-Imi vs. FST: } \mathbf{p}=\mathbf{0 . 0 3} \\
\text { FST-Imi vs. control: } \mathrm{p}=0.25 \\
\text { FST-Thi vs. FST: } \mathbf{p}=\mathbf{0 . 0 1} \\
\text { FST-Thi vs. control: } \mathrm{p}=0.11\end{array}$ \\
\hline GSK $-3 \alpha$ & $\begin{array}{l}\text { FST vs. control: } \mathbf{p}=\mathbf{0 . 0 2} \\
\text { FST-Imi vs. FST: } \mathbf{p}=\mathbf{0 . 0 4} \\
\text { FST-Imi vs. control: } \mathrm{p}=0.32 \\
\text { FST-Thi vs. FST: } \mathbf{p}=\mathbf{0 . 0 2} \\
\text { FST-Thi vs. control: } \mathrm{p}=0.94\end{array}$ & $\begin{array}{l}\text { FST vs. control: } \mathrm{p}=0.56 \\
\text { FST-Imi vs. FST: } \mathrm{p}=0.12 \\
\text { FST-Imi vs. control: } \mathrm{p}=0.09 \\
\text { FST-Thi vs. FST: } \mathrm{p}=0.307 \\
\text { FST-Thi vs. control: } \mathrm{p}=0.18\end{array}$ \\
\hline IL-1 $\beta$ & $\begin{array}{l}\text { FST vs. control: } \mathbf{p}=\mathbf{0 . 0 3 6} \\
\text { FST-Imi vs. FST: } \mathbf{p}=\mathbf{0 . 0 4} \\
\text { FST-Imi vs. control: } \mathrm{p}=0.51 \\
\text { FST-Thi vs. FST: } \mathbf{p}=\mathbf{0 . 0 2} \\
\text { FST-Thi vs. control: } \mathrm{p}=0.48\end{array}$ & $\begin{array}{l}\text { FST vs. control: } \mathrm{p}=0.84 \\
\text { FST-Imi vs. FST: } \mathrm{p}=0.56 \\
\text { FST-Imi vs. control: } \mathrm{p}=0.62 \\
\text { FST-Thi vs. FST: } \mathrm{p}=0.72 \\
\text { FST-Thi vs. control: } \mathrm{p}=0.19\end{array}$ \\
\hline TNF & $\begin{array}{l}\text { FST vs. control: } \mathbf{p}=\mathbf{0 . 0 3} \\
\text { FST-Imi vs. FST: } \mathbf{p}=\mathbf{0 . 0 4} \\
\text { FST-Imi vs. control: } \mathrm{p}=0.35 \\
\text { FST-Thi vs. FST: } \mathbf{p}=\mathbf{0 . 0 4} \\
\text { FST-Thi vs. control: } \mathrm{p}=0.17\end{array}$ & $\begin{array}{l}\text { FST vs. control: } \mathbf{p}=\mathbf{0 . 0 1} \\
\text { FST-Imi vs. FST: } \mathbf{p}=\mathbf{0 . 0 1} \\
\text { FST-Imi vs. control: } \mathrm{p}=0.52 \\
\text { FST-Thi vs. FST: } \mathbf{p}=\mathbf{0 . 0 2} \\
\text { FST-Thi vs. control: } \mathrm{p}=0.09\end{array}$ \\
\hline COX-1 & $\begin{array}{l}\text { FST vs. control: } \mathbf{p}=\mathbf{0 . 0 4} \\
\text { FST-Imi vs. FST: } \mathbf{p}=\mathbf{0 . 0 2} \\
\text { FST-Imi vs. control: } \mathrm{p}=0.28 \\
\text { FST-Thi vs. FST: } \mathbf{p}=\mathbf{0 . 0 3} \\
\text { FST-Thi vs. control: } \mathrm{p}=0.14\end{array}$ & $\begin{array}{l}\text { FST vs. control: } \mathrm{p}=0.84 \\
\text { FST-Imi vs. FST: } \mathrm{p}=0.708 \\
\text { FST-Imi vs. control: } \mathrm{p}=0.12 \\
\text { FST-Thi vs. FST: } \mathrm{p}=0.42 \\
\text { FST-Thi vs. control: } \mathrm{p}=0.47\end{array}$ \\
\hline c-Fos & $\begin{array}{l}\text { FST vs. control: } \mathbf{p}=\mathbf{0 . 0 1} \\
\text { FST-Imi vs. FST: } \mathbf{p}=\mathbf{0 . 0 4} \\
\text { FST-Imi vs. control: } \mathrm{p}=0.55 \\
\text { FST-Thi vs. FST: } \mathbf{p}=\mathbf{0 . 0 2} \\
\text { FST-Thi vs. control: } \mathrm{p}=0.97\end{array}$ & $\begin{array}{l}\text { FST vs. control: } \mathbf{p}=\mathbf{0 . 0 3} \\
\text { FST-Imi vs. FST: } p=0.61 \\
\text { FST-Imi vs. control: } p=0.63 \\
\text { FST-Thi vs. FST: } \mathbf{p}=\mathbf{0 . 0 0 2} \\
\text { FST-Thi vs. control: } \mathrm{p}=0.75\end{array}$ \\
\hline
\end{tabular}




\section{Chapter 4}

Neuroinflammation and aberrant hippocampal plasticity in a mouse model of emotional stress evoked by exposure to ultrasound of alternating frequencies 
Neuroinflammation and aberrant hippocampal plasticity in a mouse model of emotional stress evoked by exposure to ultrasound of alternating frequencies

Dmitrii Pavlova,b,c,d, Lucien Bettendorffc, Anna Gorlovab,c,e, Andrey Olkhovikb, Allan Kaluefff, Eugene Ponomarevg, Anatoly Inozemtsevb, Vladimir Chekhoninh, Klaus-Peter Lescha,e,i, Daniel C. Anthonyj*, Tatyana Strekalovaa,d,e*

aDepartment of Neuroscience, Maastricht University, Universiteitssingel 40, NL 6229ER, Maastricht, Netherlands

bDepartment of Biology, Lomonosov Moscow State University, Leninskie Gory1-12, 119991, Moscow, Russia

cLaboratory of Neurophysiology, GIGA-Neurosciences, University of Liège, Av. Hippocrate 15, 4000-Liège, Belgium

dInstitute of General Pathology and Pathophysiology, Baltiiskaya str, 8, Moscow, Russia, 125315

eSechenov First Moscow State Medical University, Institute of Molecular Medicine, Laboratory of Psychiatric Neurobiology, Trubetskaya street 8-2, 119991, Moscow, Russia

flnstitute of Translational Biomedicine, St.Petersburg State University, Universitetskaya nab. 7-9, 199034, St.-Petersburg, Russia

gSchool of Biomedical Sciences, Faculty of Medicine, The Chinese University of Hong Kong, Shatin, N.T., Hong Kong 
hSerbsky Federal Medical Research Center for Psychiatry and Narcology, Department of Basic and Applied Neurobiology, Kropotkinsky per 23, 119034, Moscow, Russia

iDivision of Molecular Psychiatry, Center of Mental Health University of Wuerzburg, Josef-Schneider-Straße 2, 97080, Wuerzburg, Germany

¡Department of Pharmacology, Oxford University, Mansfield Road, OX1 3QT, Oxford, UK

*Joint Corresponding authors

\section{Dr. Tatyana Strekalova}

\section{Anthony}

Department of Neuroscience, Maastricht University

Universiteitssingel 40, NL 6229 ER

Maastricht, Netherlands

Tel: 31433884 110;

Fax: 31433671096

email: t.strekalova@maastrichtuniversity.nl

\section{Prof. Daniel C.}

Department of Pharmacology

University of Oxford

Mansfield Road, OX1 3QT, UK

Tel: 441865 281136;

Fax: 441865271853

email: daniel.anthony@pharm.ox.ac.uk 


\section{ABSTRACT}

Emotional stress is a form of stress evoked by processing negative mental experience rather than an organic or physical disturbance and is a frequent cause of neuropsychiatric pathologies, including depression. Susceptibility to emotional stress is commonly regarded as a human-specific trait that is challenging to model in other species. Recently, we showed that a 3-weeklong exposure to ultrasound of unpredictable alternating frequencies within the ranges of $20-25 \mathrm{kHz}$ and $25-45 \mathrm{kHz}$ can induce depression-like characteristics in laboratory mice and rats. In an anti-depressant sensitive manner, exposure decreases sucrose preference, elevates behavioural despair, increases aggression, and alters serotonin-related gene expression. To further investigate this paradigm, we studied depression/distressassociated markers of neuroinflammation, neuroplasticity, oxidative stress and the activity of glycogen synthase kinase-3 (GSK-3) isoforms in the hippocampus of male mice. Stressed mice exhibited a decreased density of Ki67-positive and DCX-positive cells in the subgranular zone of hippocampus, and altered expression of brain-derived neurotrophic factor (BDNF), its receptor TrkB, and anti-apoptotic protein kinase B 
phosphorylated at serine 473(AktpSer473). The mice also exhibited microglial activation, increased oxidative stress, increased levels of interleukin-1 $\beta$ (IL-1 $\beta$ ), interleukin-6 (IL-6) in the hippocampus and plasma, and elevated activity of GSK-3 isoforms. Together, the results of our investigation have revealed that unpredictable alternating ultrasound evokes behavioural and molecular changes that are characteristic of the depressive syndrome and validates this new and simple method of modeling emotional stress in rodents.

Keywords: depression, ultrasound radiation, plasticity, neuroinflammation, glycogen synthase kinase 3 (GSK-3), mice.

Abbreviations: Iba-1 - ionized calcium binding adaptor molecule 1, AktpSer473 - phosphorylated at Serine 473 protein kinase B, BDNF - brainderived neurotrophic factor, BLBP - brain lipid binding protein, CNS central nervous system, DG - dentate gyrus, DCX - doublecortin, FOXO3a - forkhead box O3, GSK-3 - glycogen synthase kinase-3, IL-1 $\beta$ - interleukin-1 $\beta$, IL-2 - interleukin-2, IL-6 - interleukin-6, IL-8 interleukin-8, IL-15 - interleukin-15, MD- malondialdehyde, NGF - nerve 
growth factor, PCR - polymerase chain reaction, PTEN - phosphatase and tensin homolog deleted on chromosome 10, SGZ - subgranular zone of hippocampus, TrkB - tropomyosin receptor kinase B, TNF- $\alpha$ - tumor necrosis factor- $\alpha$, VEGF - vascular endothelial growth factor, 3-NT - 3nitrotyrosine. 


\section{Introduction}

Emotional stress is defined as mental distress or anxiety suffered as a response to a sudden, severe, and saddening experience, which is not primed by any organic or physical disturbance (Simonov, 1997; Bao et al., 2008; Fontes et al., 2014). The term "emotional stress" is often used interchangeably with other terms such as "psychological stress" or "mental stress", which all referred to a state that is primarily triggered by perception and cognitive evaluation of adverse events (Chrousos and Gold, 1992). Challenges such as humiliation or defeat, loss of relatives, deterioration of a financial, marital or social status are typical drivers of emotional stress. Other clinically relevant conditions associated with a stress response, such as chronic pain, physical stressors, infection and inflammation, hormonal disbalances are frequently accompanied by negative emotions that are downstream of these organic factors (Selye, 1974) and may interact with emotional stress.

Emotional stress is suggested to play a major role in the development of major depressive disorder (Lesch, 2004; Roy et al., 2014; Kessler et al., 2015). For example, it was demonstrated that chronic, uncontrollable and unpredictablele stress can trigger maladaptive changes in humans and 
animals leading to the development of a depressive syndrome (McEwen and Stellar, 1993; de Kloet et al., 2005; Willner et al., 2005; Strekalova et al., 2011). Based on this evidence, we recently reported the development of a new rodent model of emotional stress in which chronic ultrasound exposure employing "emotionally negative" sound cues that avoids the application of physical stressors (restraint, food and water deprivation, cold temperatures or forced swim for example) (Morozova et al., 2016; Strekalova et al., 2018). In this new model, mice and rats are continuously exposed to ultrasound of variable frequencies for three weeks; the frequencies used during the ultrasound exposure are chosen to mimic ultrasonic vocalizations of rodents in nature (Brudzynski and Fletcher, 2010). The ultrasound is randomly alternated between 20 and $25 \mathrm{kHz}$, which corresponds to a rodent vocalization of a negative emotional state, and frequencies of $25-45 \mathrm{kHz}$, that are associated with a neutral emotional state (Kuraoka and Nakamura, 2010). Ultrasound signals of $>50 \mathrm{kHz}$ are known to be emitted by mice during physiologically positive experiences, including mother-pup interactions, mating and others, whereas the sounds in a range of $20-25 \mathrm{kHz}$ are generated by them in life-threatening conditions, such as social confrontation, pain and maternal separation (Constantini and D'Amato, 2006; Panksepp et al., 2007; Okabe et al., 2010). 
We previously reported that both rats and mice exposed to the three-week ultrasound exposure resulted in decreased sucrose preference, locomotion and social exploration, increased aggressive behaviour and elevated “despair" behaviour in a swim test (Morozova et al., 2016; Strekalova et al., 2018). These depression-like behaviours were accompanied by increased expression of the serotonin transporter and 5-HT2A receptor, decreased expression of 5-HT1A receptor and brain-derived neurotrophic factor $(\mathrm{BDNF})$ in the brain. Treatment with the selective serotonin reuptake inhibitor (SSRI) fluoxetine at the dose of $10 \mathrm{mg} / \mathrm{kg}$, largely ameliorated these depression-like changes. Separate experiments that involved exposure of experimental animals to ultrasound of similar intensity and duration as used in our study, but of mixed frequency ("white noise") or similar frequencies with lower intensity or duration, failed to induce depressivelike behavioural syndrome, thus, suggesting the specificity of the adverse effects of selected regime of ultrasound radiation (Morozova et al., 2016, see also below).

Furthermore, short exposures of Balb/c mice to the ultrasound of “emotionally negative" frequencies of $20-25 \mathrm{kHz}$ versus "physiologically neutral" frequencies of about 16 or $50-60 \mathrm{kHz}$ revealed temporary behavioural effects only in the $20-25 \mathrm{kHz}$ frequency range, further 
demonstrating physiological relevance of selected parameters of the ultrasound stimulation (Morozova et al., 2016).

The aim of the present study was to further explore the cellular and molecular changes, such as brain plasticity and neuroinflammation, that underpin the depressive-like syndrome induced by ultrasound exposure in comparison to stress regimes that employ physical factors (Dantzer et al., 2008; Masi and Brovedani, 2011; Strekalova et al., 2011, 2016; Willner et al., 2005, 2018).

Accumulated evidence suggests functional interconnections exist between inflammation in the brain, oxidative stress, the glycogen synthase kinase 3 (GSK-3) cascade, and the inhibition of brain plasticity mechanisms during depression-like syndromes (Leonard and Maes, 2012; Chesnokova et al., 2016; Strekalova et al., 2016). In particular, elevated concentrations of proinflammatory cytokines in the CNS trigger changes in microglial morphology (Lee et al., 1993; Bluthe et al., 1994; Dantzer et al., 2008), which are associated with the suppression of plasticity and the production, survival, migration, and recruitment of new neurons (Ekdahl et al., 2003; Lazarini et al., 2012; Chen et al., 2012; Belarbi et al., 2013). 
Furthermore, the change in morphology of microglia from a highly ramified to a more rounded phenotype is often associated with increased oxidative stress within the brain that may promote progressive neuronal damage (Block and Hong, 2007; Mao et al., 2007; Roy et al., 2008; Saliba et al., 2017). Local and circulating pro-inflammatory cytokines can stimulate expression of c-Jun-N-terminal kinase (JNK) which, in turn, inhibits a production of phosphorylated Akt kinase (Karin et al., 2005), a functional antagonist of major pro-apoptotic molecules: glycogen synthase kinase-3 beta (GSK-3 $\beta$ ), forkhead box protein O3a (FOXO3a) and PTEN (phosphatase and tensin homolog deleted on chromosome 10) (Wu et al., 2009; Fey et al., 2012; Pomytkin et al., 2015). Increased expression and protein activities of GSK-3 $\beta$ are well-documented correlates of neuronal degeneration and behavioural abnormalities during depression (Polter et al., 2009; Fey et al., 2012; Huang et al., 2013; Cline et al., 2015a, 2015b; Pavlov et al., 2017). As such, GSK-3ß/Akt/FOXO3a cascade is an important pathophysiological regulator of depression that is functionally related to the above mentioned mechanisms of neuroinflammation, excessive oxidative stress and deficient brain plasticity associated with this condition (Kaidanovich-Beilin and Woodgett, 2011; Beurel et al., 2015). 
Here we found that mice exposed to ultrasound stress had lowered immunohistochemical markers of neuronal proliferation in the hippocampus, gene and protein expression of neurotrophin brain-derived neurotrophic factor (BDNF) and its receptor TrkB, marker of glial proliferation Nestin and several other regulatory molecules of plasticity whose changes were previously shown to be associated with depressive syndrome: brain lipid binding protein (BLBP), vascular endothelial growth factor (VEGF) and neuron growth factor (NGF) (Duman, 2004; Colle et al., 2015; Oglodek et al., 2016; Xie et al., 2017; Fukunaga and Moriguchi, 2017).

To explore the possible role of the host immune system in the hippocampus in this stress paradigm, we studied the microglial marker, ionized calcium binding adaptor molecule 1 (Iba-1), and found that ultrasound exposure increased the density of Iba-1-positive cells. The hippocampal gene and protein expression of the pro-inflammatory interleukins (IL) IL-1 $\beta$, IL-6, and anti-inflammatory interleukins IL-2, IL-8 and IL-15, as well as plasma concentrations of IL-1 $\beta$, IL-6 and tumor necrosis factor- $\alpha$ (TNF $\alpha)$ was also investigated; changes the levels of these cytokines is associated with the depressive state (Maes et al., 2012; Couch et al., 2013, 2016). 
In addition, hippocampal concentrations of 3-nitrotyrosine and malondialdehyde were determined as markers of oxidative stress (Bakunina et al., 2015; Vignisse et al., 2014, Vignisse et al., 2017). Hippocampal gene and protein expression of beta and alpha isoforms of GSK-3 (GSK-3 $\beta$ and GSK-3 $\alpha$ ) and molecules that are functionally related to GSK-3 $\beta$ cascade, FOXO3a, 10 PTEN and phosphorylated at Serine 473 protein kinase B (AktpSer473), were evaluated. Finally, correlational analysis of the molecular expression profile was to assess functional impact of neurobiological alternations during stress for behavioural changes and, to address potential cross-correlations between parameters of inflammation, plasticity and depressive-like behaviours.

We found that in addition to the increase in microglial density, mice exposed to the ultrasound exhibited increased oxidative stress and proinflammatory cytokines in the hippocampus and plasma, and elevated activity of GSK-3 isoforms. In summary, our results reveal that unpredictable alternating ultrasound evokes behavioural and molecular changes in mice that are characteristic of the depressive syndrome described in depressed patients and in animals subjected to physical stressors.

\section{Materials and methods}




\subsection{Animals}

Experiments were performed using 10-weeks-old male Balb/c mice that were obtained from certified Charles River provider, Stolbovaja, RAS, Moscow region (http://www.spf-animals.ru/about/providers/animals). Animals were housed individually in the standard plastic cages $(27 \times 22 \times 15)$ and maintained on a 12-h light/dark cycle (lights on at 19:00), under controlled laboratory conditions $\left(22 \pm 1{ }^{\circ} \mathrm{C}, 55 \%\right.$ humidity, room temperature $+23{ }^{\circ} \mathrm{C}$ ), with food and water provided ad libitum. Housing conditions and all experimental procedures were set up and maintained in accordance with Directive 2010/63/EU of 22 September 2010 and carried out under the approval of the local veterinarian committee (10-02-15 N72). All efforts were undertaken to minimize the potential discomfort of experimental animals.

\subsection{Study design}

One day prior to the onset of ultrasonic exposure, mice were weighed, tested for sucrose preference (see below) and assigned to control and stress groups (data not shown); each group was comprised of twelve mice (Fig. 1A). Stress group was subjected to a three-week ultrasound radiation in a separate room as described elsewhere (Morozova et al., 2016; Strekalova et 
al., 2018; see below). Control group was housed under similar conditions, but not exposed to the ultrasound radiation. On the next day after the threeweek stress (Day 22), sucrose preference test was conducted in all mice. On Day 23, animals were subsequently tested in the open field test, residentintruder paradigm, and forced swim test (see below; Fig. 1A). On day 24, mice were sacrificed: right hippocampi from seven randomly chosen mice of each group were harvested for quantitative real-time polymerase chain reaction (qRT-PCR) and Western Blot, left hippocampi of these mice were harvested to study malondialdehyde or 3-nitrotyrosine concentrations; blood plasma was collected. Using customized method for brain perfusion (Couch et al., 2013, 2016, see below), right hippocampi from remaining five mice of each group were additionally dissected for subsequent qRT-PCR and Western Blot, left hippocampi were collected for the immunohistochemical study (Fig. 1A); blood was collected from all animals (see below). Together, all twelve animals from each group were studied for gene expression, Western blot and ELISA experiments. Brain oxidative stress was studied in seven mice with a malondialdehyde assay and in five mice with 3- nitrotyrosine assay. Five mice were used for immunohistochemical studies.

\subsection{Ultrasound radiation}


Stress procedure of ultrasound exposure was carried out as described elsewhere (Morozova et al., 2016; Strekalova et al., 2018). Ultrasound radiation of average intensity of $50 \pm 5 \mathrm{~dB}$ and variable frequencies in a 20$45 \mathrm{~Hz}$ range was constantly delivered in a laboratory room to the experimental groups of mice using a random schedule of alternating frequencies via a manufactured device (Weitech, Wavre, Belgium). The range of ultrasound stimulation frequency was alternating each $10 \mathrm{~min}$ between the following intervals: low frequencies $(20-25 \mathrm{kHz})$, middle range frequencies $(>25<40 \mathrm{kHz})$ and high range frequencies $(40-45 \mathrm{kHz})$. During the 10-min periods, ultrasound frequencies were fluctuating at variable short time spans of $\leq 1 \mathrm{~s}$ (averaged frequency $70 \mathrm{~Hz} \pm 10 \mathrm{~Hz}$ ) at the above-indicated intervals. $35 \%$ of the emission time consisted of $20-25$ and $25-40 \mathrm{kHz}$ intervals, and $30 \%$ of the emission time was constituted of $40-$ $45 \mathrm{kHz}$.

The intensity of the sound during above-indicated intervals was fluctuating at the range $\pm 10 \%$ of the averaged value, i.e., $\pm 5 \mathrm{~dB}$. The shape of the ultrasound signals was fluctuating that mimics natural ultrasonic vocalizations of rodents (Fig. 1B; Brudzynski and Fletcher, 2010). 
Distribution of the ultrasound radiation was controlled by the ultrasound detector (Discovery Channel, Rochester, NY, USA) during the study. The ultrasound device was hung $2 \mathrm{~m}$ above the cages of the experimental groups with an average horizontal distance to cages of $2.5 \mathrm{~m}$. The position of the cages, with respect to the stimulator, was changed weekly. The selectivity of the adverse effects of low-frequency ultrasound during the radiation period versus the potential general negative effects of a constant noise accompanying the procedure described here has been previously described by us (Morozova et al., 2016). As part of these studies, when mixed frequencies ("white noise") at the range of $16-20 \mathrm{kHz}$ were employed no changes in social and depressive-like behaviours were observed (Morozova et al., 2016). A comparison of immediate behavioural effects of the ultrasound exposure of fluctuating frequency $20-45 \mathrm{~Hz}$ at varying intensities revealed that $50 \mathrm{~dB}$ and $90 \mathrm{~dB}$ ultrasound signs will supress burying, feeding and drinking in a home cage after, but no such changes were observed at $30 \mathrm{~dB}$ stimulation (see Supplementary material, Figs. 13). Furthermore, we also found that a shortened period of ultrasound exposure of 1 to 2-weeks duration were not as effective as 3-weeks of continuous exposure to of animals to a fluctuating signal of $20-45 \mathrm{~Hz}$ with an average intensity of $50 \mathrm{~dB}$ (Morozova et al., 2016). 


\subsection{Behavioural tests}

\subsubsection{Sucrose test}

Mice were given a free choice between a bottle with $1 \%$-sucrose solution and another one with tap water for $24 \mathrm{~h}$, as described elsewhere (Strekalova et al., 2004, see Supplementary material). At the beginning and the end of the test, the bottles were weighed and consumption was calculated. The percentage preference for sucrose over water was calculated using the following formula: Sucrose Preference $=$ Volume (Sucrose solution)/(Volume (Sucrose solution)+ Volume (Water)) x 100.

\subsubsection{Forced swim test}

This test was carried out as described previously (Strekalova and Steinbusch, 2010; Malatynska et al., 2012, see Supplementary material). Mice were placed in the pool and their latency to float and total duration of floating behavior was scored during the 6 min offline using Any-maze software (Stoelting Co, Wood Dale, IL, USA).

\subsubsection{Open field test}

The open field test was performed as described elsewhere (Strekalova and Steinbusch, 2010; Morozova et al., 2016, see Supplementary material), 
using white light; time spent in the central zone and number of grooming events were scored for a 5 min period using automated video tracking AnyMaze software (Stoelting Co, Wood Dale, IL, USA).

\subsubsection{Resident-intruder test}

The resident-intruder test procedure was adapted from the previously described protocols (Couch et al., 2016; Strekalova et al., 2018, see Supplementary material); during the 10-min observation period, mice were scored for the latency to attack and the number of attacks. 
A
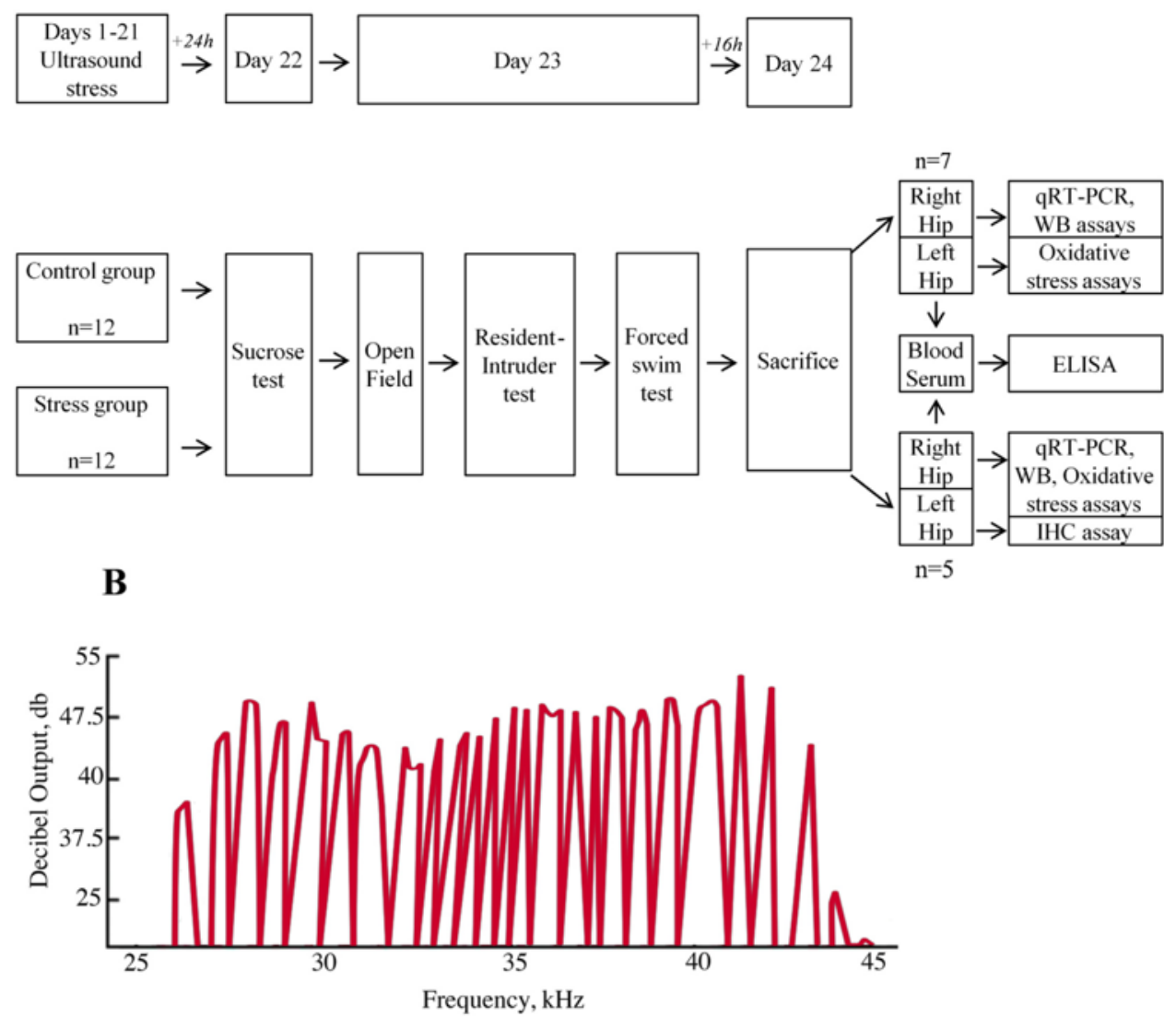

Fig. 1. Experiment design. A. Schematic study outline. After 21 dayperiod of ultrasound stress exposure, both control and stress group were tested in a battery of behavioural tests and used for subsequent in vitro assays ( $\mathrm{n}=12$ and 5-7 per group, respectively). Hip - hippocampus, qRTPCR - quantitative reverse transcription polymerase chain reaction, WB assay - western blot, ELISA - enzyme-linked immunosorbent assay, IHC assay - immunohistochemical assay. B. Representation of the ultrasound signal mimicking a natural sound of mice: frequency-intensity fluctuations.

\subsection{Brain and blood collection}


Mice were terminally anaesthetized with an intraperitoneal injection of Nembutal (Bayer, Wiesbaden, Germany). Blood collection was performed transcardially and was followed by perfusion of the left ventricle with 10 $\mathrm{ml}$ of the ice-cold $0.9 \% \mathrm{NaCl}$. Blood was stored in heparinized vials prior to centrifugation $\left(10,000 \mathrm{rpm}, 15 \mathrm{~min}, 4{ }^{\circ} \mathrm{C}\right)$; plasma was removed and immediately stored at $-20^{\circ} \mathrm{C}$ until use. The brain of seven mice from each group was dissected and the right and left hippocampi were isolated and immediately frozen at $-80^{\circ} \mathrm{C}$ on a dry ice. Five mice from each group were first subjected to the same procedure where only the right hemispheres and hippocampi were dissected as previously reported (Couch et al., 2013; see Supplementary material). Thereafter, these mice were transcardially perfused by $4 \%$ - paraformaldehyde (PFA) in $0.1 \mathrm{M}$ phosphate buffer. Left hemispheres and hippocampi were removed and postfixed in 4\%-PFA for $12 \mathrm{~h}$ at $+4{ }^{\circ} \mathrm{C}$, and thereafter were immersed in $0.1 \mathrm{M}$ phosphate-buffered saline (PBS, $\mathrm{pH} 7.4$ ) for $12 \mathrm{~h}$ at $+4{ }^{\circ} \mathrm{C}$. Finally, samples from the left hippocampi perfused with 4\% PFA were processed for paraffin embedding as described elsewhere (Morozova et al., 2016).

\subsection{Brain sectioning and immunohistochemistry}


All steps were essentially performed as described previously, five animals per group were used in these experiments (Strekalova et al., 2015, 2018; Vignisse et al., 2017, see Supplementary material). 20- $\mu$ mthick coronal sections were obtained from paraffin brain blocks using a Leica CM 1850 cryostat (Leica Microsystems, Wetzlar, Germany) and mounted on gelatincovered glass with coverslips. Hippocampal sections were taken from lateral 3.6 to lateral $0.4 \mathrm{~mm}$ along the mediallateral axis ahead of bregma (Paxinos and Franklin, 2001). The dorsal and ventral hippocampus was examined in our studies. The area examined was rostro-caudal from Bregma $-2.5 \mathrm{~mm}$ to $4.5 \mathrm{~mm}$ and medial-lateral from $-1 \mathrm{~mm}$ to $-3 \mathrm{~mm}$. Details on paraffin removal, antigen retrieval and blocking of non-specific staining are presented in the Supplementary material. Three sections per each animal were then incubated overnight at $4{ }^{\circ} \mathrm{C}$ with primary antibodies: rat anti-Ki67 (Dako, Glostrup, Denmark), or rabbit polyclonal anti-DCX (Chemicon, Temecula, CA, USA), or rabbit anti-ionized calcium binding adaptor molecule 1 (Iba-1; Dako, Glostrup, Denmark). Subsequently, sections were incubated with respective secondary antibodies, using or anti-rat-Alexa Fluor 594, donkey anti-rabbit-Alexa Fluor 488 and anti-rabbit- Alexa Fluor 647, respectively (Life Technologies-Molecular Probes, Grand Island, NY, USA). 
In addition, to visualize the nuclei of the hippocampal cells, sections were double-stained with 4',6-diamidino-2-phenylindole (DAPI) (Santa Cruz Biotechnology, Dallas, TX, USA). Quantification of Ki67-, DCX and Iba1- positive cells was carried out by an experimenter blind to the experimental conditions as described elsewhere (Strekalova et al., 2015, 2018; Vignisse et al., 2017). Briefly, images were acquired using a microscope BX51 (Olympus, Tokyo, Japan), photographed with a digital DP70 camera (Olympus, Tokyo, Japan) and were simultaneously quantified in the control and stress groups using ImageJ Software (NIH, Bethesda, MD, USA).

Ki67- and DCX-positive cells were counted in the area of the subgranular zone of the hippocampus (SGZ), which was defined as previously described (Vignisse et al., 2017, see Supplementary material, Suppl. Fig. 4). Seven coronal sections were randomly selected to perform Nissl staining to calculate densities of Ki67- and DCX- positive cells per mm3 (see Supplementary material, Vignisse et al., 2017; Strekalova et al., 2018). Iba1-positive cells were counted in the area of the hilus of the hippocampus and their densities per $\mathrm{mm} 2$ were calculated as described previously, only cells with distinct DAPI-stained nuclei were counted as positive (Vignisse et al., 2017, see Supplementary material, Suppl. Fig. 6). Further details of 
the size of the examined area, section selection, and application of mathematical formulas can be found in the Supplementary material.

\subsection{Quantitative real-time PCR}

Quantitative real-time PCR was carried out as described elsewhere (Morozova et al., 2016; Couch et al., 2013, 2016). Briefly, first-strand cDNA synthesis was performed using random primers and Superscript III transcriptase (Invitrogen, Carlsbad, CA, USA); $1 \mu \mathrm{g}$ total RNA was converted into cDNA. qRT-PCR was performed using the SYBR Green master mix (Bio-Rad Laboratories, Philadelphia, PA, USA) and the CFX96 Deep Well Real-Time PCR Detection System (Bio-Rad, Hercules, CA, USA). Further details in the protocol used and sequences of primers can be found in Supplementary material and Suppl. Table 1. The housekeeping gene glyceraldehyde-3-phosphate dehydrogenase (GAPDH) was selected as the reference gene since previous experiments demonstrated relatively low variability in GAPDH expression in the limbic structures of the rodents exposed to the ultrasound stress (Morozova et al., 2016). Data were normalized to GAPDH mRNA expression and calculated as relative-fold changes compared to control mice as described elsewhere (Morozova et al., 2016; Couch et al., 2016; Pavlov et al., 2017). 
Tissue samples were prepared using glass-glass homogenization followed by a sonification in ice-cold buffer (Roche Diagnostics, Indianapolis, IN, USA). Details of the Western blot analysis can be found in the Supplementary material. Briefly, protein concentration was quantified using the BCA protein assay kit (Pierce, Rockford, IL, USA, see Supplementary material), $25 \mu \mathrm{g}$ of proteins were treated with SDS-PAGE and electroblotted on the PVDF membrane (EMD Millipore, Billerica, MA, USA). These samples were incubated with primary antibodies overnight at $4{ }^{\circ} \mathrm{C}$ (for information on antibodies used, see Suppl. Table 2) that was followed by the incubation with respective secondary antibodies (SigmaAldrich, St. Louis, MO, USA) for $2 \mathrm{~h}$ at room temperature. Immunoreactive bands were detected using Bio-Rad Molecular Imager Software (BioRad Laboratories, Richmond, CA, USA). $\beta$-tubulin was used as a reference protein as low fluctuation of its expression was found previously in similar experiments (Morozova et al., 2016; Gorlova et al., 2018, 2019); expression of proteins of interest were calculated in fold changes from levels of $\beta$ tubulin, as described elsewhere (Morozova et al., 2016). 
2.9. Enzyme-linked immunosorbent assays of plasma cytokines and brain 3nitrotyrosine

To study the concentrations of IL-1 $\beta$, IL-6, and TNF- $\alpha$ in a blood plasma, mouse enzyme-linked immunosorbent assay (ELISA) was performed using MOUSE IL-1 $\beta$, IL-6, and TNF- $\alpha$ ELISA MAX ${ }^{\mathrm{TM}}$ Deluxe Sets (BioLegend, San Diego, CA, USA) according to the manufacturer's instructions (see Supplementary material). Protein concentrations were measured using the BCA protein assay kit (Pierce, Rockford, IL, USA, see Supplementary material). The microwell absorbance was measured at $450 \mathrm{~nm}$ with Promega microplate reader for all cytokines (Madison, WI, USA).

Concentrations of 3-nitrotyrosine in protein samples of hippocampi were determined using OxiSelect ${ }^{\mathrm{TM}}$ Nitrotyrosine ELISA Kit (Cell Biolabs, Inc., San Diego, CA, USA) according to the manufacturer's instructions (see Supplementary material). Microwell absorbance was measured as described elsewhere (Vignisse et al., 2017).

\subsection{Malondialdehyde assay}

Malondialdehyde content in hippocampal samples was measured with the OxiSelect ${ }^{\mathrm{TM}}$ TBARS Assay Kit (Cell Biolabs, Inc., San Diego, CA, USA). Tissue samples were homogenized and sonicated on ice, in a proportion of 
$1 \mathrm{ml}$ of sample per $1 \mathrm{ml}$ of Sample Diluent (OxiSelect ${ }^{\mathrm{TM}}$ kit, Cell Biolabs, Inc., San Diego, CA, USA). Butylated hydroxytoluene (BHT) solution in methanol was added to samples in a proportion 1:100. Samples were centrifuged at $10.000 \mathrm{rpm}$ at $4{ }^{\circ} \mathrm{C}$ for $5 \mathrm{~min}$ and the supernatant was collected. Total protein concentration was adjusted to $10 \mathrm{mg} / \mathrm{ml}$. Samples were diluted 1 to 10 , and malondialdehyde content was determined using the GloMax Multi Detection System equipped with a fluorescence module (reading range 540-590 nm; Promega, Madison, WI, USA) according to the guidelines of the manufacturer.

Protein concentrations were measured using the BCA protein assay kit (Pierce, Rockford, IL, USA, see Supplementary material). Results were normalized to protein concentration as described previously (Vignisse et al., 2017).

\subsection{Statistical analysis}

Data analysis was performed using GraphPad Prism software version 5.03 for Windows (San Diego CA, USA). A comparison of two groups was carried out with a Mann-Whitney U test, and Spearman correlation was used for the correlation analysis of the molecular and behavioural data. Statistical significance was set at $p<.05$. Data are shown as mean \pm SEM. 


\section{Results}

3.1. Ultrasound exposure induces depressive-like syndrome

In the sucrose preference test, mice exposed to the ultrasound, as compared with control group, displayed a significant reduction in sucrose preference and decreased sucrose intake $(U=17.5, p=.012$, and $U=15, p=.0064$, MannWhitney test; respectively, Fig. 2A,B), suggesting diminished sensitivity to reward in stressed mice. Water intake did not significantly differ between the groups $(U=28, p=.1008$, Fig. $2 C)$. In the forced swim test, the stressed group of mice showed a significant prolongation of the duration of floating as compared to control $(\mathrm{U}=21, \mathrm{p}=.027$, Fig. 2D) indicating increased helplessness in the former group. There was a trend to shorter latency to float in stressed animals as compared to control group $(U=27, p=.085$, Fig. 2E). 
SUCROSE TEST
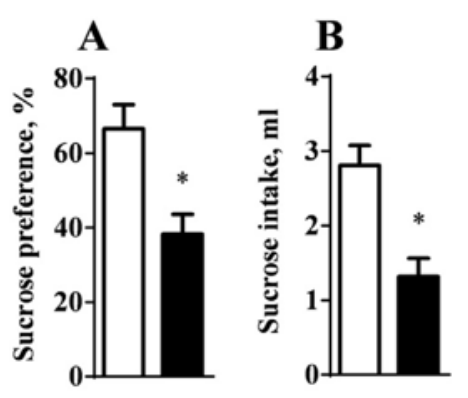

OPEN FIELD TEST
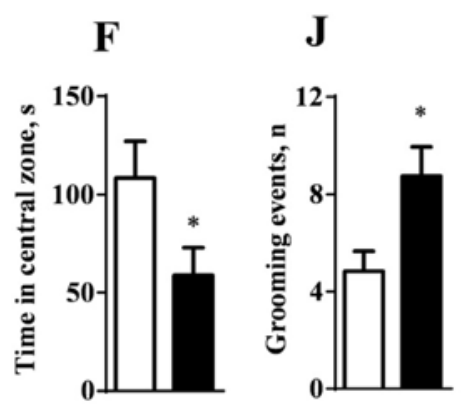
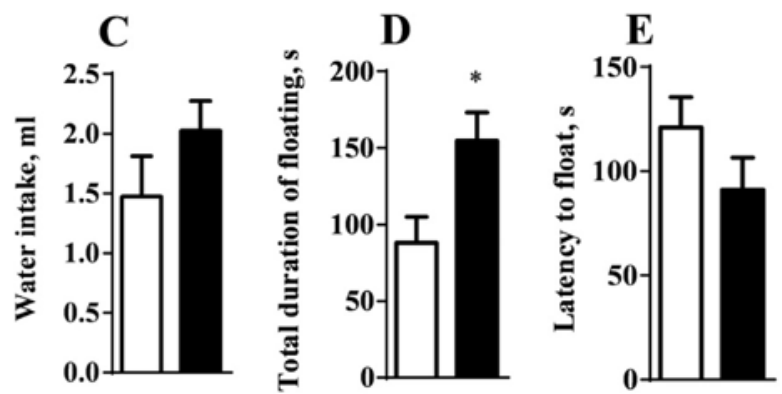

RESIDENT-INTRUDER TEST

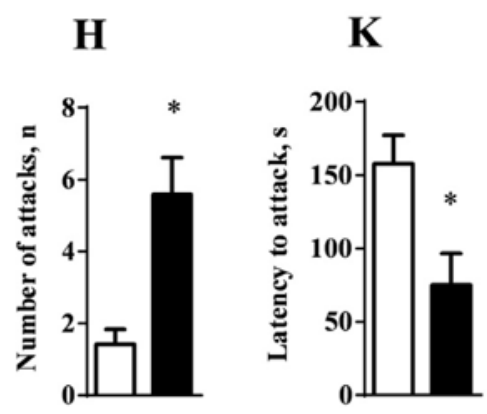

$\square$ Control

Stress

Fig. 2. Ultrasound stress exposure induces depressive- like syndrome in mice. In the test, in comparison to the control group, stress group showed a significant decrease of (A) sucrose preference and (B) sucrose intake demonstrating decreased sensitivity to reward $(* p<.05$ vs. control, MannWhitney test). (C) No significant group differences were found in water intake ( $p>.05$ vs. control, Mann-Whitney test). In the forced swim test, in comparison to the control group, stressed animals showed (D) elevated total duration of floating (*p $<.05$ vs.control, Mann-Whitney test); (E) latency to float did not change significantly ( $p>.05$ vs.control, Mann- Whitney test). In the open field test, in comparison to control group, stressed mice demonstrated (F) significantly shorter time spent in the central zone, a sign of anxiety-like behaviour and $(\mathrm{J})$ increased number of grooming events, a sign of behavioural invigoration ( ${ }^{*} \mathrm{p}<.05 \mathrm{vs}$. control, Mann-Whitney test). In the resident-intruder test, in comparison with control animals, stressed mice displayed $(\mathrm{H})$ increased number of attacks and $(\mathrm{K})$ decreased latency to attack $(* \mathrm{p}<.05$ vs. control). Bars are Mean \pm SEM, 12 animals per group were used. 
In addition to behavioural manifestations of anhedonia and helplessness, mice exposed to the ultrasound stress displayed a decrease in time spent in the central zone of the open field ( $U=36, p=.037$, Mann-Whitney test, Fig. 2F), a sign of anxiety-like behavior. In addition, stressed animals showed a significant increase in the number of grooming events $(\mathrm{U}=18.5, \mathrm{p}=.0014$, Fig. 2J) that is commonly regarded as a sign of behavioural invigoration of rodents subjected to stressed conditions.

In line with the previous findings, ultrasound exposure has affected aggressive behavior in the Resident-intruder test, in which increased aggressive behaviour in mice subjected to ultrasound exposure was found. In comparison with control group, stressed animals displayed a significantly elevated number of attacks ( $\mathrm{U}=16.5, \mathrm{p}=.007$, Mann-Whitney test, Fig. $2 \mathrm{H}$ ) and shortened latency to first attack ( $\mathrm{U}=15, \mathrm{p}=.04$, Fig. $2 \mathrm{~K})$.

Merged staining of the neuronal nuclear marker DAPI and markers of cell proliferation Ki67 and progenitor neuronal cells DCX (Fig. 3A) revealed decreased, in compared with control group, density of Ki67- and DCXpositive cells in the SGZ of the hippocampus of stressed mice $(\mathrm{U}=1.5$, $\mathrm{p}=.023$ and $\mathrm{U}=2.5, \mathrm{p}=.039$, Mann-Whitney test, respectively, Fig. 3B,C), 
suggesting that ultrasound stress inhibits neuronal proliferation in this brain structure.

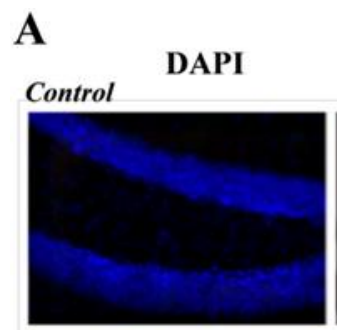

Ki67

DCX

MERGE
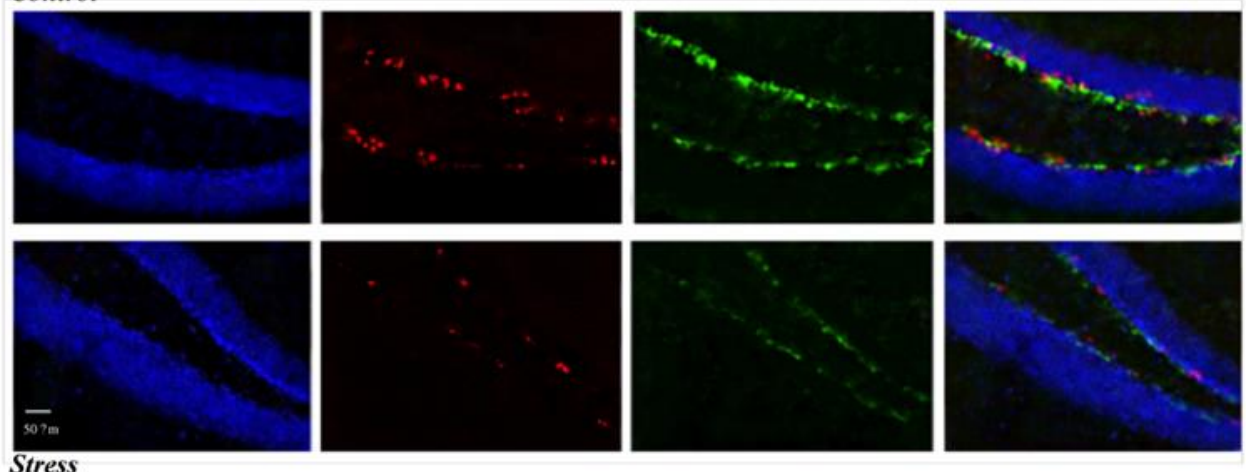

B

C

D
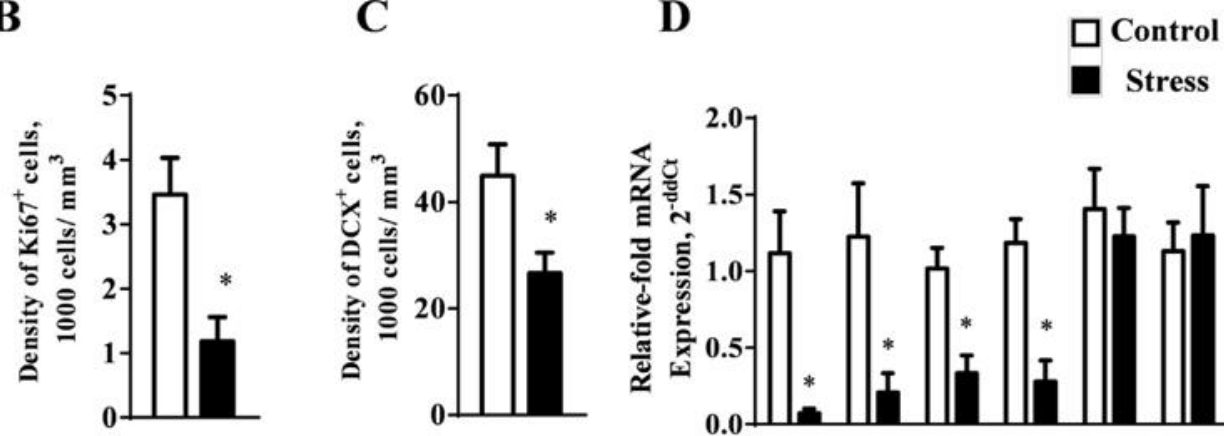

$\mathbf{E}$
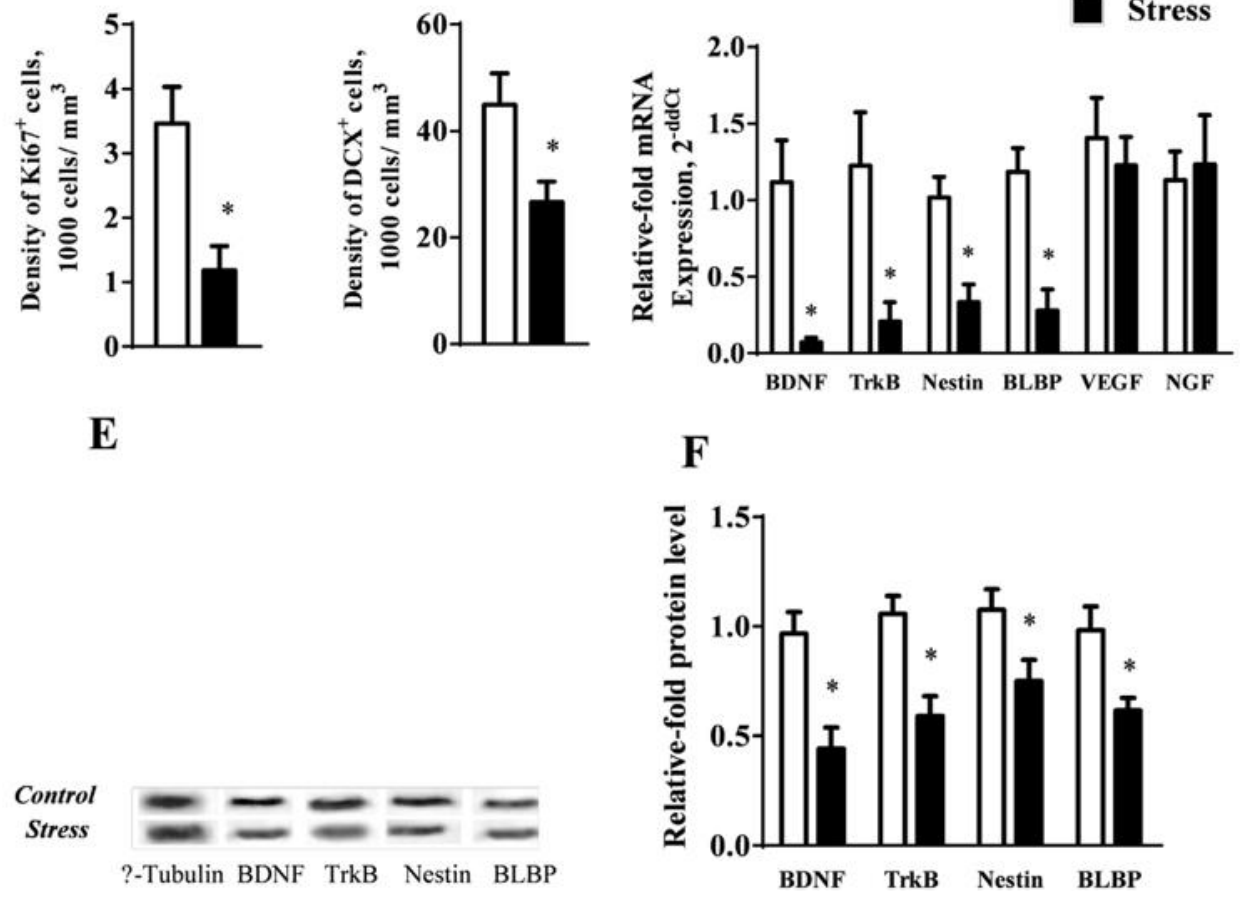
Fig. 3. Effects of ultrasound stress on the markers of hippocampal plasticity. (A) Immunohistochemical staining of DAPI, Ki67, DCX, and analysis of their merged images with DOPI-staining revealed diminished numbers of Ki67- positive and DCX - positive cells in the hippocampus of stressed mice as compared with control animals. In comparison to the control group, stressed mice had a significant decrease in the density of (B) Ki67- positive and (C) DCX - positive cells in the subgranular zone of the dentate gyrus of the hippocampus $(* \mathrm{p}<.05$ vs. control, Mann-Whitney test; 5 animals per group were used). (D) Stressed mice had a significant decrease of mRNA concentrations of plasticity factors BDNF, TrkB, Nestin, and BLBP as compared with control mice $(* \mathrm{p}<.05$ vs. control, Mann-Whitney test; 12 animals per group were used) that suggests reduced levels of neurotrophic factors in animals subjected to the ultrasound exposure; mRNA expression of VEGF and NGF was unchanged ( $p>.05$ vs. control, Mann-Whitney test). In comparison with control mice, there was a significant decrease of hippocampal levels of BDNF, TrkB, Nestin, and BLBP in stressed mice in the gene expression in the (E) RTPCR and (F) Western blot assays (*p < .05 vs. control, Mann-Whitney test; 12 animals per group were used). Scale bar is on the microphotograph is 50 $\mu \mathrm{m}$. Ki67+-Ki67- positive cells, DCX+-DCX-positive cells. Bars are Mean \pm SEM. $\beta$-tubulin was used as a

reference in the Western blot assay, the expression of all proteins is normalized to $\beta$-tubulin expression.

In addition, hippocampal gene expression of markers of morphological plasticity was significantly reduced in mice exposed to the ultrasound stress.

In comparison with control group, mRNA concentrations of neurotrophin BDNF, its receptor TrkB, early progenitor cells marker Nestin and a marker of immature neurons BLBP were significantly decreased in comparison with control group $(U=1, p=.0001 ; U=3, p=.016, U=5, p=.042$, and $U=1$, $\mathrm{p}=.015$, respectively, Mann-Whitney test; Fig. 3D). 


\subsection{Ultrasound stress suppresses hippocampal plasticity}

mRNA levels of plasticity factors VEGF and NGF did not differ significantly between the groups $(\mathrm{U}=9, \mathrm{p}=.24$ and $\mathrm{U}=8, \mathrm{p}=.67$ respectively; Fig. 3D). Changes found in gene expression were further confirmed with Western blot method. In this assay, we found a significant reduction of hippocampal levels of BDNF, TrkB, Nestin, and BLBP in stressed mice as compared with control group $(\mathrm{U}=4, \mathrm{p}=.016 ; \mathrm{U}=2, \mathrm{p}=.025, \mathrm{U}=0, \mathrm{p}=.009$; $\mathrm{U}=1, \mathrm{p}=.004$, respectively, Fig. 3E,F).

\subsection{Pro-inflammatory effects of the ultrasound stress}

Merged staining of the hippocampal slices with DAPI, a marker of neuronal nuclei, and Iba-1, a marker of microglia (Fig. 4A), revealed increased densities of Iba-1-positive cells in the hilus of hippocampi of stressed mice as compared with control animals $(\mathrm{U}=2, \mathrm{p}=.031$, Mann-Whitney test; Fig. 4B).

Gene expression analysis of the hippocampus of stressed mice showed a significant up-regulation of mRNA levels of pro-inflammatory cytokines $\mathrm{IL}-1 \beta(\mathrm{U}=2, \mathrm{p}=.007)$ and IL-6 $(\mathrm{U}=4, \mathrm{p}=.029$, respectively, Fig. 4C), but not anti-inflammatory cytokines IL-2, IL-8 and IL-15 (U=9, $\mathrm{p}=.27 ; \mathrm{U}=7, \mathrm{p}=.09$; $\mathrm{U}=8, \mathrm{p}=.51$; respectively), as compared with control groups (Fig. 4D). Up- 
regulation of pro-inflammatory cytokines was further supported in the Western blot assay.

A

Control
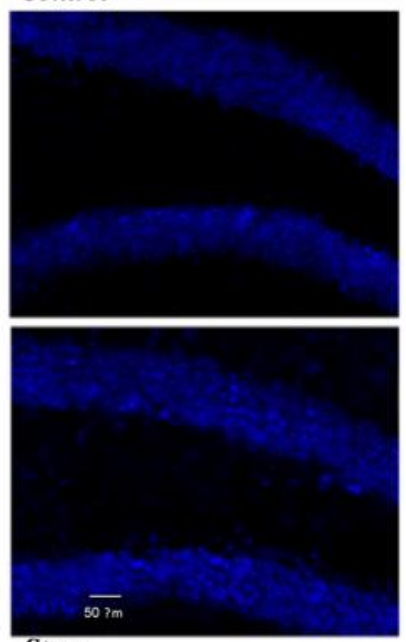

B

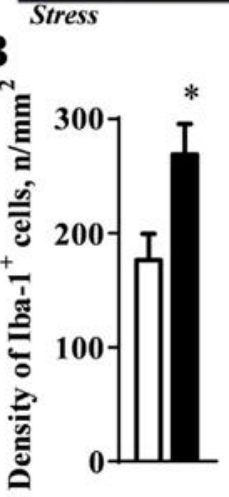

E

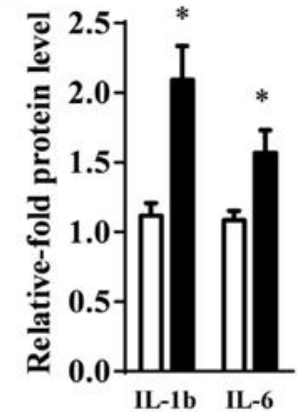

Iba-1
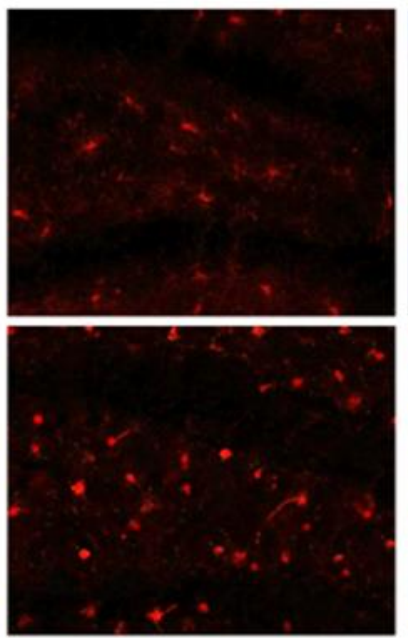

C

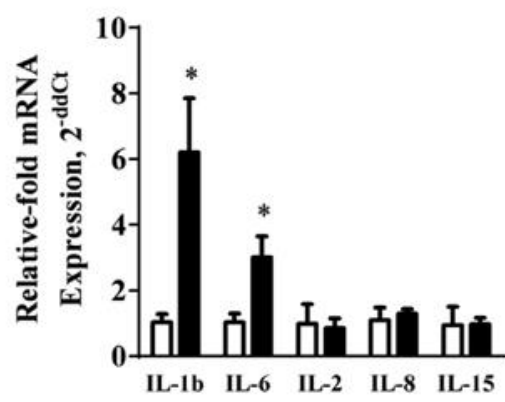

MERGE
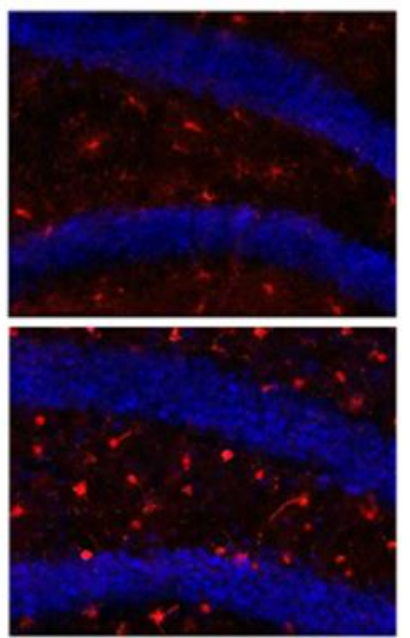

D

$\square$ Control

Stress

\section{Control}

Stress

b-Tubulin IL-1b IL-6

F

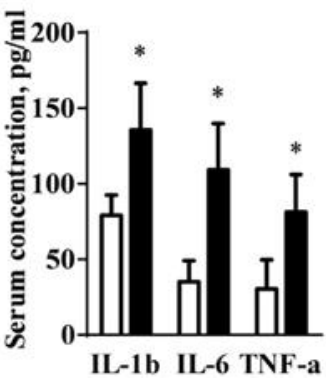

G

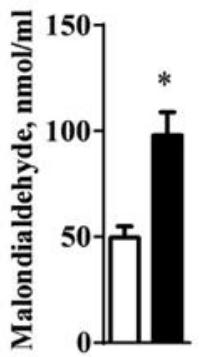

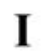

I

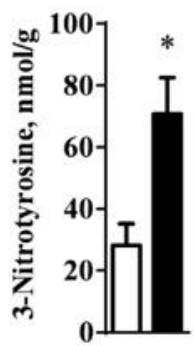


Fig. 4. Ultrasound stress induces inflammation and oxidative stress in the hippocampus. (A) Analysis of immunohistochemical staining of Iba1- and DAPIpositive cells revealed increased numbers of Iba-1- positive neuronal cells in the stressed group, as compared with control mice. (B) Stressed mice had a significantly increased density of Iba-1-positive cells, as compared with control group $\left({ }^{*} \mathrm{p}<.05\right.$ vs. control, Mann-Whitney test; 5 animals per group were used) and the appearance of the microglia was more rounded in these animals (see Suppl Fig. 6). In the assays performed here, an $n=12$ was used. A qRTPCR experiment (C) revealed significantly elevated levels of mRNA of IL-1 $\beta$ and IL-6 in stressed animals, in comparison with control mice $(* \mathrm{p}<.05$ vs.control, Mann-Whitney test); no such changes were found for IL-2, IL-8 and IL-15 ( $p>.05$ vs.control, MannWhitney test). (D, E) In the Western Blot assay, similar group differences were found for IL-1 $\beta$ and IL-6 (*p <.05 vs.control, Mann-Whitney test); no group changes were shown for IL-2, IL-8 and IL-15 ( $p>.05$ vs.control, Mann-Whitney test). (F) In ELISA assay, plasma concentrations of IL-1 $\beta$, IL-6 and TNF- $\alpha$ in the stressed group were significantly higher than in controls (*p $<.05$ vs.control, Mann-Whitney test). Hippocampal levels of (G) malondialdehyde and (I) 3-nitrotyrosine were significantly higher in stressed mice than in the control group $\left({ }^{*} \mathrm{p}<.05 \mathrm{vs}\right.$. control, Mann-Whitney test). Bars are Mean \pm SEM. The scale bar on the microphotograph is 50 $\mu \mathrm{m}$. $\beta$-tubulin was used as a loading control in the Western blot assay; the expression of all proteins is normalized to $\beta$-tubulin expression.

In comparison with control group, stressed animals had a significant increase in protein fold expression of IL-1 $\beta$, IL-6 in the hippocampal formation $(U=3, p=.06 ; U=6, p=.031$, respectively; Fig. 4D,E). In addition, concentrations of all these factors and TNF- $\alpha$ were significantly higher in the plasma of stressed versus control groups of mice, as shown in ELISA assay $(U=2, p=.035 ; U=6, p=.002 ; U=6, p=.007$, respectively; Fig. 4F). 
Finally, hippocampal concentrations of markers of oxidative stress, whose accumulation is known to be associated with up-regulated neuroinflammatory processes, malondialdehyde, and 3-nitrotyrosine content, were significantly elevated in the stress group as compared with control mice $(\mathrm{U}=7.6, \mathrm{p}=.019 ; \mathrm{U}=1.8, \mathrm{p}=.012$, respectively, Mann-Whitney test; Fig. 4G,I).

3.4. Altered activities of GSK-3 $\beta$ and related pathways during ultrasound stress

In this study, we sought to discover whether GSK-3 $\beta$ and related pathways would be altered during the ultrasound stress. We found a significant increase in mRNA levels of GSK-3 $\beta(\mathrm{U}=5, \mathrm{p}=.009$, Mann- Whitney test) as well as of GSK-3 $\alpha(U=7, p=.034)$ in stressed versus control mice (Fig. 5A). Western blot analysis revealed significant upregulation of these molecules on a protein level $(U=6, p=.041, U=4, p=.047$, respectively, Fig. 5B,C). 

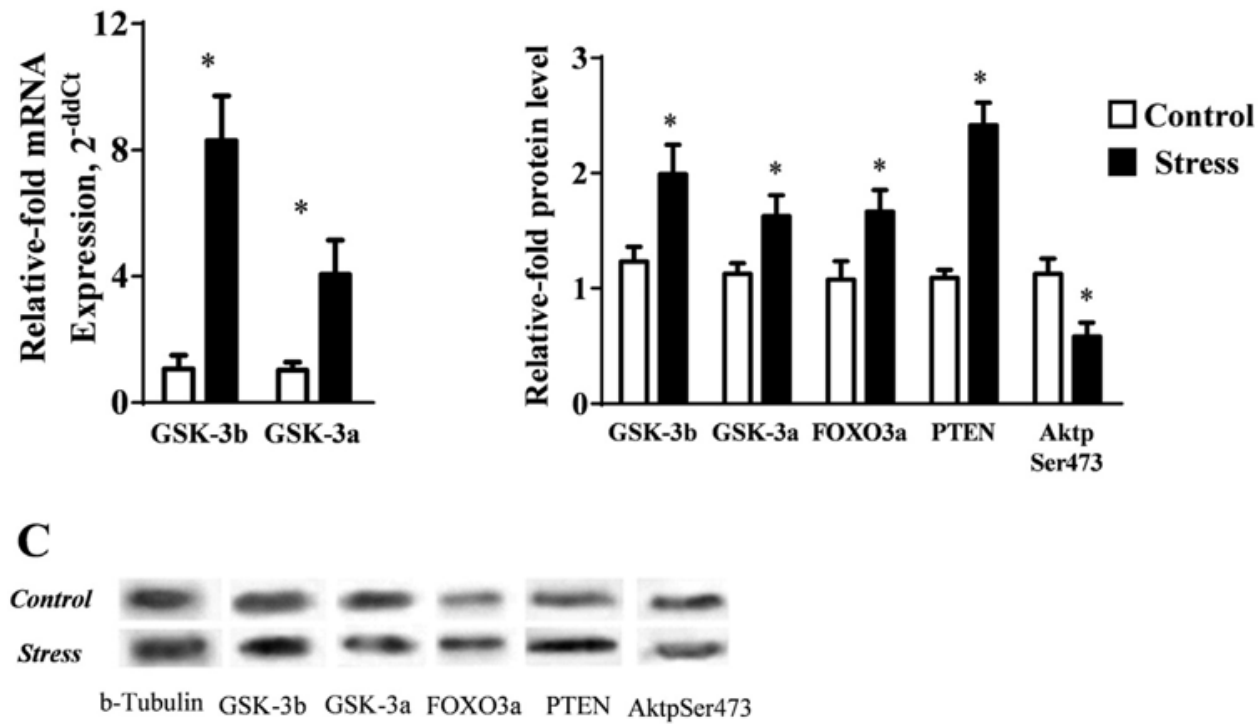

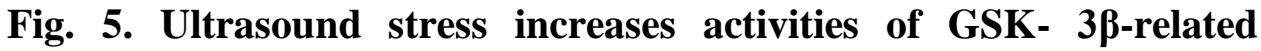
mechanisms in the hippocampus. (A) Stressed animals, as compared with the control group, had significantly higher hippocampal concentrations of both $\beta$ and $\alpha$ isoforms of GSK-3 (*p <.05 vs. control, Mann-Whitney test). $(\mathrm{B}, \mathrm{C})$. In stressed mice, in comparison with the control group, protein fold expression of GSK-3 $\beta$, GSK-3 $\alpha$, FOXO3a and PTEN was significantly elevated, and expression of AktpSer473 was significantly decreased $\left({ }^{*} \mathrm{p}<\right.$ .05 vs. control, Mann-Whitney test). Bars are Mean \pm SEM; 12 animals per group were used in all assays. $\beta$-tubulin was used as a loading control in the Western blot assay, the expression of all proteins is normalized to $\beta$-tubulin expression.

Moreover, a significant increase of FOXO3a and PTEN molecules (functionally related to GSK-3 pathway), as well as decreased expression of AktpSer473, were observed $(\mathrm{U}=30.5, \mathrm{p}=.0148, \mathrm{U}=11.5, \mathrm{p}=.0001$ and $\mathrm{U}=37, \mathrm{p}=.0425$, respectively; Fig. $5 \mathrm{~B}, \mathrm{C})$. Thus, exposure of mice to the 
ultrasound resulted in heightened brain activities if the GSK-3-related cascades.

\subsection{Correlation analysis of behavioural and hippocampal changes during}

ultrasound stress

To assess potential relationship between depressive-like behaviours and molecular changes in the hippocampal formation we performed a correlation analysis between individual parameters. Significant correlations were found exclusively within the stress groups, but not in the control groups. However, owing to the smaller group sizes used in immunohistochemical and oxidative stress assays, these data were not included in the analysis. We found that total duration of floating positively correlated with GSK-3 $\beta$ expression on gene and protein levels $(p=.003$, $\mathrm{r}=0.62$ and $\mathrm{p}=.04, \mathrm{r}=0.58$, respectively, Spearman correlation), but not with measures of GSK- $3 \alpha$ expression $(\mathrm{p}=.17, \mathrm{r}=0.41$, and $\mathrm{p}=.48, \mathrm{r}=-0.22$, respectively, Fig. 6A).

Similarly, there was a significant positive correlation of GSK-3 $\beta$ mRNA expression and GSK-3 $\beta$ fold protein changes with the number of attacks $(\mathrm{p}=.01, \mathrm{r}=0.69, \mathrm{p}=.01, \mathrm{r}=0.7)$ that was not found for alpha form of GSK-3 in either measurement $(\mathrm{p}=.63, \mathrm{r}=0.15, \mathrm{p}=.68, \mathrm{r}=0.13$, respectively, Fig. $6 \mathrm{~B})$. 


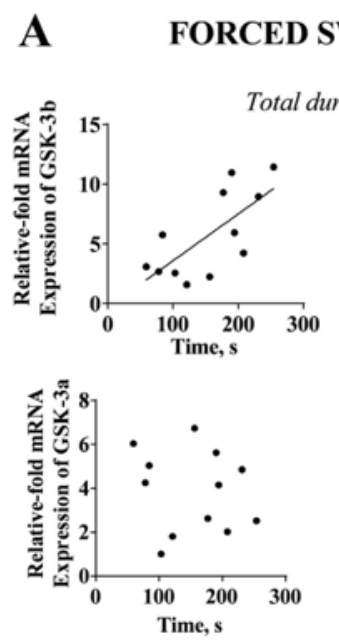

\section{B RESIDENT-INTRUDER TEST}
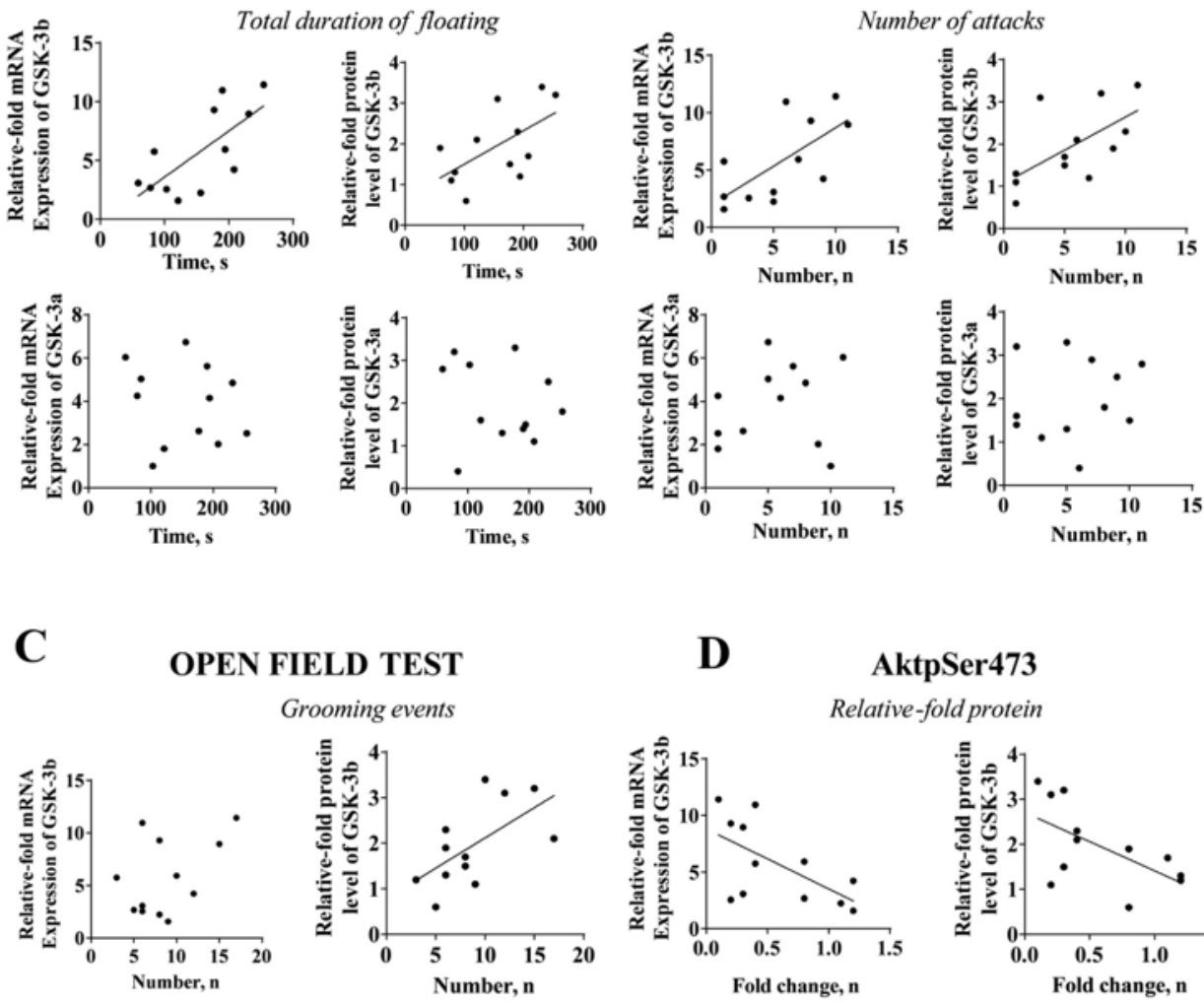

AktpSer473

\section{Relative-fold protein}
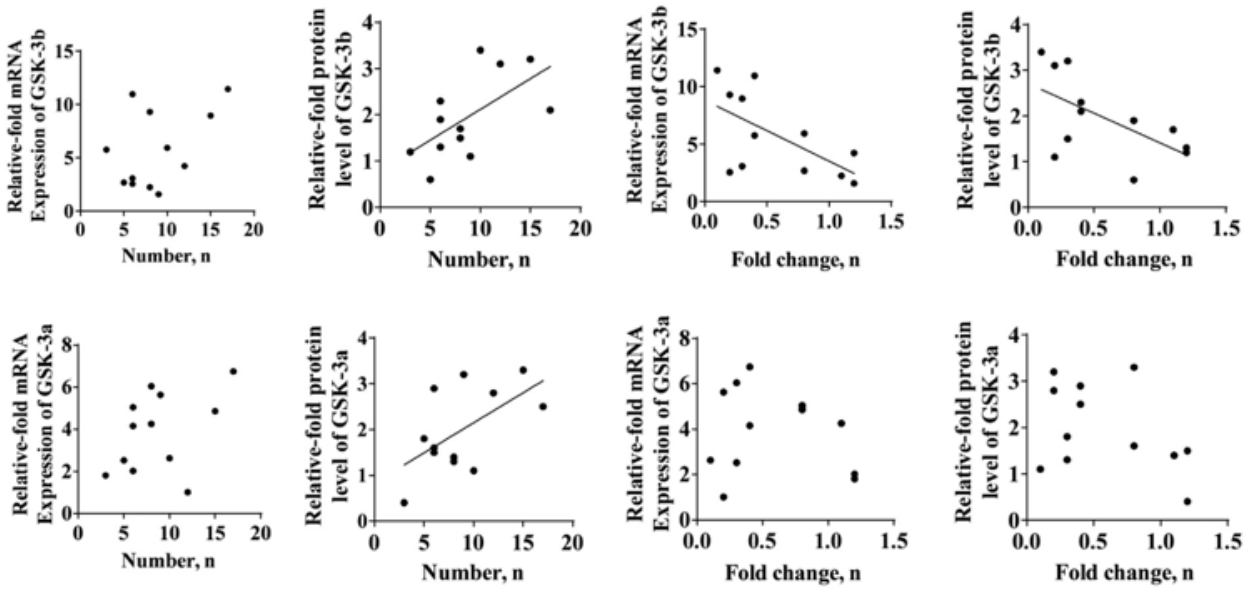

Fig. 6. Correlation analysis of depressive-like behaviours and gene and

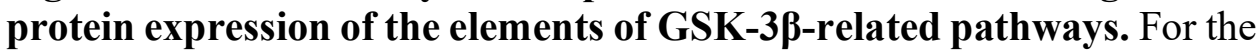
most of cases, significant correlations between mRNA and protein level of GSK-3 $\beta$ but not GSK-3 $\alpha$ were found, and (A) protein level of AktpSer473, behavioural parameters of (B) the forced swim test, (C) resident-intruder test, but not in (D) open field, as well as were found in stressed mice. Grooming behavior in the open field test has significantly correlated with mRNA levels of GSK-3 $\alpha$; there was a trend toward such correlation for 
mRNA GSK-3 $\beta$. Line: $p<.05$, Spearman correlation for linear trend; 12 animals per group were used in all assays.

Number of grooming events has positively correlated with GSK-3 $\beta$ or GSK$3 \alpha$ expression on protein level $(\mathrm{p}=.04, \mathrm{r}=0.58 ; \mathrm{p}=.02, \mathrm{r}=0.63$, respectively, Spearman correlation), but not in gene expression measures $(\mathrm{p}=.17, \mathrm{r}=0.41$, $p=.31, r=0.31$, respectively Fig. $6 C$ ). Finally, we found significant negative correlations between mRNA and protein changes of GSK-3 $\beta$, and AktpSer473 on a protein level $(\mathrm{p}=.03, \mathrm{r}=-0.61, \mathrm{p}=.04, \mathrm{r}=-0.59$, respectively, Fig. 6D). No such correlations were revealed for the expression of GSK $-3 \alpha$ on either gene or protein levels $(p=.66, r=-0.12$, $\mathrm{p}=.47, \mathrm{r}=-0.21$, respectively). No other significant correlations were found $(\mathrm{p}>.05$, Spearman $)$.

\section{Discussion}

The present study demonstrated profound neurobiological changes, characteristic for a depressive syndrome in humans and experimental animals, in mice subjected to the ultrasound stress of alternating frequencies. In addition to previously reported decrease in reward sensitivity, elevated "despair behaviour" during forced swimming, increased aggression, anxiety and behavioural invigoration, mice exposed 
to the ultrasound stress have displayed morphological and molecular signs of deficient hippocampal plasticity, pro-inflammatory and pro-oxidative changes, and dysregulated activities of the GSK-3ß/Akt/FOXO3a pathway.

Our experiments reveal that ultrasound stress decreased the densities of Ki67-positive and DCX-positive cells and expression of neurotrophins, including BDNF and its receptor TrkB in the hippocampus. Together these findings suggest that plasticity and the production of neuronal progenitors during ultrasound stress are decreased. Stressed mice displayed increased plasma levels of TNF $\alpha$ and cytokines IL-1 $\beta$ and IL-6 and of hippocampal expression of IL-1 $\beta$ and IL-6. These proinflammatory changes were accompanied by increased microglia, and of oxidative stress markers 3nitrotyrosine and malondialdehyde, indicating increased oxidative stress in the brain of mice exposed to the ultrasound of unpredictably alternating frequencies. Furthermore, brain expression of beta and alpha isoforms of GSK-3 and the functionally related molecules FOXO3a, PTEN and AktpSer473 were significantly altered in stressed mice, suggesting the involvement of GSK-3 $\beta / \mathrm{Akt} / \mathrm{FOXO} 3 \mathrm{a}$ pathway, in the depressive-like syndrome induced by the ultrasound exposure. 
Extensive literature of the last decade has evidenced the impact of neuroinflammatory processes, in particular, changes in microglial morphology and number and over-expression of pro-inflammatory cytokines, in the development of depressive syndrome in clinical and preclinical situations (Dantzer et al., 2008; Paolicelli et al., 2011; Couch et al., 2013, 2016). Similarly to these results, the current study revealed signs of the activation of resident microglia in the hippocampus of mice exposed to the ultrasound stress. As activated microglia can suppress the production, survival, migration, and recruitment of new neurons (Qin et al., 2002; Ekdahl et al., 2003; Wang et al., 2005; Lazarini et al., 2012; Chen et al., 2012), this mechanism is likely to underlie abovedescribed manifestations of deficient hippocampal neuroplasticity.

Our previous studies with the ultrasound stress model revealed that brain expression of the serotonin transporter and the receptors 5-HT1A and 5HT2A are significantly altered in the stressed animals (Morozova et al., 2016). These components of the serotoninergic system and serotonin itself are known to be involved in neuronal plasticity (Mahar et al., 2014; CarhartHarris and Nutt, 2017) and their expression is also regulated by proinflammatory mediators secreted by microglia (Müller, 2014; Dukhinova et al., 2018). Thus, it seems likely that the hippocampal plasticity changes 
observed here might be underpinned by serotoninergic mechanisms. The normalizing effects of SSRI fluoxetine on the BDNF levels further support this view (Morozova et al., 2016).

Changes in microglial morphology and number may be triggered by local over-production of cytokines by neurons (Bluthe et al., 1994) or/and excessive penetration of inflammatory cytokines from the systemic circulation to the brain (Dantzer et al., 2008). Increased gene and protein expression of not anti-, but pro-inflammatory cytokines, and their elevated plasma concentrations in animals subjected to the ultrasound stress suggest the role of both central and peripheral mechanisms of activation of microglia by cytokines in the present study.

Moreover, resident microglia can be a source of pro-inflammatory cytokines (Lee et al., 1993) and inflammatory prostaglandins (Saliba et al., 2017) that can further aggravate neuroinflammation and its inhibitory effects on the neurogenesis (Wang et al., 2005). Perturbation of microglia has been reported to stimulate an oxidative stress that drives progressive neuronal damage (Qin et al., 2002; Block and Hong, 2007; Mao et al., 2007; Roy et al., 2008). The latter fact is important for the interpretation of the outcomes from our study in light of our findings that the concentration of 
markers of oxidative stress - malondialdehyde and 3-NT - are increased in the hippocampus of stressed mice. Thus the increase in microglial number and the pro-inflammatory changes in the hippocampus suggest that microglia may be responsible for the increase in oxidative stress induced by the ultrasound stress paradigm. Microglia may also affect neuronal function by directly altering synaptic transmission by the release of mediators (chemokines for example) or, indirectly, by contributing to a physical remodeling process. With regard to the modulation of neuronal activity by an altered microglial phenotype, an intimate relationship between astrocytes, neurons, and microglial processes has been described (Tremblay et al., 2012). However, electron microscopy studies have also shown that only a small percentage of synapses receive direct contact by a microglial process (Sogn et al., 2013). In relation to the structural changes, microglia can actively remove live and dying neurons from the brain as part of a "phagoptosis" process (Brown and Neher, 2012). A smaller hippocampal CA1 in post-traumatic stress disorder, consistent with model systems in rodents that exhibit increased anxiety-like behaviour that occurs after repeated exposure to stress (Chen et al., 2018). While we did not measure hippocampal volume in our studies, we might speculate that the increased numbers of Iba-1-positive microglia may reflect an increase in phagoptosis 
within the hippocampus that could lead to adaptive structural changes. Ongoing work in our laboratory is seeking to discover how long-lived are the stress induced changes.

In addition to phagocytosis and the clearance of cellular fragments (Hosmane et al., 2012; Schafer et al., 2012), microglia may also be involved in synaptic stripping in neurodegenerative conditions (Perry and O'Connor, 2010). For example, the role of microglia in the active elimination of extranumerary synapses was proposed many years ago in the context of the developing retinogeniculate system, where a complement-dependent remodeling process leads to eye-specific segregation (Stevens et al., 2007). However, in the early phase of prion disease, the loss of synapses is not associated with microglia processes, and thus it cannot be assumed that the presence of microglia with a more rounded appearance means that they are playing an active role in a remodeling process. However, following stress, we and others have noted that there is an increase in the number of microglia and a change in their morphology in key brain regions associated with mood. While altered Iba-1 staining in these circumstances is often associated with regional increases in cytokine expression, it still remains unclear how microglia might be contributing to stress-induced structural remodelling of the hippocampus or the modulation of neuronal activity. We 
found that ultrasound stress altered hippocampal mRNA gene and protein expression of GSK-3 $\beta$, a marker of distress and depression (Beurel et al., 2015), as well as the associated molecules FOXO3a, PTEN and AktpSer473. GSK-3 $\beta$ is known as a key regulator of cell apoptosis, metabolism, and plasticity and its up-regulation accompanies the development of depressive-like syndrome in a clinical and in animal models (Kaidanovich-Beilin and Woodgett, 2011; Markova et al., 2016; Strekalova et al., 2016). In this context described here, over-expression of GSK-3 $\alpha$, FOXO3a, and PTEN in the hippocampus of stressed animals is well known to be functionally synergistic to over-production of GSK-3 $\beta$. Heightened activities of these molecules can result in cell death and associated with maladaptive stress responses (Polter et al., 2009; Fey et al., 2012; Cline et al., 2015b; Pomytkin et al., 2015; Pavlov et al., 2017). Increased activity of GSK-3 $\beta$ activates PTEN and FOXO3a, consequently resulting in activation of mechanisms of apoptosis, while AktpSer473, whose hippocampal expression was decreased in mice subjected to the ultrasound stress, is a molecule with anti-apoptotic functions (Wu et al., 2009; Fey et al., 2012); its production is known to be suppressed by the above-mentioned factors (Chang et al., 2003; Huang et al., 2013). Thus, changes in expression of the GSK-3 $\beta /$ Akt/FOXO3a cascade suggest the activation of pro-apoptotic and 
pro-inflammatory mechanisms which are consistent with effects of stress reported here, including impairments in hippocampal plasticity.

In a similar manner to other established depression paradigms in mice, exposure to the ultrasound stress in the current study resulted in the overexpression of hippocampal GSK-3 $\beta$ (Gould et al., 2006; Garza et al., 2012; Cline et al., 2015b; Strekalova et al., 2016; Pavlov et al., 2017). Moreover, these increases positively correlated with the measures of behavioural despair and aggression, but not with grooming behaviour in the open field. While the upregulation of GSK-3 $\beta$ activities in stressed animals was accompanied by similar over-expression of hippocampal GSK-3 $\alpha$, no correlation between the latter and behavioural changes were found with the exception of grooming, a sign of behavioural invigoration (Willner and Belzung, 2015), and suggests that there are differences in the functional and dynamic characteristics of two GSK-3 isoforms (Liang and Chuang, 2007; Beurel et al., 2015; Pavlov et al., 2017).

Additional studies employing the ultrasound stress model have demonstrated molecular and biochemical changes in other brain areas of the limbic system, which were similar to the changes reported here within the hippocampal formation. Such a result was not unexpected, given that 
emotional stress activates the hypothalamus-pituitaryadrenal stress system, which receives inputs from a number of limbic structures, such as amygdala and the prefrontal cortex (Tsigos and Chrousos, 2002; Mehta et al., 2018). As in the hippocampus, the prefrontal cortex of mice exposed to the ultrasound was found to exhibit downregulated BDNF, TrkB, and other plasticity factors. Furthermore, there was over-production of proinflammatory cytokines IL-1 $\beta$ and IL6, and signs of oxidative stress (Morozova et al., 2016; Gorlova et al., 2018, 2019). These mice showed an increase of protein carbonyl content, a decrease of levels of glutathione and mitogen-activated protein kinase phosphatase (MKP1); systemic prooxidative changes in the brain were further suggested by the recent findings of the elevated total glutathione levels in the amygdala, striatum and raphe dorsalis (o be corrected: Gorlova et al., 2018, 2019). Given distinct functional roles of dorsal versus ventral hippocampus in the regulation of memory processes and mood / stress responses (Maras et al., 2014; Bagot et al., 2015, Calabrese et al., 2015), it would be of interest to explore other anatomical differences at a more detailed level now that we have established that ultrasound stress can induce such profound changes.

Elevated protein levels of GSK-3 $\beta$ and PTEN, coupled with decreased concentrations of Akt in the prefrontal cortex in these animals suggest that 
ultrasound stress induces more widespread changes throughout the brain (Gorlova et al., 2018, 2019). The present study with ultrasound stress provides further validation for the use of this model for translational research on stress and depression. There has been a general move toward the use of experimental approaches in mice that employ a naturalistic element. For example the exposure of rodents to altered maternal care (Rice et al., 2008; Baram et al., 2012), social confrontation and defeat, social isolation, social fear conditioning, chronic subordinate colony housing, conditions of social instability (Buwalda et al., 2005; Nestler and Hyman, 2010; Chaouloff, 2013; Toth and Neumann, 2013), and housing in the deficient cage environment (Baram et al., 2012) have all been employed. While naturalistic stress depression models appear to have more validity in modeling depressive disorder (Pollak et al., 2010; Iraci et al., 2016), numerous limitations exist that limiting their practical application and include a lack of reliability in the induction of the depressive phenotype, and high sensitivity to subtle alterations in the environmental conditions (van Hasselt et al., 2012; Bouwknecht, 2015; Willner and Belzung, 2015). These limitations can explain, at least in part, why the use of artificial physical stressors to give more controllable and predictable outcomes is an attractive alternative (Strekalova and Steinbusch, 2010, Strekalova et al., 
2011; Overstreet, 2012; Willner and Belzung 2015; Willner et al., 2018).

No systematic comparisons of the behavioural and neurobiological outcomes of naturalistic or physical stress paradigms has been undertaken. However, the current literature suggests that both types of models evoke overall similar degrees of the neurobiological changes in animals, including the pro-inflammatory changes, impairment of the hippocampal morphological and functional plasticity, as well as increases in the oxidative

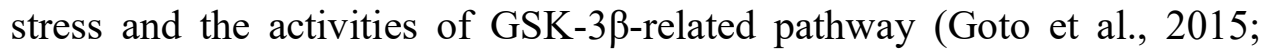
Bakunina et al., 2015; Bian et al., 2015; Anacker and Hen, 2017; Lisboa et al., 2018). Many results suggest that the use of established chronic stress models can be more reliable than naturalistic paradigms to induce anhedonic behaviour, but the use of social avoidance stress, maternal separation, and other naturalistic stress paradigms seem better able to evoke helpless behaviour and alter social interactions in the experimental animals. In this context, and taking into account the present results, we believe that the ultrasound stress employed here can offer a useful compromise between the two types of stress models by combining etiological relevance with improved reliability and reproducibility of the physical stress paradigms.

\section{Conclusion}


In summary, the ultrasound stress model with alternating frequencies that mimic the features of emotional stress in humans is able to induce the typical behavioural and neurobiological hallmarks of the depressive state, including deficient hippocampal plasticity, neuroinflammation, oxidative stress and altered activity of the GSK-3 $\beta /$ Akt/FOXO3a cascade. These inter-connected processes result in aberrant hippocampus activity and the activity of other limbic structures, including prefrontal cortex and amygdala resulting in the behavioural, vegetative and hormonal features of depressive disorder (Tsigos and Chrousos, 2002; Buwalda et al., 2005; Mahar et al., 2014; Chesnokova et al., 2016; Anacker and Hen, 2017). Accumulating clinical evidence suggests that repeated exposure to psychological stress in humans profoundly impacts peripheral immune responses and perturbs the function of brain microglia, increases levels of circulating proinflammatory cytokines, which can together contribute to the neurobiological changes underlying depressive symptoms (Wohleb et al., 2016; Miller and Raison, 2016).

The data reported here are consistent with these and other clinical findings suggesting cross-talk between GSK-3 $\beta / \mathrm{Akt} / \mathrm{FOXO} 3 \mathrm{a}$ as a hub of the stress response, the neuroimmune system and neuroplasticity mechanisms during 
depression (Pomytkin et al., 2015; Jope et al., 2017). Anti-neuroplastic changes which occur in depressed patients include a decrease in proliferation of neural stem cells, decreased survival of neuroblasts and immature neurons, reduced levels of neurotrophins and spine density, as well as increases of IL-1, IL-6, TNF- $\alpha, \mathrm{CD} 4+\mathrm{CD} 25+\mathrm{T}$ regulatory cells, monocyte-derived macrophages and altered behavior of microglia (Eyre and Baune, 2012). Together, the present study highlights the utility and relevance of using ultrasound radiation to study the molecular basis of clinical depression.

\section{Conflict of interest}

The authors declare that there is no conflict of interest.

\section{Acknowledgements}

This work was supported by Erasmus foundation (E+2016-KA107- SM to

DP and LB), Helix Laboratory Services (to AO) the European Union's Seventh Framework Programme under Grant No. 602805 (Aggressotype), the Horizon 2020 Research and Innovation Programme under Grant No. 728018 (Eat2beNICE), Research Grant Council- General Research Fund grant, reference no. 14113316 (Hong Kong Government, Hong Kong), a Research Grant Council - Areas of Excellence Fund grant (Hong Kong 
Government, Hong Kong), reference no. AoE/M-604/16 (to EDP) and "5100” Russian Research Excellence program (to TS and KPL). The funding bodies had no influence on the study design, the collection, analysis and the interpretation of data, the writing of the report and in the decision to submit the article for publication. LB is Research Director of the F.R.S.-FNRS (Belgium). We would like to acknowledge valuable contribution of Dr. Elizaveta Muravieva (Rochester University, USA) and Arina Kazakova (Mount Holyoke College, USA) in this paper.

\section{Supplementary data}

Supplementary data to this article can be found online at https://

doi.org/10.1016/j.pnp.2018.11.014.

\section{References}

Anacker C, Hen R, 2017. Adult hippocampal neurogenesis and cognitive flexibility - linking memory and mood. Nat Rev Neurosci; 18(6), 335-346. https://doi.org/10.1038/nrn.2017.45. 
Bakunina N, Pariante CM, Zunszain PA, 2015. Immune mechanisms linked to depression via oxidative stress and neuroprogression. Immunology144(3), 365-373. https://doi.org/10.1111/imm.12443.

Bao AM, Meynen G, Swaab DF, 2008. The stress system in depression and neurodegeneration: focus on the human hypothalamus. Brain Res Rev. 57, 531-553. https://doi.org/10.1016/j.brainresrev.2007.04.005.

Baram TZ, Davis EP, Obenaus A, Sandman CA, Small SL, Solodkih A, Stern H, 2012. Fragmentation and unpredictability of early-life experience in mental disorders. Am. J. Psychiatry.169(9) , 907-915. https://dx.doi.org/10.1176\%2Fappi.ajp.2012.11091347.

Belarbi K, Jopson T, Arellano C, Fike JR, Rosi S, 2013. CCR2 deficiency prevents neuronal dysfunction and cognitive impairments induced by cranial irradiation. Cancer Res.73(3) , 1201-1210. https://doi.org/10.1158/0008-5472.CAN-12-2989.

Beurel E, Grieco SF, Jope RS, 2015. Glycogen synthase kinase-3 (GSK3): regulation, actions, and diseases. Pharmacol. Ther.;148, 114-131. https://doi.org/10.1016/j.pharmthera.2014.11.016. 
Bian Y, Yang L, Wang Z, Wang Q, Zeng L, Xu G, 2015. Repeated threehour maternal separation induces depression-like behavior and affects the expression of hippocampal plasticity-related proteins in C57BL/6N mice. Neural Plast. http://dx.doi.org/10.1155/2015/627837.

Block ML, Hong JS, 2007. Chronic microglial activation and progressive dopaminergic neurotoxicity. Biochem Soc Trans.35, 1127-1132. https://doi.org/10.1042/BST0351127.

Bluthe RM, Walter V, Parnet P, Laye S, Lestage J, Verrier D, 1994. Lipopolysaccharide induces sickness behaviour in rats by a vagal mediated mechanism. C R Acad Sci III.317, 499-503. Brudzynski S.M. and N.H. Fletcher, 2010. Rat ultrasonic vocalization: Short-range communication. Handbook of Behavioral Neuroscience.19, 6976. https://doi.org/10.1016/B978-0-12-374593-4.00008-5.

Bouwknecht JA, 2015. Behavioral studies on anxiety and depression in a drug discovery environment: keys to a successful future. Eur $\mathrm{J}$ Pharnacol.;15(753), 158-176. https://doi.org/10.1016/j.ejphar.2014.09.051.

Buwalda B, Kole MH, Veenema AH, Huininga M, de Boer SF, Korte SM, Koolhaas JM, 2005. Long-term effects of social stress on brain and 
behavior: a focus on hippocampal functioning. Neurosci. Biobehav. Rev.29(1), 83-97. https://doi.org/10.1016/j.neubiorev.2004.05.005.

Chang F, Lee JT, Navolanic PM, Steelman LS, Shelton JG, Blalock WL, Franklin RA, McCubrey JA, 2003. Involvement of PI3K/Akt pathway in cell cycle progression, apoptosis, and neoplastic transformation: a target for cancer chemotherapy. Leukemia. 17(3), 590-603. https://doi.org/10.1038/sj.leu.2402824.

Chaouloff F, 2013. Social stress models in depression research: what do they tell us? Cell Tissue Res. 354(1), 179-190. https://doi.org/10.1007/s00441-013-1606-x.

Chen Z, Jalabi W, Shpargel KB, Farabaugh KT, Dutta R, Yin X, 2012. Lipopolysaccharide-induced microglial activation and neuroprotection against experimental brain injury is independent of hematogenous TLR4. J Neurosci. 32, 11706-11715. https://doi.org/10.1523/JNEUROSCI.073012.2012.

Chesnokova V, Pechnick RN, Wawrowsky K, 2016. Chronic peripheral inflammation, hippocampal neurogenesis, and behavior. Brain, Behavior, and Immunity. 58, 1-8. https://doi.org/10.1016/j.bbi.2016.01.017. 
Chrousos GP, Gold PW, 1992. The concepts of stress and stress system disorders. Overview of physical and behavioral homeostasis. J.Am. Med. Assoc. 267(9), 1244-1252.

Cline BH, Anthony DC, Lysko A, Dolgov O, Anokhin K, Schroeter C, Malin D, Kubatiev A, Steinbusch HW, Lesch KP, Strekalova T, 2015. Lasting downregulation of the lipid peroxidation enzymes in the prefrontal cortex of mice susceptible to stress-induced anhedonia. Behav Brain Res.276, 118-129 (a). https://doi.org/10.1016/j.bbr.2014.04.037.

Cline BH, Costa-Nunes JP, Cespuglio R, Markova N, Santos AI, Bukhman YV, Kubatiev A, Steinbusch HW, Lesch KP, Strekalova T, 2015. Dicholine succinate, the neuronal insulin sensitizer, normalizes behavior, REM sleep, hippocampal pGSK3 beta and mRNAs of NMDA receptor subunits in mouse models of depression. Front Behav Neurosci.26, 9-37 (b). https://doi.org/10.3389/fnbeh.2015.00037.

Colle R, Deflesselle E, Martin S, David DJ, Hardy P, Taranu A, Falissard B, Verstuyft C, Corruble E, 2015. BDNF/TRKB/P75NTR polymorphisms and their consequences on antidepressant efficacy in depressed patients. Pharmacogenomics. 16(9), 997-1013. https://doi.org/10.2217/pgs.15.56. 
Constantini F, D'Amato F, 2006. Ultrasonic vocalization in mice and rats: social contexts and functions. Acta Zool. Sin.52, 619-633.

Couch Y, Trofimov A, Markova N, Nikolenko V, Steinbusch HW, Chekhonin V, Schroeter C, Lesch KP, 2016. Low-dose lipopolysaccharide (LPS) inhibits aggressive and augments depressive behaviours in a chronic mild stress model in mice. $\mathrm{J}$ Neuroinflammation.13(1), 1-8. https://doi.org/10.1186/s12974-016-0572-0.

Couch Y, Anthony DC, Dolgov O, Revischin A, Festoff B, Santos AI, Steinbusch HW, Strekalova T, 2013. Microglial activation, increased TNF and SERT expression in the prefrontal cortex define stress-altered behaviour in mice susceptible to anhedonia. Brain Behav. Immun.29, 136146. https://doi.org/10.1016/j.bbi.2012.12.017.

Dantzer R, O’Connor JC, Freund GG, Johnson RW, Kelley KW, 2008. From inflammation to sickness and depression: when the immune system subjugates the brain. Nat Rev Neurosci.9, 46-56. https://dx.doi.org/10.1038\%2Fnrn2297.

Duman RS, 2004. Role of neurotrophic factors in the etiology and treatment of mood disorders. Neuromolecular Med.5(1), 11-25. 
Ekdahl CT, Claasen JH, Bonde S, Kokaia Z, Lindvall O, 2003. Inflammation is detrimental for neurogenesis in adult brain. Proc Natl Acad Sci U S A. 100, 13632-13637. https://doi.org/10.1073/pnas.2234031100.

Fey D, Croucher DR, Kolch W, Kholodenko BN, 2012. Crosstalk and signaling switches in mitogen-activated protein kinase cascades. Front Physiol.3, 1-21. https://doi.org/10.3389/fphys.2012.00355.

Fontes MA, Xavier CH, Marins FR, Limborço-Filho M, Vaz GC, MüllerRibeiro FC, Nalivaiko E, 2014. Emotional stress and sympathetic activity: Contribution of dorsomedial hypothalamus to cardiac arrhythmias. Brain Research. 1554, 49-58. https://doi.org/10.1016/j.brainres.2014.01.043.

Franklin B, Paxinos G, 1997. The mouse brain atlas in stereotaxic coordinates. Academic Press, San-Diego.

Fukunaga K, Moriguchi S, 2017. Stimulation of the Sigma-1 Receptor and the Effects on Neurogenesis and Depressive Behaviors in Mice. Adv Exp Med Biol. 964, 201-211. https://doi.org/10.1007/978-3-319-50174-1_14.

Garza JC, Guo M, Zhang W, Lu XY, 2012. Leptin restores adult hippocampal neurogenesis in a chronic unpredictable stress model of depression and reverses glucocorticoid-induced inhibition of GSK-3 $\beta / \beta$ - 
$\begin{array}{llll}\text { catenin } & \text { signaling. } & \text { Mol } & \text { Psychiatry. }\end{array}$ https://doi.org/10.1038/mp.2011.161.

Goto T, Kubota Y, Toyoda A, 2015. Plasma and liver metabolic profiles in mice subjected to subchronic and mild social defeat stress. J Proteome Res. 14(2), 1025-1032. https://doi.org/10.1021/pr501044k.

Gould TD, Picchini AM, Einat H, Manji HK, 2006. Targeting glycogen synthase kinase-3 in the CNS: implications for the development of new treatments for mood disorders. Curr Drug Targets.7(11), 1399-409.

Huang W, Zhao Y, Zhu X, Cai Z, Wang S, Yao S, Qi Z, Xie P, 2013. Fluoxetine Upregulates Phosphorylated-AKT and Phosphorylated-ERK1/2 Proteins in Neural Stem Cells: Evidence for a Crosstalk between AKT and ERK1/2 Pathways. J Mol Neurosci. 49(2), 244-249. https://doi.org/10.1007/s12031-012-9822-5.

Iraci N, Leonardi T, Gessler F, Vega B, Pluchino S, 2016. Focus on Extracellular Vesicles: Physiological Role and Signalling Properties of Extracellular Membrane Vesicles. Int J Mol Sci.17(2), 171-177. https://doi.org/10.3390/ijms17020171. 
Kaidanovich-Beilin O, Woodgett JR., 2011. GSK-3: Functional Insights from Cell Biology and Animal Models. Front Mol Neurosci.4, 40-49. https://doi.org/10.3389/fnmol.2011.00040.

Kessler RC, Sampson NA, Berglund P, Gruber MJ, Al-Hamzawi A, Andrade L, Bunting B, Demyttenaere K, Florescu S, de Girolamo G, Gureje O, He Y, Hu C, Huang Y, Karam E, Kovess-Masfety V, Lee S, Levinson D, Medina Mora ME, Moskalewicz J, Nakamura Y, Navarro-Mateu F, Browne MA, Piazza M, Posada-Villa J, Slade T, Ten Have M, Torres Y, Vilagut G, Xavier M, Zarkov Z, Shahly V, Wilcox MA, 2015. Anxious and non-anxious major depressive disorder in the World Health Organization World Mental Health Surveys. Epidemiol Psychiatr Sci.24(3), 210-226. https://doi.org/10.1017/S2045796015000189.

de Kloet ER, Joels M, Holsboer F, 2005. Stress and the brain: from adaptation to disease. Nat. Rev. Neurosci. 6, 463475. https://doi.org/10.1038/nrn1683.

Kuraoka K, Nakamura K, 2010. Vocalization as a specific trigger of emotional responses. Handbook of mammalian vocalization. 167-177.

Lazarini F, Gabellec MM, Torquet N, Lledo PM, 2012. Early activation of microglia triggers long-lasting impairment of adult neurogenesis in the 
$\begin{array}{llll}\text { olfactory } & \text { bulb. } & \mathrm{J} & \text { Neurosci.32, }\end{array}$ https://doi.org/10.1523/JNEUROSCI.6394-11.2012.

Lee SC, Liu W, Dickson DW, Brosnan CF, Berman JW, 1993. Cytokine production by human fetal microglia and astrocytes. Differential induction by lipopolysaccharide and IL-1 beta. J Immunol.150, 2659-2667.

Leonard B, Maes M, 2012. Mechanistic explanations how cell-mediated immune activation, inflammation and oxidative and nitrosative stress pathways and their sequels and concomitants play a role in the pathophysiology of unipolar depression. Neuroscience \& Biobehavioral Reviews. 36(2), 764-785. https://doi.org/10.1016/j.neubiorev.2011.12.005.

Lesch KP, 2004. Gene-environment interaction and the genetics of depression. Journal of Psychiatry \& Neuroscience.29(3), 174-184.

Lisboa SF, Niraula A, Resstel LB, Guimaraes FS, Godbout JP, Sheridan JF, 2018. Repeated social defeat-induced neuroinflammation, anxiety-like behavior and resistance to fear extinction were attenuated by the cannabinoid receptor agonist WIN55,212-2. Neuropsychopharmacology. https://doi.org/10.1038/s41386-018-0064-2. 
Malatynska E, Steinbusch HW, Redkozubova O, Bolkunov A, Kubatiev A, Yeritsyan NB, Vignisse J, Bachurin S, Strekalova T, 2012. Anhedonic-like traits and lack of affective deficits in 18-month-old C57BL/6 mice: implications for modeling elderly depression. Exp. Gerontol.47(8), 552564. https://doi.org/10.1016/j.exger.2012.04.010.

Maes M, Fišar Z, Medina M, Scapagnini G, Nowak G, Berk M, 2012. New drug targets in depression: Inflammatory, cell-mediated immune, oxidative and nitrosative stress, mitochondrial, antioxidant, and neuroprogressive pathways. And new drug candidates-Nrf2 activators and GSK-3 inhibitors. Inflammopharmacology.20(3), 127-150. https://doi.org/10.1007/s10787-011-0111-7.

Malykhin NV, Coupland NJ, 2015. Hippocampal neuroplasticity in major depressive disorder. 200-213. https://doi.org/10.1016/j.neuroscience.2015.04.047.

Markova N, Bazhenova N, Anthony DC, Vignisse J, Svistunov A, Lesch KP, Bettendorff L, Strekalova T, 2016. Thiamine and benfotiamine improve cognition and ameliorate GSK-3 $\beta$ - associated stress-induced behaviours in mice. Prog Neuro-Psychopharmacol Biol Psychiatry.75, 148-156. https://doi.org/10.1016/j.pnpbp.2016.11.001. 
Malloul H, Bennis M, Bonzano S, Gambarotta G, Perroteau I, De Marchis S, Ba-M'hamed S, 2018. Decreased Hippocampal Neuroplasticity and Behavioral Impairment in an Animal Model of Inhalant Abuse. Front Neurosci.6, 12-35. https://doi.org/10.3389/fnins.2018.00035.

Mao H, Fang X, Floyd KM, Polcz JE, Zhang P, Liu B, 2007. Induction of microglial reactive oxygen species production by the organochlorinated pesticide dieldrin. Brain Res.1186, 267-74. https://doi.org/10.1016/j.brainres.2007.10.020.

Masi G, Brovedani P, 2011. The hippocampus, neurotrophic factors and depression: possible implications for the pharmacotherapy of depression. CNS Drugs. 25(11), 913-931. https://doi.org/10.2165/11595900000000000-00000.

McEwen BS, Stellar E, 1993. Stress and the individual. Mechanisms leading to disease. Arch. Intern. Med.153, 2093-2101.

Morozova A, Zubkov E, Strekalova T, Kekelidze Z, Storozeva Z, Schroeter CA, Bazhenova N, Lesch KP, Cline BH, Chekhonin V, 2016. Ultrasound of alternating frequencies and variable emotional impact evokes depressive syndrome in mice and rats. Prog Neuro-Psychopharmacol Biol Psychiatry.68, 52-63. https://doi.org/10.1016/j.pnpbp.2016.03.003. 
Nestler EJ, Hyman SE, 2010. Animal models of neuropsychiatric disorders. Nat. Neurosci.13, 1161-1169. https://doi.org/10.1038/nn.2647.

Oglodek EA, Just MJ, Szromek AR, Araszkiewicz A, 2016. Melatonin and neurotrophins NT-3, BDNF, NGF in patients with varying levels of depression severity. Pharmacological Rep.68(5), 945-951. https://doi.org/10.1016/j.pharep.2016.04.003.

Okabe S, Nagasawa M, Kihara T, Kato M, Harada T, Koshida N, Mogi K, Kikusui T, 2010. The effects of social experience and gonadal hormones on retrieving behavior of mice and the responses to pup ultrasonic $\begin{array}{llll}\text { vocalizations. } & \text { Zool. } & \text { Sci. } & \text { 27(10), }\end{array}$ https://doi.org/10.2108/zsj.27.790.

Overstreet DH, 2012. Modeling depression in animal models. Methods Mol. Biol.829, 125-144. https://doi.org/10.1007/978-1-61779-458-2_7.

Panksepp JB, Jochman KA, Kim JU, Koy JJ, Wilson ED, Chen Q, 2007. Affiliative behavior, ultrasonic communication and social reward are influenced by genetic variation in adolescent mice. PLoS One. 2(4), e351 doi: 10.1371/journal.pone.0000351. 
Paolicelli RC, Bolasco G, Pagani F, Maggi L, Scianni M, Panzanelli P, Giustetto M, Ferreira TA, Guiducci E, Dumas L, Ragozzino D, Gross CT, 2011. Synaptic pruning by microglia is necessary for normal brain development. Science.333(6048), $1456-1458$. https://doi.org/10.1126/science.1202529.

Pavlov D, Markova N, Bettendorff L, Chekhonin V, Pomytkin I, Lioudyno V, Svistunov A, Ponomarev E, Lesch KP, Strekalova T, 2017. Elucidating the functions of brain GSK3 $\alpha$ : Possible synergy with GSK3 $\beta$ upregulation and reversal by antidepressant treatment in a mouse model of depressivelike behaviour. Behav Brain Res. 335, 122-127. https://doi.org/10.1016/j.bbr.2017.08.018.

Pollak, DD, Rey CE, Monje FJ, 2010. Rodent models in depression research: classical strategies and new directions. Ann. Med.42(4), 252-264. https://doi.org/10.3109/07853891003769957.

Polter A, Yang S, Zmijewska AA, van Groen T, Paik JH, Depinho RA, 2009. Forkhead box, class O transcription factors in brain: regulation and behavioral manifestation. Biol Psychiatry.65(2), 150-159. https://doi.org/10.1016/j.biopsych.2008.08.005. 
Pomytkin IA, Cline BH, Anthony DC, Steinbusch HW, Lesch KP, Strekalova T, 2015. Endotoxaemia resulting from decreased serotonin transporter (5-HTT) function: a reciprocal risk factor for depression and insulin resistance? Behav Brain Res. 276, 111-117. https://doi.org/10.1016/j.bbr.2014.04.049.

Rice CJ, Sandman CA, Lenjavi MR, Baram TZ, 2008. A novel mouse model for acute and long-lasting consequences of early life stress. Endocrinology. 149(10), 4892-4900. https://doi.org/10.1210/en.20080633.

Roy A, Jana A, Yatish K, Freidt M, Fung Y, Martinson J, Pahan K, 2008. Reactive oxygen species upregulate $\mathrm{CD} 11 \mathrm{~b}$ in microglia via nitric oxide: Implications for neurodegenerative diseases. Free Radic Biol Med. 45, 686699. https://dx.doi.org/10.1016\%2Fj.freeradbiomed.2008.05.026.

Saliba SW, Marcotegui AR, Fortwängler E, Ditrich J, Perazzo JC, Muñoz E, de Oliveira ACP, Fiebich BL, 2017. AM404, paracetamol metabolite, prevents prostaglandin synthesis in activated microglia by inhibiting COX $\begin{array}{llll}\text { activity. } & \mathrm{J} & \text { Neuroinflammation. } & \text { 246-254 }\end{array}$ https://doi.org/10.1186/s12974-017-1014-3. 
Selye H, 1974. Stress Without Distress. J.B. Lippincott Company, Philadelphia, p.171.

Roy M, Tapadia MG, Joshi S, Koch B, 2014. Molecular and genetic basis of depression. J. Genet.93(3), 879-892.

Simonov PV, 1997. Brain mechanisms of emotions. Neurosci. Behav. Physiol.27(4), 405-413.

Strekalova T, Spanagel R, Bartsch D, Henn F, Gass P, 2004. Stress-induced anhedonia in mice is associated with deficits in forced swimming and exploration. Neuropsychopharmacology.29, 2007-2017. https://doi.org/10.1038/sj.npp.1300532.

Strekalova T, Evans M, Chernopiatko A, Couch Y, Costa-Nunes J, Cespuglio R, Chesson L, Vignisse J, Steinbusch HW, Anthony DC, Pomytkin I, Lesch KP, 2015. Deuterium content of water increases depression susceptibility: the potential role of a serotonin-related mechanism. Behav Brain Res. 277:237-44. doi: 10.1016/j.bbr.2014.07.039. Epub 2014. 
Strekalova T and Steinbusch H, 2010. Measuring behavior with chronic stress depression model in mice. Progr Neuro-Psychopharm Biol Psych. 34, 348-361. https://doi.org/10.1016/j.pnpbp.2009.12.014.

Strekalova T, Bahzenova N, Trofimov A, Schmitt-Böhrer AG, Markova N, Grigoriev V, Zamoyski V, Serkova T, Redkozubova O, Vinogradova D, Umriukhin A, Fisenko V, Lillesaar C, Shevtsova E, Sokolov V, Aksinenko A, Lesch KP, Bachurin S, 2018. Pro-neurogenic, Memory-Enhancing and Anti-stress Effects of DF302, a Novel Fluorine Gamma-Carboline Derivative with Multi-target Mechanism of Action. Mol Neurobiol. 55(1), 335-349. https://doi.org/10.1007/s12035-017-0745-6.

Strekalova T, Markova N, Shevtsova E, Zubareva O, Bakhmet A, Steinbusch HM, Bachurin S, Lesch KP, 2016. Individual Differences in Behavioural Despair Predict Brain GSK-3beta Expression in Mice: The Power of a Modified Swim Test. Neural Plast.ID 5098591. http://dx.doi.org/10.1155/2016/5098591.

Strekalova T, Couch Y, Kholod N, Boyks M, Malin D, Leprince P, Steinbusch HM, 2011. Update in the methodology of the chronic stress paradigm: internal control matters. Behav Brain Funct. 7. https://doi.org/10.1186/1744-9081-7-9. 
Qin L, Liu Y, Cooper C, Liu B, Wilson B, Hong JS, 2002. Microglia enhance beta-amyloid peptide-induced toxicity in cortical and mesencephalic neurons by producing reactive oxygen species. J Neurochem.83, 973-983. $\quad$ https://doi.org/10.1046/j.14714159.2002.01210.x.

Wang T, Pei Z, Zhang W, Liu B, Langenbach R, Lee C, Wilson B, Reece JM, Miller DS, Hong JS, 2005. MPP-induced COX-2 activation and subsequent dopaminergic neurodegeneration. Faseb J .19, 1134-1136. https://doi.org/10.1096/fj.04-2457fje.

Xie T, Stathopoulou MG, Andres F, Siest G, Murray H, Martin M, Cobaleda J, Delgado J, Lamont J, Penas-Lledo E, LLerena A, Visvikis-Siest S, 2017. VEGF-related polymorphisms identified by GWAS and risk for major depression. Transl Psychiatry.7:e1055. https://doi.org/10.1038/tp.2017.36. 


\section{SUPPLEMENTARY MATERIAL}

\section{Ultrasound exposure}

A study of a dose-response effect, the threshold and duration of sound intensity of ultrasound stimulation on mouse emotional behaviour

To define for the dose-response effect and the threshold sound intensity of ultrasound stimulation at the frequencies of $20-45 \mathrm{kHz}$ on animals' emotional behaviour, in a separate preliminary study, Balb/c mice were exposed to a 24-h ultrasound of about $50 \mathrm{~dB}$ or $90 \mathrm{~dB}$, their emotional behaviours were scored in a battery of tests during the first 15 min of this period. In another experiment, BALB/c mice were subjected to the same housing and experimental conditions as is described in the main text ultrasound stress study, except the ultrasound exposure lasted also 1 week or 2 weeks. On the next day, emotional and social behaviours of control and stressed mice was investigated. Six-eight mice per group were used in these studies. 
$\mathbf{A}$

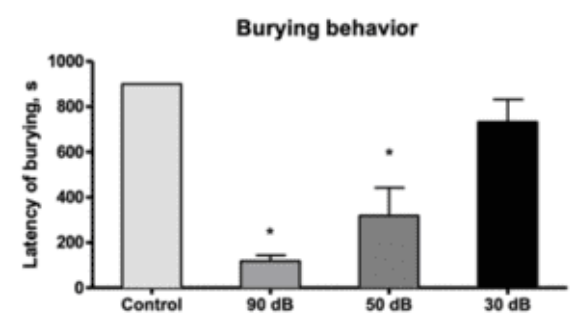

C

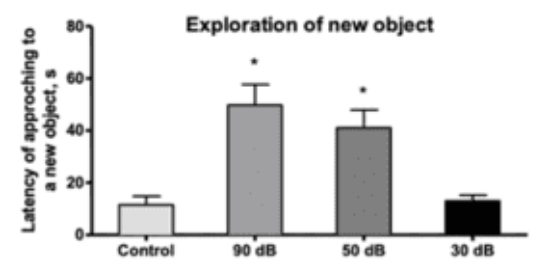

B

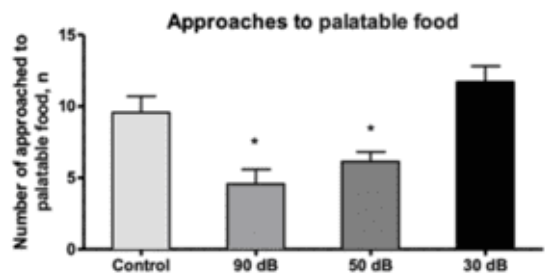

Figure 1. Ultrasound of $50 \mathrm{~dB}$ or $90 \mathrm{~dB}$, but not $30 \mathrm{~dB}$ produces immediate behavioral effects in BALBc mice. Mice exposed to ultrasound of variable frequency $20-45 \mathrm{~Hz}$ and intensity of $50 \mathrm{~dB}$ or $90 \mathrm{~dB}$, but not $30 \mathrm{~dB}$ display (A) significantly reduced latency of burying behavior, (B) significantly decreased number of approached to palatable food (C), significantly elevated latency of approaching to a new object, in comparison to non-stressed control mice. Mice exposed to a sound of the highest loudness tended to display greater changes $\left({ }^{*} p<0.05\right.$ vs. control group, one-way ANOVA and post-hoc Tukey test). Bars are means \pm SEMs. 
A

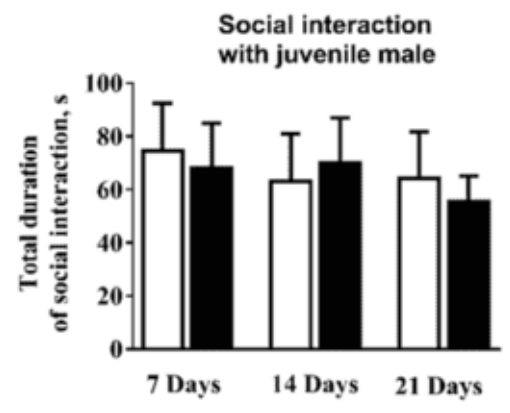

C

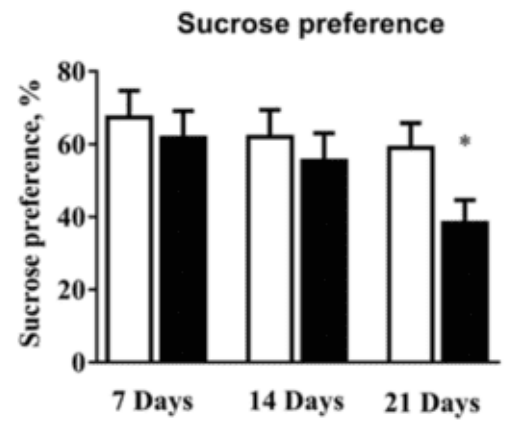

B

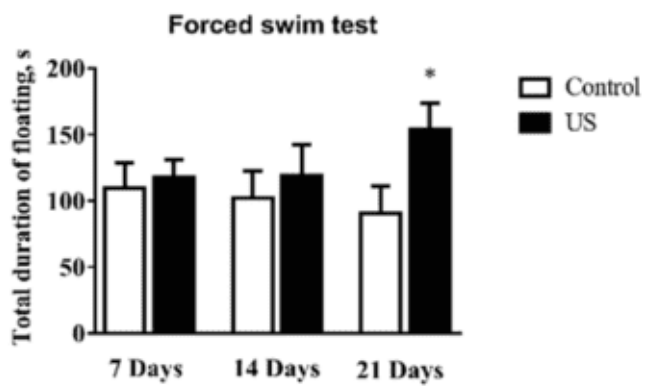

Figure 2. Lack of behavioral effects of a 1-week and 2-week exposure to a 50-dB ultrasound of variable frequency of $20-45 \mathrm{~Hz}$. In comparison to intact control groups, groups of animals exposed to a 1-week or 2-week 50 $\mathrm{dB}$-ultrasound of mixed frequencies at the range of $16 \mathrm{kHz}$ displayed similar (A) duration of social interaction (B) total time spent with floating and (C) sucrose preference, thus, demonstrating a lack of significant changes of 
shortened ultrasound stimulation on depressive-like behaviours. ( $p>0.05$ vs. control group, one-way ANOVA and post-hoc Tukey test). Only 3-week ultrasound exposure resulted in significant increase of total time spent with floating and significant decrease of sucrose preference. Bars are means \pm SEMs.

\section{A study of effects of a frequency range of ultrasound stimulation on mouse emotional behaviour}

In the next study, we compared immediate behavioural effects of ultrasound with an "emotionally negative" frequency range of $20-25 \mathrm{kHz}$ against effects of ultrasound of "emotionally neutral" frequencies of about 16 and 50-60 kHz (Figure 3). Six BALB/c mice were exposed for 15 min to the ultrasound of either frequency and averaged loudness $50 \mathrm{~dB}$, or not exposed to any stimulation (control group, $n=6$ ). Ultrasound at the range of 20-25 $\mathrm{kHz}$, but not of other frequencies, appeared to alter freezing behaviour (Fig. 3A), defensive burying (Fig. 3B), approaches to palatable food (Fig. 3C) and new object (Fig. 3D). 
A

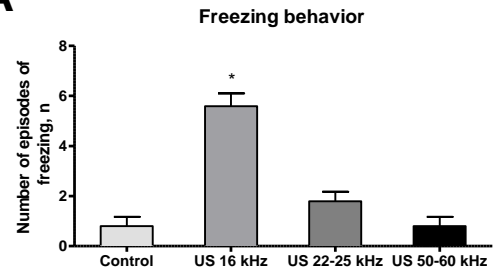

C

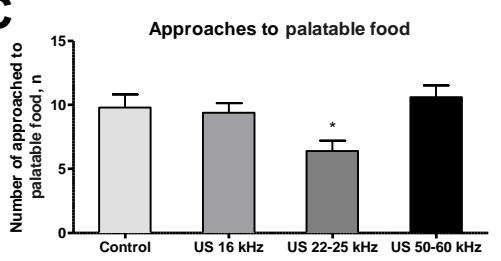

B Burying behavior
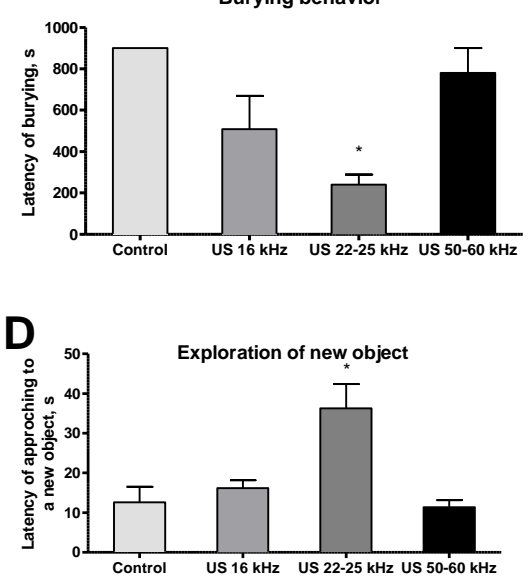

Figure 3. Ultrasound of selective ranges of frequencies produces immediate behavioral effects in BALBc mice. Mice exposed to ultrasound of frequencies $20-25 \mathrm{kHz}$, frequencies of 16 and $5-60 \mathrm{kHz}$, display (A) increased number of freezing episodes, (B) reduced latency of burying behaviour, (C) decreased number of approached to palatable food (D) elevated latency of approaching to a new object. Thus, ultrasound of freequences of 50-60 Hz did not affect any of measured behavioural parameters. ${ }^{*} \mathrm{p}<0.05$ vs. control group, one-way ANOVA and post-hoc Tukey test. Bars are means \pm SEMs. 
Thus, both studies on rats and mice evidence a lack of effects of loudness alone in the induction of a depressive-like state, as well as the specificity of “emotionally meaningful” ultrasound of frequencies $20-25 \mathrm{kHz}$.

\section{Sucrose test}

Mice were given a free choice between a bottle with $1 \%$-sucrose solution and another one with tap water for 24 hours, as described elsewhere. At the beginning and end of the test, the bottles were weighed and consumption of liquids was calculated. The test was started with the onset of the dark (active) phase of the animals' cycle. To prevent the possible effects of sidepreference in drinking behavior, the positions of the bottles in the cage were switched after 12 hours; no previous food or water deprivation was applied before the test. Other conditions of the test were applied as described elsewhere (Strekalova and Steinbusch, 2010; Strekalova et al., 2011). Percentage of preference for sucrose was calculated using the following formula: Sucrose Preference $=$ Volume (Sucrose solution) $/($ Volume (Sucrose solution) + Volume (Water)) x 100. 


\section{Forced swim test}

A plastic transparent pool (diameter of $15 \mathrm{~cm}$ and a height of $25 \mathrm{~cm}$ ) was filled with water to the depth for approximately $17 \mathrm{~cm}$; water temperature was $+23^{\circ} \mathrm{C}$ and the light intensity was 15 Lux. Mice were placed into the pool and their floating behavior was scored during the $6 \mathrm{~min}$, at three 2-min intervals. Floating was defined by the absence of any directed movements of animals' head and body; total duration of floating and the latency to float were scored offline using Any-maze software (Stoelting Co, Wood Dale, IL, USA) as described elsewhere (Strekalova and Steinbusch, 2010; Malatynska et al., 2012).

\section{Open field test}

The open field test was performed in the square gray plastic box $(45 \times 45 \times 45 \mathrm{~cm})$ illuminated with white light (25 lux) as described elsewhere (Strekalova and Steinbusch, 2010). The mice were placed near the wall and the time spent in the central zone $(15 \times 15 \mathrm{~cm})$, as well as the number of grooming events were recorded for a 5 min period with a digital camera placed above the arena. The recordings were subsequently analyzed using the automated video-tracking AnyMaze software (Stoelting Co, Wood Dale, IL, USA). 


\section{Resident-intruder test}

The resident-intruder test procedure was adapted from previously the described protocols (Couch et al., 2016; Strekalova et al., 2018). Briefly, the Balb/c mice from the experimental group were placed individually in an observation cage $(30 \times 60 \times 30 \mathrm{~cm})$ for $30 \mathrm{~min}$ to acclimatize. Thereafter, a previously group-housed naïve male Balb/c mouse of a similar weight and age to that of the resident was introduced as an intruder to the same cage and left with the resident mouse for $10 \mathrm{~min}$. During the observation period, mice were scored for the latency to attack and the number of attacks.

\section{Immunohistochemical analysis}

Immunohistochemical analyses were performed as described previously (Strekalova et al., 2002, 2015, 2018; Vignisse et al., 2016). Ki67 immunofluorescent staining was performed to identify proliferating cells; doublecortin (DCX) immunofluorescent staining was performed to examine neuronal differentiation; Ionized calcium binding adaptor molecule 1 (Iba1) immunofluorescent staining was performed to study microglial activation. 
To produce paraffin blocks of dissected hippocampi, PFA-fixed hemispheres were incubated 2 times for $1 \mathrm{~h}$ with $70 \%$-ethanol solution, for $1.5 \mathrm{~h}$ with $80 \%$-ethanol solution, for $1 \mathrm{~h}$ with $95 \%$-ethanol solution, 3 times for $1.5 \mathrm{~h}$, in $100 \%$-ethanol solution, 3 times for 1.5 hour in xylene, for 2 $\mathrm{h}$, in paraffin first wax paraplast $\mathrm{X}$ tra $\left(\right.$ at $\left.58^{\circ} \mathrm{C}\right)$, for $2 \mathrm{~h}$ paraffin second wax paraplast Xtra (at $58^{\circ} \mathrm{C}$ ) in cassettes (Sigma-Aldrich, St. Louis, MO, USA). Initially, a small amount of molten paraffin was dispensed in mold from paraffin reservoir. Tissue was transferred into the mold using warm forceps. Subsequently, the mold was placed on a cold plate for paraffin to solidify into a thin layer. Hot paraffin was added to the mold from the paraffin dispenser to cover the front surface of the plastic cassette. Then paraffin blocks were stored until use at the room temperature.

Samples were sectioned using a cryostat Leica CM 1850 cryostat (Leica Microsystems, Wetzlar, Germany). Serially cut sections were taken from lateral 3.6 to lateral $0.4 \mathrm{~mm}$ along the medial-lateral axis ahead of bregma (Paxinos and Franklin, 2001). Paraffin sections were picked up with forceps and placed on the surface of deionized water in the bath (Leica HI1210 Water bath, Wetzlar, Germany) at $40^{\circ} \mathrm{C}$. Subsequently, they were mounted onto glass slides. Sections were air dried for 30 minutes and then covered with coverslips. 
To remove paraffin, sections were incubated 3 times for $5 \mathrm{~min}$ with xylene, 2 times for 10 min with $100 \%$-ethanol solution, 2 times for 10 min with 95\%-ethanol solution, 2 times for $10 \mathrm{~min}$ with $70 \%$-ethanol solution, $2 \mathrm{~min}$ for 10 min with $50 \%$-ethanol solution (Sigma-Aldrich, St. Louis, MO, USA) and 2 times for $5 \mathrm{~min}$ in ice-cold deionized water.

For antigen retrieval with Ki67- and DCX- staining assays, 3 randomly selected hippocampal sections were incubated for 30 minutes at $90^{\circ} \mathrm{C}$ in 10 $\mathrm{mM}$ sodium citrate and $0.05 \%$ Tween 20, pH 6.0 (Applichem, Darmstadt, Germany) per each assay. For Iba-1-staining, 3 randomly selected sections were incubated 3 times during 10 min per each step, in a Tris-buffered saline (TBS), $\mathrm{pH} 7.6$, and then treated with $2 \mathrm{~N} \mathrm{HCl}$ during 30 min at $37^{\circ} \mathrm{C}$ and washed in $0.1 \mathrm{M}$ borate buffer $\mathrm{pH} 8.5$ for $10 \mathrm{~min}$ (Applichem, Darmstadt, Germany). We used water bath for heat-induced epitope retrieval.

Blocking of non-specific staining was performed with $1 \%$ bovine serum albumin (BSA, Fluka, Buchs, Switzerland) in PBS, pH 7.4, at room temperature for $1 \mathrm{~h}$ with all three assays. Sections were drained for a few seconds and wiped with a tissue paper. Subsequently, overnight incubation at $4{ }^{\circ} \mathrm{C}$ with primary antibodies was performed using rat anti-Ki67 (Dako, Glostrup, Denmark), rabbit polyclonal anti-DCX (Chemicon, Temecula, 
CA, USA), rabbit polyclonal anti-Iba-1 (Dako, Glostrup, Denmark) which were diluted in TBS containing $0.1 \%$ Triton, $0.1 \%$ Tween 20 and 5\% normal donkey serum in following concentrations: Ki67 (1:100), DCX (1:20) and Iba-1 (1:1000).

Thereafter, sections were washed 3 times with $0.1 \%$ BSA in PBS, pH 7.4 and for 2 hours at $4^{\circ} \mathrm{C}$ in the dark incubated with secondary antibodies: donkey anti-rat-Alexa Fluor 594, anti-rabbit-Alexa Fluor 488 and antirabbit-Alexa Fluor 647, respectively (Life Technologies-Molecular Probes, Grand Island, NY, USA).

To visualize cell nuclei, DAPI staining was performed. $10 \mathrm{mg}$ of DAPI (1:1000; Santa Cruz Biotechnology, Dallas, TX, USA) was dissolved in 2 $\mathrm{ml}$ of dimethylformamide (DMF) to prepare a stock solution that was further diluted to a concentration of $30 \mathrm{nM}$ in PBS; $350 \mu 1$ of this staining solution was used per each slice that was cover-slipped and incubated for $30 \mathrm{~min}$ at the room temperature thereafter. After rinsing of slices with PBS, fluorescent microscopy with maximal fluorescence excitation/emission at $358 / 461 \mathrm{~nm}$ was carried out. 
With each assay, control samples with secondary antibody alone were included for internal autofluorescence reference. Immunofluorescent images were captured and analyzed by an experimenter blind to the experimental conditions as described elsewhere (Vignisse et al., 2016, Strekalova et al., 2015, 2018). Subgranular zone (SGZ) of the hippocampus was defined as a two-cell-body wide zone between the hilus and the base of the granular layer of the dentate gyrus and was measured using ImageJ software (NIH, Bethesda, MD, USA).

Nissl staining was performed to determine the reference volume and, subsequently, the densities of Ki67- and DCX-positive cells defined as cell numbers in a volume of $\mathrm{mm} 3$ of SGZ (Fig.4A). Therefore, seven saggital sections were randomly selected, dewaxed with xylene (Sigma-Aldrich, St. Louis, MO, USA), treated with 95\%-ethanol solution (Sigma-Aldrich, St. Louis, MO, USA), stained with $0.1 \%$ cresyl violet for 15 min (SigmaAldrich, St. Louis, MO, USA) and washed with distilled water.

Iba-1- positive cells were counted in the defined area of the hilus of the hippocampus (Vignisse et al., 2017; Fig.4B); cell densities were calculated per $\mathrm{mm} 2$ as described previously (Couch et al., 2013). Image analysis was performed using Image J software (NIH, Bethesda, MD, USA). 


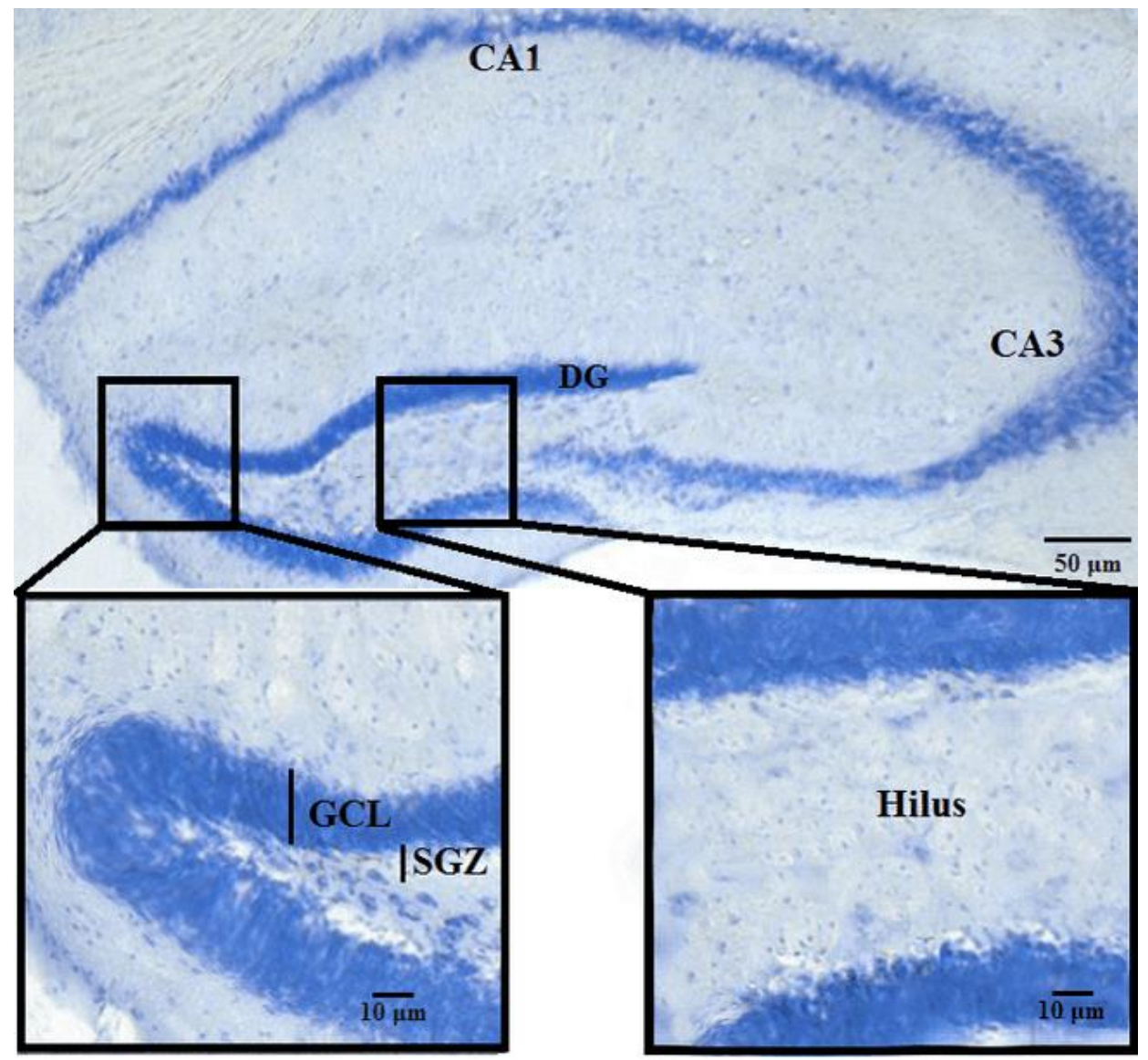

A

B

Figure 4.Hippocampal areas defined for scoring of (A) Ki67- and DCXpositive cells, (B) Ida-1- positive cells in a Nissle staining study. CA1 cornu ammonis 1, CA3 - cornu ammonis 3, DG - dentate gyrus, GCL granule cell layer, SGZ - subgranular zone. Scale bars are $10 \mu \mathrm{m}$ (A) and $50 \mu \mathrm{m}$ (B). 


\section{Quantitative reverse transcription polymerase chain reaction analysis}

\section{(qRT-PCR)}

Total mRNA was isolated from each hippocampus with TRI Reagent (Invitrogen, Carlsbad, CA, USA). First-strand cDNA synthesis was performed using random primers and Superscript III transcriptase (Invitrogen, Carlsbad, CA, USA); $1 \mu \mathrm{g}$ total RNA was converted into cDNA. qRT-PCR was performed using the SYBR Green master mix (BioRad Laboratories, Philadelphia, PA, USA) and the CFX96 Deep Well RealTime PCR Detection System (Bio-Rad, Hercules, CA, USA). qRT-PCR was performed in a $25 \mu \mathrm{l}$ reaction volume containing a 10xPCR Buffer

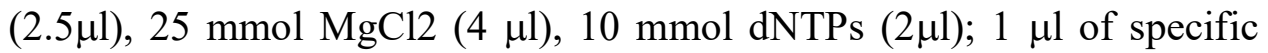
forward and reverse primers were used at the concentration $20 \mathrm{pmol} / \mu \mathrm{l}, 2 \mu \mathrm{l}$ of cDNA, $1 \mu \mathrm{l}$ of DNA polymerase $(5 \mathrm{u} / \mu \mathrm{l})$ and $10 \mu \mathrm{l}$ of ddH2O.

Glyceraldehyde-3-phosphate dehydrogenase (GAPDH) was selected as a reference gene, since in previous experiments it was observed relatively low variability in its hippocampal expression in ultrasound model (Morozova et al., 2016). The initial denaturation step for qRT-PCR was at $95^{\circ} \mathrm{C}$ for $4 \mathrm{~min}$ 
followed by 40 cycles of denaturation at $95^{\circ} \mathrm{C}$ for 20 seconds. Annealing was at $54^{\circ} \mathrm{C}$ for 90 seconds.

Further details, as well as the sequences of primers used are listed below (Table 1); all primers were purchased from Evrogen, Moscow, Russia. All samples were run in triplicate. Data were normalized to GAPDH mRNA expression and calculated as relative-fold changes compared to control mice that were not exposed to stress, as described elsewhere (Morozova et al., 2016; Pavlov et al., 2017).

Table 1. Sequences of primers for qRT-PCR 


\begin{tabular}{|c|c|c|}
\hline Gene & Forward primer 5' -3' $^{\prime}$ & Reverse primer 5'-3' \\
\hline GAPDH & TGCACCACCAACTGCTTAG & GGATGCAGGGATGATGTTC \\
\hline GSK3 $\alpha$ & AATCTTGGCCAGTCTGAGCT & TCAGTCCTGGTGAACTGTCC \\
\hline GSK3 $\beta$ & TCCATTCCTTTGGAATCTGC & CAATTCAGCCAACACACAGC \\
\hline IL-1 $\beta$ & TGTAATGAAAGACGGCACACC & TCTTCTTTGGGTATTGCTTGG \\
\hline IL-2 & CCAAGCAGGCCACAGAATTG & TCCAGCGTCTTCCAAGTGAA \\
\hline IL-6 & ACTCACCTCTTCAGAACGAATTG & CCATCTTTGGAAGGTTCAGGTTG \\
\hline IL-8 & AAACCACCGGAAGGAACCAT & CCTTCACACAGAGCTGCAGAAA \\
\hline IL-15 & CCATCCAGTGCTACTTGTGTTTAC & CCAGTTGGCTTCTGTTTTAGGAA \\
\hline NGF & CGACTCCAAACACTGGAACTCA & GCCTGCTTCTCATCTGTTGTCA \\
\hline VEGF & CAAGACAAGAAAATCCCTGTGG & CCTCGGCTTGTCACATCTG \\
\hline BDNF & AGCCTCCTCTGCTCTTTCTG & CGCCGAACCCTCATAGACAT \\
\hline TrkB & TCTCATTTTAGGCCGCTTTG & GGGTTTGAGGTGGGTGAAG \\
\hline Nestin & CAGCGTTGGAACAGAGGTTGG & TGGCACAGGTGTCTCAAGGGTAG \\
\hline BLBP & AACCAGCATAGATGACAGAAACTG & ACTTCTGCACATGAATGAGCTT \\
\hline
\end{tabular}

\section{Western Blot assay}

Frozen hippocampal tissue was treated with lysis buffer containing $20 \mathrm{mM}$ of Tris- $\mathrm{HCl}$ (pH 7.5), $450 \mathrm{mM}$ of $\mathrm{NaCl}, 1 \%$-solution of Triton X-100, $1 \mathrm{mM}$ of EDTA, $1 \mathrm{mM}$ of $\mathrm{NaF}, 1 \mathrm{mM}$ of $\mathrm{Na}_{3} \mathrm{VO}_{4}$ and protease inhibitor (Roche Diagnostics, Indianapolis, IN, USA); $50 \mu \mathrm{l}$ of buffer per $1 \mathrm{~g}$ of tissue was used. Samples were centrifuged at $16000 \mathrm{rpm}$ for $20 \mathrm{~min}$ at $4^{\circ} \mathrm{C}$. The supernatant was collected and stored until use at $-20^{\circ} \mathrm{C}$. Subsequently, 25 
$\mu \mathrm{g}$ of protein from each sample was mixed with $35 \mu 1$ of Laemmli buffer. A sample of identical volume, comprising of $26 \mu \mathrm{l}$ of Laemmli buffer, $5 \mu \mathrm{l}$ of Page Ruler and $4 \mu 1$ of Magic Mark (Sigma, Munich, Germany) was used as a reference. For electrophoresis, samples were diluted in a solution containing MilliQ $\mathrm{H}_{2} \mathrm{O}, 1.5 \mathrm{M}$ of Tris Buffer ( $\mathrm{pH} 8.8$ ), 30\%-solution of Acrylamide, 10\%-solution of SDS Temed, 10\%-solution of ammonium persulfate (APS). For the next step, a solution containing MilliQ $\mathrm{H}_{2} \mathrm{O}, 0.5$ $\mathrm{M}$ of Tris Buffer ( $\mathrm{pH} 8.8$ ), 30\%-solution of Acrylamide, 10\%-solution of SDS Temed, 10\%-solution of APS and gel (Sigma, Munich, Germany) was used. The percentage of gel solution was adjusted to sizes of proteins of interest and was $20 \%$ for proteins of size of $4-40 \mathrm{kDa}, 12.5 \%$ for proteins of the size of $40-70 \mathrm{kDa}, 10 \%$ for proteins of the size of $70-100$, and $7.5 \%$ for proteins over $100 \mathrm{kDa}$. A buffer containing $25 \mathrm{mM}$ of Tris Base buffer, $192 \mathrm{mM}$ of Glycine (Sigma, Mannheim, Germany), 10\%-solution of SDS and MilliQ $\mathrm{H}_{2} \mathrm{O}$ ( $\mathrm{pH}$ 8.3) was used for gel electrophoresis which was carried out under the constant voltages of $80 \mathrm{~V}$ and $130 \mathrm{~V}$.

Polyvinylidene difluoride (PVDF) membrane (9 x $6 \mathrm{~cm}$, EMD Millipore, Billerica, MA, USA) was consequently incubated in a $99 \%$-methanol solution for $1 \mathrm{~min}$ (Brocacef, Amsterdam, the Netherlands), a MilliQ $\mathrm{H}_{2} \mathrm{O}$ 
for $5 \mathrm{~min}$, and a transfer buffer for $15 \mathrm{~min}$. The latter contained $25 \mathrm{mM}$ of Tris Base, $192 \mathrm{mM}$ of glycine, 20\%-solution of methanol, MilliQ $\mathrm{H}_{2} \mathrm{O}(\mathrm{pH}$ 8.3). For the next step, blot "transfer sandwich" was composed of buffer soaked sponge, consisting of two buffer soaked Whatman filter papers, gel, activated membrane, ice-cold transfer buffer; the constant current of 300 $\mathrm{mA}$ was used for $2 \mathrm{~h} 30 \mathrm{~min}$.

Thereafter, the membrane was treated with a 5\%-dry milk solution the TBST, containing $50 \mathrm{mM}$ of Tris- $\mathrm{HCl}(\mathrm{pH}=8.2), 150 \mathrm{mM}$ of $\mathrm{NaCl}, 0.05 \%$ solution of Tween 20 (Sigma, Munich, Germany) for $1 \mathrm{~h}$ at the room temperature and subsequently incubated with primary antibodies at $4{ }^{\circ} \mathrm{C}$ overnight that was followed by the incubation with respective horseradish peroxidase-conjugated secondary (HRP) antibodies (Sigma-Aldrich, St. Louis, MO, USA) for $2 \mathrm{~h}$ at room temperature on a roller. The membrane was washed in TBST three times, 5 min each time and placed on the plastic cover. Thereafter, Western Brightтм ECL kit (Advansta Inc, Menlo Park, CA, USA). A relative optical density of immunoreactive protein bands was examined using ImageJ software (NIH, Bethesda, MD, USA). Results were normalized to the relative intensity of the $\beta$-tubulin band that was selected as a reference protein as described elsewhere (Morozova et al., 2016). Blots 
were stripped by incubation with Restore Western Blot stripping Buffer (Thermo Scientific, Rockford, IL, USA) at the room temperature for $15 \mathrm{~min}$.

To normalize the data, the value of each protein of interest was expressed in percent from the concentration value of $\beta$-tubulin, the reference protein. The choice of a reference protein was based on the previous observations where its expression was found to vary moderately across various experimental conditions as well as the linear representation of its signal intensity was demonstrated (Morozova et al., 2016; Bettendorff et al., unpublished data).

Table 2. Primary antibodies used in the Western blot assay 


\begin{tabular}{|c|c|}
\hline Antibody & Dilution \\
\hline $\begin{array}{l}\text { Anti- } \beta \text {-tubulin (Abcam, Cambridge, MA, USA) } \\
(\text { ab6160) }\end{array}$ & $1: 700$ \\
\hline $\begin{array}{c}\text { Anti-TrkB (Abcam, Cambridge, MA, USA) } \\
(\text { ab18987) }\end{array}$ & $1: 800$ \\
\hline $\begin{array}{c}\text { Anti-BDNF (Abcam, Cambridge, MA, USA) } \\
(\text { ab108319) }\end{array}$ & $1: 1000$ \\
\hline $\begin{array}{c}\text { Anti-Nestin (Abcam, Cambridge, MA, USA) } \\
(\text { ab6142) }\end{array}$ & $1: 1000$ \\
\hline $\begin{array}{l}\text { Anti-BLBP (Cell Signaling Technology, Beverly, MA, USA) } \\
\text { \#70076 }\end{array}$ & $1: 900$ \\
\hline $\begin{array}{l}\text { Anti-GSK-3 } \alpha \text { (Cell Signaling Technology, Beverly, MA, USA) } \\
\# 4337\end{array}$ & $1: 300$ \\
\hline $\begin{array}{c}\text { Anti-GSK-3 } \beta \text { (Cell Signaling Technology, Beverly, MA, USA) } \\
\# 9832\end{array}$ & $1: 300$ \\
\hline $\begin{array}{l}\text { Anti-IL-1 } \beta \text { (Cell Signaling Technology, Beverly, MA, USA) } \\
\# 12242\end{array}$ & $1: 800$ \\
\hline $\begin{array}{l}\text { Anti-IL-6 (Cell Signaling Technology, Beverly, MA, USA) } \\
\# 12153\end{array}$ & $1: 600$ \\
\hline $\begin{array}{c}\text { Anti-PTEN (Cell Signaling Technology, Beverly, MA, USA) } \\
\# 9188\end{array}$ & $1: 800$ \\
\hline $\begin{array}{l}\text { Anti-AktpSer473 (Cell Signaling Technology, Beverly, MA, USA) } \\
\# 4060\end{array}$ & $1: 300$ \\
\hline $\begin{array}{c}\text { Anti-FOXO3a (Cell Signaling Technology, Beverly, MA, USA) } \\
\# 12829\end{array}$ & $1: 400$ \\
\hline
\end{tabular}

\section{Determination of protein concentration}

Protein concentration was quantified using the BCA protein assay kit (Pierce, Rockford, IL, USA). Working reagent was prepared in accordance with manufacturer instructions. $25 \mu 1$ of each standard or sample preparations were pipetted into a microplate well, $200 \mu 1$ of the working reagent was added to each well and mixed thoroughly on a plate shaker for 30 seconds; assay was run in duplicates. Covered plate was incubated at 
$37^{\circ} \mathrm{C}$ for 30 minutes and cooled to room temperature for $10 \mathrm{~min}$. The absorbance was measured at $562 \mathrm{~nm}$ in a Biotek Microplate Reader (Biotek Instruments, Winooski, VT, USA). Ascent Software Program (Winooski, VT, USA ) coupled to the microplate reader was used to calculate protein values based on comparing optical densities readings of the experimental samples with those obtained from the standard curve; the blank value was subtracted from all other optical densities readings. A standard curve was generated by plotting the average blank-corrected 562 $\mathrm{nm}$ measurements for each BSA standard vs. its concentration in $\mu \mathrm{g} / \mathrm{ml}$.

Table 3. Primary and secondary antibodies used in the ICH assay 


\begin{tabular}{|c|c|}
\hline Antibody & Dilution \\
\hline Anti-Ki67 antibody (Abcam, Cambridge, MA, USA) & $1: 1000$ \\
ab15580 & $1: 1000$ \\
\hline anti-Doublecortin antibody (Abcam, Cambridge, MA, USA) & $1: 1000$ \\
\hline $\begin{array}{c}\text { Anti-Iba-1 antibody produced in rabbit (Sigma-Aldrich, St. Louis, MO, USA) } \\
\text { HPA049234-100UL }\end{array}$ & $1: 1000$ \\
\hline $\begin{array}{c}\text { Donkey anti-Rat IgG (H+L) Highly Cross-Adsorbed Secondary Antibody, Alexa } \\
\text { Fluor 594 (Thermo Scientific, Rockford, IL, USA) } \\
\text { AB_2535795 }\end{array}$ & $1: 1000$ \\
\hline $\begin{array}{c}\text { Donkey anti-Rabbit IgG (H+L) Highly Cross-Adsorbed Secondary Antibody Alexa } \\
\text { Fluor 488 (Thermo Scientific, Rockford, IL, USA) } \\
\text { AB_2535792 }\end{array}$ & \\
\hline $\begin{array}{c}\text { Donkey anti-Rabbit IgG (H+L) Highly Cross-Adsorbed Secondary Antibody, } \\
\text { Alexa Fluor 647 (Thermo Scientific, Rockford, IL, USA) } \\
\text { AB_2536183 }\end{array}$ & $1: 1000$ \\
\hline
\end{tabular}

Ultrasound stress suppresses hippocampal plasticity

Staining with the neuronal nuclear marker DAPI (4',6-diamidino-2phenylindole) and markers of cell proliferation Ki67 and progenitor neuronal cells DCX revealed decreased, in compared with control group, density of Ki67- and DCX-positive cells in the SGZ of the hippocampus of 
stressed mice, suggesting that ultrasound stress inhibits neuronal proliferation in this brain structure.

Hippocampal staining for plasticity markers

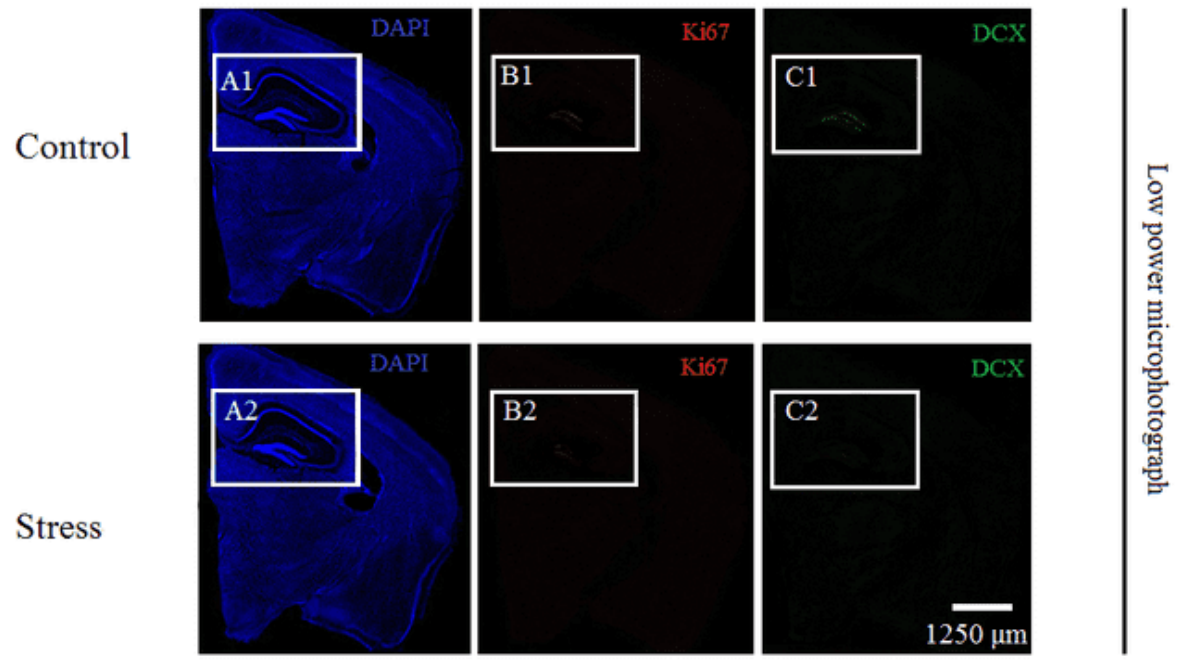




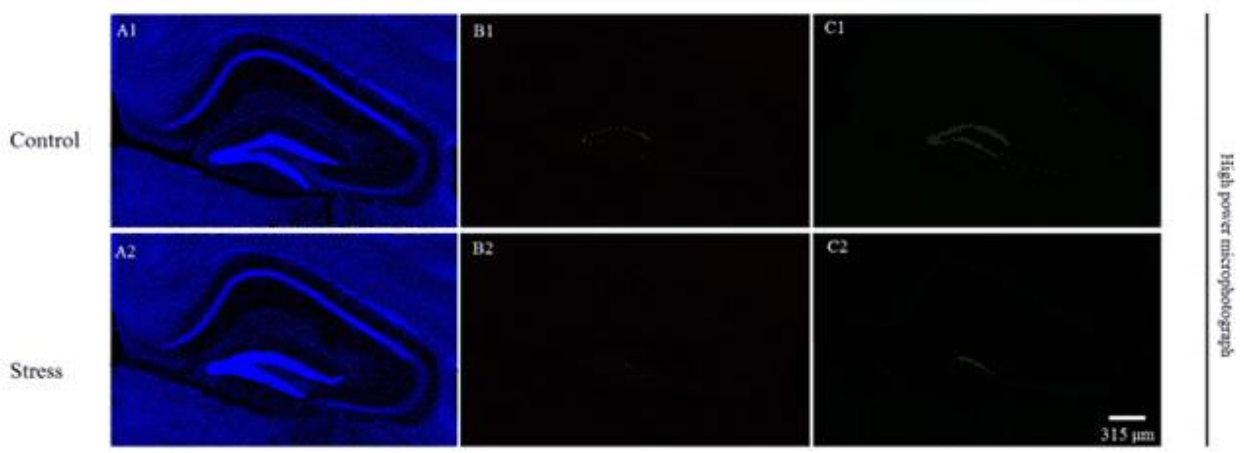

Figure 5. Low and high power microphotographs of DAPI/Ki67/DCX hippocampal immunostaining. Fluorescence microscopy of DAPI (blue), Ki67 (red) and DCX (green) represents suppressed hippocampal proliferation rate as a result of stress exposure in Balb/c mice. (A1-A2) DAPI-staining of hippocampus of stressed and control animals. (B1-B2) Ki67- positive cells in the hippocampus of stressed mice and control animals. (C1-C2) DCX - positive cells in the hippocampus of stressed and control animals. Images A1-C2 represent 4 times magnification of the original images. The scale bar is $1250 \mu \mathrm{m}$ for low power figures and 315 $\mu \mathrm{m}$ for high power figures. 


\section{Analysis of phenotypes of microglia}

Phenotypes of microglia were analyzed in according to a method of Lawson (1990). Round cells with up to three thick branches were counted as reactive (amoeboid) microglia; cells with three or more thick branches were counted as ramified (resting) microglia. Representative microphotographs demonstrate these types of microglial cells in control and stressed animals (Fig.6).

\section{Pro-inflammatory effects of the ultrasound stress}

Staining of the hippocampal slices neuronal nuclear marker DAPI and Iba1 (Ionized calcium binding adaptor molecule 1), a marker of microglia, revealed increased densities of Iba-1-positive cells in the hilus of hippocampi of stressed mice as compared with control animals.

\section{Hippocampal staining for activated microglia}



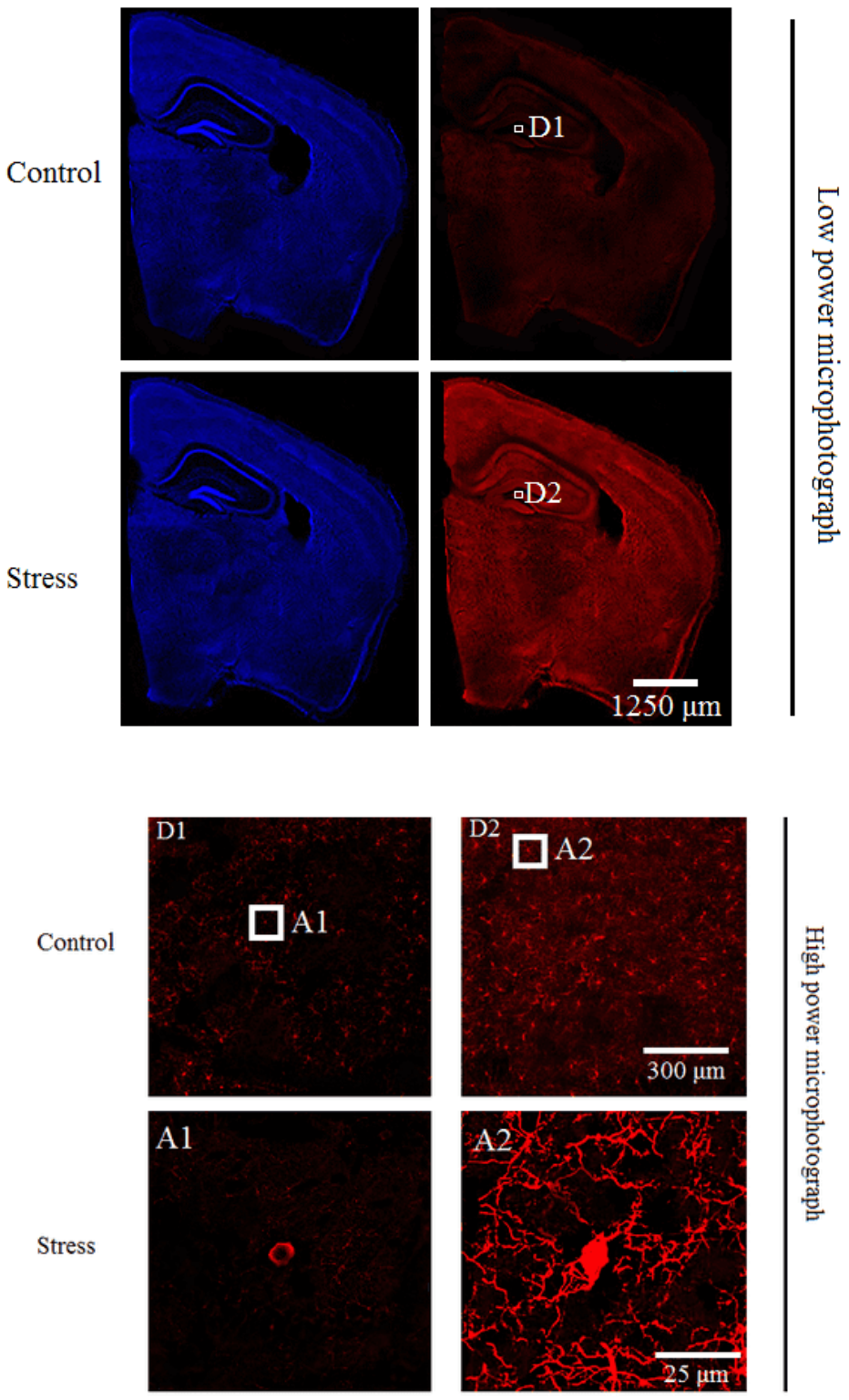

Figure 6. Low and high power microphotographs of DAPI / Iba-1 hippocampal immunostaining. Fluorescence microscopy of DAPI (blue) and Iba-1 (red) displayed microglial activation in stressed Balb/c mice. (D1- 
D2) Image of microglial clusters in the hippocampus of stressed and control animals, 4 times magnification of the original images. (A1-A2) Single microglial cells in the hippocampus of stressed and control animals, 12 times magnification of the images D1-D2. The scale bar is $1250 \mu \mathrm{m}$ for low power figures and 300 or $25 \mu \mathrm{m}$ for high power figures. 


\section{CHAPTER 5. DISCUSSION AND SOCIETAL IMPACT}

\subsection{GSK-3-related molecular and neuroinflammatory changes as common mechanisms of the depressive syndrome}

In the examined models we have seen pro-inflammatory changes that were accompanied by an increase of oxidative stress markers. Activation of the immune system following stress exposure is an adaptive mechanism to protect the host from a pathogenic environment and to hasten wound healing (Miller et al., 2016; Fig. 6). At the same time, this hyperactivation can be maladaptive under certain conditions and here, in the ultrasound stress study, we have demonstrated potent activation of microglia that are an important source of ROS in the brain. Activation of microglia can be triggered by local or systemic overproduction of pro-inflammatory cytokines (Bluthe et al., 1994; Dantzer et al., 2008). Notably, while we have seen an upregulation of pro-inflammatory cytokines, no changes in the production of anti-inflammatory cytokines was observed in our study, which is in the line with reports that GSK-3 $\beta$, overexpressed in our model, can inhibit production of anti-inflammatory cytokines (Jope et al., 2017). An upregulation of pro-inflammatory cytokine production both on systemic 
and local levels suggests a role of peripheral and central mechanisms of microglial activation in our model.

It is important to note that microglial cells can produce pro-inflammatory cytokines as well (Lee et al., 1993) that can additionally enhance microglial activation; activated microglia were shown to be implicated in neuroplasticity disruption (Wang et al., 2005). Interestingly, activated microglia can facilitate local oxidative stress and lead to an additional damage on -a neuronal level and neurodegeneration on a structural level (Mao et al., 2007). This observation is crucial in terms of our results regarding elevated content of oxidative stress markers such as 3-NT and MDA in animals following ultrasound radiation as microglial activation can be an important factor for oxidative stress in this case. Microglia are implicated in synaptic pruning, dendritic remodeling, and can regulate neurotransmission. Microglia can phagocyte neurons thus increased number of activated microglial cells may reflect higher rate of phagocytosis in this brain area and a reduction in volumetric parameters that was observed in our preliminary studies.

The GSK-3 $\beta$ isoform is often regarded as a molecular marker of distress, anxiety and depression (Beurel et al., 2015). In our study its expression was 
upregulated following stress exposure as well as expression of FOXO3a and PTEN, while protein kinase B was downregulated. GSK-3 is implicated in a wide spectrum of cell functions ranged from metabolism to apoptosis, it is important for neuroplasticity and neurogenetic processes, as well as for the development of affective disorders including depression (Markova et al., 2016; Strekalova et al., 2016). Regarding described data from our experiments, such as overexpression of FOXO3a and PTEN, that are functionally related to an upregulation of GSK-3, the collective activities of these molecules can provoke cell death and neurodegenerative brain changes due to maladaptation (Polter et al., 2009; Pavlov et al., 2017). Activity of beta isoform of GSK-3 activates FOXO3a and PTEN thus triggering apoptosis. Protein kinase B can be downregulated by these cascades; Akt has anti-apoptotic functions (Wu et al., 2009). To sum up, observed changes in GSK-3/FOXO3a/Akt pathway represent pro-apoptotic alterations which are consistent with the pro-inflammatory profile that we revealed previously. Schematically these pathways are outlined in Fig.5. 


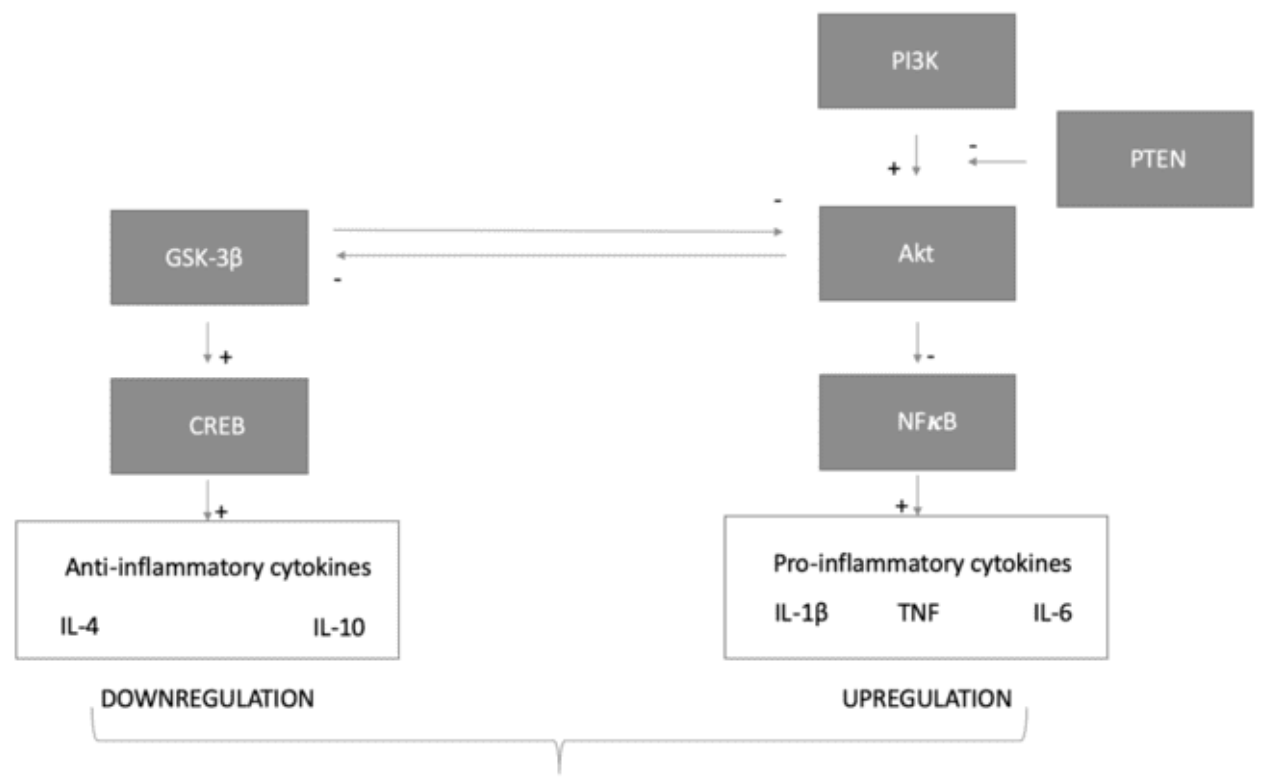

\section{DEPRESSION}

Figure 5. Schematic outline of GSK-3-mediated pro-inflammatory pathway. GSK-3 $\beta$ - glycogen synthase kinase 3 beta; Akt - protein kinase B; PI3K -phosphoinositide 3-kinase; NF-kB - nuclear factor kappa-lightchain-enhancer; CREB - cAMP response element-binding protein; IL interleukin, PTEN - phosphatase and tensin homolog, TNF - tumor necrosis factor (Adapted from Golpich et al., 2015).

In the modFST study we have established that repeated exposure to the same contextual adverse experiences results in the prolonged duration of floating behavior and brain overexpression of GSK-3 isoforms and that they are positively intercorrelated (Markova et al., 2017; Pavlov et al., 2017). As 
forced swim re-exposure results in the increased systemic CORT content (Pavlov et al., 2019), and given that this upregulation is accompanied by GSK-3 overexpression, we may suggest that these changes trigger neuroinflammation manifested in central overexpression of TNF, IL-6 and COX-1 (Chang et al., 2013; Beurel et al., 2015; see Fig. 5-6). Presumably, GSK-3 exerts its pro-inflammatory activities through NF-kB-dependent mechanisms (Chang et al., 2013).

In both the ultrasound and modFST projects we have demonstrated the overexpression of TNF, an important pro-inflammatory cytokine and a prominent marker of inflammation. The involvement of this cytokine in the development of depressive syndrome and its potentials to contribute to the vulnerability mechanisms of predisposition to a depressive syndrome has gained an extensive attention in the recent years. Genetic knock-out models provided the evidence for anti-depressant-like behavioral alterations after the selective switching off of genes encoding TNF or its cognate receptors (Simen et al., 2006). These data are in the line with reports about depressive syndrome ameliorations under selective blockage of TNF signaling (Krugel et al., 2013). TNF is upregulated centrally and systemically in patients suffering from major depressive disorder (Misener et al., 2008) and in animal models of depressive syndrome (Krugel et al., 2013). Our data are 
consistent with these reports and we demonstrated a link not only between limbic TNF upregulation and enhanced learning to adverse memories but also have shown that TNF overexpression has contributed to the development of depressive-like traits in depressive syndromes of various aetiologies.

IL-1 $\beta$ is known for its role in induction of sickness behavior, chronic fatigue and depression (Misener et al., 2008). There is an emerging concern about the role of IL-1 $\beta$ and related signaling pathways in mediation of chronic stress effects on an animal emotionality (D'Mello and Swain, 2017). This cytokine exerts an important role in the interindividual vulnerability mechanisms of a host predisposition to a depressive syndrome in an extensive literature (Couch et al., 2013; Fang et al., 2019). Our data from both sub-experiments is in the line with these observations that gives us a notion about universal mechanisms of involvement of IL-1 $\beta$ in depressivelike conditions induced by distinct triggers. Notably, overexpression of IL$1 \beta$ is a characteristic trait for patients with depression comorbid with PTSD (Toft et al., 2019).

We assessed mRNA expression of COX-1 as it was shown that knock-out COX-1 mice are resilient to stress-induced depressive like states (Tanaka et 
al., 2012), and that PTSD patients displayed upregulated COX-1 in the central nervous system (Powers et al., 2019). Repeated swimming sessions elevated COX-1 content in the examined limbic structures thus additionally emphasizing the profound proinflammatory changes in brain regions involved in enhanced learning of adverse memories.

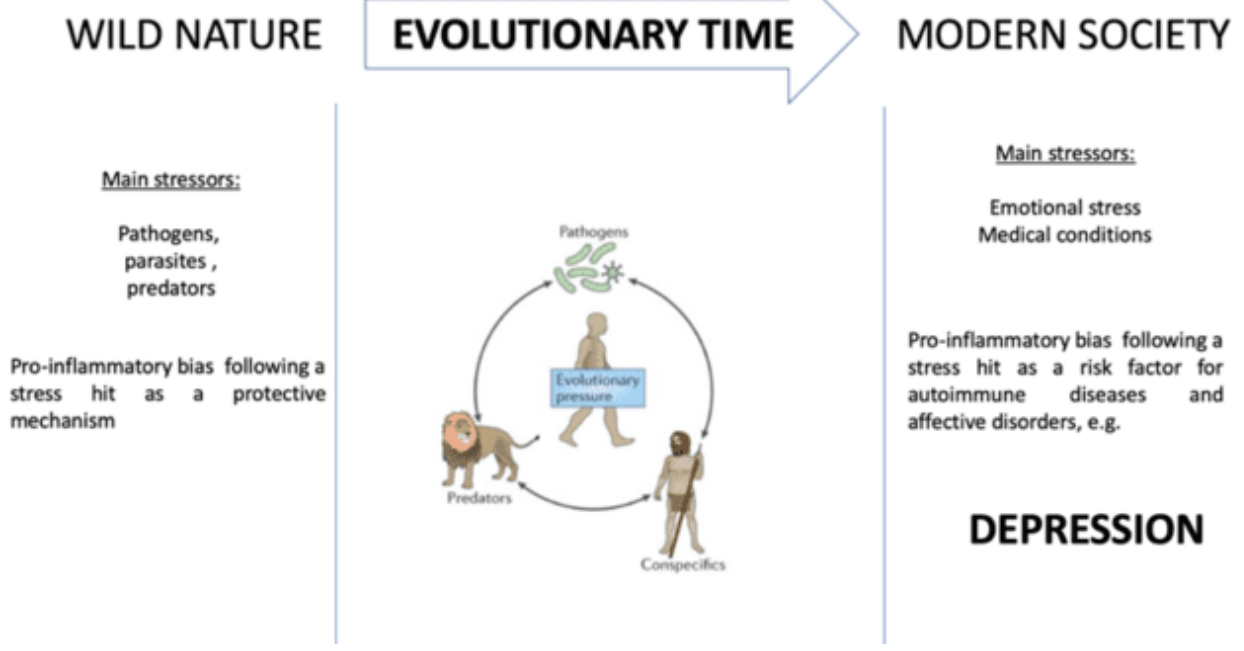

Figure 6. Inflammatory bias in evolution. Adapted from Miller et al., 2016. Recent theories hypothesize that sickness behavior and conditions related to depression, such as social avoidance, serve to preserve energy resources required for metabolically expensive tasks such as to escape predators, heal wounds or fight infections. Thus, from an evolutionary point of view some of the depressive-like traits could serve to enhance chances of survival. In the modern world these pro-inflammatory changes are largely detrimental when experienced in response to psychosocial stressors. 
Of particular significance, thiamine and imipramine treatments largely ameliorated the effects of stress on depressive-like behaviour, as well as stress-mediated GSK-3 upregulation and increased oxidative stress markers (Vignisse et al., 2017; Gorlova et al., 2019). My present results confirm our previous findings and also demonstrate the anti-inflammatory effect of these treatments.

\subsection{The role of GSK-3 isoforms in altered neuroplasticity and oxidative stress in depressive syndromes}

An extensive literature search suggests that GSK-3 isoforms can affect neuroplasticity and increase production of ROS thus exacerbating depressive traits and suppressing plasticity mechanisms.

In the ultrasound study observed behavioral changes were accompanied by downregulated markers of hippocampal neuroplasticity, such as BDNF and its cognate receptor TrkB. The immune system was also affected and we revealed activation of microglia shown as an increased population of Iba1 positive cells and an overexpression of the prominent pro-inflammatory cytokines IL-1 $\beta$, IL-6 and TNF. These changes were paralleled by an increased hippocampal content of 3-NT and MDA that reflects oxidative stress (Vignisse et al., 2014). Hippocampal overexpression of both isoforms 
of GSK-3 and functionally related molecules such as FOXO3a and PTEN along with downregulation of Akt suggests that interrelation of GSK-3 cascades, oxidative stress and abnormal neuroplasticity exists. This means that GSK-3-mediated cascades are important regulators of depressive syndrome as they are involved in many cellular functions.

We showed that ultrasonic exposure leads to reduction of hippocampal population of both Ki67- and DCX-positive cells alongside with a downregulation of BDNF/TrkB that suggests diminished neurogenesis and neuroplasticity. Our preliminary research showed aberration of serotonergic neurotransmission in the limbic structures, especially 5-HT1a and 5-HT2a receptors-mediated cell signaling, that are known for their involvement in neuronal plasticity mechanisms (Mahar et al., 2014; Morozova et al., 2016). Notably, expression of these types of serotonergic receptors can be modulated by pro-inflammatory cytokines which were upregulated in our model as well (Muller, 2014). In this regard, the changes that were displayed in our model can be linked to serotonergic system; of particular significance, selective serotonin reuptake inhibitor fluoxetine upregulated BDNF level in limbic brain structures in our preliminary study (Morozova et al., 2016). 
Consistent with this result we showed an important role of GSK-3 isoforms in our modFST study. As GSK-3 is a crucial factor in the regulation of neuroplasticity, aberrant expression of this factor can underlie augmented acquisition to negative experiences (Beurel et al., 2015). It is importantly to note that it is the beta isoform that is ubiquitously expressed in the brain structures (Graef et al., 1999) and knock-in mutant models that display urpregulated content specifically of beta isoform of GSK-3 demonstrate vulnerability to depressive syndrome (Beurel et al., 2015). Importantly, lack of active GSK-3 $\beta$ prevented long term potentiation in the rodent hippocampus. In 2008 Kimure and colleagues revealed that inhibition of this kinase prior to context re-exposure but not to conditioning itself impairs memory formation, thus beta isoform of GSK-3 is implicated in the consolidation phase of learning. Additionally, there is data that indicates an association between decreased content of inactive GSK-3 beta in the longterm negative memories in a model of PTSD (Dahlhoff et al., 2010). The role of GSK-3 in regulation of NMDA-dependent mechanisms was also addressed (Peineau et al., 2009) which leads us to speculate about an important role of this kinase in the synaptic mechanisms, particularly in the balance between long term potentiation and long-term depression. 
Increased production of GSK-3-dependent pro-inflammatory cytokines was shown to be closely associated with hypercorticosteronaemia, a condition triggered by excessive activation of the HPA axis (Uchoa et al., 2014). Increased production of CORT and activation of GSK-3-mediated proinflammatory pathways can provoke oxidative stress and mitochondrial changes (Sato et al., 2010), an important vulnerability factor for the development of a depressive-like conditions (Oliveira et al., 2017). In our modFST model these changes were replicated and we detected increased brain content of carbonylated proteins, a marker of irreversible protein damage associated with increased content of reactive oxygen species (Frijhoff et al., 2015; Gorlova et al., 2019). Oxidative stress was accompanied by GSK-3 overexpression and increased CORT production that are in the line with the data discussed above. Our results suggest overlapping pro-inflammatory mechanisms in these two models of depressive syndrome of various aetiologies.

\subsection{Pro-inflammatory changes during stress, depression and} neuropsychiatric pathology associated with abnormal retention of adverse memories 
Neuropsychiatric pathologies associated with augmented retention of negative experiences constitute an important mechanism of depressive syndrome development (Gold and Korol, 2012). Depressive syndrome is a highly heterogeneous phenomenon and interindividual differences in enhanced acquisition of adverse memories can affect efficacy of applied antidepressant treatments. Role of neuroinflammatory mechanisms in the vulnerability mechanisms to depression has been debated and there is a concern that features of neuroinflammation associated with the development of a depressive syndrome can underlie higher efficacy of novel anti-inflammatory antidepressant treatments as compared to standard procedures.

From clinical data we know that a positive correlation exists between signs of inappropriate retention of memories about negative or traumatic experiences in patients suffering from PTSD and systemic content of proinflammatory cytokine profile, CRP, INF gamma and COX-1 (Miller et al, 2018; Toft et al., 2019). Consistent with these studies, similar differences were shown for central pro-inflammatory profiles, where brain overexpression of IL-6, TNF and other cytokines was associated with drug resistance in patients with depression comorbid with PTSD (CostemaleLacoste et al., 2016). Of particular importance, GSK-3-dependent 
functionally related mechanisms have been shown to contribute in the drug resistance mechanisms as well (Costemale-Lacoste et al., 2016).

In our modFST study we aimed to further examine neuroinflammatory conditions associated with inappropriate retention of adverse memories and thus we have shown that limbic overexpression of IL-1 beta, TNF and COX1 are associated with increased floating duration. These data are in the line with our reports that functionally related isoforms of GSK-3 are overexpressed in two major limbic brain structures, hippocampus and prefrontal cortex, and positively correlated with behavioral signs of augmented learning of adversity. Together, our data are consistent with the notion that both hippocampus and prefrontal cortex are key brain regions for animal emotionality and memorizing of environmental adversities in the development of PTSD (Jope et al., 2006; Lopresto et al., 2016).

Concerning GSK-3-dependend mechanisms of abnormal retention of adverse memories, we showed distinct patterns of mRNA expression of alpha and beta isoforms of GSK-3. For instance, no significant changes were found in the prefrontal cortex for alpha or beta isoforms of GSK-3 nor in thiamine-, nor in imipramine-treated groups, while in hippocampus we observed changes in beta isoform expression following modFST procedure. 
Thiamine-dependent changes in hippocampal expression of alpha isoform can be explained with known thiamine memory-enhancing properties. Overall, our data showed similar anti-stress activity of both treatments on alpha and beta limbic expression that can support a notion that alpha isoform can serve as a molecular analogue of beta isoform under certain conditions. This notion leads us to examine alpha isoform as an additional target for the depression treatment. These data support the view that alpha isoform can be an important molecular regulator of depressive syndrome associated with abnormal retention of adverse memories.

\subsection{Validity of novel models of depression using an ultrasound-induced- "emotional stress" and modified swim test of enhanced conditioning of adverse memories}

Emotional stress is a form of distress resulted from suffering a sudden and strong negative experience that is not triggered by any invasive manipulation (Fontes et al., 2014). Repeated defeat, death of relatives, and maternal separation are among the leading causes of emotional stress commonly regarded as a mental stress or psychological stress. Multiple factors of organic nature such as pain conditions, infectious diseases, neuroendocrine pathologies and inflammation are associated with stress 
response and can be downstream drivers of depressive symptomology (Selye, 1974).

Here, in the ultrasound stress study, we showed that chronic and unpredictable stress based on random alterations of emotionally negative ultrasound cues can provoke maladaptive changes that lead to the development of a depressive syndrome in rodents. This model lacked any physical or organic stressors such as animal immobilization, deprivation of food and water or forced swimming. In the present model animal exposition to the sound cues was chronic and inescapable and mimicked animal vocalization in nature (Brudzynski et al., 2010). When rodents communicate at frequencies between 20 and $25 \mathrm{kHz}$ it indicates their negative emotional state; when rodents communicate at frequencies between 25 and $45 \mathrm{kHz}$ or higher, it indicates their positive or neutral emotional state (Kuraoka and Nakamura, 2010).

As we showed, mice exposed to ultrasound stress had anhedonic states that were manifested as decreased sucrose preference and consumption, increased despair behavior that was manifested as prolonged time spent floating in the modFST, anxiety-like behavior that was manifested as 
decreased time spent in the central zone of open filed. Animal horizontal and vertical activity were affected as well along with aggressive behavior.

These results further provide evidence that the ultrasound stress model is of importance for translational stress-induced depression studies. In recent years there was a move toward naturalistic approaches to model depressive syndrome that lack any physical or organic components for induction of the depressive-like traits (Buwalda et al., 2005; Baram et al., 2012). While existing naturalistic models had validity (Pollak et al., 2010), a great deal of limitations still exist that narrowed the reliability of these models, which were affected with minor changes in the animals' environment. Employed here, the ultrasound stress model is of particular significance as it mimics human psychological stress and provokes characteristic behavioral and biochemical changes in rodents that are typical for depressive syndrome.

Despite the fact that augmented memorizing of negative experiences constitutes an important element of the pathological alterations associated with depressive syndrome, little is known about the mechanisms of this phenomenon as multiple limitations still exist to specifically model this condition. The modified forced swim test offers a valid and reliable approach to discover molecular mechanisms of enhanced cognitive 
processing associated with depressive syndrome. Our modFST model was based on a classical forced swim test (Porsolt, 1977) that is commonly used in depression research (Lucki, 1997). This paradigm is used to model an inescapable aversive situation where rodents typically demonstrate despair behavior that is accompanied by hypothalamic-pituitary-adrenal axis activation (Cabib et al., 2012) and release of glucocorticoids. Besides these changes, repeated exposure of animals to the aversive context in our paradigm was shown to affect pathways that implicate learning and memory processes. A series of experiments has been done to specifically address the role of context re-exposure and we demonstrated key roles of timing and context conditioning for the development of aforementioned behavioral and biochemical changes (Strekalova et al., 2016). Notably, a third re-exposure to a swimming session before Day 5 showed absence of changes that we saw in our established protocol, thus highlighting an important role of timing in the development of augmented learning and depressive syndrome.

In consistency with our results, Bogdanova and colleagues in 2013 have revealed that implication of blocators of protein synthesis and biochemical memory cascades resulted in moderation of floating behavior. Thus, our paradigm of repeated swimming sessions combines both features of depression models and contextual memories approaches and is of a great 
use to study mechanisms of augmented learning of adverse memories associated with the development of a depressive syndrome.

\subsection{Clinical implications of anti-depressant-like activity of thiamine- related compounds}

Brain thiamine deficiencies can severely impact function of brain structures as thiamine is a crucial element for normal brain physiology: such deficiencies can provoke profound metabolic aberrations, deficient neuroplasticity and oxidative stress (Smidt et al., 1991). Behaviorally, thiamine deficiencies can be manifested as increased duration of floating, a sign of despair-like behavior in rodents (Nakagawasai et al., 2007).

Thiamine-related compounds display anti-oxidant and anti-stress effects in animal stress research (Bozic et al., 2015). Our data suggest that 14 daylong thiamine pre-treatment prevents development of stress-induced depressive syndrome as well as overexpression of GSK-3 isoforms further support these results (Pavlov et al., 2017). We have chosen the pretreatment of imipramine as an internal control to anti-depressant-like activity of thiamine as previously these two medications were shown to counteract stress-induced signs of behavioral despair and ameliorate brain GSK-3 overexpression (Pan et al., 2010; Markova et al., 2017). 
Of particular significance are findings that thiamine is able to restore hippocampal neuroplasticity and neurogenesis in a model of predation stress (Vignisse et al., 2017) presumably via Nrf2 antioxidant response element mediated mechanisms (Tapias et al., 2018). Thiamine was efficient to prevent brain oxidative stress in our modFST study as well as overexpression of beta isoform of GSK-3 thus it can be regarded as a potent antioxidant to counteract negative stress induced brain alterations.

Some of the ameliorated thiamine effects can be due to non-enzymatic thiamine activity, presumably extracellular, where thiamine is a known molecule for its regulatory functions in the pentose phosphate pathway and Krebs cycle (Bettendorff et al., 2014). Present studies as well as other research (Mkrtchyan et al., 2015) demonstrate emerging knowledge of the anti-inflammatory properties of the thiamine (Pavlov et al., 2017; Pavlov et al., 2019). These effects can be linked to the effects of thiamine on activity of GSK-3 beta isoform. GSK-3 is known to phosphorylate Nrf2 that is a downregulator of respective genes and antioxidant response. Prevention of overexpression of beta isoform of GSK-3 with thiamine can affect antioxidant cell system and subsequently ameliorate oxidative stress that we saw as decreased levels of protein carbonyls. Importantly, an upregulation of expression of proinflammatory cytokines, combined with increase of 
depressive-like behavioral traits, that were prevented by thiamine administration, provide the first evidence that thiamine can affect proinflammatory mechanisms in a model of augmented conditioning to environmental adversity. The pro-inflammatory profile of examined limbic structures was paralleled with increased oxidative stress, manifested in increased content of carbonylated proteins that was counteracted by thiamine pretreatment as well.

It is established that central upregulation of proinflammatory cytokines stimulates glutamatergic microglial and astroglial signaling (Bezzi et al., 2001; Takeuchi et al., 2006; Fischer et al, 2014) that in turn increases production of reactive oxygen species (Dargelos et al., 2010). Reactive oxygen species can oxidize proteins leading to protein carbonylation, an irreversible process that can be reliably measured. Alleviation of these conditions with thiamine supplementation suggests that thiamine exerts the capacity to normalize the balance of oxidation processes. Taken together, thiamine exerts strong anti-inflammatory and anti-depressant-like properties induced by stress. These features indicate that thiamine supplementation has the potential to be used in the treatment of depressive syndrome and to investigate its underlying mechanisms in the translational and clinical research of depression. 


\section{REFERENCES}

Baram TZ, Davis EP, Obenaus A, Sandman CA, Small SL, Solodkih A, Stern H. Fragmentation and unpredictability of early-life experience in mental disorders. Am. J. Psychiatry. 2012. 169 (9): 907-915.

Bettendorff L, Lakaye B, Kohn G, Wins P. Thiamine triphosphate: a ubiquitous molecule in search of a physiological role. Metab Brain Dis. 2014. 29(4): 1069-82. DOI:10.1007/s11011-014-9509-4.

Beurel E, Grieco SF, Jope RS. Glycogen synthase kinase-3 (GSK3): regulation, actions, and diseases. Pharmacol. Ther. 2015. 148: 114131.

Bezzi P, Domercq M, Brambilla L, Galli R, Schols D, De Clercq E, Vescovi A, Bagetta G, Kollias G, Meldolesi J, Volterra A. CXCR4-activated astrocyte glutamate release via TNFalpha: amplification by microglia triggers neurotoxicity. Nat Neurosci. 2001. 4(7): 702-10. DOI:10.1038/89490.

Bluthe RM, Walter V, Parnet P, Laye S, Lestage J, Verrier D. Lipopolysaccharide induces sickness behaviour in rats by a vagal mediated mechanism. C R Acad. Sci. 1994. 317: 499-503.

Bogdanova O, Kanekar S, D'Anci K, Renshaw P. Factors influencing behaviour in the forced swim test. Physiol. Behav. 2013. 118: 22739.

Bozic I, Savic D, Laketa D, Bjelobaba I, Milenkovic I, Pekovic S, Nedeljkovic N, Lavrnja I. Benfotiamine attenuates inflammatory response in LPS stimulated BV-2 microglia. PLoS One. 2015. 10: e0118372.

Brudzynski SM, Fletcher NH. Rat ultrasonic vocalization: short-range communication. In: Handbook of Behavioral Neuroscience. 2010. 19: 69-76.

Buwalda B, Kole MH, Veenema AH, Huininga M, de Boer SF, Korte SM, Koolhaas JM. Long-term effects of social stress on brain and behavior: a focus on hippocampal functioning. Neurosci. Biobehav. Rev. 2005. 29 (1): 83-97.

Cabib S, Puglisi-Allegra S. The mesoaccumbens dopamine in coping with stress. Neurosci. Biobehav. Rev. 2012. 36: 79-89.

Chang YT, Chen CL, Lin CF, Lu SL, Cheng MH, Kuo CF, Lin YS. (2013). Regulatory role of GSK-3b on NF- $\mathrm{k}$ B, nitric oxide, and TNF-a in group A streptococcal infection. Mediators Inflamm. 2013: 720689 DOI:10.1155/2013/720689. 
Costemale-Lacoste JF, Guilloux JP, Gaillard R. The role of GSK-3 in treatment-resistant depression and links with the pharmacological effects of lithium and ketamine: A review of the literature. Encephale. 2016. 42(2): 156-64. DOI:10.1016/j.encep.2016.02.003. Couch Y, Anthony DC, Dolgov O, Revischin A, Festoff B, Santos AI, Steinbusch HW, Strekalova T. Microglial activation, increased TNF and SERT expression in the prefrontal cortex define stress-altered behaviour in mice susceptible to anhedonia. Brain Behav. Immun. 2013. 29: 136-146. DOI:10.1016/j.bbi.2012.12.017.

Dahlhoff M, Siegmund A, Golub Y, Wolf E, Holsboer F, Wotjak CT. AKT/GSK-3/beta-catenin signalling within hippocampus and amygdala reflects genetically determined differences in posttraumatic stress disorder like symptoms. Neuroscience. 2010. 169: 1216-26.

Dantzer R, O'Connor JC, Freund GG, Johnson RW, Kelley KW. From inflammation to sickness and depression: when the immune system subjugates the brain. Nat. Rev. Neurosci. 2008. 9:46-56.

Dargelos E, Brulé C, Stuelsatz P, Mouly V, Veschambre P, Cottin P, Poussard S. Upregulation of calcium-dependent proteolysis in human myoblasts under acute oxidative stress. Exp Cell Res. 2010. 316(1): 115-25. DOI:10.1016/j.yexcr.2009.07.025.

D'Mello C, Swain MG. Immune-to-Brain Communication Pathways in Inflammation- Associated Sickness and Depression. Curr Top Behav Neurosci. 2017.31: 73-94. DOI: 10.1007/7854_2016_37.

Fang $\mathrm{X}$, Zhan $\mathrm{G}$, Zhang J, Xu H, Zhu B, Hu Y, Yang C, Luo A. Abnormalities in Inflammatory Cytokines Confer Susceptible to Chronic Neuropathic Pain-related Anhedonia in a Rat Model of Spared Nerve Injury. Clin Psychopharmacol Neurosci. 2019. 17(2) : 189-199. DOI: 10.9758/cpn.2019.17.2.189.

Fischer R, Wajant H, Kontermann R, Pfizenmaier K, Maier O. Astrocytespecific activation of TNFR2 promotes oligodendrocyte maturation by secretion of leukemia inhibitory factor. Glia. 2014. 62: 272-283.

Fontes MA, Xavier CH, Marins FR, Limborço-Filho M, Vaz GC, MüllerRibeiro FC, Nalivaiko E. Emotional stress and sympathetic activity: Contribution of dorsomedial hypothalamus to cardiac arrhythmias. Brain Res. 2014. 1554: 49-58.

Frijhoff J, Winyard PG, Zarkovic N, Davies SS, Stocker R, Cheng D, Knight AR, Taylor EL, Oettrich J, Ruskovska T, Gasparovic AC, Cuadrado A, Weber D, Poulsen HE, Grune T, Schmidt HH, Ghezzi 
P. Clinical Relevance of Biomarkers of Oxidative Stress. Antioxid Redox Signal. 2015. 23(14): 1144-70. DOI:10.1089/ars.2015.6317. Graef IA, Mermelstein PG, Stankunas K, Neilson JR, Deisseroth K, Tsien RW, Crabtree GR. L-type calcium channels and GSK-3 regulate the activity of NF-ATc4 in hippocampal neurons. Nature. 1999. 401, 703-8.

Gold PE, Korol DL. Making memories matter. Frontiers integrative neuroscience. 2012. 1(12): 6:116. DOI: 10.3389/fnint.2012.00116, 2012.

Golpich M, Amini E, Hemmati F, Ibrahim NM, Rahmani B, Mohamed Z, Raymond AA, Dargahi L, Ghasemi R, Ahmadiani A. Glycogen synthase kinase-3 beta (GSK-3 $\beta$ ) signaling: Implications for Parkinson's disease. Pharmacol Res. 2015. 97: 16-26. doi: 10.1016/j.phrs.2015.03.010.

Gorlova A, Pavlov D, Anthony DC, Ponomarev ED, Sambon M, Proshin A Shafarevich I, Babaevskaya D, Lesch KP, Bettendorff L, Strekalova $\mathrm{T}$. Thiamine and benfotiamine counteract ultrasound-induced aggression, normalize AMPA receptor expression and plasticity markers, and reduce oxidative stress in mice. Neuropharmacology. 2019. 15: 156:107543. DOI:10.1016/j.neuropharm.2019.02.025.

Jope RS, Roh MS. Glycogen synthase kinase-3 (GSK3) in psychiatric diseases and therapeutic interventions. Curr Drug Targets. 2006. 7(11): 1421-34. DOI:10.2174/1389450110607011421.

Jope RS, Cheng Y, Lowell J, Worthen RJ, Sitbon YH, Beurel E. Stressed and inflamed, can GSK3 be blamed? Trends Biochem Sci. 2017. 42: 180-192.

Krügel U, Fischer J, Radicke S, Sack U, Himmerich H. Antidepressant effects of TNF-a blockade in an animal model of depression. $\mathrm{J}$ $\begin{array}{llll}\text { Psychiatr } & \text { Res. } 2013 . & \text { 67(5), }\end{array}$ DOI:10.1016/j.jpsychires.2013.01.007.

Kuraoka K, Nakamura K. Vocalization as a Specific Trigger of Emotional Responses. Handbook of Mammalian Vocalization. 2010. 167-177.

Lopresto D, Schipper P, Homberg JR. Neural circuits and mechanisms involved in fear generalization: Implications for the pathophysiology and treatment of posttraumatic stresss disorder. Neurosci Biobehav Rev. 2016. 60: 31-42. DOI:10.1016/j.neubiorev.2015.10.009.

Lucki I. The forced swimming test as a model for core and component behavioural effects of antidepressant drugs. Behav Pharmacol. 1997. 8 (6-7): 523-532. 
Mao H, Fang X, Floyd KM, Polcz JE, Zhang P, Liu B. Induction of microglial reactive oxygen species production by the organochlorinated pesticide dieldrin. Brain Res. 2007. 1186, 267274.

Markova N, Bazhenova N, Anthony DC, Vignisse J, Svistunov A, Lesch KP, Bettendorff L, Strekalova T. Thiamine and benfotiamine improve cognition and ameliorate GSK-3 $\beta$ - associated stressinduced behaviours in mice. Prog. Neuro- Psychopharmacol. Biol. Psychiatry. 2016. 75: 148-156.

Markova N, Bazhenova N, Anthony DC, Vignisse J, Svistunov A, Lesch KP, Bettendorff L, Strekalova T. Thiamine and benfotiamine improve cognition and ameliorate GSK-3b- associated stressinduced behaviours in mice. Prog. Neuro-Psychopharmacol. Biol. Psychiatry. 2017. 75: 148-156. DOI:10.1016/j.pnpbp.2016.11.001.

Mahar I, Bambico FR, Mechawar N, Nobrega JN. Stress, serotonin, and hippocampal neurogenesis in relation to depression and antidepressant effects. Neurosci. Biobehav. Rev. 2014. 38: 173-192. Miller MW, Lin AP, Wolf EJ, Miller DR. Oxidative Stress, Inflammation, and Neuroprogression in Chronic PTSD. Harv Rev Psychiatry. 2018. 2: 57-69. DOI:10.1097/HRP.0000000000000167.

Misener VL, Gomez L, Wigg KG, Luca P, King N, Kiss E, Daroczi G, Kapornai K, Tamas Z, Mayer L. Cytokine genes TNF, IL1a, IL1b, IL6, IL1RN and IL10, and childhood-onset mood disorders. Neuropsychobiology. 2008. 58: 71-80. doi: 10.1159/000159775

Mkrtchyan G, Aleshin V, Parkhomenko Y, Kaehne T, Luigi Di Salvo M, Parroni A, Contestabile R, Vovk A, Bettendorff L, Bunik V. Molecular mechanisms of the non-coenzyme action of thiamin in brain: biochemical, structural and pathway analysis. Sci. Rep. 2015. 5:12583. DOI:10.1038/srep12583.

Morozova A, Zubkov E, Strekalova T, Kekelidze Z, Storozeva Z, Schroeter, CA, Bazhenova N, Lesch KP, Cline BH, Chekhonin V. Ultrasound of alternating frequencies and variable emotional impact evokes depressive syndrome in mice and rats. Prog. NeuroPsychopharmacol. Biol. Psychiatry. 2016. 68: 52-63.

Müller N. Immunology of major depression. Neuroimmunomodulation. 2014. 21 (2-3): 123-130. https://doi.org/10.1159/000356540.

Nakagawasai O, Yamadera F, Iwasaki K, Asao T, Tan-No K, Niijima F, Arai $H$, Tadano T. Preventive effect of kami-untan-to on performance in the forced swimming test in thiamine-deficient mice: 
relationship to functions of catecholaminergic neurons. Behav. Brain Res. 2007. 177: 315-321.

Oliveira TQ, de Sousa CN, Vasconcelos GS, de Sousa LC, de Oliveira AA, Patrocínio CF, Medeiros ID, Honório Júnior JE, Maes M, Macedo D, Vasconcelos SM. Brain antioxidant effect of mirtazapine and reversal of sedation by its combination with alpha-lipoic acid in a model of depression induced by corticosterone. J Affect Disord. 2017. 219: 49-57. DOI: 10.1016/j.jad.2017.05.022.

Pan X, Gong N, Zhao J, Yu Z, Gu F, Chen J, Sun X, Zhao L, Yu M, Xu Z, Dong W, Qin Y, Fei G, Zhong C, Xu TL. Powerful beneficial effects of benfotiamine on cognitive impairment and beta-amyloid deposition in amyloid precursor protein/presenilin-1 transgenic mice. Brain. 2010. 133: 1342-1351. DOI:10.1093/brain/awq069.

Pavlov D, Markova N, Bettendorff L, Chekhonin V, Pomytkin I, Lioudyno V, Svistunov A, Ponomarev E, Lesch KP, Strekalova T. Elucidating the functions of brain GSK3 $\alpha$ : possible synergy with GSK3 $\beta$ upregulation and reversal by antidepressant treatment in a mouse model of depressive-like behaviour. Behav. Brain Res. 2017. 335: 122-127. DOI:10.1016/j.bbr.2017.08.018.

Pavlov D, Bettendorff L, Gorlova A, Olkhovik A, Kalueff AV, Ponomarev ED, Inozemtsev A, Chekhonin V, Lesch KP, Anthony DC, Strekalova T. Neuroinflammation and aberrant hippocampal plasticity in a mouse model of emotional stress evoked by exposure to ultrasound of alternating frequencies. Prog. NeuroPsychopharmacol. Biol. Psychiatry. 2019. 90: 104-116. DOI:10.1016/j.pnpbp.2018.11.014.

Peineau S, Nicolas CS, Bortolotto ZA, Bhat RV, Ryves WJ, Harwood AJ, Dournaud P, Fitzjohn SM, Collingridge GL. A systematic investigation of the protein kinases involved in NMDA receptordependent LTD: evidence for a role of GSK-3 but not other serine/threonine kinases. Mol. Brain. 2009. 2: 22.

Polter A, Yang S, Zmijewska AA, van Groen T, Paik JH, Depinho RA. Forkhead box, class $\mathrm{O}$ transcription factors in brain: regulation and behavioral manifestation. Biol. Psychiatry. 2009. 65 (2): 150-159.

Pollak DD, Rey CE, Monje FJ. Rodent models in depression research: classical strategies and new directions. Ann. Med. 2010. 42 (4): 252-264.

Porsolt R, Bertin A, Jalfre M. Behavioural despair in mice: a primary screening test for antidepressants. Arch. Int. Pharmacodyn. therapie 1977. 229: 327-36. 
Powers A, Dixon HD, Conneely K, Gluck R, Munoz A, Rochat C, Mendoza H, Hartzell G, Ressler KJ, Bradley B, Pace TWW, Umpierrez GE, Schwartz AC, Michopoulos V, Gillespie CF. The differential effects of PTSD, MDD, and dissociation on CRP in trauma-exposed women. Compr Psychiatry. 2019. 93: 33-40. DOI: 10.1016/j.comppsych.2019.06.007.

Sato H, Takahashi T, Sumitani K, Takatsu H, Urano S. Glucocorticoid Generates ROS to Induce Oxidative Injury in the Hippocampus, Leading to Impairment of Cognitive Function of Rats. J Clin Biochem Nutr. 2010. 47(3): 224-32. DOI: 10.3164/jcbn.10-58.

Strekalova T, Markova N, Shevtsova E, Zubareva O, Bakhmet A, Steinbusch H, Bachurin S, Lesch K.P. Individual differences in Behavioural despair PredictBrain GSK-3beta Expression in mice: the Power of a Modified Swim Test. Neural Plast. 2016. ID 5098591.

Simen BB, Duman CH, Simen AA, Duman RS. TNFalpha signaling in depression and anxiety: behavioral consequences of individual receptor targeting. Biol Psychiatry. 2006. 59(9): 775-85. DOI:10.1016/j.biopsych.2005.10.013.

Selye H. Stress without Distress. J.B. Lippincott Company, Philadelphia, 1974. 171.

Simonov P. Brain mechanisms of emotions. Neurosci. Behav. Physiol. 1997. 27 (4): 405-413.

Smidt L, Creman F, Grivetti L, Clifford A. Influence of thiamine supplementation on the health and general well-being of an elderly Irish population with marginal thiamine deficiency. J. Gerontol. 1991. 146: 16-22.

Takeuchi H, Jin S, Wang J, Zhang G, Kawanokuchi J, Kuno R, Sonobe Y, Mizuno T, Suzumura A. Tumor necrosis factor-alpha induces neurotoxicity via glutamate release from hemichannels of activated microglia in an autocrine manner. J Biol Chem. 2006. 281(30): 21362-8. DOI:10.1074/jbc.M600504200.

Tanaka K, Furuyashiki T, Kitaoka S, Senzai Y, Imoto Y, Segi-Nishida E, Deguchi Y, Breyer RM, Breyer MD, Narumiya S. Prostaglandin E2mediated attenuation of mesocortical dopaminergic pathway is critical for susceptibility to repeated social defeat stress in mice. $\mathrm{J}$ Neurosci. 2012. 32(12): 4319-29. DOI:10.1523/JNEUROSCI.595211.2012.

Toft H, Lien L, Neupane SP, Abebe DS, Tilden T, Wampold BE, Bramness JG.Cytokine concentrations are related to level of mental distress in 
inpatients not using anti-inflammatory drugs. Acta Neuropsychiatr. 2019. 2: 1-22. DOI: 10.1017/neu.2019.36.

Uchoa ET, Aguilera G, Herman JP, Fiedler JL, Deak T, de Sousa MB. Novel aspects of glucocorticoid actions. J Neuroendocrinol. 2014. 26(9): 557-72. DOI:10.1111/jne.12157.

Vignisse J, Steinbusch HW, Grigoriev V, Bolkunov A, Proshin A, Bettendorff L, Bachurin S, Strekalova T. Concomitant manipulation of murine NMDAandAMPA-receptors to produce pro-cognitive drug effects in mice. Eur Neuropsychopharmacol. 2014. 24 (2): 309-320.

Vignisse J, Sambon M, Gorlova A, Pavlov D, Caron N, Malgrange B, Shevtsova E, Svistunov A, Anthony D, Markova N, Bazhenova N, Coumans B, Lakaye B, Wins P, Strekalova T, Bettendorff L. Thiamine and benfotiamine prevent stress-induced suppression of hippocampal neurogenesis in mice exposed to predation without affecting brain thiamine diphosphate levels. Mol. Cell. Neurosci. 2017. 82: 126-136. DOI:10.1016/j.mcn.2017.05.005. 


\section{SUMMARY}

In my thesis I aimed to study the role of the glycogen-synthase kinase 3 (GSK-3) expression, inflammatory mechanisms and associated changes in the brain of mice, using two distinct models of depression. These new models were the ultrasound stress model of "emotional stress" and the model of enhanced contextual learning of adverse memories. In the modified forced swim model (modFST), the classic two-day forced swim in mice is followed by an additional delayed session on Day 5, where increased "despair" behaviour and upregulated GSK-3 are contextdependent. In the ultrasound stress model of "emotional stress", mice are 
exposed to unpredictably presented ultrasound mimicking signals of anxiety and distress that are naturally emitted by small rodents. In Chapter 4 I studied hippocampal gene and protein expression of both GSK-3 $\beta$ and GSK-3 $\alpha$, as well as the associated molecules forkhead transcription factor O subfamily member $3 a$ (FOXO3a), phosphatase and tensin homolog (PTEN) and protein kinase B phosphorylated at serine 473 (AktpSer473) in mice exposed to the ultrasound stress model of "emotional stress". While the upregulation of GSK-3 $\beta$ activity in stressed animals was accompanied by similar over-expression of hippocampal GSK-3 $\alpha$, no correlation between the latter and scores of depressive-like behavior in the forced swim test and other signs of altered emotionality were found suggesting different functional roles of two GSK-3 isoforms in stress-induced depressive syndrome. We also found decreased densities of Ki67-positive and doublecortine-positive cells and downregulated expression of neurotrophins, including brain-derived neurotrophic factor (BDNF) and its receptor tropomyosin receptor kinase B (TrkB) in the hippocampus, suggesting decreased plasticity in the CNS of stressed mice. Stressed mice also displayed increased plasma levels of cytokines tumor necrosis factor (TNF), interleukin (IL)-1 $\beta$ and IL-6 and hippocampal expression of IL-1 $\beta$ and IL-6. Additionally, signs of microglia activation, increased density of 
ionized calcium binding adaptor molecule 1 (Iba1)-positive cells and concentrations of oxidative stress markers 3-nitrotyrosine and malondialdehyde were found.

In Chapter 2 and Chapter 3 we studied gene expression of GSK3 isoforms and markers of neuroinflammation in the hippocampus and prefrontal cortex of mice exposed to the modFST. We found brain overexpression of GSK3 $\alpha$, a poorly studied molecule in animal models, with distinct expression dynamics from GSK3 $\beta$ after the modFST (Chapter 2). Our findings provide the first evidence for the involvement of GSK-3 $\alpha$ in a depressive-like phenotype in an animal model of depression. In Chapter 3 we report messenger ribonucleic acid (mRNA) overproduction of proinflammatory cytokines IL-1 $\beta$ and TNF, as well as cyclooxygenase-1 (COX-1) in the hippocampus and prefrontal cortex of mice subjected to the modFST. Overproduction of both IL-1 $\beta$ and TNF positively correlated with expression of GSK-3 3 , but not GSK-3 $\alpha$, and total duration of floating correlated with expression of both GSK-3 isoforms in the examined brain regions. In addition, it has been found that mice exposed to the modFST demonstrate increased plasma corticosterone concentrations, elevated concentrations of protein carbonyl, a marker of oxidative stress and overexpression of c-Fos in the brain. Most of changes induced by the modFST 
were reversed by treatments with a low dose of imipramine or thiamine (Vitamin B1) that were shown to exert anti-stress and antidepressant properties and normalize GSK-3 $\beta$ expression. Together, our results obtained in studies with two depression models suggest overlapping molecular mechanisms of over-expression of GSK-3 and proinflammatory mechanisms along with oxidative stress to underlie distinct aspects of depressive syndrome. In addition, we identified GSK-3 $\alpha$ as one of potential targets of depression treatment and further demonstrated that thiamine drugs can have a potential in reducing depressive-like changes associated with stress. 


\section{SAMENVATTING}

\section{De bijdragen van CNS-ontstekingen en glycogen synthase kinase-3 \\ (GSK-3)-cascades op het negatieve herinneringen geheugen in muismodellen van emotionele stress}

In mijn proefschrift bestudeerde ik de expressie van de glycogeen-synthase kinase 3 (GSK-3), een moleculaire substraat van stress, evenals de ontstekingsmechanismen en de bijbehorende veranderingen op moleculair en cellulair niveau in de hersenen van muizen, met behulp van twee depressiemodellen : het door ultrasonoor geluid geïnduceerd stressmodel van "emotionele stress" en de gemodificeerde gedwongen zwemtest (modFST). In het model van "emotionele stress" werd het ultrasone geluid willekeurig afgewisseld tussen 20 en $25 \mathrm{kHz}$ wat overeenkomt met het natuurlijk geluid van knaagdieren in een angst en vrees situatie, en frequenties tussen $25-45 \mathrm{kHz}$ wat overeenkomt met het geluid dat muizen produceren in een "neutrale" emotionele toestand. De muizen, 21-dagen blootgesteld aan deze afwisselende frequenties van ultrageluid, vertoonden een depressief beeld. Ten tweede hebben we een aangepaste Porsolt's test voor muizen gebruikt, een model van hulpeloos gedrag bij kleine knaagdieren, waarbij een extra vertraagde sessie op dag 5 na de initiële blootstelling resulteert in een verdere toename van hulpeloos gedrag bij de gevoelige dieren maar niet in veerkrachtige individuele muizen. Verhoogde hulpeloosheid in deze test wordt beschouwd als een teken van verbeterde contextuele conditionering van nadelige herinneringen, een belangrijk mechanisme van depressie. De upregulatie van beide isovormen van GSK- 
3 te weten GSK-3 $\beta$ en GSK-3 $\alpha$, werd gevonden in beide muismodellen van depressie. Echter, de veranderingen in de expressie van GSK-3 $\beta$ en niet de veranderingen in de expressie van GSK-3 $\alpha$ in de hersenen, was significant gecorreleerd met kernen van depressief gedrag in deze twee modellen. Voor het eerst hebben wij de verschillende functionele rollen van de twee GSK3 isovormen in het stress-geïnduceerd syndroom aangetoond. De ontstekingsbevorderende veranderingen in beide diermodellen waren verhoogde plasmaconcentraties en hersenexpressie van tumornecrosefactor (TNF), interleukine (IL) -1 $\beta$ en IL-6, evenals cyclooxygenase-1 (COX-1) . Ultrasonore stress laat tekenen van verlaagde neuronale plasticiteit zien: de densitie aan Ki67-positieve en dubbelcortine-positieve cellen en een neerwaarts gereguleerde expressie van neurotrofines, en markers van microglia-activering, evenals verhoogde concentraties van oxidatieve stressmarkers 3-nitrotyrosine en malondialdehyde. De laatste veranderingen werden ook in de modFST gevonden. Dezelfde moleculaire en cellulaire veranderingen werden gezien bij de ontwikkeling van depressie achtige syndromen van verschillende oorsprong. De meeste depressieve uitingen waargenomen in deze twee modellen werden tegengegaan door de toediening van antioxidant thiamine (vitamine B1) welke ook de expressie van GSK-3 $\beta$ normaliseerde. De overlappende veranderingen in de GSK-3-activiteiten en de gerelateerde mechanismen dragen beide bij tot het aanleren van negatieve herinneringen en "emotionele stress" in de gebruikte modellen van depressie. 


\section{VALORIZATION}

Relevance for society

Depression is a heterogeneous group of mental disorders with high prevalence. At present, the exact pathophysiological mechanism of depression and associated processes of heightened negative memory acquisition still remains unclear, while researchers put forward various hypotheses to interpret the possible links to this disease, including excessive inflammation and deficient neuroplasticity.

As an outcome from my thesis work, my data will ultimately help to understand the molecular basis of depressive disorders of various etiologies to enable targeted treatment strategies of them. I pointed out isoforms of glycogen synthase kinase 3 (GSK-3), a molecular marker of distress and human depression in clinical studies, in two translational depression models of various etiologies. Importantly, modFST model replicates enhanced contextual conditioning of adversity that enables future studies of the mechanisms of certain neurobiological susceptibility mechanisms of depressive syndrome that is problematic to model in most of currently used rodent paradigms of the disease. As targeting of oxidative stress and neuroinflammation-related mechanisms of depression are regarded as a promising approach of efficient antidepressant therapy, main pro- 
inflammatory cytokines including tumor necrosis factor (TNF), interleukin$1 \beta$ (IL-1 $\beta$ ) and interleukin-6 (IL-6) were examined in my work with and without thiamine (vitamin B1), a compound with anti-oxidant and antistress properties, and classic antidepressant imipramine treatments. I demonstrated that thiamine was effective to counteract elevations of not only pro-inflammatory cytokines but also oxidative stress markers in the similar manner as imipramine that open new possibilities for thiaminebased treatment of some depression-related states, as thiamine is a nontoxic molecule that lacks side effects. Thus, this thesis is highly valuable as it aimed to investigate the contribution of ubiquitous environmental factors to the risk of having depressive syndrome, and to determine if thiamine can have beneficial impacts on depressive syndrome management.

\section{Target groups}

I consider my target groups to be individuals that are at higher risk of a diagnosis of depression, such as war veterans and survivors of car accidents and other traumatic experiences as these factors precipitate vulnerability to the disease.

Activity / Products 
As potential outlook of presented work, I anticipate an interest of international research groups and pharmaceutical companies to use present animal paradigms in translational and academic research to study oxidative stress in depression models of various etiologies as well as study antidepressant and antioxidant activities of novel drugs in these paradigms. Using of thiamine-based compounds for targeted treatment of GSK-3 $\alpha$ mediated depression can be of additional importance.

\section{Innovation}

My work is innovative in various aspects: I broaden knowledge of two mouse depression paradigms that model various aspects of depressive syndrome. GSK-3 can be a universal marker of depressive syndrome in which the upregulation is accompanied by microglial activation, oxidative stress and neuroplasticity disruption. These changes were reversed by pretreatments with antidepressants and a prominent anti-oxidant, thiamine, that highlights utility of thiamine-based anti-oxidants to prevent development of depressive-like traits through GSK-3 overlapping molecular mechanisms. Notably, while I have shown that GSK-3 can be a universal marker of depressive syndrome of various etiologies, the expression of its isoforms GSK-3 $\alpha$ and GSK-3 $\beta$ is differentially regulated in both models. 


\section{Implementation}

I anticipate publishing my results in peer-reviewed international journals, presenting them at national and international conferences and further widen current knowledge about overlapping molecular mechanisms underlying depressive syndrome induced by "emotional stress" and enhanced learning of adverse context. 


\section{ACKNOWLEGMENTS}

Many brilliant people have contributed to my research career and scientific development and I would like to thank my supervisors: Prof. Klaus-Peter Lesch, Prof. Tatyana Strekalova and Prof. Lucien Bettendorff. Thank you very much for getting me an opportunity to undertake my interesting project, for all your patience, encouragement and advice that you have provided throughout.

I would like to start my acknowledgment part from my sincere appraisal of contribution of Prof. Klaus Peter Lesch. Prof. Lesch taught me a lot in his labs in both Russia, I.M. Sechenov First Moscow State Medical University, and Germany, Würzburg University. Together with Prof. Strekalova, he provided the financial support for my studies and configured my project. Under excellent supervision of Prof. Lesch I performed a number of interesting research sub-projects and discussed a number of challenging ideas for future directions of potential studies. Especially I am respectful to Prof. Lesch that he integrated his clinical observations into this neuroimmunology project and provided valuable comments from his neuropsychiatrist prospective. I would like to thank Prof. David Linden, head of School for Mental Health and Neuroscience, Faculty of Health, 
Medicine and Life Sciences, Prof. Jos Prickaerts, head of Division III, and administration of Maastricht University for their general support and help in organization of the defense of my PhD Thesis.

Prof. Tatyana Strekalova has made an extraordinary contribution to my research as day-to-day supervisor. Her kind help and support got my projects over a number of difficulties and resulted in several state-of-the-art studies. She was extremely helpful and taught me a lot about behavioral neuroscience and methodology, provided valuable advice for data analysis and writing manuscripts. All these years of my $\mathrm{PhD}$ training that $\mathrm{I}$ have worked under her immediate supervision were full of productive research. Prof. Strekalova has designed my studies and publications and made helpful remarks about data presentation. I feel very privileged to have worked with Prof. Strekalova. I am sincerely grateful to Prof. Strekalova for designing my studies and general training in neuroscience, organization of my traineeships abroad and all practical help I have benefit over the years 20162019.

My sincere thanks go to Prof. Lucien Bettendorff, who has brought a concept of thiamine in my research and provided me an opportunity to join his research team as an exchange $\mathrm{PhD}$ student under ERASMUS Mobility 
Grant program. His guidance and support, his immense knowledge and the warmest welcoming in Liege University, GIGA Neuroscience, made this trainingship one of the most productive time that I have had.

I am deeply indebted to Prof. Daniel Anthony who helped me throughout the project. I am deeply thankful to him for the time that he has spent teaching me of how scientific papers have to be prepared. Together with Prof. Strekalova, he walked me through the publication process that enabled me to learn each step of this important experience. Thanks to visits of Prof. Anthony to our labs, I have learned novel methods of brain dissection in mice, and several other important skills. His care and support helped me overcome the inevitable difficulties towards the end of my $\mathrm{PhD}$.

I would like to give my special thanks to Prof. Andrey Svistunov, Prof. Vladimir Chekhonin, Prof. Denis Butnary and Prof. Alexey Umriukhin who have supported my studies and trainingships, over seven for these years. I would also like to thank Dr. Careen Schroeter, Dr. Evgeny Zubkov, Dr. Anna Morozova, Mr. Rene Vandervile, Dr. Erik Wolters and Dr. Johannes de Munter who have supported and contributed in my work and made an important input and scientific insights in discussions, provided organizational and technical support of my research projects. 
I would like to acknowledge the contribution of my group members who greatly helped me out during my $\mathrm{PhD}$ studied and contributed to my papers: Anna Gorlova, Ekaterina Veniaminova, Margaux Sambon and Judit Alhama Riba, as well as Margarita Oplatchikova, Diana Babevskaya. Thank you all!

Lastly, I would like to thank my mother for her love and encouragement. 


\section{ABOUT THE AUTHOR}

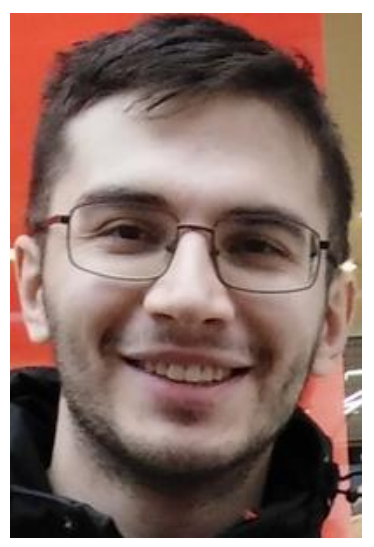

Dmitrii Pavlov was born on March 2nd, 1993 in Murmansk (Russian Federation) and graduated from Moscow State University at 2015 as a specialist in Physiology.

Since 2015 he, being a PhD student of the Faculty of Biology of the Lomonosov Moscow State University, started to take part in a collaborative study on the ultrasound-induced depressive syndrome in mice, which was co-supervised by Prof. T. Strekalova, Maastricht University, the Netherlands. During four-year collaborative research activities, Dmitrii 
achieved considerable progress in his studies and learned a great deal of surgical, neuroanatomical, biochemical, cellular and molecular biology, behavioural assessment techniques. He carried out this work with a support and under a supervision of Russian academicians Prof. Vladimir Chelhonin, Prof Anatoly Inozemtsev, Dr. Evgeniy Zubkov and Dr. Anna Morozova. In a course of this work he carried out an impressive amount of experimental work on mice and cell culture that resulted in the accumulation of new fundamental information on mechanisms of emotional stress, depressive syndrome, effects of psychoactive anti-oxidants such as vitamin B1 and its analogues and their role in neuroplasticity and neuroinflammation. Since 2016, Dmitrii enrolled a PhD Program for external students at Maastricht University. Thanks to this Program and to an award of an Erasmus fellowship, he spent an extended period of time in the laboratory of Prof. L. Bettendorff (GIGA Neuroscience, University of Liege, Belgium) to learn a wide range of biochemical analysis. In the course of the $\mathrm{PhD}$ training period, he extensively applied different behavioural methods and has successfully acquired RT-PCR, Western Blot, ELISA, HPLC and immunohistochemical methods. Additionally, this work was supported by EURON grant of Maastricht University, thanks to organizational support of Prof. Gunter Kenis and Nicole Senden. 
Be privileged by an international exchange programs, he conducted his $\mathrm{PhD}$ studies in different labs in Russia, Belgium, Germany and the Netherlands. This multi-culture research environment was really advantageous, Dmitrii obtained a solid and multidimensional training. By end of 2019, he has published 13 papers in the field of stress and depression, with 6 as first author under supervision of senior authors Prof. Tatyana Strekalova and Prof. Daniel Anthony with cumulative IF=16. There are 2 other manuscripts are under revision. He was also attended international conferences, and gave 20 oral or poster presentations in international conferences in Moscow (Russia), Goettingen and Berlin (Germany), Maastricht and Kirkrade (Netherlands), Lisbon (Portugal).

Dmitrii performed detailed characterization of GSK-3 cascade and effects of thiamine compounds in a model of enhanced learning of adverse experiences, the modified swim test, on mice. He was able to reveal differential roles of GSK-3 $\beta$ and GSK-3 $\alpha$ in the individual susceptibility to enhanced retention of adverse conditioned memories in this mouse model of depression, as well as positive effects of chronic administration of thiamine. Additionally, he effectively combined a variety of in vivo and in vitro approaches in validating a paradigm of "emotional stress", a newly proposed model of depression in small rodents, which receives increasing 
attention in the field (Pavlov et al., 2018). Using the ultrasound stress exposure of unpredictably changing frequencies in mice, he had obtained data that serve as a solid foundation to regard this novel paradigm as highly valid in modeling of clinical depression. Moreover, as a student of Lomonosov University, he was involved in the organization of yearly National Olympics in Biology at School level, a highly demanding and privileged task. Besides, as a coach in plant and animal physiology, he prepared over 50 high school sophomores. Currently Dmitrii is taking a researcher position in McGill University, Canada.

In the acknowledgment part, Dmitrii would like to thank Prof. Andrey Svistunov, Prof. Denis Butnary and Prof. Alexey Umriukhin that have contributed to his training ships, over seven for these years, and supported his scientific activity. Dr. Careen Schroeter, Mr. Rene Vandervile and Dr. Erik Wolters with Mr. Johannes de Munter made an important input and scientific insights in discussions, organizational and technical support of his research projects. 
Tel: +7 (977) 3807135

E-mail: mitchellalexpavlov@gmail.com

Employment

2019 - present Researcher, Laboratory of orofacial pain, McGill University, Montréal, Canada (1 fte)

2018 - 2019 Researcher, Laboratory of Psychiatric Neurobiology, Sechenov First Moscow State Medical University, Moscow, Russia (1 fte)

Since 2017 - External PhD student, School for Mental Health and Neuroscience, European Graduate School of Neuroscience, Maastricht University, Maastricht, Netherlands (0 fte)

2016 - 2018 Junior Researcher, Laboratory of Psychiatric Neurobiology, Sechenov First Moscow State Medical University, Moscow, Russia (0.5 fte) 2016 - 2017 Lab Technician, Laboratory of Normal Physiology, Sechenov First Moscow State Medical University, Moscow, Russia (0.5 fte) 
Trainings in domestic and international labs:

March 2019 - May 2019 - training in IHC. Laboratory of Translational

Neuroscience, Department of Psychiatry, Psychosomatics and Psychotherapy, University of Wuerzburg, Wuerzburg, Germany.

Supervisor: Prof. K.P.Lesch

November 2018, February 2019 - training in malondialdehyde assay. GIGA Neuroscience, Centre de Neurobiologie Cellulaire et Moléculaire, University of Liege, Liege, Belgium Supervisor: Prof. L. Bettendorff

October 2017 - June 2018 - training in protein carbonyl fluorometric assay and glutathione fluorometric assay, HPLC, 3-NT assay and western blot technique. GIGA Neuroscience, Centre de Neurobiologie Cellulaire et Moléculaire, University of Liege, Liege, Belgium Supervisor: Prof. L. Bettendorff

November 2016 - December 2016 - training in behavioural analysis of depressive-like behavior in mice using a model of modified swim test. Department of Normal Physiology and VP Serbsky Federal Medical Research Centre of Psychiatry and Narcology, 
Moscow, Russia

Supervisor: Prof. Tatyana Strekalova

October 2016 - training in protein carbonyl fluorometric assay and glutathione fluorometric assay. GIGA Neuroscience, Centre de Neurobiologie Cellulaire et Moléculaire, University of Liege, Liege, Belgium

Supervisor: Prof. L. Bettendorff

February 2016 - June 2016 - training in RT-PCR analysis. Division of Immunochemistry, VP Serbsky Federal Medical Research Centre of Psychiatry and Narcology, Moscow, Russia Supervisor: Prof. V.P. Chekhonin

June 2016 - September 2016 - training in behavioural analysis of aggressive behavior, anxiety-like behavior, rat exposure stress, brain dissection and perfusion. Department of Normal Physiology and VP Serbsky Federal Medical Research Centre of Psychiatry and Narcology, Moscow, Russia

Supervisor: Prof. Tatyana Strekalova 
October 2015 - June 2016 - training in brain perfusion, brain dissection (hippocampus, prefrontal cortex, raphe dorsalis, amygdala, striatum, cerebellum), blood collection, liver, thymus, spleen and adrenals dissection in mice and rats. Department of Basic and Applied Neurobiology, VP Serbsky Federal Medical Research Centre of Psychiatry and Narcology, Moscow, Russia

Supervisor: Prof. V.P. Chekhonin

October 2015 - June 2016 - training in behavioral methods of residentintruder test, elevated O-maze, elevated plus-maze, object recognition test, Morris water maze, dark/ light box, tail suspension, forced swim test, Barnes test, tail-flick test, passive avoidance test and glucose tolerance test. Department of Basic and Applied Neurobiology, VP Serbsky Federal Medical Research Centre of Psychiatry and Narcology, Moscow, Russia

Supervisor: Prof. A.N. Inozemtsev 
October 2014 - June 2015 - training in stereotaxic surgery. Biology department, Lomonosov Moscow State University, Moscow, Russia Supervisor: Prof. A.N. Inozemtsev

February 2014 - June 2014 - training in thymectomy. Biology department, Lomonosov Moscow State University, Moscow, Russia

Supervisor: Prof. A.N. Inozemtsev 
Conferences attended:

Pavlov D, Lesch KP, Anthony DC, Strekalova T. Depressive syndrome and pro-oxidative changes in a fused-in-sarcoma transgene mouse model of amyotrophic lateral sclerosis. 19th WPA World Congress of Psychiatry, Lisbon, Portugal, 23-24.08.2019 (poster presentation)

Pavlov D. Oxidative stress and accompanying pro-inflammatory and neurodegenerative changes in rodent depression models. Workshop Inflammation and oxidative stress in translational research: new models and treatments. Estoril, Portugal, 20.08.2019 (oral presentation)

Pavlov D, Gorlova A, Lesch KP, Anthony D, Strekalova T. Depressivelike syndrome and neuroinflammation in FUS-tg mice. UK-Russia Young Medic Conference, I.M. Sechenov First Moscow State Medical University, Moscow, Russia, 01.03.2019 (poster presentation) 
Pavlov D. Pro-inflammatory CNS changes and altered behavior in FUS transgenic mice, a new model of the amyotrophic lateral sclerosis syndrome. Talk at Maastricht University, Maastricht, Netherlands, 12.02.2019 (oral presentation)

Pavlov D, Gorlova A, Bettendorff L, Strekalova T, Lesch KP. Oxidative stress and neuroinflammation in a FUS-tg mouse model of ALS. Poster session at the department of Normal Physiology, I.M. Sechenov First Moscow State Medical University, Moscow, Russia, 24.01.2019 (poster presentation)

Pavlov D, Gorlova A, Bettendorff L, Strekalova T, Lesch KP. Oxidative stress and neuroinflammation in a FUS-tg mouse model of ALS. Poster session at the department of Normal Physiology, I.M. Sechenov First Moscow State Medical University, Moscow, Russia, 24.01.2019 (poster presentation) 
Pavlov D, Gorlova A, Inozemtsev A, Lesch KP, Strekalova T, Bettendorff L. Supplementaion with thiamine aluminum chloride reduce neuroinflamation induced by aluminium chloride. FENS, Berlin, Germany, 7-11.07.2018 (poster presentation).

Pavlov D, Gorlova A, Sambon M, Lesch KP, Inozemtsev A, Strekalova T, Bettendorff L. Thiamine supplementation alleviates neuroinflamation induced by aluminium chloride. International Sechenov Biomedical Summit, Moscow, Russia, 21.05.2018 (poster presentation).

Pavlov D. Treatment with thiamine ameliorates aluminum-induced neurotoxicity in Sprague-Dawley rats. EURON $\mathrm{PhD}$ days in Maastricht University, Kirkrade, Netherlands, 25.11.2017 (oral presentation).

Pavlov D, Gorlova A, Bettendorff L, Lesch KP, Strekalova T. Treatment with thiamine ameliorates aluminum-induced neurotoxicity in SpragueDawley rats. EURON PhD days in Maastricht University, Kirkrade, Netherlands, 25-27.11.2017 (poster presentation). 
Pavlov D. Treatment with probiotics, thiamine and melatonin ameliorates aluminum-induced neurotoxicity in rats. International Evaluation Conference of the Laboratory of Psychiatric Neurobiology, I.M. Sechenov First Moscow State Medical University, Moscow, Russia, 06.04.2017 (oral presentation).

Pavlov D, Gorlova A, Zubkov E, Morozova A, Cherdyntseva T, Karpuchina O, Inozemtsev A, Strekalova T, Chekhonin V. Treatment with probiotics, thiamine and melatonin ameliorates aluminum-induced neurotoxicity in rats. The 12th Meeting of the German Neuroscience Society, Goettingen, Germany, 22-25.03.2017 (poster presentation).

Veniaminova E, Shevtsova E, Markova N, Gorlova A, Pavlov D, Morozova A, Chekhonin V, Lesch KP, Anthony D, Strekalova T. Behavioural, molecular and metabolic consequences of cholesterol-enriched diet and ameliorating effect of dicholine succinate, 12th Meeting of the German Neuroscience Society, Goettingen, Germany, 22-25.03.2017 (poster presentation) 
Bazhenova N, Waider J, Bonopartes D, Veniaminova E, Markova N, Costa- Nunes J, Zubkov E, Gorlova A, Pavlov D, Morozova A, Lesch KP, Strekalova T. Stress-induced aggression in mice and evidence for preventive effects of drugs with pro-neurogenetic activity, 12th Meeting of the German Neuroscience Society, Goettingen, Germany, 22-25.03.2017 (poster presentation)

Pavlov D, Gorlova A, Zubkov E, Cherdyntseva T, Karpukhina O, Inozemtsev A, Strekalova T, Chekhonin V. Treatment with probiotics ameliorates stressinduced pathological aggression in mice, Microbiology and infection 2017, Wurzburg, Germany, 5-8.03.2017 (poster presentation).

Pavlov D. Treatment with probiotics, thiamine and melatonin ameliorates aluminum-induced neurotoxicity in rats. International Evaluation Conference of the Laboratory of Psychiatric Neurobiology, I.M. Sechenov First Moscow State Medical University, Moscow, Russia, 06.04.2017 (oral presentation). 
Pavlov D. Study of effects of Vitamine B1 (thiamine) in the rat-exposure stress model in $\mathrm{C} 57 \mathrm{Bl} / 6$ mice and on aluminum-induced intoxication in Sprague- Dawley rats. International Conference of 16.12 .16 at the I.M. Sechenov First Moscow State Medical University, Moscow, Russia, 16.12.2016 (oral presentation).

Pavlov D, Gorlova A, Ushakova V, Inozemtsev A, Zubkov E, Chekhonin V. An impact of chronic ultrasound exposure of variable frequencies on aggression of mice CBA and Balb/c strains. The XVIIIth International congress «Lomonosov», Moscow, Russia, 10-15.05.2016 (poster presentation).

Gorlova A, Pavlov D, Novoseletskaya A. Impact of thymulin on rats' anxiety. The XVIIth International conferention «Fundamental science and clinical therapies» St. Petersburg, Russia, 24-26.06.2014 (oral presentation). 
Pavlov D, Olkhovik A, Novoseletskaya A, Kiseleva N, Inozemtsev A, Arion V. Impact of thymulin and tactivine on stress-induced analgesia. $\mathrm{XV}$ th International congress «Health and education in the XXI century», Moscow, Russia, 14-17.12.2013 (oral presentation).

Awards:

2019 - 2020 fellowship in pain research of McGill University

2019 EURON grant of Maastricht University

2018 - 2019 ERASMUS scholarship certificate of Wuerzburg University

2017 - 2018 ERASMUS scholarship certificate of Liege University

2015 Moscow State University Gold medal for excellent academic record

2014 Presidential award of Moscow State University

2010 Gold Diploma of Moscow State University National Biology Olympiad for high school student 


\section{LIST OF PUBLICATIONS}

Pavlov D, Gorlova A, Bettendorff L, Kalueff A, Umriukhin A, Proshin A, Lysko A, Landgraf R, Anthony DC, Proshin A, Strekalova T. Enhanced conditioning of adverse memories in the mouse modified swim test is associated with neuroinflammatory changes: effects of treatments with antidepressant properties. Neurobiology of Learning and Memory (under revision).

De Munter H, Lyundup A, Pavlov D, Walters E, Gorlova A, Veniaminova E, Umrukhin A, Kalueff A, Svistunov A, Kramer B, Lesch KP, Strekalova T. Neuro-Cell therapy improves motor outcomes and suppresses inflammation during experimental syndrome of amyotrophic lateral sclerosis in mice. CNS Neuroscience \& Therapeutics. 2019. 00: 1-14.

Costa-Nunes JP, Gorlova A, Pavlov D, Cespuglio R, Gorovaya A, Proshin A, Umriukhin A, Ponomarev E, Kalueff A, Strekalova A, Schroeter C. Ultrasound stress compromises the correlates of emotional-like states and brain AMPAR expression in mice: effects of antioxidant and anti-inflammatory herbal treatment. Stress (in press). 
Gorlova A, Pavlov D, Anthony DC, Ponomarev E, Proshin A, Sambon M, Schmitt-Boeher A, Lesch KP, Bettendorff L, Strekalova T. Ameliorative effects of thiamine and benfotiamine on stress-induced aggression, brain oxidative processes and molecular factors of neural plasticity in mice. Neuropharmacology, 2019, 156: 107543.

Pavlov D, Bettendorff L, Gorlova A, Olkhovik A, Kalueff A, Ponomarev E, Inozemtsev A, Chekhonin V, Lesch KP, Anthony DC, Strekalova T. Neuroinflammation and aberrant hippocampal plasticity in a mouse model of emotional stress evoked by exposure to ultrasound of alternating frequencies. Progress in Neuropsychopharmacology and Biological Psychiatry. 2019. 90: 104-116.

Pavlov D, Markova N, Bettendorff L, Chekhonin V, Pomytkin I, Lioudyno V, Svistunov A, Ponomarev E, Lesch KP, Strekalova T. Elucidating the functions of brain GSK3 $\alpha$ : possible synergy with GSK3 $\beta$ upregulation and reversal by antidepressant treatment in a mouse model of depressive-like behaviour. Behav.Brain Res. 2017. 335: $122-127$.

Vignisse J, Sambon M, Gorlova A, Pavlov D, Caron N, Malgrange B, Shevtsova E, Svistunov A, Anthony D, Markova N, Bahzenova N, Coumans B, Lakaye B, Wins P, Strekalova T, Bettendorff L. 
Thiamine and benfotiamine prevent stress-induced suppression of hippocampal neurogenesis in mice exposed to predation without affecting brain thiamine diphosphate levels. "Molecular and Cellular Neuroscience”, 2017. 82: 126-136.

Gorlova A, Pavlov D, Zubkov E, Morozova A, Inozemtsev A, ChekhoninV. Chronic ultrasound exposure leads to anhedonia, decrease of explorative activity and change of anxiety level in rats. Zhurnal Vysshei Nervnoi Deyatelnosti Imeni I.P. Pavlova. 2019. 69: 743751.

Ushakova V, Gorlova A, Zubkov E, Morozova A, Zorkina Y, Pavlov D, Inozemtsev A, Chekhonin V. Experimental models of depressive disorder. Zhurnal Vysshei Nervnoi Deyatelnosti Imeni I.P. Pavlova,. 2019. 69: 230-247.

Gorlova A, Pavlov D, Zubkov E, Morozova A, Inozemtsev A, Chekhonin V. Three-week isolation does not lead to depressive-like disorders in rats. Bulletin of Experimental Biology and Medicine. 2018. 165: $1-3$.

Ushakova V, Zubkov E, Morozova A, Gorlova A, Pavlov D, Inozemtsev A, Chekhonin V. Effect of electroconvulsive therapy on cognitive functions of rats with depression-like disorders induced by 
ultrasound exposure. Bulletin of Experimental Biology and Medicine. 2017. 163: 599-601.

Gorlova A, Pavlov D, Ushakova V, Zubkov E, Morozova A, Inozemtsev A, Chekhonin V. Dynamics of the development of depressive-like state in rats stressed by chronic exposure of ultrasound of variable frequency. Bulletin of Experimental Biology and Medicine. 2017. 163: 296-298.

Pavlov D, Gorlova A, Ushakova V, Zubkov E, Morozova A, Inozemtsev A, Chekhonin V. Effects of chronic exposure to ultrasound of alternating frequencies on the levels of aggression and anxiety in $\mathrm{CBA}$ and $\mathrm{BALB} / \mathrm{c}$ mice. Bulletin of Experimental Biology and Medicine. 2017. 163: 409-411. 